\title{
Adaptation to climate change as a key element in strategic planning of biodiversity conservation in Latin America, with special reference to the Santa Cruz department, Bolivia
}

\author{
Dissertation \\ zur Erlangung des Doktorgrades \\ der Mathematische-Naturwissenschaftlichen Fakultäten \\ der Georg-August-Universität zu Göttingen \\ im Promotionsprogramm Geowissenschaften / Geographie \\ der Georg-August University School of Science (GAUSS) \\ vorgelegt von
}

Verónica Lizet Chávez Calvimontes

aus Bolivien

Göttingen, Juni 2014 
Betreuungsausschuss: Prof. Dr. Pierre L. Ibisch, Centre for Econics and Ecosystem Management. Fachbereich Wald und Umwelt, Hochschule für nachhaltige Entwicklung Eberswalde

Prof. Dr. Gerhard Gerold, Landschaftsökologie des Geographischen Instituts der Georg-August-Universität Göttingen

Mitglieder der Prüfungskommission:

Referent: Prof. Dr. Gerhard Gerold, Landschaftsökologie des Geographischen Instituts der Georg-August-Universität Göttingen (Vorsitzender)

Korreferent: Prof. Dr. Pierre L. Ibisch, Centre for Econics and Ecosystem Management. Fachbereich Wald und Umwelt, Hochschule für nachhaltige Entwicklung Eberswalde

weitere Mitglieder der Prüfungskommission:

- Prof. Dr. Martin Kappas. Abteilung Kartographie, GIS, Fernerkundung. Geographisches Institut

- Prof. Dr. Heiko Faust. Abteilung Humangeographie, Dekanat Fakultät für Geowissenschaften und Geographie. Geographisches Institut

- Dr. Stefan Erasmi. Abteilung Kartographie, GIS und Fernerkundung. Geographisches Institut

- Dr. Felix Heitkamp. Abteilung Landschaftsökologie. Geographisches Institut

Tag der mündlichen Prüfung: 11.06.2014 
A mis queridos

Mamá, papá, hermanos y

esposo.

A mi querido rio Parapetí_La

Esperanza

To my dear

Mom, Dad, brothers and

husband.

To my dear Parapetí river_La

Esperanza 


\section{Acknowledgements}

I wish to very sincerely thank and acknowledge all the people and institutions which were with me in one way or another during my journey along this long road.

I will personally hug and thank my family and friends, so I will be very brief here with my words; they already know how much they have meant and mean to me.

To the institutions which funded this research through an academic fellowship: In the first years, Andrea Santy with the Education for Nature (EFN) Program of Word Wildlife Fund WWF (Russell E. Train Scholarship). During the final year to finish my thesis, Renate Flügel, Dorit Raderschatt, Thomas Krüggeler, with the Catholic Academic Exchange Service (KAAD) (Katholischer Akademischer Ausländer-Dienst) and Katharina Bosl von Papp (of the Hildesheim Diocese). It would have been impossible to have completed my thesis without their cherished support and friendship.

To my advisor, Prof. Dr. Pierre L. Ibisch, of the Eberswalde University for Sustainable Development (University of Applied Sciences), Centre for Econics and Ecosystem Management; an excellent individual and professional- I really do not have sufficient words to thank him for his support, time, guidance, constant motivation and his positivity. It was an honor for me to have him accept the guidance of the development of this doctoral thesis (years ago when this began as a distant dream) and a pleasure for me to have been mentored by a professional of such integrity. Many thanks from for all, and also for providing me with facilities and logistical support in Germany and Eberswalde to allow me to develop this thesis. For his family: Claudia, his wife, and their children, for having made me feel at home (you are my German family ;-) I also thank the staff of Eberswalde University for the great support.

To my advisor at the University of Gottingen, Prof. Dr. Gerhard Gerold, another excellent person and professional. Many thanks for your valued guidance, and time, plus for allowing me to be a student at the prestigious Georg-August University of Göttingen. It was an honor to develop my thesis under your leadership.

I also thank all members who took part in the thesis commission of the Georg August University of Göttingen.

To Steffen Reichle with The Nature Conservancy (TNC) in Bolivia, and to part of the TNC team in the US with whom we worked in discussion groups, thank you for allowing me to use the ConPro database. In Bolivia, María Teresa Vargas, director at Fundación Natura; the technical staff and all of the participants at the Área Natural de Manejo Integrado Rio Grande Valles Cruceños, Santa Cruz. To Juan Carlos Añez, director of the Administration of Protected Areas (DIAP), for allowing me to access all of the protected areas of Santa Cruz and special thanks to the directors and staff of each of the protected areas of the department of Santa Cruz, who responded to my requests. I also thank my friends Marianela Barriga for being the contact person at the office of protected areas and Liliana Soria, of the Geography Department at the Museo de Historia Natural Noel Kempff Mercado, for her help and patience with my data.

To my dear friends in Germany: with your friendship, you lessened my homesickness and softened being far from home. Special thanks to Stefan Kreft, my dear friend and colleague, for the chats, laughs, time and constant support, I don't have enough words!! He knows! To Christoph Nowicki, for always helping me with a smile (I knew both of them in Bolivia and I'll be waiting for them there). Danke schön!. For Malea Birke, my dear friend, all my love and 
thanks, if I saw and enjoyed more of Germany, it was because of her, thanks for her enthusiasm, strength, chats and laughs. Thank you so much, dear Male! And to each of my friends which made each part of student life special and enjoyable: fellow doctoral students Juliane (she contributed to the CAP analysis, as well as Steffen Reichle), Sabine and Alex, and to Paulina V., Paulina S., Ariane, Cyprian, Wanda, Johannes, Undine, Andreas, Franciska, Daniela, Lena, Elizabeth, Laura, Anja, Lisa, Aischa and Julia.

For my friends and colleagues in Bolivia (special thanks to Marbel Morales). Your longdistance friendship and support was key for me to keep going, and as you are many, I will say "Thank you very much_Muchisimas gracias" to you as a group. We'll talk there (:).

Special thanks to my friend and aunt Stephanie for her patience with the translation.

To my beloved family: Mom Margie Calvimontes, Dad Roberto Chávez, dear brothers José María (thank you for the maps) and Roberto Ignacio, to my sisters-in-law and to Marietita, my niece. Anything I could say to thank you would be little in relation to the value of your support, love and motivation in Bolivia and from Bolivia. My success is your success. It is not enough to say "muchisimas gracias". They know how much they mean to me.

To my partner, friend and husband, Fernando Del Águila; what more can I say! We'll talk so much! It would be complicated to find sufficient words to thank you for your support, understanding and love in each and every one of the days since the first steps in this journey: we began, progressed and completed this dream together. Again, it is not enough just to say Thank you so much! We have our whole lives to be together, enjoying, talking and laughing!.

To my large and beloved family: aunts, uncles, cousins, nieces and nephews, from La Esperanza, Ñaurenda, Monteagudo, Santa Cruz, Cañón del Ingre, Villa Montes and Tarija "yasurupai" !; I share my happiness with you for what this achievement means to me.

Thank you very much again, I dedicate all my effort, sacrifice and time which I gave to complete this thesis and I am happy to have finished it!.

Thank you all for your support! Danke schön!, Muchisimas gracias!. 


\section{Abstract}

This study is based on a conceptual analysis of climate-induced stresses as well as the revision of management plans of protected areas across the Americas, with a particular focus on the protected areas of the Santa Cruz department in Bolivia. The effects of climate change- altered temperature and weather patterns, such as increased frequency and intensity of extreme climate events, pose new challenges to conserving Earth's natural ecosystems. Therefore, it is critical to integrate consideration of climate change in conservation planning and management in order to address and reduce the vulnerability to climate change. In Latin America, the inclusion of climate change as a threat to protected areas represents a significant paradigm shift in strategic planning and management practices. In order to facilitate such a shift, we first aim to understand the management of protected areas and assess the capacity to respond to the issue of climate change, based on response analyses of biodiversity by gathering and analysing questionnaire responses from protected areas managers. The need for dealing with relatively rapid and uncertain environmental change calls for the enhancement of adaptive capacity of both biodiversity and conservation management systems. Under the hypothesis that most of the conventional biodiversity conservation tools do not sufficiently stimulate a dynamic management of protected area, which takes rapid environmental change into account, we evaluated almost 900 of The Nature Conservancy's (TNC) site-based Conservation Action Plans (CAPs) across the Americas. We then selected 103 CAPs which were elaborated prior to a TNC climate change clinic in 2009, an intensive revision of existing plans and climate change training of the planning teams. We also compared these results with 22 plans elaborated after the climate change clinic. Before 2009, 20\% of the CAPs employed the term "climate change" in their description of site viability, and $45 \%$ identified key ecological attributes related to climate. Eight percent of the conservation strategies were directly or indirectly related to climate change adaptation. After 2009, a significantly higher percentage of plans took climate change into account. Our data show that many planning teams face difficulties in integrating climate change in their management and planning. However, technical guidance and concrete training can facilitate management teams' learning processes, so we generated and tested an additional planning methodology, an extended version of the "Conservation Action Planning" methodology, which strongly incorporates climate change in each of the planning steps. We tested the extended CAP in a case study with the Area de Manejo Integrado Rio Grande Valles Cruceños, a protected area in the department of Santa Cruz, Bolivia. In this pilot application, the participants selected a total of eight species and natural communities as conservation targets, representative of the biodiversity of the site. The target of "water", which was selected based on the quality of ecological processes and function associated with it, proved to be a challenge within the planning exercise. There was a focus on climate change in each of the planning steps. The results of the study showed: The current vulnerability of the protected area was rated as "Good" and the future climate-dependent viability as "Fair". Additionally, through managers' responses to a questionnaire regarding climate change and the management of protected areas of Santa Cruz, Bolivia, we evaluated the consideration of climate change in the management of protected areas and the vulnerability of these sites with respect to their ability to adapt to climate change. Eighty-eight percent of the areas answered the questionnaire, a total of 32 in the department (national-, departmental- and municipal-level protected areas). The results show that all areas have noticed some effects of climate change and with different levels of knowledge and 
action are looking for ways to adapt their management accordingly. They pointed out that they are experiencing high exposure to extreme weather events, especially in the Amazon, with increased frequency and intensity of temporary flooding, droughts and forest fires, in recent years. Less than half of the areas had a management plan; none had knowledge of the Ecosystembased adaptation methodology and instead used other types of adaptive management; $11 \%$ of the areas practice risk management; $46 \%$ work with neighbouring private landowners and $86 \%$ believe that conservation work is more difficult now than it was 20 years ago. National-level protected areas were the least vulnerable according to the climate vulnerability index, followed by the departmental-level areas. The municipal-level areas had the highest vulnerability ratings across various analyses. Through this research, we have shown that conservation planning with a specific approach to climate change is not easy, but is possible. By addressing these challenges, we hope to instil a more proactive vision for biodiversity conservation, which is more systematic, better-documented and climate-change-inclusive. This new approach will require pragmatic and strategic actions to cope with climate change and adapt to it. Emerging new tools for adaptive conservation management that explicitly incorporate options for handling future scenarios, vulnerability analyses and risk management into the management process have the potential of making protected area management more proactive and robust in the face of climate change. 


\section{Zusammenfassung}

Die vorliegende Untersuchung umfasst eine konzeptionelle Analyse von klimawandelbedingten Stressen sowie eine systematische Überprüfung der Managementpläne von Schutzgebieten auf dem amerikanischen Kontinent, mit besonderem Augenmerk auf dem Department Santa Cruz in Bolivien. Die Wirkungen von sich klimawandelbedingt ändernden Mustern der Temperatur und des Wetters, z.B. häufigeren und intensiveren Extremwetterereignissen, sind neuartige Herausforderungen für die natürlichen Ökosysteme der Erde. Es ist deshalb von entscheidender Bedeutung, den Klimawandel bei Planung und Management im Naturschutz zu berücksichtigen und so seine Vulnerabilität gegenüber dem Klimawandel $\mathrm{zu}$ thematisieren und mithin $\mathrm{zu}$ reduzieren. Die Anerkennung des Klimawandels als Bedrohung für Schutzgebiete stellt in Lateinamerika einen beträchtlichen Paradigmenwechsel für die strategische Planungs- und Managementpraxis dar. Um einen solchen Fortschritt zu befördern, versuchen wir im ersten Schritt das aktuelle Schutzgebietsmanagement zu erfassen und seine Fähigkeit einzuschätzen, auf das Klimawandel-Problem einzugehen. Diese Einschätzung erfolgte auf Grundlage von Analysen einer schriftliche Umfrage bei Schutzgebietsmanagern zu Beobachtungen über Reaktionen von Biodiversität auf den Klimawandel. Um mit relativ schnellem und mit Unsicherheit behaftetem Umweltwandel umgehen zu können, bedarf es der Verbesserung der Anpassungsfähigkeit sowohl der Biodiversität als auch der Naturschutz-Systeme. Unter der Hypothese, dass die meisten ,konventionellen' Instrumente des Naturschutzes ein dynamisches Schutzgebietsmanagement, das schnellen Umweltwandel ausreichend berücksichtigt, nicht ausreichend befördern, werteten wir fast 900 gebietsspezifische Conservation Action Plans (CAPs) des Naturschutzverbandes The Nature Conservancy (TNC) aus. Dann wählten wir 103 CAPs aus, die vor einer intensiven Überprüfung existierender Pläne und einem Klimawandel-

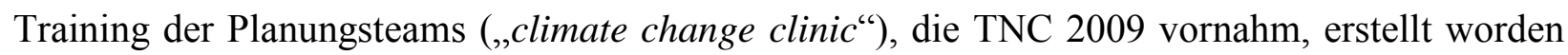
waren. Wir verglichen die Ergebnisse mit 22 Plänen aus der Zeit nach der climate change clinic. Vor 2009 gebrauchten 20\% der CAPs den Begriff „Klimawandel“ in der Beschreibung der Viabilität des Gebiets, und $45 \%$ identifizierten ökologische Schlüsselattribute, die mit Klimawandel in Beziehung stehen. Acht Prozent der Schutzstrategien bezogen sich direkt oder indirekt auf die Anpassung an den Klimawandel. Nach 2009 zog ein signifikant höherer Prozentsatz der Pläne den Klimawandel in Betracht. Unsere Daten zeigen auf, dass viele Planungsteams Schwierigkeiten haben, den Klimawandel in Management und Planung zu berücksichtigen. Eine allgemeine fachliche Anleitung und konkretes Training können jedoch Lernprozesse von Managementteams befördern. Daher entwickelten und erprobten wir eine erweiterte Version der Conservation Action Planning-Methode als zusätzliche Planungsmethode. Dieses erweiterte CAP legt einen Schwerpunkt auf die Berücksichtigung des Klimawandels in allen Planungsschritten. Wir erprobten das erweiterte CAP in einer Fallstudie im Schutzgebiet mit integrierter Nutzung („Area de Manejo Integrado“) Río Grande Valles Cruceños im Department Santa Cruz. Im Zuge dieser Pilotanwendung wählten die Teilnehmer als Schutzobjekte insgesamt acht Arten und Biozönosen aus, die zusammen die Biodiversität des Gebiets repräsentieren. Das Schutzobjekt, Wasser', aufgrund von Qualitätsmerkmalen von ökologischen Prozessen und mit ihnen verbundenen Funktionen ausgewählt, erwies sich als Herausforderung bei der Anwendung. Dem Klimawandel wurde in jedem einzelnen Planungsschritt besondere Beachtung geschenkt. Im Ergebnis wurden die aktuelle Viabilität des Schutzgebiets als „Gut“ und die zukünftige Viabilität unter dem Einfluss des Klimawandels als 
„Mäßig“ eingeschätzt. Anhand der Antworten von Schutzgebietsmanagern auf einem Fragebogen zu Klimawandel und Schutzgebietsmanagement in Santa Cruz, Bolivien, bewerteten wir die Berücksichtigung des Klimawandels im Schutzgebietsmanagement und der Vulnerabilität der betreffenden Gebiete im Hinblick auf ihre Fähigkeit, sich an den Klimawandel anzupassen. Achtundachtzig Prozent der Gebiete füllten den Fragebogen aus, das sind insgesamt 32 (nationale, departmentale und munizipale) Schutzgebiete im ganzen Department. Die Ergebnisse zeigen, dass alle Gebiete einige Wirkungen des Klimawandels wahrgenommen haben und, bei unterschiedlichem Stand des Wissens und der Umsetzung, auf der Suche sind nach Mitteln und Wegen, wie sie ihr Management entsprechend anpassen können. Sie legten dar, dass sie sei einigen Jahren in hohem Maße Extremwettereignissen und häufigeren und intensiveren Überschwemmungen, Dürren und Waldbränden ausgesetzt sind, insbesondere in der Amazonasregion. Weniger als die Hälfte der Gebiete verfügten über einen Managementplan; keines besaß Kenntnis vom Ansatz der ökosystembasierten Anpassung. Stattdessen benutzten sie andere Arten adaptiven Managements; $11 \%$ der Gebiete praktizierten Risikomanagement; $46 \%$ arbeiteten mit benachbarten privaten Grundeigentümern zusammen, und $86 \%$ sind der Auffassung, dass die Naturschutz-Arbeit heute schwieriger ist als noch vor 20 Jahren. Nationale Schutzgebiete waren, einem Index der Klimawandel-Vulnerabilität zufolge, am wenigsten vulnerabel, gefolgt von departmentalen Schutzgebieten. Munizipale Schutzgebiete wiesen gemäß verschiedenen Analysen die höchsten Vulnerabilitätswerte auf. Mit dieser Studie haben wir gezeigt, dass Naturschutzplanung unter besonderer Berücksichtigung des Klimawandels zwar nicht einfach, aber durchaus möglich ist. Indem wir diese Herausforderung herausarbeiten, hoffen wir, zu einem proaktiveren Blick auf die Erhaltung der Biodiversität, der systematischer, umfassender dokumentiert und auf den Klimawandel ausgerichtet ist, anzuregen. Dieser neue Ansatz fordert zu pragmatischen wie auch strategischen Handlungen heraus, die dazu angelegt sind, mit dem Klimawandel zurechtzukommen und sich an ihn anzupassen. Neue Instrumente für adaptives Naturschutzmanagement, die explizit Möglichkeiten zum Umgang mit Zukunftsszenarien, Vulnerabilitätsanalysen und Risikomanagement integrieren, können das Schutzgebietsmanagement angesichts des Klimawandels proaktiver und robuster machen. 


\section{CONTENTS}

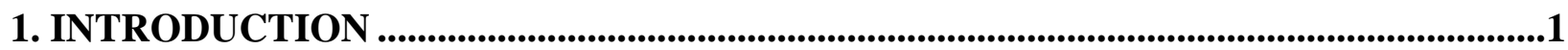

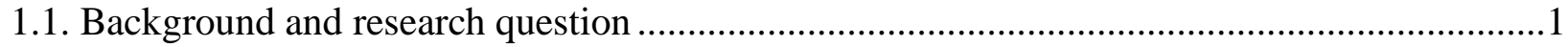

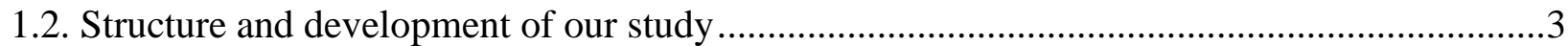

1.2.1. Review of Conservation Action Plans from the Americas .................................................. 3

1.2.2. Local case study: Area Natural de Manejo Integrado Rio Grande Valles Cruceños (ANMI

RG-VC). (Integral Management Natural Area of Rio Grande Valles Cruceños)..........................4

1.2.3. Regional case study: protected areas of the Santa Cruz department .................................5

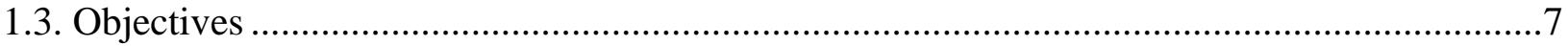

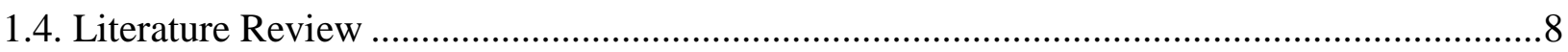

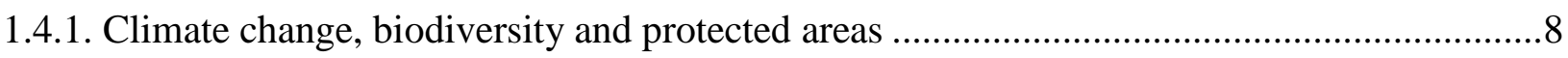

1.4.2. Political and social context relative to protected areas in Bolivia ....................................11

1.4.3. Classification of Climate Change Stresses ..................................................................12

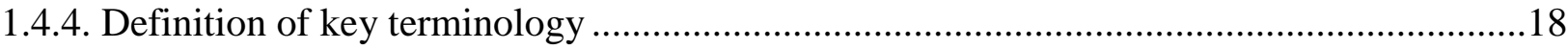

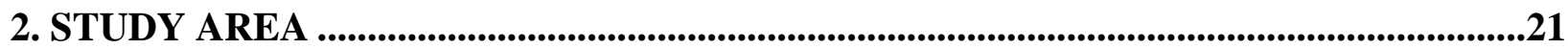

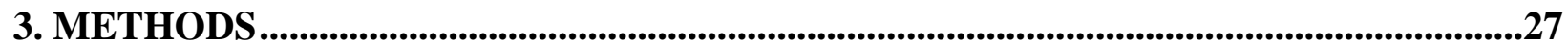

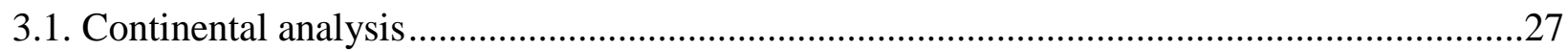

3.2. Local case study: Área Natural de Manejo Integrado Rio Grande Valles Cruceños .............30

3.3. Regional case study: analysis of perceived adaptive capacity in Santa Cruz protected areas 39

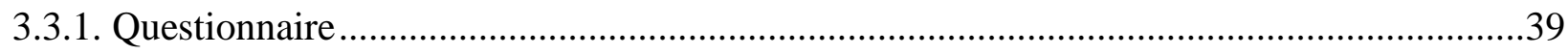

3.3.1.1. Additional information for evaluation of the PAs ......................................................40

3.3.2. Evaluation of the vulnerability of the protected areas of Santa Cruz as a function of their

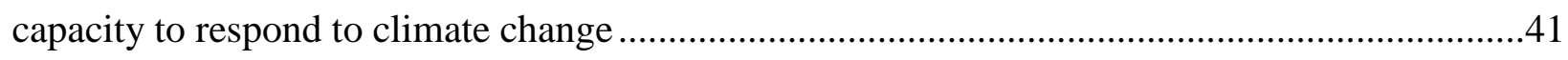

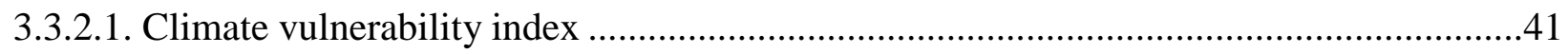

3.3.2.2. Defined matrix: Climate Vulnerability Index for the protected areas of the department of

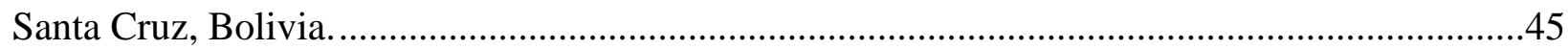


4.1. Conservation Action Planning on the continental scale (America) ......................................55

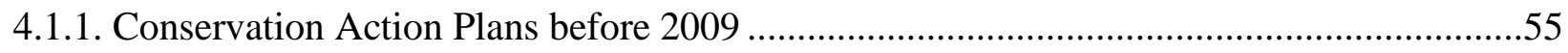

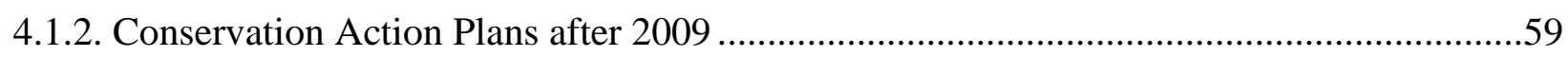

4.2. Local case example: Área Natural de Manejo Integrado Rio Grande Valles Cruceños.........60

4.3. Regional analysis of climate change in protected areas ..................................................69

4.3.1. Evaluation of the vulnerability of the protected areas of Santa Cruz as a function of the manager's observations with respect to the areas' capacity to respond to climate change ...........79

4.3.1.1. Climatic vulnerability perceived of the PAs, according to weighted percentages by

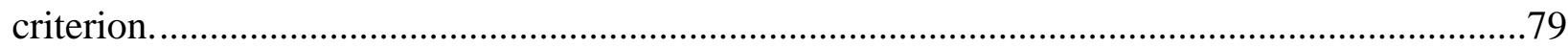

4.3.1.2. Results of the climate vulnerability perceived of the PAs, by individual subcriteria ......82

4.3.1.2.1. Results of the climate vulnerability of the PAs, by administrative level.....................82

4.3.1.2.2. Climate vulnerability rating by protected area in the department of Santa Cruz ..........87

4.3.1.2.3. Graphic patterns of climate vulnerability by protected area.......................................90

4.3.1.2.4. Climate vulnerability by management by protected area of Santa Cruz, Bolivia, according to subcriteria with percentages of highest rating .....................................................93

5. DISCUSSION

5.1. Review of Conservation Action Planning (CAP) in the Americas ......................................96

5.2. The local case study experience with ANMI Rio Grande Valles Cruceños (ANMI RG-VC)

5.2.1. Current state of the ANMI Rio Grande and Valles Cruceños protected area...................101

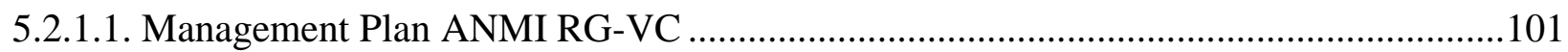

5.2.1.2. Institutional support for ANMI Rio Grande and Valles Cruceños protected area .........102

5.2.2. Local case study of Extended CAP experience (consolidated methodology + MARISCO)

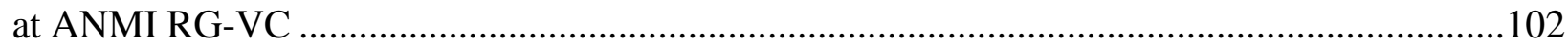

5.3. Applied climate vulnerability index. Regional study case ..........................................108

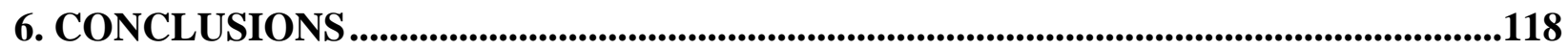

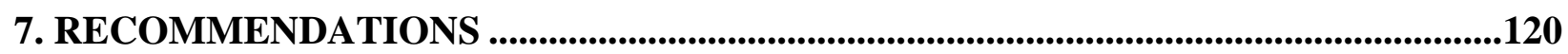

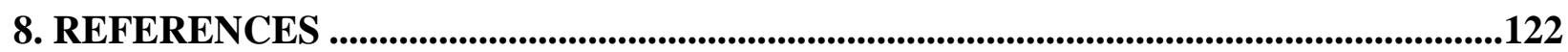

Annex .136 


\section{Index of tables}

Table 1. Classification of climate-change related stresses.......................... 14

Table 2. Overview of effects of climate change on ecosystem services................. 17

Table 3. Evaluation questions for each of CAP's methodological steps................ 29

Table 4. Principal general differences between the conventional CAP and the proposed 31 extended version of CAP

Table 5. Instruction Manual Guide for CAP applicable to conservation planning for the $\mathbf{3 5}$ biodiversity of protected areas.

Tabla 6. Example spreadsheet analyzed for studying the protected areas (PA).

Tabla 7. Comparison between the principal modifications to the vulnerability index of

Kreft et al. (2013) for PAs of Santa Cruz relative to their capacity to respond to climate change.

Tabla 8. Description of the Climate Vulnerability Index matrix applied to the protected areas of the department of Santa Cruz, Bolivia.

Table 9. Viability values assigned for each area (on the basis of individual target-viability ratings)

Table 10. Climate-change-induced stresses to biodiversity identified in the 103 Conservation Action Plans

Table 11. Overall threat ratings by area and region.

Table 12. Summary of current and future Climate-Dependent Viability for the ANMI RG-VC (Miradi)

Table 13. Threats for the ANMI Río Grande Valle Cruceños.

Table 14. Variables description and results.

Table 15. Vulnerability rating (perceived/estimated) by administrative level.

Table 16. Rating of climate vulnerability (perceived/estimated) according to administrative level.

Table 17. Comparison of the vulnerability ratings by administrative level 82

Table 18. Comparison of the MARISCO methodology, with the extended CAP 86 methodology which was used in our case study 


\section{Index of figures}

Figure 1. Map of protected areas in the department of Santa Cruz, Bolivia........... 23

Figure 2. Map showing Área Natural de Manejo Integrado Río Grande Valles $\quad 25$

Cruceños.

Figure 3. Conceptual framework Climate Vulnerability Index ................... 45

Figure 4. Comparison between CAPs evaluated before and after 2009 (\%) (TNC 60 2011).

Figure 5. Conceptual model of prioritized threats and primary stakeholders in ANMI $\quad \mathbf{6 5}$

RG-VC.

Figure 6. Threats situation analysis of two conservation targets in ANMI RG-VC.... $\mathbf{6 6}$

Figure 7. Present ratings and projected future ratings of threats in ANMI RG-VC... $\quad 67$

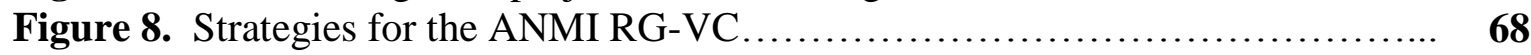

Figure 9. Location Map of Protected Areas in Santa Cruz, Bolivia................ 70

Figure 10. Managers' observations of climate change in their PAs $(n=28)$ by $\mathbf{7 8}$ administrative level.

Figure 11. Climatic Vulnerability (perceived/estimated) ratings by administrative level of Pas.................................................................

Figure 12. Climate vulnerability (perceived/estimated) of protected areas at the national administrative level

Figure 13. Climate vulnerability (perceived/estimated) of protected areas at the departmental administrative level.

Figure 14. Perceived climate vulnerability, rating for municipal-level protected areas

Figure 15. Percentages of low, medium and high vulnerability according to

administrative level

Figure 16. Vulnerability of the protected areas in Santa Cruz, Bolivia, according to general ratings...

Figure 17. Ratings of (perceived) climate vulnerability by protected area, according to the rated subcriteria

Figure 18. Graphic patterns of perceived climate vulnerability, by protected area ...... Figure 19. Estimated climate vulnerability by percentage of highest rating for protected areas $(n=28)$ of Santa Cruz, Bolivia

Figure 20. Map of perceived/estimated climate vulnerability by percentage of highest rating for protected areas of Santa Cruz, Bolivia

5 5 65 6 8 78

83

85

86

87

87

89

91

94

95 


\section{Acronyms}

\begin{tabular}{|c|c|}
\hline CAP & Conservation Action Planning \\
\hline CBD & Convention on Biological Diversity \\
\hline $\mathrm{CC}$ & Climate Change \\
\hline CMP & Conservation Measures Partnerships \\
\hline ConPro & Conservation Project \\
\hline CT & Conservation Target \\
\hline DIAP & Dirección de Áreas Protegidas (Departmental Office of Protected Areas) \\
\hline EBA & Ecosystem-based Adaptation \\
\hline ENSO & El Niño-Southern Oscillation \\
\hline FAN & Fundacion Amigos de la Naturaleza (Friends of the Nature Foundation) \\
\hline GIS & Geographic Information System \\
\hline IPCC & Intergovernmental Panel on Climate Change \\
\hline KEA & Key ecological attributes \\
\hline ANMI RG-VC & $\begin{array}{l}\text { Area Natural de Manejo Integrado Rio Grande Valles Cruceños / Natural Area } \\
\text { of Integral Management_ NAIM RGVC }\end{array}$ \\
\hline MARISCO & $\begin{array}{l}\text { Manejo Adaptativo de RIesgo y vulnerabilidad en Sitios de COnservación - } \\
\text { adaptiverisk and vulnerability management at conservation sites (acronym of } \\
\text { the Spanish name_Manejo Adaptativo de RIesgo y vulnerabilidad en Sitios } \\
\text { de Conservación) }\end{array}$ \\
\hline MHNKM & $\begin{array}{l}\text { Museo de Historia Natural Noel Kempff Mercado (Museum of Natural } \\
\text { History NKM) }\end{array}$ \\
\hline MP & Management Plan \\
\hline NGO & Non Governmental Organization \\
\hline PA & Protected Area \\
\hline PNCC & $\begin{array}{l}\text { Programa Nacional contra el Cambio Climático (National Programme on } \\
\text { Climate Change) }\end{array}$ \\
\hline REDD+ & $\begin{array}{l}\text { Reducing Emissions from Deforestation and Forest Degradation (plus } \\
\text { sustainable management of forests, conservation and enhancement of carbon } \\
\text { stocks). (Reducción de Emisiones por Deforestación y Degradación) }\end{array}$ \\
\hline SERNAP & Servicio Nacional de Áreas Protegidas (National Protected Areas Service) \\
\hline SNAP & $\begin{array}{l}\text { Sistema Nacional de Áreas Protegidas (National System of Protected Areas } \\
\text { NSPA) }\end{array}$ \\
\hline TNC & The Nature Conservancy \\
\hline UNDP & United Nations Development Programme (PNUD) \\
\hline
\end{tabular}




\section{INTRODUCTION}

\subsection{Background and research question}

More dynamic and adaptive conservation strategies have been demanded for many years and ever more intensively (e.g., Peters \& Darling 1985; Peters \& Myers 1991; Peters \& Lovejoy 1992; Hannah et al. 2002; Hannah 2008; Heller \& Zavaleta 2009). Whilst there is increasing evidence for and understanding of the diverse climate-change induced stresses on conservation targets (Geyer et al. 2011) and options for action are increasingly being suggested and compiled (Heller \& Zavaleta 2009; Ibisch \& Kreft 2008; Thuiller et al. 2008; Glick et al. 2011), concrete management efforts on the ground still struggle with the integration of climate change adaptation with conservation planning and site management (McClanahan et al. 2008; Poiani et al. 2011; Groves et al. 2012; Ibisch \& Hobson 2014). Regarding climate change, the IPCC (2013) refers to a change in the state of the climate that can be identified (e.g., by using statistical tests) by changes in the mean and/or the variability of its properties, and that persists for an extended period, typically decades or longer.

Adaptive conservation management, almost by definition, should be an adequate way of addressing multiple, sudden and often unpredictable threats arising directly or indirectly from climate change. Warming of the climate system is unequivocal, and since the 1950s, many of the observed changes are unprecedented over decades to millennia. The atmosphere and ocean have warmed, the amounts of snow and ice have diminished, sea level has risen, and the concentrations of greenhouse gases have increased (IPCC 2013a). Adaptive conservation management arose decades ago (Holling 1978) and was significantly conceptualized and implemented through practical iterative approaches (Margoluis \& Salafsky 1998) and through instruments such as Conservation Action Planning (CAP) (Groves et al. 2000; Granizo et al. 2006; Dudley et al. 2007).

Adaptive management is characterized by a systematic process of the implementation of lessons learned deduced from ongoing reflection and monitoring of action effectiveness on the basis of the original goal and priority-setting as well as strategy design. However, adaptive management can be purely reactive, implementing adaptation measures after detecting ineffectiveness or success. Thus in the case of conservation, strategic adaptation that only follows realized failure is often a little late. Therefore, merging the approaches of adaptive management and risk management is recommended. Such a blended approach takes into account emerging or future threats and stresses, for example those related to climate change (Pidgeon \& Butler 2009; Ibisch et al. 2009). Climate-change adaptive conservation also might focus more strongly on ecosystem targets or even ecological processes related to system resilience or reduction of vulnerability. In this context those ecological functions will be especially relevant that reduce the ecosystems` sensitivity to climate change, e.g., by water retention, microclimate regulation and buffering), or enhance adaptive capacity. 
The evaluation of management (effectiveness) has become a major challenge to protected areas. The importance of protected areas as instruments for global biodiversity conservation (UNEPWCMC 2008; Chape et al. 2008) has resulted in a growing interest to know and communicate the outcomes and to what degree protected areas meet the goals for which they were designed. (EUROPARC-España 2010). Additionally, climate change will pose increasingly significant challenges to managers of parks and other types of protected areas around the world and there continues to be a limited response from practitioners both in policy development and implementation of policy and management strategies (Scott \& Lemieux 2007; West et al. 2009; Lawler et al. 2009; Lemieux et al. 2011; Lemieux \& Scott 2011). There is an urgent need to develop updated planning approaches to provide for biodiversity conservation in the face of altered climate (Groves et al. 2012).

Although authors as Mawdsley et al. (2009); Stein et al. (2013), Ibisch \& Hobson (2014), indicate natural resource managers already have many tools that can be used to address climatechange effects, major advances in the development of climate-adaptation principles, strategies, and planning processes have occurred over the past few years, although implementation of adaptation plans continues to lag (Berrang-Ford et al. 2011; Stein et al. 2013). Conservation scientists, planners, and practitioners are actively exploring options for climate change adaptation (e.g., Araújo 2009; Ferdaña et al., in Pérez et al. 2010; Hansen et al. 2010).

In the framework of all macro-ecological approaches from different schools, such as ecosystem management, bioregional or ecoregional management, in the context of classical conservation visions, protected areas are a key tool to conserve biodiversity. Protected areas throughout the world are key for conserving biodiversity, while at the same time land is needed and used to provide food, fiber, and other ecosystem services essential for human sustenance (DeFries et al. 2007). What the climate change adaptation literature has not yet covered, according to Lemieux et al. (2010), is the convenience, feasibility or viability of the options for adaptation available to those responsible for planning and overseeing protected ares and their management. Welch (2005) also states that the literature contains few references to guide managers who are responsible for existing protected areas. The mainstreaming of adaptation considerations into existing institutional decision-making processes can lead to policies that reduce vulnerability to climate change and better position agencies to exploit opportunities while simultaneously addressing other priorities (Lemmen et al. 2008; Ogden \& Innes 2009).

Against these backgrounds we sensed that the issue of climate change is not sufficiently considered in the management of protected areas, both in the North and South America and particularly in Bolivia. We were interested in the question: Do the plans for biodiversity conservation consider and allow for adaptation to climate change?.

We started to develop this study under the hypothesis that most of the conventional biodiversity conservation tools for the Americas do not sufficiently stimulate dynamic protected areas management, which takes rapid environmental change into account. Especially in Bolivia there is little (or no) knowledge about how to integrate climate change and adaptation issues into conservation area planning. We think the capacity of the protected areas in Santa Cruz, Bolivia to respond to the effects of climate change is very low, so climate change-related standards 
(among others) could only be incorporated when managers are guided by obligatory steps in the course of a planning process.

To address this weakness, we reviewed conservation plans for protected areas across the Americas and in Bolivia in particular and evaluated how each plan took the issue of climate change into consideration. We also proposed the extended CAP methodology, incorporating a focus on climate change and tested the method in a pilot planning experience with a protected area of the department of Santa Cruz, Bolivia. Through an index of climate vulnerability, we rated the ability of natural areas management practices in the department of Santa Cruz to respond to climate change, based on the survey responses of the protected area staff.

\subsection{Structure and development of our study}

We developed our research along three overarching and complimentary themes which address the main objective, ranging from a general analysis to a specific analysis.

We began with a review of Conservation Action Plans (CAP) from across the Americas with special emphasis on Latin America, to answer the question: "Is the Conservation Action Planning (CAP) process adapting to climate change?"1

Subsequently, based on the first analysis, we facilitated a planning exercise with a focus of integrating climate change into conservation planning. This local case study workshop was for the Bolivian protected area of Área Natural de Manejo Integrado Rio Grande-Valles Cruceños (ANMI RG-VC) (Integrated Management Natural Area Rio Grande-Valles Cruceños).

Focusing on the regional situation in the administrative department of Santa Cruz, Bolivia, we administered a questionnaire and used the responses along with other data to rate climate vulnerability of the protected areas.

\subsubsection{Review of Conservation Action Plans from the Americas}

In the framework to answer if Conservation Action Planning (CAP) is adapting to climate change, better approaches and tools of adaptive management, are tested such as CAP which is a relatively simple, straight forward and proven approach for planning, implementing and measuring success for conservation projects (TNC 2007). Another planning methodology which was included in this study is The Open Standards for the Practice of Conservation. The standards provide the principles, tasks, and guidance necessary for the successful implementation of conservation projects. In order to assist practitioners and improve the practice of conservation we synthesized common concepts, approaches, and terminology in conservation project design, management, and monitoring. (CMP 2004; 2007; Schwartz et al. 2012) We compared accessible CAPs from 1998 to 2009, and summarized the prevalent conservation strategies from these plans

\footnotetext{
${ }^{1}$ This part of the study has been prepared as a paper for publication. The author of this thesis is the main author, and the co-authors: Pierre Ibisch, Steffen Reichle and Juliane Geyer (They have also contributed to the analysis and the writing of the corresponding texts).
} 
for site management. We were primarily interested in the measures each planning team took to integrate climate change throughout the steps of the planning process.

To evaluate a larger number of structurally comparable management plans, we opted for the evaluation of CAPs stored in the Conservation Project (ConPro) database in the Microsoft Excel format established by The Nature Conservancy (TNC). This enabled us also to compare how planning within TNC before and after a climate change clinic organized by TNC in 2009 (Poiani et al. 2011), evolved to include climate change related threats more readily identifiable and to enhance CAP with respect to climate change.

We present out results of the extended CAP implementation, for each of the CAP steps: the selection of conservation targets and total ratings of both viability and threats for the areas, where both climate and non-climate factors influenced the approach of the planning teams.

\subsubsection{Local case study: Área Natural de Manejo Integrado Rio Grande Valles Cruceños (ANMI RG-VC). (Integral Management Natural Area of Rio Grande Valles Cruceños)}

To begin to integrate climate-change into conservation planning, we held a pilot exercise for the Bolivian protected site: ANMI RG-VC according to an extended methodology of Conservation Action Planning (CAP).

Several CAPs have been applied in different parts of Bolivia, such as in the Parque Nacional Noel Kempff Mercado (2004) and the Unidad de Conservación Amboró-Carrasco (2006) (V. Chávez (ed.), unpublished documents). Other protected areas with CAPs are Altamachi, Reserva Eduardo Avaroa, Parabanó, Área Protegida Curichi el Cuajo, San Nicolas and the privately owned area El Corbalán-Cañada El Carmen. Likewise other methodologies such as regional and/or national planning exercises have been performed and compared (Ibisch, Columba \& Reichle 2002; Ibisch, Araujo \& Nowicki 2007), among others.

We designed an extension of the conventional CAP methodology (Ibisch \& Chávez, 2008, unpublished), with the aim of making the CAP more anticipatory and proactive, with guidance on how to incorporate climate change at various stages of planning. The idea for modifying the CAP came after a collaborative discussion with a work group from TNC about adaptation to climate change and the CAP planning methodology. The extended CAP fits within the framework of the other planning initiatives we mentioned and was shaped by accessing finished CAPs in The Nature Conservancy's (TNC) database of conservation projects (ConPro).

We also developed a step-by-step manual to guide to process of the proposed extended CAP. The manual provides ideas, data, and suggestions to assist a planning team in incorporating climate change throughout the planning process, seeking to achieve that change climate impact is strongly considered as a current and future factor that will continue to affect conservation. As noted by Heller \& Zavaleta (2009) broad and regional adaptation requires improved institutional coordination, thinking in larger spatial and temporal scales and incorporation of climate change scenarios into all planning and action. 
We held our case study at the Área Natural de Manejo Integrado Rio Grande Valles Cruceños (ANMI RG-VC) (Integrated Management Natural Area Rio Grande-Valles Cruceños) a rich site with a diversity and variability at many levels: biological, geographical, climate, social and cultural. This diversity automatically made our pilot experience a challenge. The participatory planning process was a specific process that led to the creation of an overall plan for the management, monitoring and evaluation, implementation and execution.

Implementing the extended CAP was a pilot experience which, from our perspective, provided with useful results to further improve and enrich the task of protected areas planning (especially for Bolivia). Through the process we were also able to assess the feasibility of working with a strong focus on climate change. Another benefit was that the some of the outcomes from the pilot planning experience were included in the final and official Management Plan for the PA.

Methodologies themselves are adapted and modified over time and the same is true for the extended CAP. Ultimately, the extended CAP grew into what is now known as MARISCO (acronym of the Spanish name for the approach: Manejo Adaptativo de RIesgo y vulnerabilidad en Sitios de COnservación - Adaptive risk and vulnerability management at conservation sites) (Ibisch \& Hobson 2014).

\subsubsection{Regional case study: protected areas of the Santa Cruz department}

We evaluated the protected areas in the Santa Cruz department, Bolivia by taking into account the opinions, observations and perceptions of those who manage the protected areas. As climate change is a current important topic in the conservation sector, and with all the scientific literature about climate change and it impacts, we were interested in how managers were taking climate change into account through their management practices. We did not seek specific and/or technical answers about climate change (e.g., about changes in risk; degree of temperature variation; climate modeling, projections, shifting averages, etc.), but rather we aimed for examples of actions or strategies referring directly or indirectly to CC. We were looking for these types of responses: Activities, strategies or approaches to regional/ecosystem conservation management; Establishment of biological corridors; Ecoregional planning; Territorial Planning (discourage human settlements in vulnerable locations); Reforestation; Reduction of flood severity/watershed management ); Irrigation (reduction of impacts to the PAs in areas with precipitation changes or fire); actions or strategies for reducing deforestation and reducing emissions of greenhouse gases (GGE); Intersection between ecological and social systems (social participation in PA management); Maintenance of ecological and evolutionary processes; Avoid climate change impacts by maintaining a synergistic relationship between the mentioned activities and strategies to address land use change; Preservation of ecosystem services such as regulation of water cycles and carbon sequestration).

With this in mind, the survey questions were designed to gather a basic understanding of the approach the managers took for their PAs with respect to adaptation to CC. The IPCC defined adaptation to $\mathrm{CC}$ as the adaptation to adjustments provided on ecological, social and economic systems in response to the effects of current or anticipated climate stimuli (Leary et al. 2008). It is appropriate they we designed our questionnaire to look for specific actions (e.g., conservation 
of a species or ecosystem highly vulnerable to $\mathrm{CC}$ ) and to look for institutional changes (e.g., reflected in the design of public policies and their implementation).

For the purpose of our study, to rate or evaluate something is to measure its value. In the area of program and project development and implementation, the purpose of rating is to measure the value of what is done (Feuerstein 1986). Rating is a systematic and objective assessment of the design, implementation, efficiency, effectiveness, processes and outcomes of a program or project completed or underway. Through the rating process we sought to understand: how each PA considered climate risks in their management activities; the PAs experience with adaptation measures; and the types and degrees of climate change observed at each PA.

However, the effectiveness of climate risk management depends heavily upon the ability to reduce uncertainties linked with climate risk to a level at which risk management tools can be reliably implemented (MacGray 2007).

Bolivia has a methodology for assessing management effectiveness at the national level (MEMS) (Guachalla \& Zegada 2001; Guachalla et al. 2002) but this has not been used continuously and systematically. Adoption and use of MEMS has been hindered by lack of time and financial resources. The goal with our climate vulnerability analysis in this study is to show that climate vulnerability can be considered and evaluated without a lot of investment in terms of staff time and budget. The information from the survey responses of the PA managers gave us a quick yet approximated look at the present situation at each of the PAs. The climate vulnerability index is also adaptable- criteria can be edited according to the information available for a given PA.

The results show that there is little consideration of the climate change issue in the management of protected areas (as defined according to this assessment), and most PAs of the department of Santa Cruz, especially the municipal-level PAs have high climate vulnerability. Similar results related to the lack of action on the part of management are shared by Lemieux \& Scott (2011) who cite several authors, noting: the scientific literature has been dominated by ecology and failed to integrate scientific and social considerations (e.g., decision-making, policy, etc.); nonbiological management objectives for areas have been largely ignored in assessments of climate change impacts (e.g., tourism and recreation, ecosystem services in relation to human health and welfare); assessments with a high degree of uncertainty about the impact of climate change make it difficult for managers to translate information into practical management decisions.

In Bolivia, according to the National Program on Climate Change (PNCC 2010) there is high climate vulnerability due to the combination of these factors: extreme poverty of the rural population living in high risk areas, highly biodiverse ecosystems, significant surface area of the nation are lowlands which are vulnerable due to deforestation and flooding, predominance of an unstable climate and the a large number of tropical glaciers which are disappearing rapidly. Our results echo that there is high climate vulnerability among the protected areas within the department which have low management capacity and hence low responsiveness to weather events. 


\subsection{Objectives}

In order to develop our research on the adaptation to climate change as a key element in strategic planning of biodiversity conservation in the protected areas of the Americas and especially in Bolivia, the present project has the following main objective:

- To understand the management of protected areas and assess their capacity in response to the issue of climate change, based on response analyses of biodiversity, targeted in conservation sites and of particular management regimes in South America, with an emphasis on the Santa Cruz Department, Bolivia.

To accomplish the overall objective, we propose the following specific objectives:

- Provide an overview of prevalent strategies in conservation site management focussing on how climate change has been integrated into the steps of management planning.

- To generate and implement a step-by-step guide for climate-change relevant planning, based on the mix of methodologies, especially Conservation Action Planning (CAP).

- To evaluate the vulnerability of protected areas with respect to their management and ability to adapt to climate change according to the opinions and observations of the PA managers. 


\subsection{Literature Review}

\subsubsection{Climate change, biodiversity and protected areas}

It is certain that global mean surface temperature has increased since the late 19th century. Each of the past three decades has been successively warmer at the Earth's surface than any of the previous decades recorded with instruments, and the decade of 2000-2010 has been the warmest. The globally averaged combined land and ocean temperature data as calculated by a linear trend, show a warming of $0.85^{\circ} \mathrm{C}$, over the period 1880-2012, when multiple independently produced datasets exist, about $0.89^{\circ} \mathrm{C}$ over the period $1901-2012$, and about $0.72^{\circ} \mathrm{C}$ over the period $1951-$ 2012 when based on three independently-produced data sets (Stocker 2013).

Authors such as Williams et al. 2007 suggest that by 2100, the climate of between $4 \%$ and $39 \%$ of Earth will be different from conditions that currently exist anywhere on the planet; these regions will have 'new' so far unknown climates. The resulting changes in species distributions occurring at all spatial extents may confound the ability of parks and reserves to restore current or past composition of species assemblages. Changing distributions are evident from observations of gradual latitudinal and elevational migrations (Edwards et al. 2005; Parmesan 2006) and in extensive mortality of trees, such as "piñon" in Bandelier National Monument (Allen 2007).

Across the Americas particularly in the landscapes of the western United States, the impacts of climate change are already being seen. Forest ecosystems are experiencing changes in fire regimes, insect outbreaks, and tree mortality (Ryan et al. 2008). Higher temperatures and prolonged drought have led to increases in erosion and invasive species establishment in arid areas (CCSP 2008), and changes in surface temperature and precipitation patterns are reducing the livable habitat for many alpine species. Baron et al. (2009) comment, that after interviewing 270 U.S. National Parks about the management of natural resources within protected national parks and similarly managed reserves under continuing climate, climate change imposes fundamentally new and different management problems for park and reserve managers. There is high confidence that atmospheric carbon dioxide concentrations will increase, sea levels will rise, snow packs across most of North America will shrink, global temperature will increase, fire seasons will become longer and more severe, and the severity of storms will increase (IPCC 2007). There is a strong understanding from the physical sciences of why the timing of snowmelt is likely to change in regions with winter and spring temperatures between -3 and $0^{\circ} \mathrm{C}$ as the climate warms (Knowles et al. 2006). Scientists cannot yet model species-specific tree mortality thresholds in response to climate stress on real landscapes (McDowell et al. 2008; Purves \& Pacala 2008, in Baron et al. 2009), making it difficult to project when such extensive, rapid ecological shifts will occur. Past and present climate has shaped the valued ecosystems currently protected in parks and reserves, but future climate change will redefine these conditions. Adaptive management increases our ability to address the multiple scales at which species and processes function, and increases the speed of knowledge transfer among scientists and managers (Baron et al. 2009). 
In Latin America, tropical forests, particularly in the Amazon region, are increasingly susceptible to fires due to increased drought and the direct and indirect impacts of El Niño (Magrin et al. 2007). This climatic phenomenon has the potential to generate large-scale forest fires due to extended periods without rain in the Amazon, exposing even undisturbed, dense forest to the risk of understory fire. Due to its geographic and topographic features, Latin America and the Caribbean are markedly vulnerable to climate change and at the same time play an important role as carbon sinks. It is calculated that between $18 \%$ and $26 \%$ of the global total carbon in forest ecosystems; $11 \%$ content in pastures; and $17 \%$ in agricultural ecosystems (Samaniego 2009) is contained in Latin America, however, the same author notes that because of inadequate historical management of these natural resources, they have been subject to constant degradation. It is expected (Bezauri 2009) that the most significant increase in temperature and higher variability of precipitation will occur in the Amazon region, across both the dry and wet seasons. Protected areas in Mexico provide at least USD 3,500,000 annually to the economy. In 2007 (EDELCA 2008, in PNUD 2010) 73\% of Venezuela's electricity was generated by hydroelectric plants from water that is derived from several national parks.

South America, according to data from PNUD (2010), has more than $40 \%$ of the biodiversity of the Earth and over a quarter of forests. The Mesoamerican Reef in the Caribbean is the Western Hemisphere's largest coral reef. Central America, despite being only $0.5 \%$ of global landmass, contains $10 \%$ of global biodiversity. Fifty percent (50\%) of plant taxa found in the Caribbean do not occur in any other part of the world. Latin America including the Caribbean covers $16 \%$ of the land mass of the globe and contains $10 \%$ of world population.

Studies indicate that the effects of climate change in South America include possible transformation of tropical forest to savanna, conversion of semi-arid vegetation to arid vegetation, significant loss of biodiversity, loss of crops, reduction in livestock production and reduced availability of fresh water (Bernstein et al. 2007; West et al. 2011; Wu et al. 2011, in Rios 2013). In the early 1990s, according to Piepenstock \& Maldonado (2011), Latin America had 1,100 million hectares of forests and jungles. In 10 years (1990-2000), 46.7 million of these hectares were lost, mainly due to deforestation.

According to the report on the Millennium Development Goals (2009), only $12 \%$ of the planet is under some form of protection. However, in Latin America and the Caribbean there is a particularly high number of protected areas (PAs): E.g., Brazil has 1,280 PAs (excluding Indian lands) while the rest of South America (excluding Brazil) reports 1,507 terrestrial PAs, covering $22 \%$ of the continent's land surface, and 114 marine reserves. In Central America, terrestrial protected areas cover more than a quarter of the land area; in particular, Costa Rica, Guatemala and Panama each have a large proportion of protected land. In the Caribbean there are 973 protected sites, many of which are marine areas.

The preliminary report of Working Group II of the IPCC 2014 (Report V) (Field et al. 2014), reaffirms the statement by Group I (Chapter 27): key trends in precipitation and temperature have been observed in Central America (CA) and South America (SA) (high confidence). In addition, changes in climate variability and extreme events have severely affected the region (medium confidence). The climate projections suggest an increase in temperature and increase or 
decrease in precipitation for CA and SA (medium confidence). Changes in flow evaporation and water availability have been observed and are projected to continue into the future in $\mathrm{CA}$ and SA, affecting vulnerable regions already (high confidence). The conversion of natural ecosystems is the main cause of the loss of biodiversity and ecosystems from the region, and is a causal factor of anthropogenic climate change (high confidence). It is expected that climate change will increase extinction rates (medium confidence).

Bolivia, which is one of the 17 megadiverse countries (Ibisch \& Merida 2003; PNCC 2010), is facing numerous climate-related threats, ranging from water scarcity due to rapidly retreating glaciers in the Andes to a partial loss of the Amazon forest in the lowlands (Seiler 2009; Seiler et al. 2013; Rios et al. 2013). Meanwhile, Urrutia \& Vuille (2009) and Hoffmann \& Weggenmann (2011) among others, recognize that the impact of climate change in the country is likely to be stronger in tropical high mountain regions.

For Bolivia, El Niño (El Niño-Southern Oscillation_ENSO) is associated with rainfall deficit in the Altiplano, Andean mountain ranges, inter-Andean valleys and the Chaco region and excess rainfall in the north-eastern plains (Ibisch \& Merida 2003). Studies like Seiler (2009), say that recent climate change and the ENSO events which occurred during 2006/07, 2004/05, 2002/03, 1997/98, 1993/94, 1991/92 and 1986/87 have been closely associated with disturbances in rainfall regimes in Bolivia and other hydrometeorological hazards, including floods in the lowlands region of the country and drought in the highlands and valleys (Salamanca 2008). The increased frequency and intensity of El Niño events since 1976 and the shorter duration of the cold phase (La Niña) are contributing to the rapid retreat of glaciers in the central Andes (Horstmann 2006; CEPAL 2007; Rios et al. 2013). The International Development Bank (IDB) estimates that during the period 1970-1999 the losses from natural disasters in Bolivia amounted to $21 \%$ of the Gross Domestic Product (GDP) (PNCC 2010).

Due to the increasing temperature, so-called hot spots have increased markedly during the period 2001-2010, causing greater numbers of more intensive and larger surface fires, according to a study in the northern Amazon region (Barra 2011). Ibisch \& Merida (2003), state that rainforests in Bolivia (which are far from primary precipitation sources such as oceans) are threatened when other forests are deforested (such as in Brazil); causing a serious impact on the living conditions of the inhabitants of these areas. Wetlands, particularly those in the high mountains and those which are groundwater-dependent will be affected in their permanence, area and biogeochemical cycles. The humid forests are likely to be replaced by ecosystems, which are more resilient to the multiple stresses of temperature increase, droughts and fires. The extent of savanna will expand into present forest areas and many species dependent on forest ecosystems could become extinct, at least on a local scale, through migration to wetter systems.

Seiler et al. (2013) confirm that Bolivia's future climate will be warmer and drier the near-term future. Droughts and floods would impact lowlands ecosystems, while increasing temperatures and drought might represent important changes in the Andes. Actually, dry forests could be more sensitive to rainfall anomalies than wet forests (Seiler et al. 2014). 
The PNCC (2010), based on their studies of climate modeling to Bolivia, notes that some ecosystems could disappear completely as in the case of temperate rainforest. In the short-term, more impacts are expected in the ecosystems of mountain slopes and closed valleys.

Movement of species to and from protected areas is expected. This includes positive species movements and also negative (as in exotic species invasions). Climate change will also affect farming, such as shifting potato cultivation to higher altitudes due to temperature increases. (Hoffmann 2010). Authors like Hole et al. (2012), have identified the altitudinal ranges and intersections between ecosystems, such as between the Chiquitano dry forest and marshland ecoregions as potential key gaps against climate change. Unpublished studies (Herzog, not published, cited in Herzog et al. 2012) from the inter-Andean dry valleys of Bolivia, show that avian reproduction is highly seasonal and is largely restricted to the austral spring and summer. The primary factors for reproduction are rainfall and insect biomass which is highly correlated with precipitation. According to Montaño (2007), the phenology of bats in montane forest (1300$1750 \mathrm{~m})$ on the eastern slopes of the Andes in Bolivia showed various seasonal reproductive peaks per year related to the availability of resources and linked to precipitation. During a process of monitoring biodiversity in the valleys of the department of La Paz (Aparicio 2007, in PNUD 2013) noted the presence of species of bats and birds in places where none existed before, which may be related to a altitudinal migration of species under new climate conditions.

Ocampo \& Aparicio (2010) have identified the two highest-elevation populations of lizards in Bolivia, probably in response to the emergence of new ecosystems that were previously covered by ice and snow. Meanwhile, Seimon et al. (2006), in PNUD (2013) have observed an increase in the altitudinal limit of frogs in response to the retreat of glaciers in the tropical Andes and located three species at altitude records $(5.244-5.400 \mathrm{~m})$.

\subsubsection{Political and social context relative to protected areas in Bolivia}

Bolivia currently faces new and changing political, economic and social scenarios for handling and managing protected areas, forest management and climate change. In 2006, the socialist party MAS came to power through elections, led by indigenous president Evo Morales. Morales was an organizer for coca growers and a main opponent of the institutional reforms in the country during the 1990s. A new Constitution was drafted and ratified under Morales' administration, with gradual changes in policy and legislation, including the nationalization of protected areas and national parks (including the natural resources of economic value within the PAs (hydrocarbon reserves, minerals, timber, etc.) (Salinas 2007). In the past five years of his administration, many social conflicts occurred mainly related to land tenure, land use and the problem of coca eradication in the coca-producing areas. These conflicts led to a general government crisis in the wake of growing public discontent in the middle of a major political dispute between new political parties, opposition leaders and regional elites who have emphasized the process of political autonomy (Müller et al. 2014).

The climate change policies made by the Bolivian government (referring to the proposal discussed in the framework of the CMNUCC (Convención Marco de las Naciones Unidas sobre el Cambio Climático) that has linked the deforestation of tropical forests to climate change have 
taken a position against market options for reducing emissions from deforestation and promoting carbon sequestration in forests as part of the mitigation options climate Change: REDD+ (Reducing Emissions from Deforestation and Degradation). In this respect we quote the analysis conducted by Muller et al. (2014) who comment that Bolivia's position on climate change is not without internal political conflict and that has found its current expression in the alternative position to REDD+ internationally called "Joint Mitigation and Adaptation Mechanism for Integrated and Sustainable Management of Forests and Mother Earth" The government also promotes "Live well in harmony and balance with Mother Earth", which has been one of the main themes of current government discourse, regarding land and forest policy adjustments (indigenous land titles, forest regulations). The Bolivian constitution defines a government model for "living well" which aims at developing comprehensive policies which aren't based solely on economic aspects development, thus establishing a framework to recover the link between nature and society (Araujo et al. 2010). The role and rights of indigenous peoples and peasant communities in conservation is also recognized. Emphasizing the importance of mechanisms that are not market-based, the government of Bolivia has created the "Joint Mitigation and Adaptation Mechanism for Integrated and Sustainable Management of Forests and Mother Earth." This proposal was formally adopted as public policy as part of the Mother Earth law, in 2012 and made into law in 2013. Despite the legal status, there have not yet been substantial changes in policy and regulations regarding land and forest which align with the vision of the Mother Earth law, and a new forest law is under discussion at present.

Relative to protected areas work, the current government's vision of social participation, (Mendoza 2010), constitutes a suitable scenario to develop effective participatory processes, so the National Service of Protected Areas (SERNAP) has promoted the concept of shared management, in which the main local stakeholders assume higher levels of responsibility, lead public committees, make joint strategic management decisions with local and national social organizations. "SERNAP now demands increased funding from the General Treasury and reports that of the total budget, $95 \%$ comes from international cooperation, $4 \%$ generated by the PA and 1\% from the government." Regarding funding sources, Castro (2012) points out that funding has decreased in recent years as part of the impact of different financial crises worldwide and from a reduction in resources from international cooperation for environmental and conservation issues in Bolivia. The hope continues for the right conditions (Zambrana \& Silva 2008) where social and conservation processes come together to create and develop a governance model oriented to "shared land management" where indigenous rights and selfadministration and conservation of natural heritage.

\subsubsection{Classification of climate change stresses}

We elaborated a "Classification of Climate-Change-Induced Stresses on Biological Diversity" (Geyer et al. 2011). In this current study we use our classification for our analysis of threats in addition to the other CAP concepts developed in the process of publication.

The Classification of Climate-Change-Induced Stresses on Biological Diversity refers to the need for conservation actions to consider the changes that will occur from climate change and apply an adaptive management approach to address these changes. Any impact of climate change 
is considered a stress, since its effect is a (positive or negative) change in key parts of an ecosystem and the ecological attributes. In this classification we used a systematic method and a hierarchical framework to integrate the types of stress to biological diversity caused directly by climate change.

We identified the kinds of stress by analyzing 20 conservation sites across 7 countries and the through literature review. We grouped the types of stresses according to 3 levels of biological diversity: 1) those that affect individuals and populations, 2) those that affect biological communities and 3) those that affect the structure and function of the ecosystem. For each category of stress, we identified three hierarchical levels: Coarse resolution (8 types of stresses); Specific stresses (21 types of stresses); Detailed stresses (90 types of stresses) (Table 1 below). We also compiled an overview of the effects of climate change on ecosystem services using the categories of the Millennium Ecosystem Assessment and two additional categories. Our classification can be used to identify key types of stress related to climate change and can help to develop appropriate conservation strategies. The classification is in a list format, but takes into account the types of stresses induced by climate change (Table 2 ). 
Table 1. Classification of climate-change related stresses (Geyer et al. 2010)

\section{Stress classification}

\section{Change at individual and population level}

1.1 Direct stresses to individuals and populations

\subsubsection{Change in physiology and behavior of individuals}

\subsubsection{Change in morphology}

1.1.1.2 Change in metabolism and physiology

1.1.1.3 Change in immune function

1.1.1.4 Change in growth rate

1.1.1.5 Change in photosynthetic rate

1.1.1.6 Change in rate, timing, and frequency of life-cycle events

1.1.1.7 Change in behavior

1.1.1.8 Immediate death due to extreme events

\subsubsection{Change in population dynamics}
1.1.2.1 Change in population growth rate
1.1.2.2 Change in sex determination and sex ratio
1.1.2.3 Change in gene pool
1.1.2.4 Change in dispersal, recruitment and colonization

1.2 Habitat-related stresses to individuals and populations

\subsubsection{Loss of habitat}

1.2.1.1 Reduction of local or global quantity of habitat due to elevational and latitudinal shifting of climate space (includes barriers [mountains, coastlines] and poor connectivity between recent and potential future habitats)

1.2.1.2 Mismatch of required climate and non-climate habitat components

1.2.1.3 Reduction of climateally suitable space

1.2.1.4 Reduction due to sea level rise and coastal erosion

1.2.1.5 Physical surface conversion of formerly inhabited area

1.2.1.6 Melting of ice sheets

\subsubsection{Change in habitat quality}

1.2.2.1 Change in abiotic habitat components and factors (cf. 3.1)

1.2.2.2 Change in biotic habitat components and interactions (cf. 2)

1.2.2.3 Change in disturbance regimes (cf. 3.3.3)

1.2.2.4 Change in resource and food availability

\section{Change at community level}

2.1 Change in synecological relations (trophic interactions, symbioses, competition)

\subsubsection{Loss or decoupling of synecological interactions and interdependencies}

2.1.1.1 Loss of interactions due to differential range shifting of interacting species

2.1.1.2 Loss of interaction due to local extinction or abundance loss of a partner species

2.1.1.3 Loss of interactions due to phenological mismatch

\subsubsection{Change in the character of existing interactions}

2.1.2.1 Change of interaction due to changed fitness or competitiveness of a partner (including pathogens and parasites)

2.1.2.2 Changed interactions due to change in behavior of an interacting species 
2.1.2.3 Changes of interactions and resource availability or accessibility due to phenological mismatch

\subsubsection{New species interactions}

2.1.3.1 Appearance of new competitors that affect species richness or abundance of individuals

2.1.3.2 Appearance of new predators

2.1.3.3 Appearance of new pathogens and parasites

2.1.3.4 Appearance of new prey and host species

2.2 Change in community structure

\subsubsection{Change in community composition}

2.2.1.1 Loss or disassembly of community

2.2.1.2 Loss of species

2.2.1.3 Appearance of new species

\subsubsection{Change in relative abundances}

2.2.2.1 Abundance change due to changed competitive relations between species at same trophic level

2.2.2.2 Abundance change due to changed species interactions between trophic levels (e.g., predation, symbioses, disease)

\section{Change at ecosystem level}

3.1 Change of abiotic conditions

3.1.1 (Micro)climate changes (average, variability and seasonality)

3.1.1.1 Change in interannual and long-term variability

3.1.1.2 Change in annual average temperatures and temperature variability

3.1.1.3 Change in amount, distribution and form of precipitation

3.1.1.4 Change in wind patterns and strengths

3.1.1.5 Change in evaporation and humidity

3.1.1.6 Change in cloud cover

\subsubsection{Change in marine water characteristics}

3.1.2.1 Change in water temperature regime

3.1.2.2 Change in water chemistry (including salinity, $\mathrm{pH}$ )

3.1.2.3 Change in sea currents and upwelling

3.1.2.4 Change in wave and spray patterns

3.1.3 Change in freshwater hydrological regimes (wetlands)

3.1.3.1 Permanent change in water levels

3.1.3.2 Change in water level variability in wetlands

3.1.3.3 Change in groundwater tables

3.1.3.4 Change in flood occurrence, frequency, intensity and area flooded (including hydroperiod)

3.1.3.5 Change in run-off and river flow

3.1.3.6 Change in water temperatures

3.1.3.7 Change in chemical water characteristics

3.1.3.8 Change in evaporation

3.1.4 Change in snow or ice regimes

3.1.4.1 Change in snow pack

3.1.4.2 Change in snow loads

3.1.4.3 Change in snow cover period 
3.1.4.4 Change in thickness of permanent ice sheets and melting of glaciers and permanent snow cover

3.1.4.5 Change in duration and thickness of seasonal ice sheets and freezing of water bodies

3.1.4.6 Melting of permafrost soils

\subsubsection{Change in abiotic soil conditions}

3.1.5.1 Change in soil moisture

3.1.5.2 Change in soil temperature

3.1.5.3 Change in physical soil composition

3.1.5.4 Change in chemical characteristics

3.2 Change in ecosystem structure

\subsubsection{Change in the abiotic structure}

3.2.1.1 Change in surface structure and terrain

3.2.1.2 Sea-level rise, fluctuation, and coastal impacts

\subsubsection{Change in the biotic structure}

3.2.2.1 Change in basic biotic structural elements (e.g. structure-constituting species such as trees or corals)

3.2.2.2 Change in synecological interactions (cf. 2.1)

3.2.2.3 Change in community composition and structure (cf. 2.2)

3.3 Change in ecosystem processes and dynamics

\subsubsection{Change in geophysical and disturbance processes}

3.3.1.1 Change in evapotranspiration and cloud formation

3.3.1.2 Change in type, frequency, intensity and/or length of climate extreme events (e.g., droughts, hurricanes)

3.3.1.3 Change in flood frequency, intensity and area flooded (e.g., potamic flooding, tsunamis, stormfloods)

3.3.1.4 Change in surface movements (avalanches, erosion, landDIAPs)

3.3.1.5 Change in seismic and volcanic processes

3.3.1.6 Change in fire frequency, intensity, or extent

3.3.2 Change in energy flow and nutrient or matter cycle-related ecosystem processes

3.3.2.1 Change in decomposition rates

3.3.2.2 Change in nutrient availability

3.3.2.3 Change in primary production

3.3.2.4 Change in oxygen cycle

3.3.2.5 Change in carbon cycle

3.3.2.6 Change in nitrogen cycle

3.3.2.7 Change in phosphorous cycle

3.3.2.8 Change in accumulation of non-nutrient elements, pollutants and heavy metals

\subsubsection{Change in succession processes and ecosystem development}

3.3.3.1 Change in short-term succession processes (seasonal, small-scale disturbances, individual and species turnover)

3.3.3.2 Change in long-term succession and ecosystem development

3.4 Change in ecosystem presence and global distribution

3.4.1 Change in global distribution of ecosystems

3.4.1.1 Spatial extent of individual ecosystems

3.4.1.2 Spatial distribution of ecosystem types

3.4.2 Change in diversity of ecosystems 
3.4.2.1 Loss or dissolving of known ecosystems

3.4.2.2 Emergence of formerly unknown ecosystems

Table 2. Overview of effects of climate change on ecosystem services ${ }^{\mathrm{a}}$

\section{Change in provisioning services}

1.1 Availability of and access to food

1.2 Availability of and access to fiber

1.3 Availability of and access to genetic resources

1.4 Availability of and access to biochemicals, natural medicines, and pharmaceuticals

1.5 Availability of and access to ornamental resources

1.6 Availability of and access to fresh water

\section{Change in supporting services}
2.1 Soil formation
2.2 Photosynthesis
2.3 Primary production
2.4 Nutrient cycling
2.5 Water cycling

\section{Change in regulating services}
3.1 Air-quality regulation
3.2 Local, regional, or global climate regulation
3.3 Regulation of atmospheric gases ${ }^{\mathrm{b}}$
3.4 Water regulation
3.5 Water purification and waste treatment
3.6 Erosion regulation
3.7 Disease regulation
3.8 Pest regulation
3.9 Pollination
3.10 Seed dispersal ${ }^{\mathrm{c}}$
3.11 Natural-hazard regulation

\section{Change in cultural services}
4.1 Cultural diversity
4.2 Spiritual and religious values
4.3 Knowledge systems
4.4 Educational values
4.5 Inspiration
4.6 Aesthetic values
4.7 Social relations
4.8 Sense of place
4.9 Cultural heritage values
4.10 Recreational and tourism values

\footnotetext{
${ }^{\text {a }}$ Slightly adapted from the Millennium Ecosystem Assessment (MA 2005).

${ }^{\mathrm{b}}$ Category added to MA classification; carbon sequestration and regulation of atmospheric elements and compounds including carbon dioxide, oxygen, and ozone (Costanza 1997; Groot et al. 2002; Wallace 2007).

${ }^{c}$ Category added to the MA classification from Wallace (2007).
} 


\subsubsection{Definition of key terminology}

So that readers may understand our research more fully, we felt it helpful to define some of the terms which are used frequently and which are key to explaining the topics in our work:

Adaptation: Defined as the, "adjustment in natural or human systems to a new or changing environment. Adaptation to climate change refers to adjustment in natural or human systems in response to actual or expected climate stimuli or their effects, which moderates harm or exploits beneficial opportunities. Various types of adaptation can be distinguished, including anticipatory and reactive adaptation, private and public adaptation, and autonomous and planned adaptation."(IPCC 2007).

Biological diversity: Means the variability among living organisms from all sources including, inter alia, terrestrial, marine and other aquatic ecosystems and the ecological complexes of which they are part; this includes diversity within species, between species and of ecosystems (CBD).

Climate: In a narrow sense is usually defined as the average weather, or more rigorously, as the statistical description in terms of the mean and variability of relevant quantities over a period of time ranging from months to thousands or millions of years. The classical period for averaging these variables is 30 years, as defined by the World Meteorological Organization. The relevant quantities are most often surface variables such as temperature, precipitation and wind. Climate in a wider sense is the state, including a statistical description, of the climate system (IPCC 2013).

Climate change: Refers to a change in the state of the climate that can be identified (e.g., by using statistical tests) by changes in the mean and/or the variability of its properties, and that persists for an extended period, typically decades or longer. Climate change may be due to natural internal processes or external forcing's such as modulations of the solar cycles, volcanic eruptions and persistent anthropogenic changes in the composition of the atmosphere or in land use (IPCC 2013).

Ecoregion: Defined as an area that consist of a characteristic grouping of natural communities that: 1) share many taxa, ecological dynamics and environmental conditions; 2) have greater biological and ecological interrelations and interdependences among themselves that with the communities found outside the regions; 3) show common patterns from biomass production, including forestry and agriculture (Ibisch et al. (2003).

Mitigation: An anthropogenic intervention to reduce the anthropogenic forcing of the climate system; it includes strategies to reduce greenhouse gas sources and emissions and enhancing greenhouse gas sinks. (IPCC 2007).

Viability: The status or "health" of a population of a specific plant or animal species. More generally, viability indicates the ability of a conservation target to withstand or recover from most natural or anthropogenic disturbances and thus to persist for many generations or over 
long time periods. Technically, the term "integrity" should be used for ecological communities and ecological systems with "viability" being reserved for populations and species. In the interest of simplicity, however, we use viability as the generic term for all targets (TNC 2007).

Definitions are taken from Ibisch \& Hobson (2014):

Adaptive management: Is best described as a process that allows micro-collapses within a system, whenever an external disturbance shows that the system needs reorganization. Adaptive management is mistake- friendly because it encourages systematic learning from errors in order to build more efficient and resilient systems. It is not only about effective learning from experience; it may also include unlearning in order to reorganize the knowledge required for effective management.

Biodiversity: Biodiversity is the variability of life, encompassing all its elements, patterns and processes. It is the full complement of form and function that makes up life on earth.

Conservation: Conservation describes the process of securing or restoring the optimum conditions in an ecosystem that allows it to function unsupported to its full potential. It recognizes the importance of maintaining all compositional and conformational attributes, including evolution, structures, patterns and dynamics that promote inherent resilience and adaptability - mostly to be achieved by reducing existing and imminent threats to the conservation objects, and decreasing their vulnerability against probable disturbances and changes. It does not intend to maintain the status quo for any preconceived historical or culturally desired state of a system.

Ecosystem functionality: Functionality describes the operational state of ecosystems. It is characterised by inherent structures, ecological processes and dynamics that provide ecosystems with both the necessary (energetic, material and hydric) efficiency and resilience to function effectively without (abrupt) alteration to system properties or geographical distribution during periods of external change. Ecosystems develop greater functional efficiency when they harbour more biomass, contain more information, and are organised more complexly with a high degree of connectedness among the system's elements.

Key ecological attributes (KEA): Are best described as integral elements and properties of ecological systems that maintain function and provide the necessary adaptation and resilience to cope with perturbations. According TNC (2007): Aspects of a target's biology or ecology that, if missing or altered, would lead to the loss of that target over time. KEAs can often be grouped into three classes: - Size is a measure of the area or abundance of the conservation target's occurrence. - Condition is a measure of the biological composition, structure and biotic interactions that characterize the occurrence. - Landscape context is an assessment of the target's environment including ecological processes and regimes that maintain the target occurrence such as flooding, fire regimes and many other kinds of natural disturbance, and connectivity such as species targets having access to habitats and resources or the ability to respond to environmental change through dispersal or migration. 
Risk management: Evolved in domains where the avoidance of damage was considered to be very important, such as in disaster prevention, safety management or the insurance business. In general terms, a "risk" is nothing other than a future event that will occur with a certain probability and may cause a given impact in a system. It can have either a positive or negative effect. However, popular concepts of risk imply a certain level of threat. Risk management comprises three main elements: risk search and perception; risk assessment; risk response.

Stresses: Stresses describe the symptoms and manifestations of the degradation of key ecological attributes caused by the insufficient availability or quality of master factors, and manifesting as the loss of minimum levels of biomass, information and network.

Threat: A disturbance that causes a negative change of key ecological attributes and stress in a biological or ecological system y segun TNC (2003), the final value of a threat is the sum of the individual scores: "severity" (degree of injury, severity or intensity at a given location); "Scope" (geographic extent of the pressure at the site) and "irreversibility".

Vulnerability management: In conservation is related to risk management, but it involves a more comprehensive, functional and dynamic process. It acknowledges: the relevance of dynamic and interacting risks; different entry points of strategies that tackle specific problems or enhance the viability of conservation objects by strengthening their resilience and adaptive capacity. 


\section{STUDY AREA}

At the scale of the Americas, we reviewed plans from the Caribbean, North, Central and South America: Argentina, Brazil, Bolivia, Canada, Colombia, Costa Rica, Chile, Ecuador, the Dominican Republic, Grenada, Guatemala, Jamaica, Mexico, Nicaragua, Panamá, Peru, and the USA. Our review of the Conservation Action Plans (CAPs) did not take into account geographical aspects of location by country. We only used the information contained in each of the steps in the methodology; therefore we only name the countries here for reference.

Regionally, our study focused on Bolivia which is located in the center of South America between parallels $9^{\circ} 39^{\prime}$ 'and $22^{\circ} 53^{\prime}$ of latitude south and $57^{\circ} 25^{\prime}$ and $69^{\circ} 38^{\prime}$ of longitude west and the intersection of Andean, Amazonian and Chaco regions. It is among the 17 countries with an extremely high level of biodiversity (megadiversity countries). Few countries have greater diversity of ecosystems than Bolivia, whose geographical characteristics vary in topography, altitude (between 200 and 6,000 m), precipitation (between 200 and 5,000 mm/year) and temperatures (glacial to tropical). Regional climates within Bolivia are strongly determined by the altitude (Ibisch \& Merida 2003; SERNAP 2007; Andersen \& Mamani 2009; PNCC 2010, Araujo et al. 2010).

The protected areas (PAs) in Bolivia are "natural areas with or without human intervention, declared under state protection by laws, in order to protect and conserve wildlife, genetic resources, natural ecosystems, watersheds and resources of scientific, aesthetic, historical, economic and social interest in order to conserve and preserve the natural and cultural heritage of the country" (Art. 60, Law 1333 ). The first PA in Bolivia was created in 1939. The National System of Protected Areas (SNAP) was established in 1992 by Environment Act No. 1333, with the goal of maintaining representative samples of biogeographic provinces throughout the country, so the SNAP includes all areas in the country and until 2010, according to Araujo et al. (2010), represented 123 legally-created areas with 22 national-level Pas (about 16\% of the surface of country, or 17 million ha), 23 departmental-level PAs and 78 municipal-level PAs.

Bolivia has focused its protected areas policies to those of "areas with people", since the population associated with PAs accounts for about $20 \%$ of the total population, excluding the capital municipalities of each department. Also most of the highland and lowland ethnic groups of Bolivia are among the populations living within national-level PAs or nearby (SERNAP 2001; PNCC 2010). Until 2005, according to a study by Araujo et al. (2010), there was little degradation within the protected areas of Bolivia, since only $4.5 \%$ of the 18 million ha contained in national-level PAs had some degree of degradation. This indicated healthy conservation status, despite growing pressure for resources and local, regional and national development initiatives.

Part of our research is based in the department of Santa Cruz, which covers $33.7 \%$ of the area of Bolivia. It includes several South American ecosystems of high global importance such as the Amazon, Cerrado and the Chaco, forming a mosaic of tropical rainforests, tropical dry forests and savannas. This diverse landscape is home to a wealth of important natural and cultural 
resources. Seventy-one percent (71\%) of all bird species and $78 \%$ of all amphibians species found in Bolivia are present in the Santa Cruz department (Quiroga et al. 2012).

In Santa Cruz there are 5 national parks which are administered by the National Service of Protected Areas (SERNAP). One park has a surface area of 600,000 ha and the other four parks are even larger, ranging in size from 1,000,000 to 3,500,000 hectares. There are 8 departmentallevel protected areas which are under the management of the Office of Protected Areas (DIAP) and the Ministry of Sustainable Development and Environment (SDSyMA). The sizes of these areas range from 1,300 to 1,500,000 ha. There are 19 municipal-level areas, which are administered by their respective local government in coordination with DIAP. Although there is no explicit legal mandate for the creation and management of municipal protected areas, environmental and municipal laws allow for their creation. The sizes range from 380 to 350,000 ha (Quiroga et al. 2011). In total, the 32 protected areas of Santa Cruz account for $36.4 \%$ of the department's surface area and $12.3 \%$ of Bolivia's total area $(1,098,581 \mathrm{~km} 2)$. (See Fig. 1 . Protected areas in Santa Cruz, Map) (see photographs in annex 1).

The department has four biogeographic regions: Amazon to the north; the Brazilian - Paranense region across the central-eastern part of the department; the Chaco region in the south; and tropical Andean region to the west. This variability results in a diversity of vegetation types: Amazon forest, Chiquitano dry forest, Chaco forest, flooded savannas, Yungas, Cerrado, Bolivian-Tucuman forests and Andean dry valleys. Globally, these vegetation types, along with their respective climate, soil, flora and fauna are grouped into large geographic areas known as ecoregions. In the department of Santa Cruz there are 9 ecoregions. Globally for the Chiquitano dry forest, $71 \%$ is located in Bolivia, entirely in the department of Santa Cruz, highlighting the importance of this area for conservation of this ecoregion (Ibisch \& Merida 2003).

We also highlight other ecoregions of Bolivia- Cerrado, dry Chaco and Pantanal, which are entirely located within the department of Santa Cruz and generally represent the best preserved portions of their global distribution (Quiroga et al. 2011). The same study shows that by area, $27 \%$ of the ecosystems in the Santa Cruz department, have a very good (between $80-100 \%$ of its biodiversity intact) conservation status. Just over half of these "very good" ecosystems are located within the departmental-level protected areas, representing $14 \%$ of the natural areas of Santa Cruz in very good conservation status. 
Figure 1. Map of protected areas in the department of Santa Cruz, Bolivia

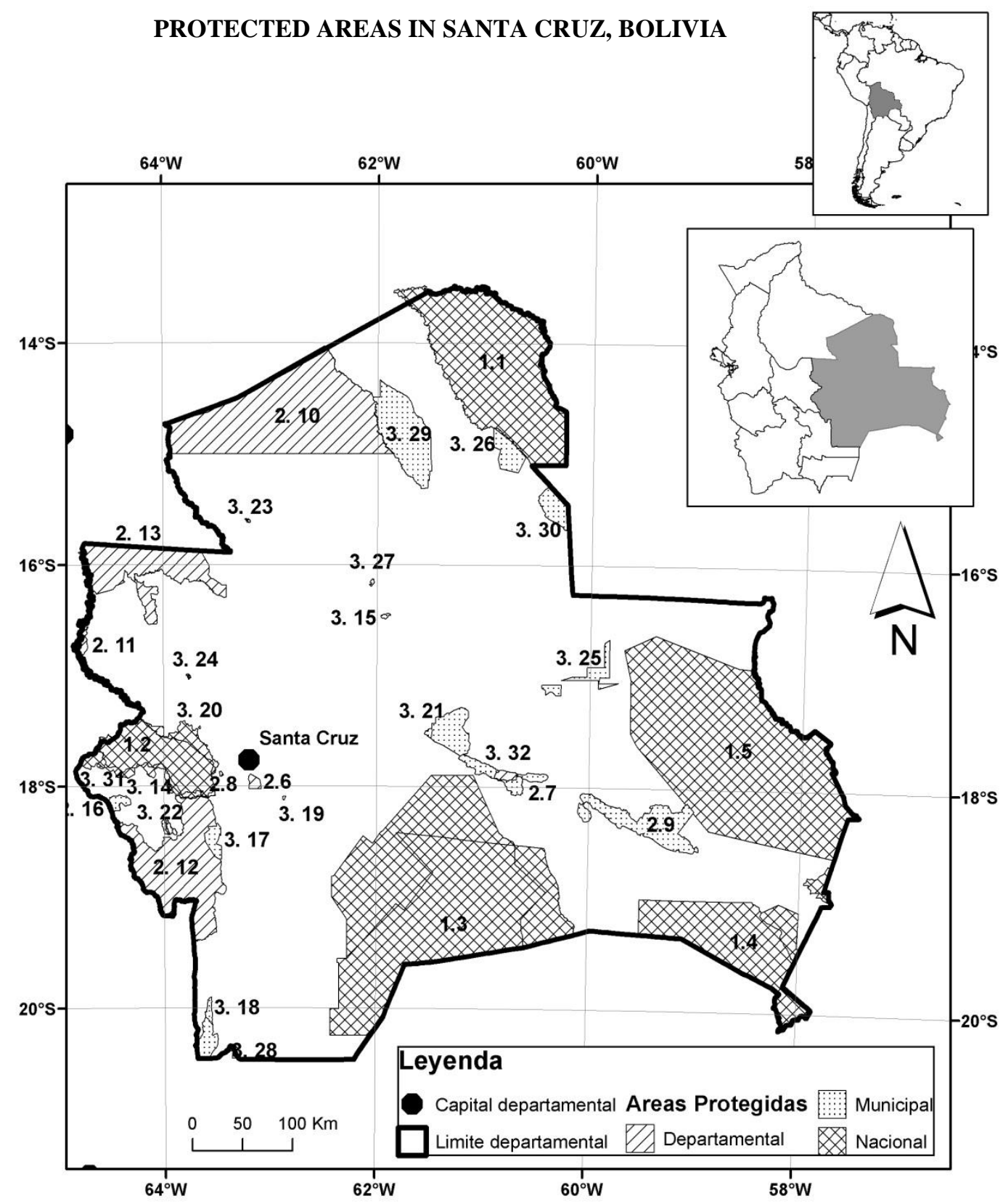

\section{National Parks (NP)}

1.1 PN Noel Kempff Mercado

1.2 PN y Area Natural de Manejo

Integrado (ANMI) Amboró

1.3 PN y ANMI Kaa-Iya del Gran Chaco

1.4 PN y ANMI Pantanal Otuquis

1.5 PN y ANMI San Matías

\section{Departmental Protected Areas}

2.6 Parque Regional Lomas de Arena

2.7 PN Histórico y Arqueológico Santa

Cruz La Vieja

2.8 Monumento Natural de Espejillos

2.9 Reserva de vida Silvestre (VS) de

Tucavaca

2.10 Reserva de VS Ríos Blanco y Negro
2.11 Meandros del Río Ichilo

2.12 ANMI Río Grande Valles Cruceños

2.13 Humedales del Norte

3. Municipal Protected Areas

3.14 Microcuenca quebrada El Chape

3.15 Orquídeas del Encanto

3.16 Jardín de Cactáceas de Bolivia

3.17 Parabanó

3.18 Sararenda

3.19 Reserva de VS Palmera de Saó

3.20 Reserva Natural Curichi El Cuajo

3.21 Reserva de VS Laguna Concepción
3.22 Santuario de VS y ANMI

Laguna Esmeralda

3.23 Laguna Yaguarú

3.24 Lagunas Santa Bárbara y Brava

3.25 Reserva Municipal de San Rafaél

3.26 Reserva Municipal de San Ignacio

3.27 Laguna de la Represa Zapocó

3.28 Monumento Natural Muela del

Diablo

3.29 Reserva de Copaibo

3.30 Laguna Marfil

3.31 Churo Negro

3.32 ANMI y P Histórico Santa Cruz La Vieja 
$40 \%$ of the total area of Santa Cruz has a conservation status of "good", according to Quiroga et al. (2012) and 35\% of the area of the department contains areas of high biodiversity conservation value, largely located in the interiors of the existing protected areas. According to Andersen \& Mamani (2009), Santa Cruz is the only department that could see an increase in biodiversity as an effect attributable to climate change. The PRECIS model predicts more rainfall in the dry areas of Santa Cruz.

The negative impact of human activities in Santa Cruz has been focused in the west central part of the department, mainly in urban footprints and transportation routes. Less than $20 \%$ of the original biodiversity remains intact in this impacted area (Quiroga et al. 2012).

The main threats to the protected areas of Santa Cruz are hydrocarbon, mining, logging, hydroelectric and geothermal operations; highway and rail infrastructure projects; and agriculture. Other major threats from human activity are forest fires, when the agricultural frontier is burned to increase cropland and pasture for cattle and from the colonization and settlement by immigrant populations who come for economic opportunities in (illegal) coca cultivation, logging and the possibility of acquiring land (SERNAP 2007 report).

The Área Natural de Manejo Integrado Río Grande Valles Cruceños (ANMI RG-VC), where we did the local case study, is within the department of Santa Cruz, Bolivia. It was created through Prefectural Resolution No. 059/07, with an area of 734,000 hectares, and crossing the jurisdictions of 7 municipalities: Pucara, Vallegrande, Moro Moro, Postrervalle, Samaipata, Cabezas and Gutierrez (Fig. 2. ANMI RG -VC Map).

We gathered data about the protected area from the Management Plan (DIAP et al 2009.): The ANMI includes some of the valleys of the department of Santa Cruz and is the only place that still has cloud forests. The ANMI provides significant amounts of water that could be used for irrigating rice, sugar cane and soya in the lowlands during the dry season. Of notable importance within this large area is the remnant forest of the Vilcas and Mosqueras Rivers, which play an important role in reducing flood frequency and severity of floods lower in the watershed. The Rio Grande watershed covers a broad altitudinal range. The headwaters begin at around 4,500 $\mathrm{m}$ and the lowest stretch of the river is at $430 \mathrm{~m}$. The region is part the sub-Andean belt characterized by parallel ridges with a northwest-southeast alignment, connecting to the eastern Andes. The average rainfall is $878 \mathrm{~mm}$ (maximum of $1,764 \mathrm{~mm}$ and minimum $281 \mathrm{~mm}$ ). The temperature ranges from $6^{\circ} \mathrm{C}$ to $26^{\circ} \mathrm{C}$. Winds are predominantly north with average speeds ranging from 5 to $15 \mathrm{~km} / \mathrm{h}$. During dry periods of the winter southerly winds occur briefly with speeds up to $50 \mathrm{~km} / \mathrm{h}$, bringing cold air masses ("surazos") which arrive with a drop in temperature, accompanied by no precipitation or with drizzle. 
Figure 2. Map showing Área Natural de Manejo Integrado Río Grande Valles Cruceños

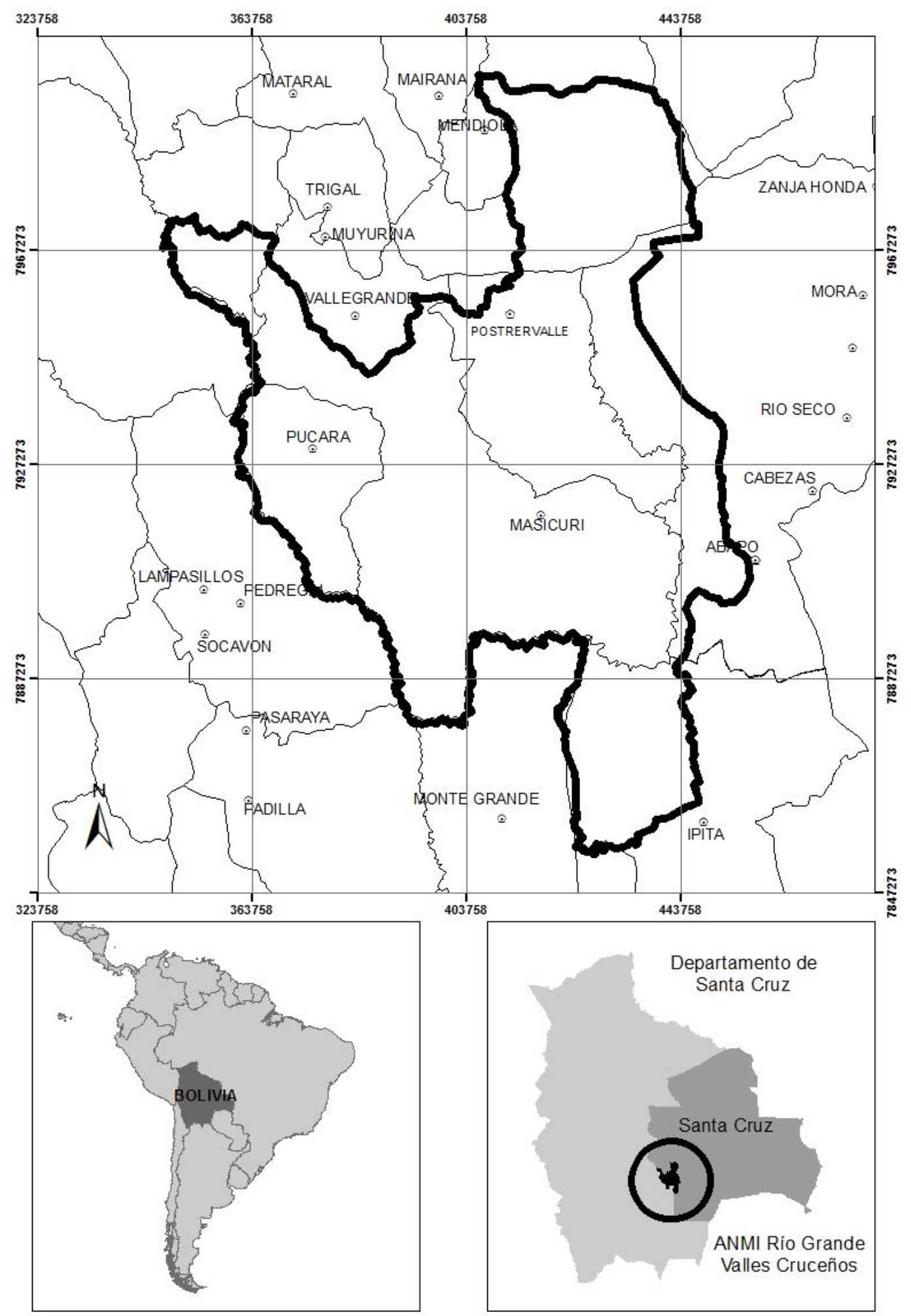


The average annual humidity ranges from 60 to $70 \%$ with significant decreases in the winter months and increases in the summer months. Two rivers drain the majority of the protected area. The Rio Grande basin covers $71 \%$ of the ANMI RG-VC and the Pirai River basin covers $15 \%$ (DIAP et al. 2009).

According to Navarro \& Maldonado (2002), the ANMI RG-VC includes three biogeographic regions: Chaco; Brazilian Parana and Andean Region. Following Ibisch et al. (2003), there are 5 ecoregions: a) Tucuman-Bolivian Forest; b) Inter-Andean Dry Forests; c) Chaco Serrano; d) Gran Chaco and e) Yungas. There are 36 vegetation series (24 as part of the Tucuman-Bolivian Forest; 4 as part of the Chiquitano Forest; 2 of the Cerrado and 6 as part of the dry forests).

The animal richness is recorded in 58 species of fish (some possibly endemic) belonging to 13 families and 3 orders; 362 bird species distributed in 52 families, 55\% are restricted to Dry Valleys (of all birds recorded in dry valleys in Bolivia ) $-66 \%$ are typical of the TucumanBolivian Forest and 34\% are typical of Yungas. Five species have been recorded with new altitude records and 3 endemic species are known from the PA. For mammals, 105 species have been recorded (DIAP et al. 2009).

The human populations in the protected area territory of the ANMI RG-VC and its area of influence are comprised of mostly Quechua (indigenous), some Guaraní (indigenous) near the town of Gutierrez, peasants and colonists (immigrants from the uplands). There are 150 communities with censused population of 19,499 inside the ANMI. The main economic activities are agriculture and livestock ranching (both intensive but small scale) (DIAP et al. 2009). 


\section{METHODS}

\subsection{Continental analysis}

To provide a macro overview of prevalent strategic settings in conservation site management focussing on how the climate change has been integrated in the steps of management planning, we review Conservation Action Planning (CAP) applied in the American continent and we see how they are adapting to climate change.

The CAP methodology has been used on all continents, but most widely in the Americas. In Latin America, the tool has been used by governmental and non-governmental entities, sometimes representing the official approach to management planning (Granizo et al. 2006). CAP allows a cyclical adaptive development of situation analyses, strategies, and effectiveness monitoring (TNC 1998; 2000; Groves et al. 2000; Granizo et al. 2006; Aldous et al. 2007). The CAPs make up a large and methodologically homogenous and well-structured set of management plans with the following iterative steps:

- the selection of a reduced number of conservation targets that adequately represent the site's biodiversity, whose viability can be estimated by evaluating so-called KEAs and which are related to the selected conservation objectives

- the situation analysis identifying impacts that threaten the conservation targets' viability or persistence, comprising both stresses and sources of stress (threats) that can be ranked according to their scope, severity and irreversibility

- the derivation of strategies to be implemented by strategic actions

- the identification of stakeholders and actors relevant for the site management

- the definition of indicators and a monitoring plan for the measurement of management success, the health of the conservation targets and the evolution of threats

The key ecological attributes (KEAs) is an aspect of a target's biology or ecology that if present, defines a healthy target and if missing or altered, would lead to the outright loss or extreme degradation of that target over time (TNC 2007). For example, a key attribute for a freshwater stream target might be some aspect of water chemistry. If the water chemistry becomes sufficiently degraded, then the stream target is no longer viable. Key ecological attributes can often be grouped into three classes: Size, Condition and Landscape.

The ConPro database comprises plans elaborated since 1998, prepared mostly by TNC staff or partner organisations (TNC 1996; 2008).

We compare plans accessible in 2008, before the TNC climate change clinic, and those elaborated after the clinic (Poiani et al. 2011). This clinic focused mainly on revision of existing plans and the training of the planning teams charged with redesigning biodiversity projects for climate change. A high level visible event with TNC, it has strongly and positively influenced inclusion of climate change in subsequent CAPs. 
In January 2008, the database contained about 900 plans, $75 \%$ for sites in the United States of America, 19\% in Latin America, and 5\% in other regions or countries. As most management plans are for sites in the Americas, where most institutional CAP knowledge and expertise has accumulated, we exclusively analysed plans (CAP) from North, Central and South America, and the Caribbean.

We reviewed all the Plans from the Caribbean, North, Central and South America; many of which did not contain sufficient information to be evaluated in a uniform manner, so instead we selected those Plans with sufficiently complete contents required to answer our guiding questions.

For the purpose of our analysis we did not differentiate between the sites' type of geographic location (e.g., coastal, island or continental). Of all plans dating from prior to 2009, we selected 103 CAPs in 15 countries that met our criteria: Nicaragua, Jamaica and Grenada with one CAP, the Dominican Republic and Chile with two; Peru, Panamá and Colombia with three; Brazil and Ecuador with four; Bolivia with seven; Guatemala with 14; Mexico with 18; and the USA with 36 Plans. Additionally, we reviewed four regional (bi- or trilateral) plans. For plans from 2009 onward, we selected 22 CAPs using the same selection method: Argentina, Brazil and Costa Rica with one plan each, Mexico with two and the US with 14. Additionally we selected one regional CAP. (See Annex 2 and 3).

To analyse each of the selected CAPs we formulated 27 guiding questions related to climate change, addressing general adaptation-relevant issues such as the selection of conservations targets, total viability, total threats value (Table 3). These questions were individually answered for every CAP, constituting a standardized basis for step-by-step analysis of the selected plans. The goal was test if a CAP is a conservation tool which sufficiently facilitates the dynamic management of protected areas accounting for rapid environmental change and the importance of conserving functionality and resilience of biodiversity. 
Table 3. Evaluation questions for each of CAP's methodological steps

Step 1. Conservation targets (CT)

How many of the selected targets are species, communities, ecosystems or ecological processes*? 1.1-Key Ecological Attributes

- Are climate-related factors taken into account such as temperature, precipitation, snow, sea level and fires in relation to climate change (CC) and conservation targets $*$ ?

- Which countries by geographical region name these factors more than others?

- Is climate change registered as "indicator" of a key attribute associated with a conservation target?

- Which countries by geographical region mention the term "climate change" more than others?

- Are there any directly climate-dependent attributes (e.g., temperature regime, precipitation regime) mentioned? *?

- Does the allocation of viability thresholds take into account future scenarios in relation to selected targets?

Thresholds mostly qualitative or quantitative?

- What is the final value of the viability of each of the sites/areas*?

- What is the value (very good, good, fair) of the viability areas by country and by geographical region?

Step 2. Threats

- Does CC appear as a threat to conservation targets*?

- Which countries by geographic region mention CC as a threat to their areas more than others?

- Which threats are considered related to $\mathrm{CC}$ and which of them are considered as conventional threats?

- Which of them are the most numerous categories?

- What is the score of each threat in each of the areas?

- What is the total threats value in each of the areas*?

- Which geographical region appears most threatened regarding the overall value of the areas?

Step 3. Conservation objectives (goals) and strategies

-Which goals take into account CC (in general relationship to the conservation targets) and what strategies were developed?

-Which countries related goals and strategies to climate change?

-What is the estimated time to achieve the goals set (also those not in relations to CC)?

- Which conservation goals, regardless to CC, repeatedly appear in the CAPs?

- Do they take into account any future scenarios in relation to climate for planning the goals?

- What kinds of strategies are most common in evaluated CAPs?

Step 4. Monitoring

- Do the sites/protected areas have a monitoring plan? Do they take CC into account*?

- Is there any direct / indirect methodology to take into account CC to monitor the conservation targets?

-What monitoring methods, although not related to $\mathrm{CC}$, are frequently used?

-What is the regular frequency of conducting monitoring (not taking into account CC) per conservation target?

* Questions that we applied to CAPs uploaded to TNC's ConPro database after 2009.

For the plans elaborated from 2009 onwards we only applied the guiding questions related to climate change (Poiani et al. 2011). These were mainly existing plans, revised to redesign biodiversity projects for climate change. We hypothesized that the visibility of climate change strongly and positively influenced its inclusion into these CAPs. Furthermore, the format of the TNC database changed after 2009 and only climate change-related questions were possible to 
answer. The aim of this exercise was to compare the integration of climate change into conservation plans before and after the TNC climate clinic.

Regarding the recorded climate change related threats (the super-set of "stresses" and "sources of stresses", according TNC, 2003), we grouped and analysed threats before 2008, according to the list of climate-change induced stresses proposed by Geyer et al. (2011) because this classification focuses on climate change and provides a comprehensive diversity of climate change-induced stresses that might become important in conservation planning. We analyzed the threats included in the 22 CAPs after 2009 using the threats classification by Salafsky et al. (2008), because in 2009 TNC introduced this categorization to Conservation Action Planning, with threats ordered in groups like: climate change and temperature extremes or climate change and droughts. Thus a more detailed and specific classification (as in Geyer et al. 2011) was not possible.

\subsection{Local case study: Área Natural de Manejo Integrado Rio Grande Valles Cruceños}

Following the revision of site Conservation Action Plans (CAP) from The Nature Conservancy (TNC) database, we created an additional instruction manual with climate-change relevant steps and applied it to a case example at the local level, towards the integration of climate-change into conservation planning ${ }^{2}$.

We sought to apply a proposed extension to the CAP planning tool, an "extended CAP", based especially on this tool with some focus on the Open Standards for the Practice of Conservation from the Conservation Measures Partnerships - CMP 2007; Ecosystems approach and management (Cherrett 1989), and the management of bio- and eco-regional conservation (Loreau et al. 2003; Ibisch \& Berzky 2006). Our proposal maintains the basic steps of the CAP methodology (TNC 2003), but strongly emphasizes the dynamics of the process with special consideration for the effects and problems related to climate change in each applied step. Additionally, the objective with the "extended CAP" is to offer a more dynamic and efficient planning tool- in instances when the exercise is repeated and to facilitate the conservation of a protected area by adapting management techniques to the local situation and to the available natural history data.

With the support of TNC-Bolivia and the Fundación Natura Bolivia, we tested the proposed extended CAP, in a protected area in the department of Santa Cruz, Boliva - Área Natural de Manejo Integrado Rio Grande Valles Cruceños (ANMI RG-VC).

Based on the case experience of using the extended CAP with ANMI RG-VC, we next give a step-by-step presentation of the principal modifications which were made to the proposed extended CAP compared to the conventional CAP method (Table 4):

\footnotetext{
${ }^{2}$ Ibisch \& Chavez (2008): Towards a proposal for an enhanced and climate change-proof Proactive Conservation Action Planning (PROCAP). Eberswalde University for Sustainable Development, Germany (Document to internal use) (named to this study as "extended CAP”).
} 
Table 4. Principal general differences between the conventional CAP and the proposed extended version of CAP

\section{Traditional methodology}

Conservation Action Planning CAP (TNC 2003)

1) Systems: The conservation targets occurring at a site, and the natural processes that maintain them, that will be the focus of site-based planning.

\section{Step I.- Conservation targets}

-Identify the focal conservation targets (ecological systems and species groups) for site planning and measuring success

-Determine the characteristics of viable conservation targets

-Rank the focal conservation targets for viability

-Determine "Biodiversity Health" of the site.

\section{I.1.-Key Ecological Attributes}

What factors, including key ecological processes, must be maintained to ensure the long-term viability of the conservation targets? Calificar y seleccionar.

\section{Applied methodology}

\section{Extended Conservation Action Planning}

Proposal to be included:

prepared the Plans. To give sources of affirmations, data, etc.

$$
\text { Step I.- Conservation targets }
$$

Similar steps, and we added:

richness of a site) taken also into account the climate change. considered this. tangible targets, normally no ecosystem processes targeted.
-To integrate climate change and adaptation issues into conservation area planning.

-Document the information in order to understand the logic of the managers who

-To lead a more systematic and objective target selection (which represent the

-There is no general notion of specific tangible targets potentially being passengers

that will leave the conservation areas. No notion of environmental dynamics, we

-Approach the target selection in the maintenance of functionality (and resilience) rather than follow the idea of representation of biodiversity patterns by specific

\section{Step II.- Key Ecological Attributes}

The same, and we added

-We performed a conventional viability analysis and also a climate-dependent viability analysis for each of the targets.

2) Stresses: the types of degradation and impairment afflicting the system(s) at a site.

3) Sources: the agents generating the stresses.

4) Strategies: the types of conservation activities deployed to abate sources of stress (threat abatement) and persistent stresses (restoration).

$$
\text { Step II.- (Stresses + Sources) }
$$

Step III.- . Threats

The same, and we added:

III.1.-Opportunity analysis (the opposite of threats) 


\section{2.- Relevant stakeholders in the area (Relevant stakeholders}

who will work together in the management of the PA to counteract the most critical and challenging threats.)

\section{Step III Conservation objectives (goals) and strategies}

What types of destruction, degradation, or impairment are significantly reducing the viability of each focal conservation target at the site?

-Identify major stresses to the focal conservation targets

-Rank the stresses

\section{Step IV.- Conservation objectives (goals) and strategies}

The same, and we added:

-To guide the strategy development more intensively. Too often, strategies follow standard 'recipes' or strategy templates and are not sufficiently customized deriving them from the viability and threat analyses.

-The strategies must go beyond the borders of the areas into the matrix (exceptions might be transboundary/adjacent areas).

\section{Step V- Risk analysis}

-We include a preventive risk management approach. Generally, it is no precautionary

-Take into account also, climate change scenarios, land use and others. Proactive plans.

5) Success: measures of biodiversity health and threat abatement at a site.

Are threats being abated, and is the viability of conservation targets being maintained or enhanced?

\section{Step IV. -Monitoring, and Adaptive Management \\ Step VI.-Monitoring and Adaptive Management}

Similar, but included: How climate change affects viability of both targets and conservation strategies?

6) Stakeholders: Those individuals, groups or organizations which affect or are affected by conservation strategies, either negatively or positively

The actors continue participating in the entire planning process 
To try out the proposed extended CAP, we created a step-by-step guide, presented below, (Table 5) for conservation planning of the area.

The guide presents the actions for each step, with an emphasis on information and data related to the issue of climate change. The guide, presented in this work, gave teaching tips to the technicians and administrators of the PA during the process of management planning within these parameters. We emphasize that the guide we present here doesn't include all of the details of the activities which were included in the workshops. Our objective in this writing is to show the fundamental steps which incorporate consideration of climate change in the planning process. (This can be adapted in the moment of application and depending on the time alloted for the workshops, work in groups, the knowledge and circumstances of each of the participants, etc.).

Based on the authors' experiences with biodiversity conservation planning projects, the extended CAP was designed to be carried out in 2-3 workshops over the course of 1-2 months.) It is not necessary that the location of the planning exercise have precise data or records (e.g., the number of bird species or climate projections for the zone, or other similar data) which in Bolivia and/or Latin America is often scarce or inaccessible. The proposal was designed to work with the knowledge base of experts, local populations, traditional knowledge, plus related literature which supports the responsible technical team. The objective remains to reach a mid-range in rapid planning, which is adaptable for management and which constitutes a first-order tool to initiate the process. The process is low-cost when compared with other related methodologies.

We tested the extended CAP process in a series of workshops which were held at the Área Natural de Manejo Integrado Rio Grande Valles Cruceños (ANMI RG-VC) in Santa Cruz Bolivia. The participants included local community representatives, local and departmental elected officials, NGO staff, representatives from the Bolivia's SERNAP (National System of Protected Areas), municipal technical staff, private landowners and scientific researchers.

In the first workshop (1-2 days), we chose the conservation targets (CT) which are key for the biodiversity in the area and then we did a viability analysis for these selected targets, following the proposed steps of the extended CAP guide. The selection of the conservation targets (CT) is a process which should be participatory, include the input of technically trained persons (especially those with training in climate issues), along with group discussion and group work. One example of participatory planning done in the workshop is documenting the traditional knowledge of the local participating stakeholders with printed and conceptual maps of the area. At this first workshop the participants also identified non-climate-related Key Ecological Attributes (KEAs) (as in a conventional CAP) as well as climate-dependent Key Ecological Attributes (including current and future viability in terms of climate change). The viability of the targets (CT) is determined in the same manner as with the conventional CAP: according to Size, Condition and Landscape Context. The climate-dependent viability analysis is determined for each target based on a future condition, considering how vulnerable each target could be or how each could be affected by climate change. These attributes are considered: Temperature regime; Vulnerability of the KEAs with respect to temperature and precipitation extremes; Precipitation regime; Seasonal distribution of precipitation; other climate parameters (winds, freezes, storms, droughts, hail, floods, etc.); and Fire regime. 
During the second workshop of the same 1-2 day length, following the proposed extended CAP guide, we identified the pressure and threats to the targets and the stakeholders which are associated with these threats. We also included an opportunity analysis, following the steps in the extended CAP guide. The final value for a threat is the sum of individual points as functions of Severity, Scope and Irreversibility.

The third workshop, of the same structure as the first two, formed and proposed strategies (goals and steps) to confront the prioritized threats and risks which had been identified. For this process, we created conceptual maps for each conservation target with the associated threats, strategies, risks, and relevant stakeholders, in order to brainstorm solutions. We used the term "risk" as the probability of occurrence of an adverse event, problem or damage and the consequences of such to the area.

Throughout the entire process of testing out the extended CAP, we worked with the team professionals to guide the use and application of the proposed planning process and facilitate the workshop activities and assignment valorization of the points.

We began the workshops with explanations about the planning objectives for the PA, each of the steps involved in the planning process and the define and clarify definitions and necessary concepts in this case with particular reference to climate change, vulnerability, viability among others and the context of the PA (social and economic frameworks). For the programmed activities, we used instructive materials such as printed maps of the ANMI RG-VC (especially to delimit distributions of the targets and the location of threats) conceptual maps to do the analysis, colored cards to do the ratings, photographs, species lists for the PA, among others.

We began the application of the extended CAP with the selection of the conservation targets for the area, following the instructions in the guide (in Table 5, below):

In order for a target to be selected (from an initial list made by the technicians and participants) it passes through a filtering step of a series of questions listed in the instruction manual, according to the rating which has been assigned to it as a function of subcriteria of representativeness of the biodiversity of the PA, having obtained the highest score. Each of the following steps is the same.

We used Miradi software, developed by the Conservation Measures Partnerships (CMP), to analyze the ratings, the conceptual maps which were used, the resulting data and the application of the pilot extended CAP planning process: 
Table 5. Instruction Manual Guide for CAP applicable to conservation planning for the biodiversity of protected areas

\begin{tabular}{|c|c|c|c|}
\hline \multirow{3}{*}{$\begin{array}{l}\text { Steps } \\
\text { 1.Selection of } \\
\text { key } \\
\text { attributes } \\
\text { and } \\
\text { Conservation } \\
\text { Targets }\end{array}$} & \multicolumn{3}{|c|}{ Guide to conservation planning for biodiversity of protected areas } \\
\hline & $\begin{array}{l}\text { Criteria to follow for } \\
\text { selection: }\end{array}$ & $\begin{array}{l}\text { - If you select Spatial Ecological Units_SEU, processes } \\
\text { and/or functions }\end{array}$ & $\begin{array}{c}\text { - If you select communities } \\
\text { and/or species }\end{array}$ \\
\hline & $\begin{array}{l}\text { What are the range } \\
\text { characteristics of the } \\
\text { conservation target relative to } \\
\text { neighboring PAs? }\end{array}$ & $\begin{array}{l}\text {-Is the range/distribution of the CT significant (in size, } \\
\text { uniqueness, etc.) in relation to other conservation areas? }\end{array}$ & \\
\hline & $\begin{array}{l}\text { How does the conservation } \\
\text { target fit in relative to the } \\
\text { landscape context and spatial } \\
\text { patterns of the area? }\end{array}$ & & $\begin{array}{l}\text {-Is the population vulnerable or not? } \\
\text {-Is the species or community } \\
\text { protected elsewhere? } \\
\text {-The area holds the conditions for the } \\
\text { survival of the species or community. } \\
\text { (reproductive sites, food sources, etc) }\end{array}$ \\
\hline & Geographic distribution & $\begin{array}{l}\text {-Is the target present in more than half the area? } \\
\text {-Does the species have high importance in the context of the } \\
\text { PA? }\end{array}$ & $\begin{array}{l}\text {-What is the significance- Is the } \\
\text { species distribution restricted to a } \\
\text { specific sub-area of the PA or is it } \\
\text { found across the whole PA? }\end{array}$ \\
\hline & $\begin{array}{l}\text { Specific biological or } \\
\text { ecological characteristics }\end{array}$ & $\begin{array}{l}\text {-The selected target (spatial ecological unit, processes or } \\
\text { functions) has significant ecological importance. (e.g. for } \\
\text { cloud forest species). } \\
\text {-Is there good connectivity? } \\
\text { - If the target is a plant community, does it have a High } \\
\text { percentage of connectivity? } \\
\text {-Is compatible use (the relationship between human needs/uses } \\
\text { and biodiversity conservation) a priority? (montane forests, } \\
\text { headwaters)? }\end{array}$ & $\begin{array}{l}\text {-If the targets are species or } \\
\text { communities, are they adapted to } \\
\text { extremes (droughts, poor soils, etc.)? } \\
\text {-Which types of adaptations exist for } \\
\text { dispersal and regeneration (e.g. } \\
\text { pioneer populations)? }\end{array}$ \\
\hline & $\begin{array}{l}\text { Key importance in terms of } \\
\text { functionality/ecological } \\
\text { processes/resilience in the } \\
\text { face of environmental } \\
\text { changes }\end{array}$ & $\begin{array}{l}\text {-Does the conservation target have a high biodiversity and is it } \\
\text { a genetic resource? } \\
\text {-Is the target (SEU) distributed at a variety of altitudes and does } \\
\text { it have a(n) indicator species? (for example, in rain forests } \\
\text { there are species which have wide distribution ranges). } \\
\text {-Is the target considered a principal migration route or } \\
\text { reproduction site? } \\
\text {-Does the target (SEU) play a role in reducing erosion or } \\
\text { flooding? }\end{array}$ & $\begin{array}{l}\text {-If the targets are species or } \\
\text { communities, are they adapted to } \\
\text { extremes (droughts, poor soils, etc.)? } \\
\text {-Which types of adaptations exist for } \\
\text { dispersal and regeneration (e.g. } \\
\text { pioneer populations)? }\end{array}$ \\
\hline & $\begin{array}{l}\text { Climate-related } \\
\text { characteristics }\end{array}$ & $\begin{array}{l}\text {-Does the target play an important role in the local hydrology: } \\
\text { Recharge, supply, storage, infiltration of water? Regulating }\end{array}$ & \\
\hline
\end{tabular}




\begin{tabular}{|c|c|c|}
\hline & temperature extremes, drought, holding moisture? & \\
\hline $\begin{array}{l}\text { Mobility and migration of } \\
\text { individuals and/or } \\
\text { populations }\end{array}$ & $\begin{array}{l}\text {-Does the target allow gene flow and maintain ecological } \\
\text { processes (river corridors, forest blocks, mountain ridges)? } \\
\text { Does it allow vertical and horizontal ecological connectivity, } \\
\text { seasonal population migrations and phenological patterns? }\end{array}$ & \\
\hline $\begin{array}{l}\text { Services for humans within } \\
\text { or outside the protected area. }\end{array}$ & $\begin{array}{l}\text {-How important is the target as a source of food or income for } \\
\text { human populations within and outside the PA? } \\
\text {-Is there watershed protection, water sources for human } \\
\text { consumption and for hydroelectric energy generation, greater } \\
\text { availability of sustainable natural resources (wood, fiber, } \\
\text { bushmeat, honey, etc.)? } \\
\text {-Are soil fertility, water quality and climate regulation } \\
\text { maintained? } \\
\text {-Are aquifers maintained? } \\
\text {-Is the aesthetic beauty and eco-tourism value maintained? }\end{array}$ & $\begin{array}{l}\text {-Can the species or community be } \\
\text { considered as a source of food or a } \\
\text { genetic resource? } \\
\text {-Does it generate economic benefits } \\
\text { through traditional uses (handicrafts, } \\
\text { fiber, etc.)? } \\
\text {-Are the targets appealing for } \\
\text { tourism? }\end{array}$ \\
\hline $\begin{array}{l}\text { Significance for the } \\
\text { mitigation of climate change. }\end{array}$ & $\begin{array}{l}\text {-Regulation of water source, mitigation of droughts, special } \\
\text { relevance to the formation of subterranean water, fog capture? } \\
\text { Regulation of water cycle and capture of horizontal water flow? } \\
\text {-Systems which hold a lot of carbon, highly active sinks. } \\
\text {-Mitigation of temperature extremes: hydric balance } \\
\text { (precipitation/runoff) and/or lessens the negative effects of } \\
\text { wind? }\end{array}$ & \\
\hline $\begin{array}{l}\text { Significance as primary } \\
\text { habitat, ecological } \\
\text { importance/ rare species }\end{array}$ & $\begin{array}{l}\text {-Is there protection for CITES species and for timber species } \\
\text { with high biological and commercial value? }\end{array}$ & $\begin{array}{l}\text {-Are the species vulnerable or } \\
\text { threatened ( CITES e.g.) }\end{array}$ \\
\hline $\begin{array}{l}\text { Assessment of diversity, } \\
\text { endemism }\end{array}$ & -Are there high levels of diversity? Endemic occurences? & $\begin{array}{l}\text {-Are there endemic species in the } \\
\text { PA? }\end{array}$ \\
\hline $\begin{array}{l}\text { Value of natural (structural) } \\
\text { integrity }\end{array}$ & $\begin{array}{l}\text {-How natural/altered is the selected target? Targets are rated } \\
\text { with differing values according to the degree of alteration. } \\
\text { (Ratings: converted/ changed/disturbed ecosystems with many } \\
\text { species present (at least in remnants/ patches) that are typical } \\
\text { for rather undisturbed systems?) }\end{array}$ & \\
\hline $\begin{array}{l}\text { Provider of important } \\
\text { ecosystem service }\end{array}$ & & $\begin{array}{l}\text {-Are they part of a trophic chain? } \\
\text {-Are they species which disperse } \\
\text { seeds? }\end{array}$ \\
\hline
\end{tabular}




\begin{tabular}{|c|c|c|}
\hline & \multicolumn{2}{|c|}{$\begin{array}{l}\text { Final filter. } \\
\text { Do the preselected targets meet the requisites for their selection? } \\
\text { Respond to the following questions: } \\
\text { - About rank spatial ecological units. ( Spatial Ecological Units_SEU, processes and/or functions ) } \\
\text {-The highest-ranking units shall directly be candidates for landscape targets (at least } 50 \% \text { of the targets). } \\
\text { - About the highest-priority species: } \\
\text {-Is it probable that they will be adequately conserved when preliminarily selected landscape targets are conserved? } \\
\text {-If not, can species be grouped together as (sub-)communities, guilds or targets related to whole families/genera etc. (e.g., animals } \\
\text { of rapidly flowing streams, birds feeding on forest fruits, amphibians)? } \\
\text {-Or are there special additional requirements for the conservation of prominent single species which could justify treating them as } \\
\text { conservation targets? } \\
\text { Check preliminarily selected targets: } \\
\text {-All important spatial ecological units represented in the conservation area covered? } \\
\text {-Aquatic and terrestrial biodiversity adequately covered by selected targets? }\end{array}$} \\
\hline $\begin{array}{l}\text { 2. Viability } \\
\text { of the } \\
\text { selected } \\
\text { elements }\end{array}$ & \multicolumn{2}{|c|}{$\begin{array}{l}\text { 2.1 Identification of non-climate-related Key Ecological Attributes (as in a conventional CAP) } \\
\text { 2.2 Identification of climate-dependent Key Ecological Attributes, regarding to: } \\
\text { Adequate temperature regime, precipitation regime, regime of other climate-related parameters (e.g., storms) } \\
\text { 2.3 Identification of current viability (as in conventional CAP) } \\
\text { 2.4 Identification of future viability in terms of climate change (Also document conclusions of climate change scenarios. Climatic } \\
\text { projections) (Is it likely that the climate is going to be inadequate for the targets in the next decades?) } \\
\text { Rank with values: Very good, Good, Fair, Poor }\end{array}$} \\
\hline $\begin{array}{l}\text { 3. Stress } \\
\text { analysis and } \\
\text { opportunities }\end{array}$ & $\begin{array}{l}\text { 3.1 Threats: } \\
\text { Current threats } \\
\text { Future threats } \\
\text {-Analysis of climate change-driven threat enhancement: for } \\
\text { every source of stress it has to be stated if climate change is } \\
\text { expected to enhance the threat (and how) - if so, by when, and } \\
\text { how intensively, how probably (at least qualitatively; as a risk } \\
\text { assessment judging various dimensions of the risk). } \\
\text {-Document mid-term scenarios of projected changes of threats } \\
\text { (approx. < } 20 \text { years; e.g., land use change, expansion/rise of } \\
\text { diseases and pests, extraction rates) - document extent/scope, } \\
\text { expected time-frame, probability of changes, and sources of } \\
\text { scenarios (including personal or expert estimates/comments) } \\
\text { Rank with values: Very high, High, Medium, Low }\end{array}$ & $\begin{array}{l}\text { 3.2 Opportunity: } \\
\text { Complement conceptual model introducing } \\
\text { processes/projects/initiatives which might have a mitigating } \\
\text { influence on the sources of stresses (= opportunities) (include } \\
\text { relevant stakeholders) } \\
\text { Document opportunities in a matrix indicating the threats mitigated } \\
\text { (including information on scope/effectiveness, timeline of } \\
\text { observed/expected mitigation) }\end{array}$ \\
\hline
\end{tabular}




\begin{tabular}{|c|c|}
\hline $\begin{array}{l}\text { 4. Strategies } \\
\text { and risk }\end{array}$ & 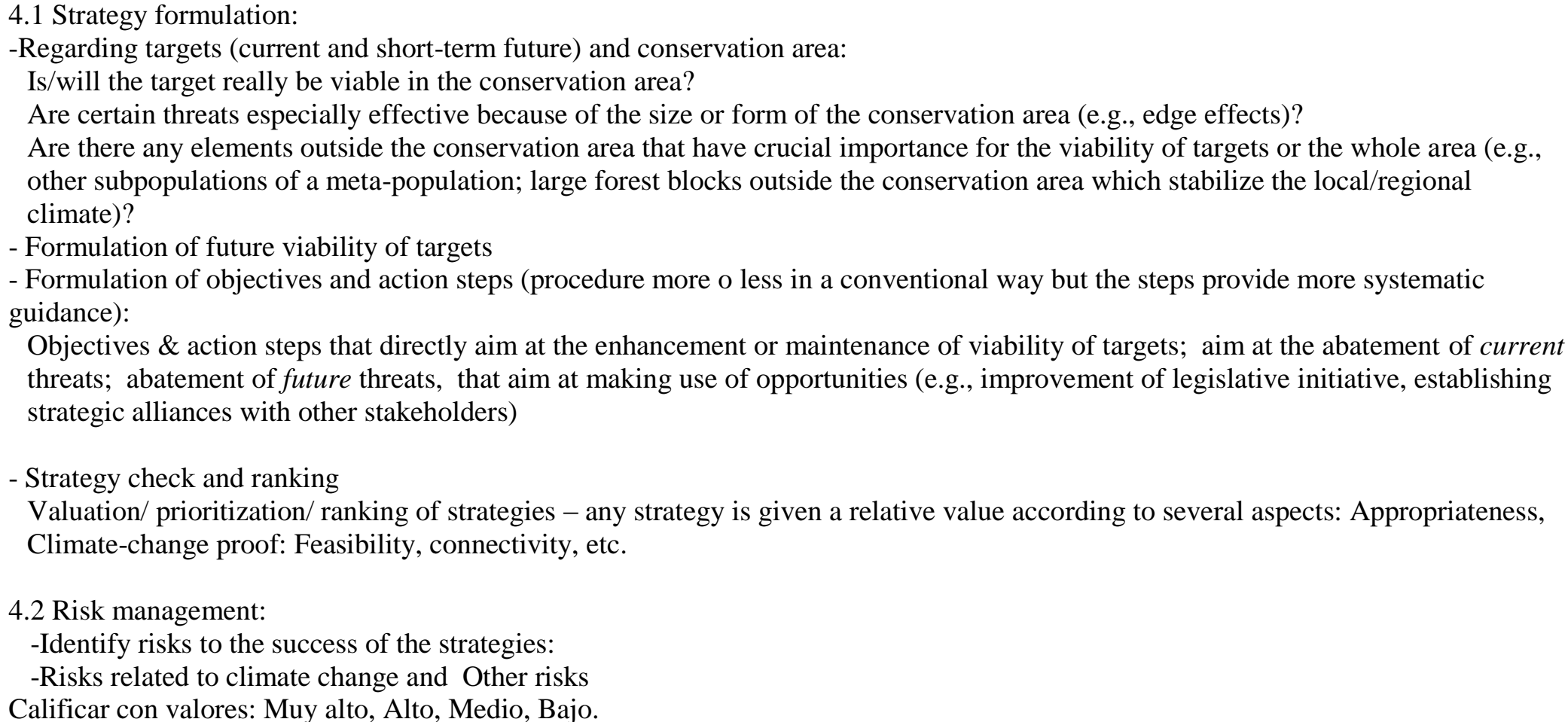 \\
\hline 6.Monitoring & As in conventional CAP, but it include/investigate how climate change affects viability of both targets and conservation strategies \\
\hline
\end{tabular}




\subsection{Regional case study: analysis of perceived adaptive capacity in Santa Cruz protected areas}

To understand the management of protected areas (PA) and the capacity of management to respond to the issue of climate change in Bolivia, we surveyed managers who administer protected areas in the department of Santa Cruz. Our study particularly focused on the perception of the administrators with respect to the issue of climate change in the management of their protected areas.

\subsubsection{Questionnaire}

We used a semi-structured questionnaire with 13 questions designed to understand the managers' perception of protected areas (PA) and the capacity (of the PA) to respond to the issue of climate change (based on Bardwell 1991, and Swaffield 1998). We spent 4 months collecting information from the questionnaire (January-April 2013). Our objective with this questionnaire was to learn how protected area managers develop views regarding climate change in their areas, the different problems each face, and how differences in opinion can be overcome. According to Bardwell (1991), how an environmental problem (or in fact any problem) is defined will determined how the problem is understood and how the problem will be approached. Swaffield (1998) also comments that one of the central issues in environmental management is how to analyze and interpret the complexity and uncertainty of this task.

We describe the questions below:

\section{Questionnaire about the perception of the protected areas managers}

1. Protected Area (PA) name and administrative category

2. What is your concept (perception) of climate change (CC)?

3. Does the PA have a Management Plan (MP) or similar tool? If it doesn't have one, explain why

4. To address climate change, do you use or have you used Ecosystem-based Adaptation (EBA) strategies? Explain

5. Is some monitoring system applied to the PA? Explain

6. Do you apply a risk management approach in the PA? Explain

7. Define the concept of "risk" you work with?

8. Presently, which climate change-related risks do you consider most critical in your PA? Explain

9. In the future, which climate change-related risks do you anticipate will impact your PA? Explain

10. Within your PA, do you practice risk management, and if yes, how is risk management prioritized, in terms of activities, time, financial resources or other? Explain

11. Is there any work that you undertake jointly with other protected area(s)? Explain

12. Do you do any work with private neighbors around the protected area? Explain

13. Do you think conservation now seems to be more difficult / challenging than 20 years ago? If so, why? 
The questionnaire was sent to the branch offices of each of the 32 PAs in the department of Santa Cruz: Five areas of the category of national protection, 8 areas at the departmental level of protection and 19 areas at the municipal level category. We sent the questionnaires by email, postal mail or fax. We assumed that wither the director of each PA or a competent technician responded to the questionnaire.

Upon receiving and reviewing the completed questionnaires, we noted that they varied in length and detail. Accordingly, we grouped the responses which shared similar styles of specificity, with the objective of being able to assign a quantitative value to then conduct and analysis. For example, with question $\# 8$ "Specifically, how would climate change-related risks impact your PA? Explain.": we created 5 groups according to the similarity of the responses: 1) Changes in the weather; 2) Impacts on biodiversity; 3) Impacts on soil, water; 4) Impacts on the economic and/or social aspect(s); 5) No answer. We treated each group of similar responses as one variable. We did a comparable grouping of responses for each of the 13 questions, although the number of groups differed according to the type of responses.

With this information, we built a spreadsheet with the column headers "PA Name" and "Variables" (see Table 6). With the responses of the 13 questions organized by similarity, we formed 55 types or groups of responses (variables per column) per PA. We coded the responses (yes $=1$, no $=0$ ) for quantitative analysis. Our objective was to create a uniform database which would allow us to use whole numbers or percentages to calculate and demonstrate the difference or similarity between the responses. Many responses from the administrators were very detailed and with precise explanations of reasoning in their answers and so we also used these descriptions to support or complement the quantitative results.

\subsubsection{Additional information for evaluation of the PAs}

To the data in the spreadsheet mentioned above, we added and completed the following additional fields:

-Size in area of the PA. For this, we generated 5 ranges or categories using "natural breaks" in the GIS program (5 variables.) For this variable and the following (deforested area), we decided to generate 5 size classes as a practical unit for our objectives since there was such a wide range of sizes from small to large (e.g. the area size ranged from 400 ha for the smallest PA to nearly 4 million ha for the largest PA).

-Size of deforested area within PA. To calculate the deforested area for each protected area, we used the shapefiles from the study "Deforestación y regeneración de bosques en Bolivia" (data base Museo de Historia Natural Noel Kempff Mercado (MHNKM), Santa Cruz, SERNAP 2013). Again we generated 5 ranges using "natural breaks" (5 variables). 
-Ecoregion. Another variable we included was the present ecoregions for each PA. We based this data according to the categories in the map of ecoregions for Bolivia (Ibisch \& Merida 2003; database MHNKM). The protected areas of the department of Santa Cruz contain a total of 14 ecoregions (14 variables) based on this method.

Finally we analyzed the spreadsheet with a total of 79 variables per PA (55 from the administrators' responses and 24 additional). See Table 6.

Tabla 6. Example spreadsheet analyzed for studying the protected areas (PA)

\begin{tabular}{|c|c|c|c|c|c|c|c|c|c|c|c|}
\hline & \multirow[t]{2}{*}{ PA Name (n 28) } & \multicolumn{10}{|c|}{ Variables $($ Yes $=1 \quad / \quad$ No=0 $)$} \\
\hline & & 1 & & & \multicolumn{5}{|c|}{ 2----- } & \multicolumn{2}{|c|}{---- 79} \\
\hline $\mathrm{n}$ & & $\mathrm{b}$ & $\mathrm{c}$ & $\mathrm{d}$ & $\mathrm{e}$ & $\mathrm{f}$ & $\mathrm{g}$ & $\mathrm{h}$ & $\mathrm{i}$ & $\mathrm{j}$ & \\
\hline 1 & PNKM & 1 & 0 & 0 & 1 & 0 & 0 & 0 & 1 & 0 & 0 \\
\hline 2 & $\mathrm{AMB}$ & 1 & 0 & 0 & 1 & 0 & 0 & 0 & 0 & 1 & 0 \\
\hline 3 & KAAIYA & 1 & 0 & 0 & 0 & 0 & 0 & 1 & 0 & 1 & 1 \\
\hline 28 & OTUQ & 1 & 0 & 0 & 0 & 0 & 0 & 1 & 0 & 0 & 0 \\
\hline
\end{tabular}

Description of the variables. Example: 1. Administrative category PA: b) National; c) Departmental; d) Municipal. 2. What is your perception regarding climate change (CC)? e) Variation of temperature; f) Altered rainfall regime, floods, droughts; g) Fire; h) Human activities cause pollution, waste, climate modification, natural disasters; i) They suggest taking mitigation and adaptation measures; j) They suggest raising public awareness.

\subsubsection{Evaluation of the vulnerability of the protected areas of Santa Cruz as a function of their capacity to respond to climate change}

\subsubsection{Climate vulnerability index}

Based on the same information from the questionnaire responses about the managers' opinions (see questionnaire), plus the additional variables of area size, deforested area and ecoregion, we determined the vulnerability of the protected areas in the department of Santa Cruz as a function of their capacity to respond to climate change.

For this analysis, we adapted the methodology of Kreft et al. (2013): "Evaluation of the vulnerability index for protected areas, based on the derivation of the options for adaptation to climate change". The authors built the vulnerability index with relevant concepts from systemic vulnerability (McCarthz et al. 2001; PIK 2003; Parry et al. 2007) and considered the value of vulnerability for an area as the sum of three criteria with differing percentages: 1) Change in exposure (35\%); 2) Management (or Administration) (50\%) and 3) Biotic sensitivity (15\%). The change in exposure is the climate change to which the PA is exposed; The biotic sensitivity is the sensitivity of the PA in the face of the change 
in exposure; and the capacity of adaptation describes the adaptive capacity of the PA to the change in exposure: the vulnerability increases with an increase in change in exposure, with an increase in sensitivity and with a decrease in the adaptive capacity in the presence of the changes.

Beginning from this methodology as a base (Kreft et al. 2013), for the present vulnerability analysis of the protected areas of the department of Santa Cruz as a function of their capacity to respond to climate change, we only used the "Management" subcriterion which in our case represented $100 \%$ of the value of the index proposed in this study and with which we measured the response capacity for the protected areas.

From the questionnaire, we had uniform data which could be used as indicators to qualify the proposed main criteria and the subcriteria for the climate vulnerability index. The data come from the same questionnaire answered by the managers of the 28 PAs in the department of Santa Cruz, about their perception with respect to the management of their areas and the consideration of climate, plus the additional data we generated for this analysis (area, deforestation, ecoregion).

Next we present a table (Tabla 7) comparing the criteria and percentages we used in this analysis, related to the original vulnerability index of Kreft et al. (2013). The objective of this table is to show that of 29 subcriteria which the original index used to rate the main criteria under Management, we had information from the questionnaire for an additional 8 subcriteria; we generated the information for the subcriterion Approximation to the ideal (circular) design of the PA, from existing data and we added 2 more subcriteria to complete the rating of climate vulnerability: Deforested area within the PA and Number of ecoregions within the PA.

Following this table, we present our climate vulnerability index and explain our reasons for choosing each and the rating which we assigned. 
Tabla 7. Comparison between the principal modifications to the vulnerability index of Kreft et al. (2013) for PAs of Santa Cruz relative to their capacity to respond to climate change

\begin{tabular}{|c|c|c|c|}
\hline & $\begin{array}{l}\text { Vulnerability Index for the Protected Areas } \\
\text { of Santa Cruz relative to their capacity to } \\
\text { respond to climate change }\end{array}$ & & Vulnerability Index Kreft et al. (2013) \\
\hline & Criteria and weight (percentage) & & Criteria and weight (percentage) \\
\hline \multirow[t]{5}{*}{$\mathbf{N}^{\circ}$} & & $\mathbf{N}^{\circ}$ & A) Change in exposure (weight: $35 \%$ ) \\
\hline & & & Change in temperature $(17,5 \%)$ \\
\hline & & & Change in annual precipitation $(17,5 \%)$ \\
\hline & MANAGEMENT (100\%) & & B) Management (50\%) \\
\hline & Administration (10\%) & & Administration B1 (5\%) \\
\hline \multirow[t]{4}{*}{1} & \multirow[t]{3}{*}{ Management/Self-Administration } & 1 & $\begin{array}{l}\text { Decentralization in the management of the protected areas }(1,67 \%) \\
\text { (Lack of coordination and/or gaps in administrative responsibilities) }\end{array}$ \\
\hline & & 2 & Self-Administration $(1,67 \%)$ \\
\hline & & 3 & Reference made to climate change in management $(1,67 \%)$ \\
\hline & Management Plan (30\%) & & Management Plan B2 (15\%) \\
\hline \multirow[t]{5}{*}{2} & Consideration of climate change threats & 4 & Consideration of climate change threats $(2,14 \%)$ \\
\hline & & 5 & Analysis of target sensitivity in light of climate change \\
\hline & & 6 & Consideration of the synergies between climate change conventional threats $(2,14 \%)$ \\
\hline & & 7 & Strategies to adapt to climate change $(2,14 \%)$ \\
\hline & & 8 & Special importance given to adaptation of ecosystems to climate change $(2,14 \%)$ \\
\hline 3 & $\begin{array}{l}\text { Management Plan Exists (Completed or in } \\
\text { revision) }\end{array}$ & 9 & Completed/revised Management Plan $(2,14 \%)$ \\
\hline \multirow[t]{2}{*}{4} & Biological and institutional monitoring & 10 & Supervision and monitoring of administrative management $(2,14 \%)$ \\
\hline & Use of adaptive management $(20 \%)$ & & Ecosystems (Landscape) approach B3 (5\%) \\
\hline \multirow[t]{4}{*}{5} & Adaptive management & 11 & Adaptive management $(0,83 \%)$ \\
\hline & & 12 & Sustainable management of ecosystem functions in appropriate spatial dimensions. $(0,83 \%)$ \\
\hline & & 13 & Sustainable management of ecosystem functions in appropriate temporal dimensions. $(0,83 \%)$ \\
\hline & & 14 & Latest research and science is taken into account $(0,83 \%)$ \\
\hline
\end{tabular}




\begin{tabular}{|c|c|c|c|}
\hline \multirow[t]{5}{*}{6} & \multirow[t]{2}{*}{$\begin{array}{l}\text { Participation by stakeholders in conservation-focused } \\
\text { activities/public strategies and others }\end{array}$} & 15 & $\begin{array}{l}\text { Participation by stakeholders in conservation-focused activities/public } \\
\text { strategies and others }(0,83 \%)\end{array}$ \\
\hline & & 16 & Balance between conservation and use of biodiversity $(0,83 \%)$ \\
\hline & & & Conservation Targets B4 (15\%) \\
\hline & & 17 & Dynamism of conservation target(s) $(7,5 \%)$ \\
\hline & & 18 & Creation of habitat networks between protected areas $(7,5 \%)$ \\
\hline & Protection Design $(40 \%)$ & & Protection Design B5 (10\%) \\
\hline \multirow[b]{3}{*}{7} & & 19 & Landscape-level management of the protected area $(0,83 \%)$ \\
\hline & & 20 & Conflicts/overlap of protected area status with other use categories $(0,83 \%)$ \\
\hline & Size of the protected area & 21 & Size of the protected area $(0,83 \%)$ \\
\hline \multirow{6}{*}{8} & & 22 & Edge effects $(0,83 \%)$ \\
\hline & & 23 & Size of the sub-areas of the protected areas $(0,83 \%)$ \\
\hline & & 24 & Number of sub-areas in the protected zone $(0,83 \%)$ \\
\hline & Creation of work networks with other neighboring PAs & 25 & Creation of work networks with other neighboring PAs $(0,83 \%)$ \\
\hline & & 26 & Presence of anthropogenic barriers $(0,83 \%)$ \\
\hline & & 27 & Adding to the size of the protected area or reserve $(0,83 \%)$ \\
\hline \multirow[t]{7}{*}{9} & Approximation to ideal shape & 28 & Approximation to ideal shape $(0,83 \%)$ \\
\hline & & 29 & Creation of a network of habitats in the protected area $(0,83 \%)$ \\
\hline & & & C) Biotic sensitivity (15\%) \\
\hline & & & For bird sanctuaries: conservation status for bird population(s) $(7,5 \%)$ \\
\hline & & & $\begin{array}{l}\text { For non-bird sanctuaries: average value for conservation status of habitat } \\
\text { types }(5 \%)\end{array}$ \\
\hline & & & $\begin{array}{l}\text { For non-bird sanctuaries: The dependence of the ecosystems on underground } \\
\text { or surface water }(5 \%)\end{array}$ \\
\hline & & & For non-bird sanctuaries: Sensitivity of the ecosystems (5\%) \\
\hline
\end{tabular}




\subsubsection{Defined matrix: Climate Vulnerability Index for the protected areas of the department of Santa Cruz, Bolivia}

With the criteria defined from the information from the questionnaire responses of the protected area managers' perceptions relative to climate change and our additional data we present the following conceptual framework (Fig.3) about the Climate Vulnerability Index which we applied to the PAs of Santa Cruz, Bolivia, and then the table (Table 8), with the descriptions.

Figure 3. Conceptual framework Climate Vulnerability Index

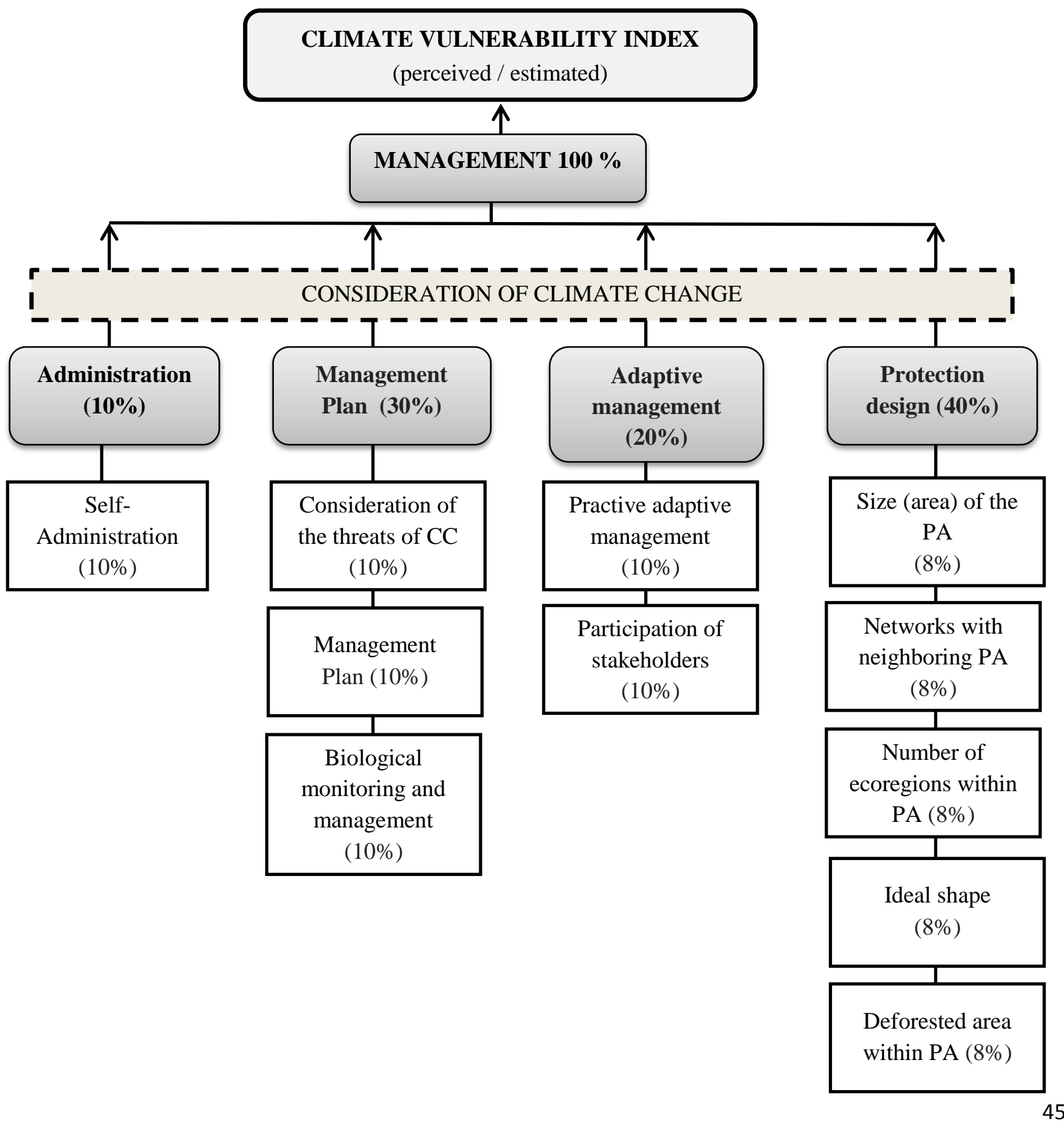


We include a parallel description for the valuation of each subcriterion in the index and explain the reasons for its inclusion:

\section{Description of the evaluated subcriteria for the present Vulnerability Index:}

MANAGEMENT (100\%)

- Administration (10\%)

1) Management/Self-Administration (10\%)

The PAs of Santa Cruz are managed through specific agencies: National level (SERNAP), Departmental level (DIAP) and Municipal/Local level (Gobierno Municipal), which are the maximum authorities within their jurisdiction, but each PA itself has guaranteed implementation of its policies, strategies and national objectives. The directors are the maximum authority for each PA. We consider a PA to have low Vulnerability (V.low) if it has its own personnel for administration of the PA (management or administration of the PA by the state with institutional support) and a V.high if the PA has a co-administration with another institution. See Table 8.

\section{- Management Plan (30\%)}

\section{2) Considers threat of climate change (10\%)}

For this subcriterion, we used information from the questionnaire response about whether the PA applied risk management practices or not. According to Ibisch et al. (2013), risk management is composed of three elemental principles: Search and perception of risk; Evaluation of the risk and Response. We sought areas that were capable of identifying and anticipating the largest number of risks possible and which had experience in adaptive management and rapid response to confront unexpected changes, especially those related to climate change. If the PA engaged in risk management practices and took into account threats from climate change, according to our climate vulnerability index, the site has a V.low. 
Tabla 8. Description of the Climate Vulnerability Index matrix applied to the protected areas of the department of Santa Cruz, Bolivia (CC: Climate Change; MP: Management Plan; PA: Protected Area; V: Vulnerability)

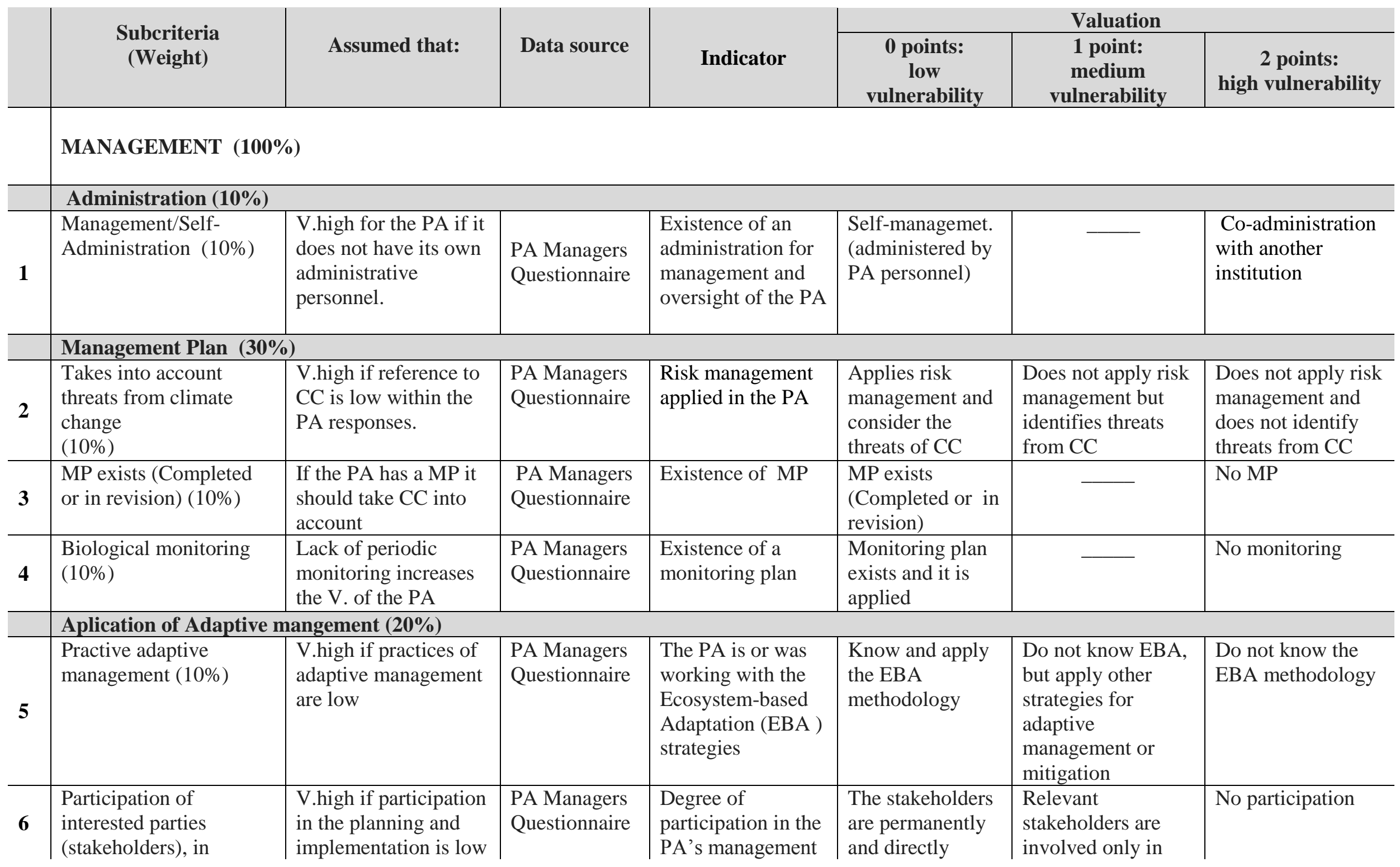




\begin{tabular}{|c|c|c|c|c|c|c|c|}
\hline & $\begin{array}{l}\text { processes of activities } \\
\text { with conservation } \\
\text { focus/public strategies } \\
\text { and other }(10 \%)\end{array}$ & & & & $\begin{array}{l}\text { involved in } \\
\text { decision-making }\end{array}$ & $\begin{array}{l}\text { parts of planning, } \\
\text { execution and other } \\
\text { activities or only } \\
\text { involved in cases of } \\
\text { conflict }\end{array}$ & \\
\hline & \multicolumn{7}{|l|}{ Protection design $(40 \%)$} \\
\hline 7 & $\begin{array}{l}\text { Size (area) of the PA } \\
(8 \%)\end{array}$ & $\begin{array}{l}\text { V.high if the area is } \\
\text { small }\end{array}$ & $\begin{array}{l}\text { SERNAP; } \\
\text { Quiroga et al. } \\
(2011)\end{array}$ & Surface area of PA & $\begin{array}{l}1,523,446- \\
3,441,500 \text { ha }\end{array}$ & $\begin{array}{l}490,051- \\
1,523,446 \text { ha }\end{array}$ & $\leq 490,051$ ha \\
\hline 8 & $\begin{array}{l}\text { Creation of work } \\
\text { networks with neighbors } \\
\text { of PA }(8 \%)\end{array}$ & $\begin{array}{l}\text { V.high when the } \\
\text { degree of work in } \\
\text { neighboring and } \\
\text { connecting areas to } \\
\text { the PA is low }\end{array}$ & $\begin{array}{l}\text { PA Managers } \\
\text { Questionnaire }\end{array}$ & $\begin{array}{l}\text { Work between } \\
\text { protected areas }\end{array}$ & $\begin{array}{l}\text { Work between } \\
\text { PA (Coordination } \\
\text { of objectives, } \\
\text { joint strategies, } \\
\text { etc.) }\end{array}$ & $\begin{array}{l}\text { Only technical, } \\
\text { legal cooperation, } \\
\text { and attend } \\
\text { workshops and } \\
\text { trainings }\end{array}$ & $\begin{array}{l}\text { Do not work } \\
\text { between PA. }\end{array}$ \\
\hline 9 & $\begin{array}{l}\text { Number of ecoregions } \\
\text { within PA. (diversity of } \\
\text { ecological/ biological/ } \\
\text { elevation levels, } \\
\text { topography, etc.) }(8 \%)\end{array}$ & $\begin{array}{l}\text { V.low when the } \\
\text { diversity of } \\
\text { ecoregions is greater }\end{array}$ & $\begin{array}{l}\text { Ibisch et al. } \\
\text { (eds.) (2003) }\end{array}$ & $\begin{array}{l}\text { Number of } \\
\text { ecoregions } \\
\text { presenting the PA } \\
\text { ( } 5 \text { is the maximum } \\
\text { we found in the } \\
\text { area of Santa Cruz, } \\
\text { Bolivia) }\end{array}$ & $\geq 4$ Ecoregions & 3 Ecoregions & $\leq 2$ Ecoregions \\
\hline 10 & $\begin{array}{l}\text { Approximation to the } \\
\text { ideal (circular) design of } \\
\text { PA }(8 \%)\end{array}$ & $\begin{array}{l}\text { V.high when the } \\
\text { shape of the PA is less } \\
\text { circular }\end{array}$ & $\begin{array}{l}\text { SERNAP; } \\
\text { Quiroga et al. } \\
(2011)\end{array}$ & Shape of the area & $\begin{array}{l}\text { Greater } \\
\text { approximation to } \\
\text { circular shape } \\
\text { (ideal form) }\end{array}$ & - & $\begin{array}{l}\text { Lesser } \\
\text { approximation to } \\
\text { circular shape }\end{array}$ \\
\hline 11 & $\begin{array}{l}\text { Deforested area within } \\
\text { PA }(8 \%) \text {. }\end{array}$ & $\begin{array}{l}\text { V.high when there is } \\
\text { greater deforestation } \\
\text { within PA } \\
\text { (deforestation triggers } \\
\text { conventional threats } \\
\text { which lead to greater } \\
\text { climate vulnerability) }\end{array}$ & $\begin{array}{l}\text { SERNAP / } \\
\text { MHNNKM, } \\
(2013)\end{array}$ & $\begin{array}{l}\text { Surface area in } \\
\text { hectares (In } \\
\text { Bolivian PA from } \\
\text { "0" deforestation } \\
\text { to } 60 \text { mil ha) }\end{array}$ & $\leq 5,058$ ha & $5,058-18,757$ ha & $18,757-66,333$ ha \\
\hline
\end{tabular}




\section{3) Existence of Management Plan (Completed or in Revision) (10\%)}

The management plan is the strategic planning which defines and support the management and conservation of resources in the PA. In Bolivia, only a few management plans have begun to incorporate CC and its possible impacts to some areas (Hoffman et al. 2012). We made the assumption that if the PA has a management plan, the PA will be better prepared to confront possible impacts generated directly or indirectly from CC (V.low): a management plan has rulers y policies for the management of the area, designation of permitted uses and activities, such as sustainable resource management programs and production activities compatible with conservation.

\section{4) Biological and institutional monitoring (10\%)}

Monitoring is a periodic process to gather and review data, in order to evaluate defined indicators for the PA and the progress or lack thereof in the execution of the project according to the operational plans. For the present evaluation, we used the responses about monitoring systems which are implemented in the PAs, as much as for the administration of the PA (follow-up to completing objectives, tracking employee activities, etc.) as for the application of biological monitoring systems (which are most used in Bolivia and which we added for this analysis) for species or populations present in the PA. In the version of Kreft et al. (2013), they only take into account the monitoring of administration (not biological monitoring). If the PA in question has a monitoring plan, its vulnerability is low.

\section{- Application of adaptive management (20\%)}

\section{5) Adaptive management (10\%)}

The subcriterion originally in Kreft et al. (2013), was: "Application of an ecosystems approach"; instead of this subcriterion we used information about the "Application to adaptive management" taken from the questionnaire data. To the extent which the impacts and the risks relative to climate change become more and more evident, it is important to remember that the adaptive management of our PA is a necessity for effective conservation management. Adaptive management is an approach which recognizes and takes into account failures, since this can promote systematic learning from the errors with end result of creating systems that are more efficient and resilient. Through adopting the practices of adaptive management, the task of protecting biodiversity will be strengthened and made more resilient (Ibisch et al. 2013). In the questionnaire about perception, we asked about familiarity and/or the application of the Ecosystem-based adaptation (EBA) methodology understood as the use of biodiversity and ecosystem services as part of a broader adaptation strategy to help human communities adapt to the adverse effects of CC (March et al. 2010). This response lets us assume that if the PAs are familiar with or apply this methodology they could use a variety of approaches for sustainable management, conservation and restoration of the ecosystems to provide services which permit people to withstand the impacts of CC (V.low). At the same time, we take into account responses about the application of other alternative strategies of adaptation and/or mitigation within the PAs and that the managers mentioned in their answer to this question. 


\section{6) Participation by stakeholders in conservation activities and public strategies and others (10\%)}

In the protected areas of Bolivia, alternative forms of management and oversight, such as communitybased conservation or joint management practices are being implemented with the objective to offer benefits to stakeholders. Bolivia is part of the "Parks with People" initiative which was launched in 2005 in order to establish a commitment between the indigenous communities and the protected areas system (Peredo-Videa 2008). The inclusion of indigenous groups and local populations in the management and administration of these areas first occurred with the formation of Management Committees (Comités de Gestión) and the concept of Shared Management (Gestión Compartida) as a new way of managing the protected areas, aimed to deepen social participation in public administration of the protected areas and in which the decision and responsibilities are shared between the State and social organizations with recognized territorial rights (SERNAP 2007). We presume that PAs with participation by the stakeholders (private property owners, neighboring communities, indigenous peoples, local government representatives, NGOs, among others) and taking into account that some PAs with previously established human settlements or soil-use activities can be less vulnerable (V.low) than PAs which don't have any participation from civil society. As a matter of fact the human population can sense climate changes or the effects, such as changes in local use patterns of soils, the need to shift cultivated areas from one spot to another, increases in temperature or evapotranspiration, among others (Hoffman et al. 2012) and their participation is (or should be) a necessity for the policies of the governments and the PAs.

\section{- Protection Design (40\%)}

\section{7) Size of the protected area $(8 \%)$}

The range used by Kreft et al. (2013), is: > 1,000 ha (V.low);./ 200-1,000 ha (V.medium) /; <200 ha (V.high).

Due to the great variation in the size of the protected areas included in our study (the smallest at 380 ha to the largest at 3,500,000 ha), we grouped the PAs into 3 size ranges using "natural breaks" within the program ArcGIS: 1,523,446 - 3,441,500 ha (V. low); / 490,051 - 1,523,446 ha (V.medium); / $\leq$ 490,051 ha (V.high) so that we could compare and analyze them. Since our evaluation uses criteria of perception as the basis of analysis, we used size of area as a value to represent the capacity of the PA to better withstand climate changes; the larger in area the ecosystems or ecoregions, the lower the Vulnerability. Despite this claim/assertion we are aware that large surface size of PA doesn't necessarily guarantee a low vulnerability, since many other factors can impact the rating (Kreft et al. 2013). Yet, as signaled by Thomas \& Kunin (1999), the smaller and more isolated an area is, the more susceptible it is to loss of biodiversity.

It is generally assumed that there are large differences in the sensivity of species and ecosystems as a function of conditional abiotic factors (Ibisch et al. 2002). "Large-scale approaches - at the level of ecosystems and landscapes - are the only way to conserve the overwhelming multitudes- millions of species - of existing biodiversity. (...) "The ecosystem (large areas) approach is the only way to conserve little-known organisms and processes or unknown habitats and ecological subsystems." 
(Franklin 1993). As pointed out by Ibisch \& Araujo (2003), it will not be possible to conserve the biodiversity of PAs which are relatively small and isolated from each other; for example, the manmade clearings in the forest canopy have a greater impact in humid regions than in drier regions since most species in drier regions are adapted to hydric stress and effect of insolation and radiation. The negative effects of forest fragmentation are more complex than were first thought; the impacts aren't only those associated with gene flow between populations and individuals but also with changing the ecological processes in the forest which means a change in the quality of the habitat (Laurance et al. 2002). The case might be that strategic areas allow for all the focal targets to be represented but if the areas are too small, the survival of the targets can't be assured. In this context, the issue of climate change and the resulting range dynamics of species distributions plus the short time scale of some ecosystems (in geologic and evolutionary terms) merits special attention (Ibisch \& Merida 2003). The same authors note that very small PAs, which require an increase in size in order to become ecologically viable or be habitat for species which are conservation targets, should be joined or grouped together as a single conservation units. At least it is certain that - in some ecoregions more so than in others - many taxa will have to shift and migrate in order to reach areas where the required habitat conditions exist (Noss 2001).

Studies in Bolivia about the impact of climate change on biodiversity (PNUD 2013) recommend the maintenance or creation of large conservation areas which contain altitudinal variation, differing vegetation types and that the conservation or creation of forest blocks be as large as possible, prioritizing zones which represent biological corridors and keystone species which maintain the health of the ecosystems, such as medium and large carnivorous mammals.

\section{8) Approximation to ideal shape (8\%)}

The design of protected natural areas constitutes an integral part of conservation biology (Barzetti 1993; Moyle \& Sato 1991; Meffe et al. 1999; Smith \& Smith 2001, in Richard et al. 2006). Diverse authors (Diamond 1975; Sullivan \& Shaffer 1975; Meffe et al. 1999) have suggested principles based on the relationships of area and shape for the design of protected areas to maximize the preservation of biodiversity. Moyle \& Sato 1991; Meffe et al. 1999, for example state, that circular united and large designs are preferable. This idea is supported by the theory of island biogeography (Fernández 2000; Smith \& Smith 2001) who state: the protected areas (in relation to the surroundings) act as islands of natural environment in a sea of anthropogenic environment and because of this they are subject to the dynamics of islands, from the perspective of population genetics. Likewise, the larger an area is, the more species it is likely to contain and support (Hastings \& Harrison 1994; Klug \& Cummings 1999; Smith \& Smith 2001, in Richard et al. 2006). Also Fontúrbel (2006), comments on the theory, the ideal shape for a PA is circular, and like a "donut" with the protected area in the center, the areas of peripheral management around this and the buffer zone encompassing and surrounding the outside. The ultimate shape of an area begins with the central, core zone (area which is not exposed to edge effects), and the circle shape has a greater area per perimeter than any elongated shape of the same area (Pauchard et al. 2006).

With respect to the design of areas, there are few references for Bolivia: Richard et al. (2006) did an actual perimeter-area analysis for an area and suggested alternatives for redesigning the park according 
to their results. Forturbel (2007) analyzed the area-perimeter relationship, core areas and design for four areas of differing classes in Bolivia. Given these antecedents and following Kreft et al. (2013), we agree that PAs with the shape most close to a circle will be the least vulnerable. For our analysis, we looked at the shape of each PA on a map and classify them for this subcriterion.

\section{9) Creation of work networks with neighbors of PA $(8 \%)$}

This subcriterion in Kreft et al. (2013) refers to the production of a network of habitats (biotopes) between protected areas.

For our analysis, we used the questionnaire responses regarding coordinated work between neighboring protected areas. We rated the responses such that when there was less coordinated work effort between protected areas, the vulnerability was higher.

Ideally what is needed is a network of protected areas with common objectives and strategies which should include management in the buffer zones, connections and corridors between the areas to facilitate the movement of animal species across the landscape and abundance of quality habitat; to be more resistant to less-local threats with strategies which go beyond the administrative borders; facilitate the viability of species in fragmented habitats, among others. It is necessary to establish vertical and horizontal corridors between PAs, thus increasing the probability of protecting the conservation targets as much as providing for species dispersion corridors, (Hannah et al. 2002; Ibisch \& Araujo 2003; Araujo et al. 2010; Ibisch et al. 2007; Hoffman et al. (2012). Additionally, ecological and evolutionary processes, such as spatial requirements for a target species, should be considered and included in conservation planning.

Within the norms of SERNAP's instruction manual for creating management plans no specific guidelines or rules exist for coordinated work between PAs, except in training workshops which are collective activities for all the PAs in Bolivia, not just neighboring ones. Any other joint work comes from the planning of each individual PA.

\section{0) Number of ecoregions in the protected area (diversity of ecological, biological, altitudinal, topographic, etc. factors) $(8 \%)$}

This is a new subcriterion which we added for this evaluation. We gave it a value of $8 \%$ in the total weight of $40 \%$ assigned to "protection design."

If we noted a wide diversity of ecoregions (areas which share and have in common many taxa, ecological dynamics and environmental conditions) within a PA, this PA would be less vulnerable in general to the effects of climate change.

As indicated by Hooper et al. (2005), both invasion of ecosystems by exotic species and the relationship between stability and diversity suggests that, all other things being equal, a species-rich ecosystem may be less vulnerable to disruption by an introduced species than a species-poor ecosystem. Protected areas with a greater diversity of ecoregions (alpha diversity), have higher 
diversity of ecosystems and may also have greater species diversity and therefore resilience to perturbations by exotic species.

Around 3,448,354 ha of the surface area of PAs in the department of Santa Cruz have high habitat heterogeneity, that is to say, diversity. There is no specific pattern to this habitat diversity; the protected areas are widely dispersed from each other in the natural landscape across varying habitats (Quiroga et al. 2012).

The areas which we evaluated in this study show a diversity of up to 5 ecoregions in one PA. e.g., a PA with $\geq 4$ Ecoregions receives a rating of V.low (see Table 8).

\section{1) Deforested area within the PA (8\%)}

This subcriterion was also included in determining the vulnerability of the areas.

It has been shown that PAs are important in sequestering and storing carbon and in mitigating the impacts of climate change (Dudley 2008; Sandwith 2008). In Andean countries, including Bolivia, project proposals are being developed which seek to prevent deforestation and degradation of forests in the areas around the PAs, such as the United Nation's program, "Reducing Emissions from Deforestation and Forest Degradation" (REDD) and within the same PAs (REDD+) (Hoffman et al. 2012). Deforestation and degradation occurs in all forest ecosystems of Bolivia, principally in Amazon forest, transitional forest, Chiquitano dry forest, sub-Andean forest and in the Chaco (Urioste 2012). Andersen \& Mamani (2009) suggest that in the low lands of Bolivia, the process of deforestation is responsible for $95 \%$ of the decrease in biodiversity levels, while climate change alone is responsible for $5 \%$. The PAs of Santa Cruz are located primarily in lowlands.

As of the year 2010, national protected areas contain 22\% of Bolivia's forests, (SERNAP 2013). The same study indicated that the majority of forest loss was the result of vegetation cover change caused by human activities related to agriculture and cattle ranching, although a considerably smaller amount of forest loss was attributable to other causes, likely those of ecosystems dynamics. The rate of forest loss in protected areas is lower than the rate of forest loss in non-protected areas. At the same time, it is important to note that in the interior regions of PAs there are significant areas in the process of natural regeneration after deforestation.

Forests play a critical role in the stabilization of soils and the regulation of hydric resources. When forests are cut, the canopy opening exposes the soil to direct rainfall, causing loss of biomass and nutrients, reduces the capture and infiltration of water and increase surface runoff. In similar fashion, rates of erosion and land degradation increase. It is know that around $75 \%$ of the increase in runoff is directly due to deforestation (Kramer et al. 1995). From this comes the issue of sedimentation of rivers, lakes and the ocean, while at the same time modifying the hydric regime and increasing the frequency and intensity of floods downstream (Calder 1998). Soil erosion also leads to loss of fertility and productivity and increases the risk of landslides and avalanches in hillsides and valleys. Local changes in climate are produced when there are land-cover changes (e.g., deforestation). In the same 
way as with the data for surface area, we used three category ranges (low, medium. high) according to deforested area to rate vulnerability, assuming that greater deforestation indicates greater vulnerability.

Once we assembled and defined the climate vulnerability, the index was applied to each of the PAs, ranking the subcriteria according to the defined rating: low, medium or high vulnerability. 


\section{4 . RESULTS}

\subsection{Conservation Action Planning on the continental scale (America)}

\subsubsection{Conservation Action Plans before 2009}

Conservation targets: On average, seven conservation targets were selected in each of the conservation plans we included in our study (refer to steps in table 4 and 5) There were a total of 680 conservation targets. Single species or species complexes/genera such as "timber species of the genus Cedrela" were the conservation targets in $21 \%$ of the sites. Biological communities or species groups/guilds such as coral communities or migratory birds accounted for conservation targets in $20 \%$ of the sites, whereas ecosystems such as "hydrological systems of the Piedemont" and "cloud and transition forests" accounted for the targets in 59\%. Only one CAP identified ecological processes or functions such as "water production" as a conservation target.

Viability of conservation targets and sites: Of the evaluated CAPs, $84 \%$ included a viability analysis of the targets. With regard to climate change or subsequent impacts, out of $120 \mathrm{KEAs,} 16 \%$ refered to temperature and $24 \%$ to precipitation (mainly in USA, Mexico, and Central America). Two percent $(2 \%)$ of the CAPs included sea level as a KEA of at least one target. Forty-two percent (42\%) of the KEAs were unrelated to climate (change), e.g., population size, fragmentation, and food availability.

Twenty percent $(20 \%)$ of the CAPs employed the term "climate change" in their site viability description, e.g., referring to the hydrological regime, the temperature or climate alteration as indicators. Of these 10 plans (or 48\%) were for sites in the USA, 9 (or 43\%) in Central America and 2 (or $10 \%$ ) in South America.

Forty-five percent $(45 \%)$ of the plans identified KEAs that are related to climate, such as temperature regime, precipitation regime, fire regime, or vulnerability to extreme precipitation events. However, $57 \%$ of these CAPs had indicators which were not related to climate change but rather measured aspects of reproduction, habitat, or biotic interactions.

We defined the viability threshold mainly on the basis of descriptions (41\%), rather than on quantitative measures (18\%) (e.g., "poor: if the Noel Kempff National Park Bolivia, sector north, has less than 10 butterfly species; regular: if the butterfly species are between 11-16, etc.). Six percent $(6 \%)$ of the plans took climate change scenarios into account (e.g., "if the current temperature of $24^{\circ} \mathrm{C}$ is maintained, all corals will survive; if temperature rises to $29^{\circ} \mathrm{C}$ in 50 years, the conservation target would be unviable"). Forty-eight percent (48\%) of the plans do not refer to climate change scenarios, and for all other sites no data were available, i.e., conservation planners left that database field empty.

Viability represents a total of climatic and non-climatic attributes for each area. Most areas have a "regular" viability. The American sites in the USA on average have a lower viability than the sites in Latin America (Table 9). 
Table 9. Viability values assigned for each area (on the basis of individual target-viability ratings)

\begin{tabular}{lccccc} 
Region & $\begin{array}{c}\text { Number of } \\
\text { CAP Areas }\end{array}$ & \multicolumn{5}{c}{ Viability of areas/sites (\%) } \\
\cline { 3 - 6 } & & Fair & Good & Very Good & No data \\
\hline South America & 25 & 28.0 & 40.0 & 0 & 32.0 \\
Mexico and Central America & 42 & 35.7 & 42.9 & 0 & 21.4 \\
USA & 36 & 63.9 & 27.8 & 0 & 8.3 \\
\hline Total & 103 & 43.7 & 36.9 & 0 & 19.4
\end{tabular}

Twenty-six CAPs (3 in South America, 11 Mexico and Central America and 12 USA) mentioned climate and atmosphere-change-related effects as threats, and included terms such as climate change, ocean acidification, changes in temperature and sea level, changes and modification in hurricane patterns of frequency and intensity, water level disturbances, altered rain and fire regimes, drought and changes in rainfall seasonality, and climate variability. The other threats were not related to climate change.

The conventional threats unrelated to climate change were arranged according to the classification of Salafsky et al. (2008). The highest scores correspond to dams and water management/use which represent $10.5 \%$ of this group of threats. Industrial and military effluents, logging, and timber harvest represent $7.6 \%$, whereas hunting of terrestrial animals, fishing, and the harvesting of aquatic resources represent $6.9 \%$. Housing, urban development, and non-timber crops (annual and perennial) account for $6.8 \%$.

Table 10 specifies how threats related to climate change were grouped according to climate changeinduced stresses classified by Geyer et al. (2011). Tikal National Park in Guatemala is the site with a "lowthreat" level. Ten percent $(10 \%)$ of the plans did not have data regarding threats. 
Table 10. Climate-change-induced stresses to biodiversity identified in the 103 Conservation Action Plans (classification according to Geyer et al. 2011)

Hierarchical levels

$\%$ of total stresses

1. Level of organisation of biological diversity where stresses arise

1.1 Stress class

1.1.1 General stress

1.1.1.1 Specific stress.

1. Change on individual and populations level

1.1 Direct stresses to individuals and populations

1.1.1 Change of physiology and behaviour of individuals

1.1.2 Change of population dynamics

1.2 Habitat-related stresses to individuals and populations

1.2.1 Loss of habitat

1.2.2 Change of habitat quality

0.5

2. Change on community level

2.1 Change of synecological relationships (trophic interactions, symbioses, and competition)

2.1.1 Loss/decoupling of synecological interactions/interdependencies

2.1.2 Change in the character of existing interactions

10.6

2.1.3 New species interactions

2.1.3.3 Appearance of new pathogens and parasites

2.2 Change of community structure

2.2.1 Change of community composition

2.2.2 Change of relative abundances

3. Change on ecosystem level

3.1 Change of abiotic conditions

3.1.1 (Micro) climatic changes (average, variability and seasonality)

3.1.2 Change of marine water characteristics

3.1.3 Change of freshwater hydrological regimes (wetlands)

3.1.3.1 Permanent change of water levels

3.1.3.4 Change of flood occurrence, frequency, intensity and area flooded

(including hydroperiod)

3.1.4 Change of snow/ice regimes

3.1.5 Change of abiotic soil conditions

3.2 Change of ecosystem structure

3.2.1 Change of the abiotic structure

$\begin{array}{ll}\text { 3.2.1.1 Change of surface structure and topography } & 0.4\end{array}$

3.2.1.2 Sea level rise, fluctuation and coastal impacts 0.4

3.2.2 Change of the biotic structure

3.3 Change of ecosystem processes and dynamics

3.3.1 Change of geophysical and disturbance processes

3.3.1.4 Change of surface movements (avalanches, erosion, and landslides) $\quad 0.4$

3.3.2 Change of energy flow and nutrient/matter cycle-related ecosystem processes

3.3.2.5 Change of carbon cycle

0.3

3.4 Change of ecosystem presence and global distribution

3.4.1 Change of global distribution of ecosystems

3.4.2 Change of diversity of ecosystems

3.4.2.1 Loss/dissolving of known ecosystems

Subtotal (Total n 792)

0.1

16.3 
Fifty percent $(50 \%)$ of the 103 CAPs qualified their areas/sites as "very highly threatened". A majority (23 sites or 64\%) of these CAPs are located in USA (Table 11). Twenty-six percent (26\%) of all CAPs were "highly threatened" and 14\% were seen as being under "medium" level of threat.

Table 11. Overall threat ratings by area and region

\begin{tabular}{lcccccc} 
Region & $\begin{array}{c}\text { Number of } \\
\text { CAPs }\end{array}$ & \multicolumn{5}{c}{$\begin{array}{c}\text { Rating threats by area } \\
\text { Qualify threats by region and percent (\%) }\end{array}$} \\
\cline { 3 - 7 } & & Very High & High & Medium & Low & No data \\
\hline South America & 25 & 36.0 & 24.0 & 16.0 & 0.0 & 24.0 \\
Mexico and Central & 42 & 45.2 & 21.4 & 21.4 & 2.4 & 9.5 \\
America & 36 & 63.9 & 33.3 & 2.8 & 0.0 & 0.0 \\
USA & 103 & 49.5 & 26.2 & 13.6 & 1.0 & 9.7
\end{tabular}

Conservation objectives and strategies: On average, four conservation objectives (goals) and four strategies were suggested per site. Only $2 \%$ of the conservation objectives (five sites in Mexico and Central America and three sites in the USA) referred more or less directly to climate change. The remaining $98 \%$ of the objectives addressed activities such as maintenance of the vegetation cover $(10 \%)$, the integrity of habitats $(14 \%)$, and the empowerment of stakeholders involved in management $(11 \%)$.

Most management teams (64\%) proposed achieving their objectives within 6 to 20 years. Only 6\% aimed for their objectives to be met in over 20 years. Twenty-one percent (21\%) of the sites did not specify a timeframe for their objectives. In $7 \%$ of the plans, climate change scenarios were taken into account when setting conservation targets.

According to the CAP procedure, strategies are designed to achieve the defined objectives. Eight percent $(8 \%)$ of the conservation strategies were directly or indirectly related to climate change adaptation. Other important strategies, which partially or indirectly can be interpreted in terms of dealing with climate change, included the strengthening of alternative strategies and the promotion of renewable energies (26\%); services for visitors, such as environmental education, rescue and assistance (24\%); strategies targeting ecological processes and functions, such as corridors, connectivity, watershed management (17\%); and habitat integrity and quality, such as forest protection and the control of invasive species (13\%). The rest are conventional strategies (13\%) (e.g., data collection and analysis information, development of system information).

Monitoring: Only 38 of the 103 CAPs we evaluated included a monitoring plan and among these, there was an average of 6 to 7 monitoring actions or steps in each plan. Eighteen percent (18\%) of the actions in the monitoring plans, proposed at only seven sites (4 in USA, 3 in Mexico/Central America), included elements that can be referred to climate change (e.g., monitoring of hydrological regime or 
microclimate, response of plants to climatic changes, and coral bleaching). Eighty-two (82\%) of the monitoring methods or actions related to rather conventional observations: field observations (9\%), biological inventories (10\%), GIS and remote sensing studies (12\%) and others (e.g., political or legislative monitoring). Sixty-three (63\%) of the monitoring activities also included indications of the intended frequency of measurements (e.g., every two years, 6\%; at least every year, 10\%, every 5 years, $11 \%)$.

\subsubsection{Conservation Action Plans after 2009}

Conservation targets: The 22 CAPs that were uploaded to ConPro from 2009 onward included 144 conservation targets. Of these targets, $6 \%$ were species, $13 \%$ biological communities or species groups/guilds, $79 \%$ ecosystems, and $1.4 \%$ were related to ecological processes (e.g., connectivity between fragments and environmental services).

Viability of conservation targets and sites: Temperature and fire related threats were identified in $27 \%$ of the CAPs, although none addressed precipitation, snowfall, or sea-level rise. Forty-one percent (41\%) named KEAs that are not related to climate and $32 \%$ of the 22 CAPs did not include KEAs.

Fifty-nine percent $(59 \%)$ of all KEAs identified in the 22 CAPs are considered as climate change dependent and correspond to the following categories: hydrologic regime (timing, duration, frequency, extent) $(64 \%)$; fire regime (21\%), ground water regime (10\%), and other climatic parameters.

Threats: The term "climate change" was highlighted as a threat in half of the CAPs from 2009 onward. These CAPs identified a total of 301 threats with an average of 12 to 13 threats. In the current ConPro format, this represents the threats according to the 11 categories established by Salafsky et al. (2008). Using these 11 categories, we found that climate change is represented by droughts (1\%), habitat shifting and alteration (3\%), and storms and flooding (1\%). Other related categories included invasive and other problematic species and genes (12\%), and natural systems modifications (19\%). The rest of the threats $(64 \%)$ were more conventional. Of the CAPs that mentioned climate change as a threat, 9.1\% ranked it as very high, $9.1 \%$ as high, $36.4 \%$ as medium and $18.2 \%$ as low. For $27.3 \%$ of the CAPs, no importance ranking of climate change was made.

Conservation objectives and strategies: We compared the CAPs developed prior to the climate change clinic (pre-2009) with those uploaded after the clinic (Poiani et al. 2010). In general, the post-clinic CAPs included an increased number of actions that are or could be related to climate change, such as resource and habitat protection $(0.89 \%$ versus $7 \%)$, site area management $(5 \%$ versus $9 \%)$, invasive species management or control (4\% versus $7 \%$ ), and species recovery ( $0 \%$ versus $3 \%$ ).

Comparing the CAPs from before and after 2009 we found that more plans (59\%) from 2009 and after used KEAs that refered to climate change. The viability values by areas were higher (good viability) in relation to before 2009 (Fig. 4). More CAPs refered to climate change as a threat after 2009 and the number of areas with "high threats" increased. 
Figure 4. Comparison between CAPs evaluated before and after 2009 (\%) (TNC 2011)

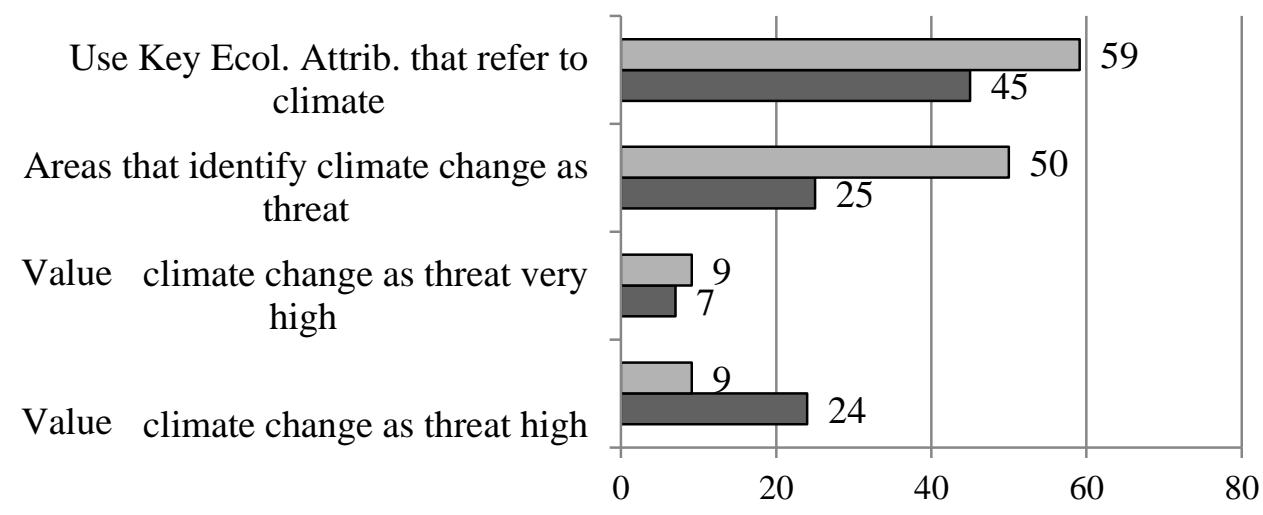

$\square$ Before $2009 \square$ After 2009

\subsection{Local case example: Área Natural de Manejo Integrado Rio Grande Valles Cruceños}

We collected results from the extended CAP workshop methodology experience with the Area Natural de Manejo Integrado Rio Grande Valles Cruceños (ANMI RG-VC) in the department of Santa Cruz, Bolivia over the course of 6 months. During this time we worked with local community members and representatives, local and departmental elected officials, NGOs, representatives of SERNAP (National Service of Protected Areas) municipal technicians, private landowners and scientists. The process of using the extended CAP led us to select 8 conservation targets (CT) with the highest scores for ANMI $\mathrm{RG}-\mathrm{VC}$ and which included the most criteria following the steps in the proposed manual. These are the selected conservation targets: 1) Water (use and production ); 2) Primary and secondary river beds of Rio Grande; 3) Forest (between $500 \mathrm{~m}$ - 1,500 m); 4) Dry forest; and 5) Cloud forests and watershed protection ( $\geq 1,500 \mathrm{~m}$ ); 6) Fish; 7) Parrots; and 8) Sunka palm (Parajubaea sunka). In this first step, we recorded the discussions, priorities and reasons for selecting each CT while considering their representativeness of biodiversity of the PA (see example in Annex 4). The selection process was participatory and stakeholders used their local knowledge of the area to draw the distribution ranges and location of CTs on paper maps of the PA. Some of the locations or ranges were in areas outside of the AMNI. This data from the maps was used extensively to determine the final distribution of targets in the area (see Annex 5).

Through the workshop process, the participants selected the montane forests and the dry forests of the area as the most inclusive CTs (ecosystems). We defined the target of "water" to mean: "maintain sources and quality" and "river beds" to mean: "watershed and river bank protection, maintain water production and its ecological function." These were selected due to their importance to conservation outside and beyond the PA, considering that this is an Integrated Management Natural Area and allows for the presence of human poplulations and use of resources within the PA. In the same way, the 
workshop group selected conventional targets such as "species" which are also considered key for the conservation of the PA.

The viability analysis of the CTs was a lively discussion, reflecting the important relationships between factors which could affect KEAs (be they climate-dependent or conventional) and therefore, the viability of the CTs.

Participants identified factors that could put stress or pressure on biodiversity, leading directly or indirectly to damage and impacts affecting the viability of the CT and therefore the biodiversity of the area and the human populations that depend on these resources.

From this analysis, the planning team generated a list of 64 key ecological attributes (KEAs) necessary to the survival and persistence of selected CTs in the PA. These were grouped as follows:

-Thirty-nine percent (39\%) of the KEAs correspond to changes in habitat (connectivity, deforestation, changes in structure, composition, continuity); $22 \%$ of the KEAs deal with dynamics and function (phenology, habitat for shelter, function); 18\% of the KEAs concern the relationships between species and its habitat (shelter, food availability, predator/prey); 13\% of KEAs are about changes at the species level (reproduction, number of individuals, populations structures, regeneration, viability of the species) and $8 \%$ of KEAs covered changes in the climate, hydric and/or fire regimes (season, duration, frequency, extent). The current viability of the targets of ANMI RG - VC (the sum of the values for each target, using Miradi) was rated as "good" (see example in Annex 6).

To determine the climate-dependent viability, both current and future, we reviewed the literature, climate projections (climate scenarios for Bolivia), plus the opinions of the participants in the workshop (qualitative data). We obtainted ratings for future climate-dependent viability for the ANMI by asking, how a CT might be affected by climate change, within a specified time period. As an example with the target of "dry forest": In a range of 30-50-100 years in the future; How could temperature $\left(\mathrm{T}^{\circ}\right)$ affect the ecosystem? The scores for each attribute (according to impact classes rated as poor, fair, good, very good) were then averaged, giving a final rating of "fair" for future viability. The table below shows the ratings of some CTs as an example. We show the ratings for the remaining CTs in Table 12. (more examples in Annex 7). 
Table 12. Summary of current and future Climate-Dependent Viability for the ANMI RG-VC (Miradi)

\begin{tabular}{|c|c|c|}
\hline$\bigcirc$ Targets $\theta$ Key Ecological Attribute (KEA) & $\begin{array}{l}\text { Current } \\
\text { viability }\end{array}$ & $\begin{array}{c}\text { Future } \\
\text { viability }\end{array}$ \\
\hline Climate-dependent viability ANMI RG-VC & GOOD & FAIR \\
\hline \multicolumn{3}{|l|}{ Example individual rating for some CTs } \\
\hline $\begin{array}{l}\text { Water, Cloud forests and watershed protection, Primary and } \\
\text { secondary river beds of Rio Grande, Fish (Condition) }\end{array}$ & Fair & Poor \\
\hline$\Leftrightarrow$ Temperature regimen & Good & Fair \\
\hline V Vulnerability of the CTs with repsect to temperature extremes & Fair & Fair \\
\hline Precipitation regimes & Fair & Poor \\
\hline Vulnerability of the CTs with repsect to precipitation extremes & Fair & Poor \\
\hline Seasonal distribution of precipitation & Good & Fair \\
\hline$\Leftrightarrow$ Other climate parameters & Good & Poor \\
\hline Fire regime & Fair & Fair \\
\hline
\end{tabular}

We made a list of threats (stresses) for each CT of the ANMI RG-VC, plus a list of stakeholders associated with these impacts. The pressures identified were largely conventional and included the following: fire and burning, pollution (agrochemicals), unsustainable livestock practices, ranching, logging, deforestation, unsustainable agricultural practices.

Participants selected "climate change" itself as an individual threat for ANMI RG-VC. According to the workshop analysis, this threat impacts both the biodiversity of the area as well as the production systems and quality of life in for the people of the communities within the ANMI. This is especially true when considering the topographic, altitudinal and climatic variation of the PA. The impact of climate change is "high" for half of the targets of the area (Table 12). In this regard, the participants discussed the issue of water levels in the area, which are highly variable between years with high rainfall or years with drought, erosion areas with vegetation cover loss, indirect effects associated with farming and the logging of forest to clear areas for farmland. The groups also discussed local population growth and immigration of settlers (who bring highland agricultural practices with them to the lowlands) to the IMNA: "The present issue of the influx of people to the area is aggravated by climate change; the beginnings and ends of the seasons are no longer distinctive and so it is less obvious when to start preparing the land; Settlers from the highlands are migrating to our lowlands, seeking better farming conditions."

The sum of the threat ratings for the ANMI RG-VC (calculated with the Miradi program) according to the degree of effect on each of the CTs, resulted in a threat rating of "very high" (Table 13). 
Table 13. Threats for the ANMI Río Grande Valle Cruceños (Miradi)

\begin{tabular}{|c|c|c|c|c|c|c|c|c|c|}
\hline \multirow[t]{2}{*}{ Threats } & \multicolumn{8}{|c|}{ Conservation Targets* } & \multirow{2}{*}{$\begin{array}{c}\text { Summary of threats } \\
\text { ratings** }\end{array}$} \\
\hline & 1 & 2 & 3 & 4 & 5 & 6 & 7 & 8 & \\
\hline Commercial and sport fishing & & & & & & & & $\mathrm{H}$ & High \\
\hline Construction of dams & & $\mathrm{L}$ & $\mathrm{L}$ & & M & & & $\mathrm{H}$ & Medium \\
\hline Fires and burning & M & M & M & $\mathrm{H}$ & M & M & $\mathrm{L}$ & $\mathrm{L}$ & High \\
\hline Pollution (from agrochemicals) & M & & & $\mathrm{L}$ & $\mathrm{H}$ & & & $\mathrm{H}$ & High \\
\hline Unsustainable livestock practices & M & M & M & $\mathrm{H}$ & M & & M & M & High \\
\hline Large cattle ranches & $\mathrm{L}$ & $\mathrm{M}$ & $\mathrm{H}$ & $\mathrm{H}$ & $\mathrm{L}$ & & M & $\mathrm{L}$ & High \\
\hline Timber harvest & $\mathrm{L}$ & $\mathrm{H}$ & $\mathrm{H}$ & $\mathrm{H}$ & $\mathrm{L}$ & & & $\mathrm{L}$ & High \\
\hline Construction of roads & $\mathrm{L}$ & $\mathrm{L}$ & $\mathrm{L}$ & M & $\mathrm{L}$ & & & M & Medium \\
\hline Deforestation & M & $\mathrm{H}$ & M & M & $\mathrm{H}$ & M & & $\mathrm{L}$ & High \\
\hline Unsustainable farming practices & $\mathrm{L}$ & M & $\mathrm{H}$ & $\mathrm{H}$ & $\mathrm{VH}$ & $\mathrm{L}$ & & $\mathrm{L}$ & High \\
\hline Climate Change & $\mathrm{H}$ & M & $\mathrm{H}$ & $\mathrm{H}$ & $\mathrm{H}$ & M & $\mathrm{L}$ & M & High \\
\hline Hunting natural predators of rodents & & & & & & & M & & Medium \\
\hline Sunka palm fiber harvest & & & & & & & $\mathrm{H}$ & & High \\
\hline Heart of palm harvest for consumption & & & & & & & $\mathrm{L}$ & & Low \\
\hline Consumer demand of wild pet trade & & & & & & $\mathrm{L}$ & M & & Low \\
\hline Capture of wild animals for pet trade & & & & & & $\mathrm{L}$ & & & Low \\
\hline Indiscriminate water use (crop irrigation) & M & & & & & & & & Medium \\
\hline Collection of firewood & & & M & & & & & & Medium \\
\hline Goat ranching & & & $\mathrm{L}$ & & & & & & Low \\
\hline Collection of mushrooms and mosses & & & & $\mathrm{L}$ & & & & & Low \\
\hline Unregulated fishing & M & & & & M & & & $\mathrm{H}$ & Medium \\
\hline Overall rating for ANMI RG_VC & $\mathrm{H}$ & $\mathrm{H}$ & $\mathrm{H}$ & $\overline{\mathrm{VH}}$ & $\mathrm{VH}$ & $\mathrm{M}$ & M & $\mathrm{H}$ & Very High \\
\hline
\end{tabular}

*Conservation Targets: 1)Water; 2)Forest; 3)Dry forest; 4)Cloud forest and watershed protection; 5)Main waterway of the Rio Grande and its tributaries; 6)Parrots; 7)Sunka Palm; 8)Fish. **Threats Ratings: Low=L; Medium=M; High=H; Very High=VH 
To categorize our list of threats we used the 11 groups proposed by Salafsky et al. (2008) and which TNC uses in its CAPs. Under this classification, the ANMI threats grouped as follows:

- Climate change and severe weather (5\%); Transportation and utility corridors (5\%); Pollution (5\%); Natural system modifications (14\%); Agriculture and aquaculture (19\%); Biological resource use (52\%); Geological events (0\%); Energy production and mining (0\%); Residential and commercial development (0\%); Human intrusions and disturbance $(0 \%)$; Invasive an other problematic species $(0 \%)$. Undefined (added by TNC) $(0 \%)$.

Of all the threats for the ANMI (see Table 13 above), we prioritized 13 with the highest ratings, following a discusion and analysis with the participants. Threats with High rating: Fires and burns; Pollution (agrichemicals); Unsustainable livestock practices; extensive livestock ranchins; timber extraction; Deforestation; Unsustainable agricultural practices. Threats with Medium rating: Sport and commercial fishing; Construction of dams; Construction of new roads; Sunka palm fiber harvest and Unregulated fishing. Some of these prioritized threats were placed on a map with the location of each in the AMNI (see map in Annex 8). Workshop participants assigned the threats to the corresponding stakeholders, the key people who are in a strategic position to positively or negatively affect the conservation outcomes for the AMNI RG -VC. There was heated debate among the participants to identify which stakeholders were linked to each of the threats. Finally, to present the results of this activity, we used a conceptual model to show where each major social group was in relation to the different threats across the PA. This group work resulted in a list of key stakeholders. We show these results from the extended pilot CAP activity in a conceptual model, showing the analysis for the 9 of the 13 prioritized threats, as an example (Fig. 5): 
Figure 5. Conceptual model of prioritized threats and primary stakeholders in ANMI RG-VC. (Miradi)

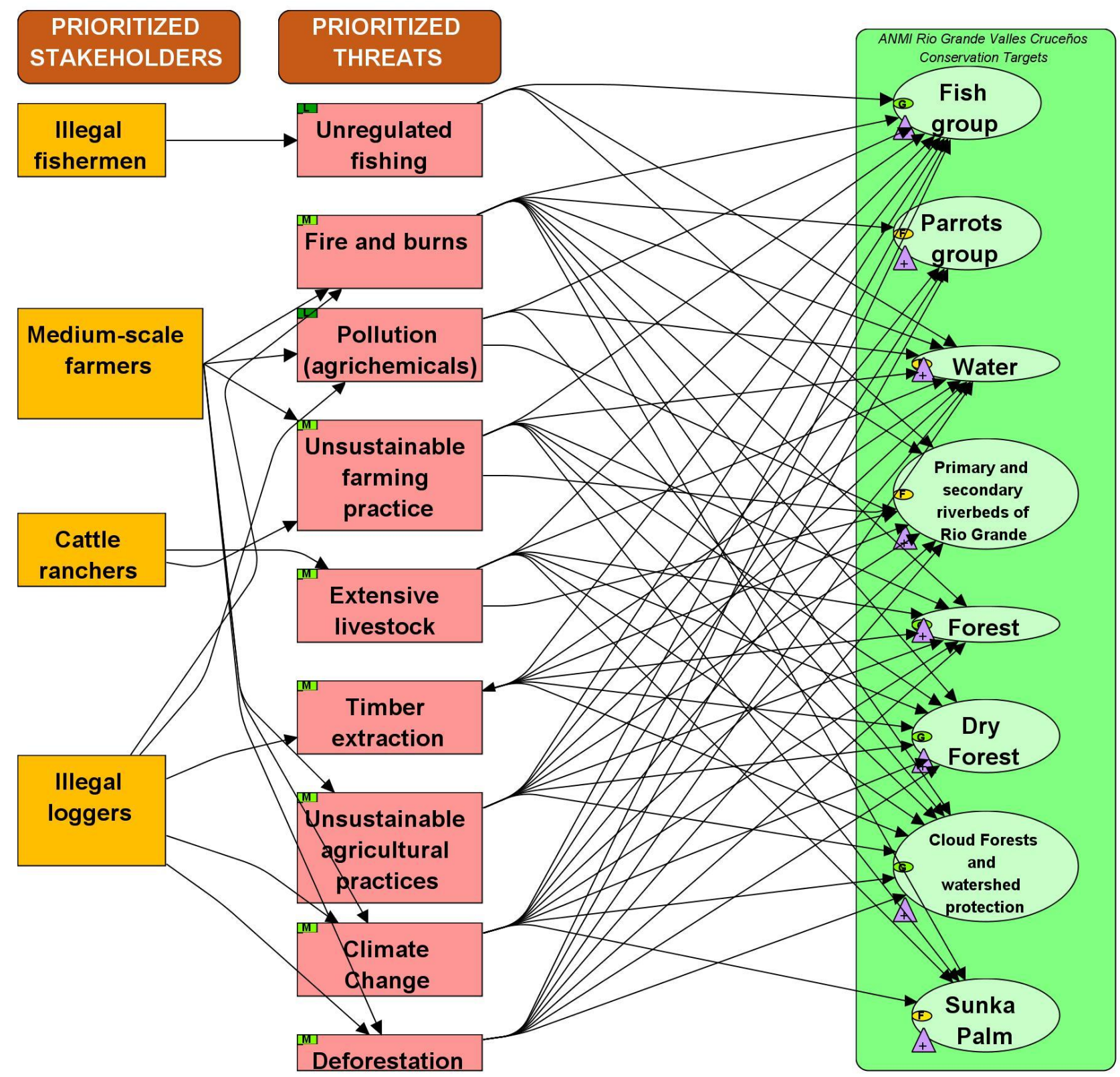


With the separate analysis of the conservation targets, we built conceptual models of the particular situation for each CT. We did an analysis relating the conservation targets (CT) with the 13 prioritized threats, the stakeholders and their motivations and behaviour-determining factors. Below we show the results of the conceptual model analysis for two targets of the AMNI, although we conducted the analysis for all of the targets. (Fig. 6).

Figure 6. Threats situation analysis of two conservation targets in ANMI RG-VC. (Miradi)

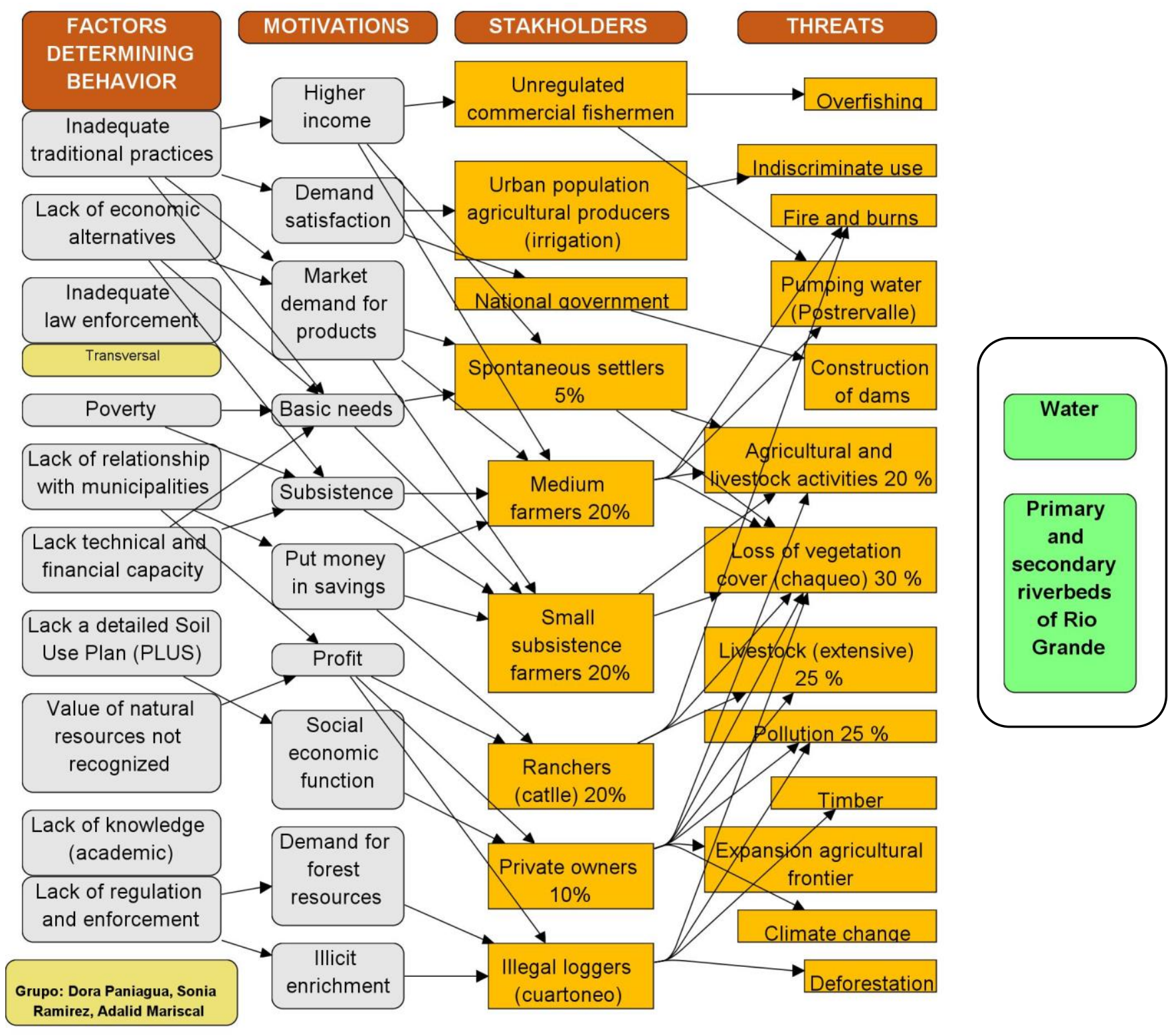


Below (Fig. 7), we show current and future projected threats. Nearly $62 \%$ of present threats are rated as "high" and $38.5 \%$ are rated as "Medium".

Using the opions of the workshop participants, we projected the impact of the same threats 20 years from now. The results show that the "high" threats increased both in scope (how far-reaching their impact will be) and in severity (the degree of their impact). For example, Threat, "Climate Change": current rating in the PA is "high"; What do workshop participants think the scope and degree of this threat will be in 20 years?: In 20 years, the degree (severity) will be "very high" and the scope will be "very high". The final rating for future climate change in the PA is "very high". We looked at each threat rating for the present and 20 years in the future.

Figure 7. Present ratings and projected future ratings of threats in ANMI RG-VC

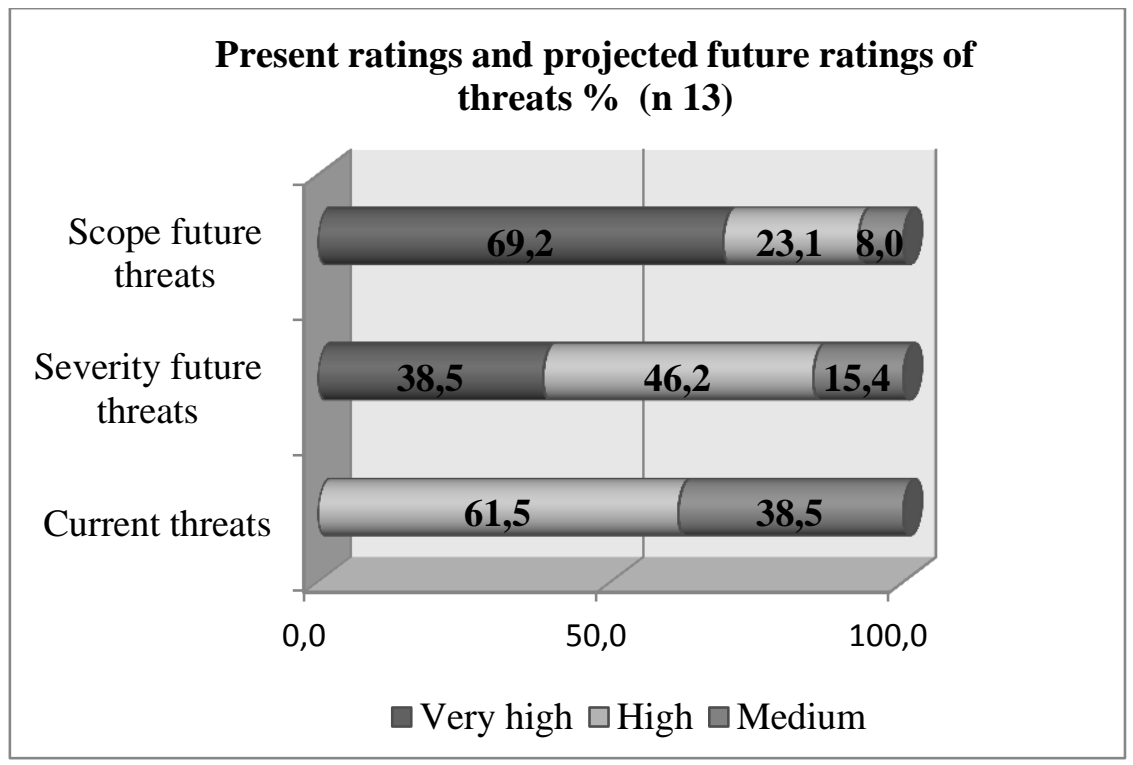

The group also prioritized the 10 most feasible and relevant conservation opportunities for the area, which were as follows:

Six (6) opportunities focus on work with conservation programs or research (including climate change program, forest and soil management, and environmental education); and the remaining 4 opportunities fit into working with financial mechanisms; building institutional capacities; and production of alternative crops and other activities for income-generation (see example procedure in Annex 9).

For each of the identified and prioritized threats, we established two or three strategies to maintain or improve habitat health and the viability of the KEAs. The strategies were developed following the pilot instruction manual, with the goal of ensuring the functionality of the CTs, so that the strategies are sufficiently focused on the best resilience/adaptation capacity and/or mitigation of the consequences of climate change and so that the strategies are viable and favor conservation of the CTs, etc. The group prioritized a total of 11 strategies that met the most criteria and could address the threats for 8 CTs of 
the AMNI RG -VC: The strategies were grouped by similarity of goals, resulting in the following focused topic strategies:

-Identify alternative production options (36\%) (this was considered the most important strategy to address the various threats to CTs of the PA); Training and education (27\%); Creation of conservation programs (18\%); and strengthening institutions related to conservation work of the PA (18\%). Shown below is an example conceptual model generated for the threat Climate change (Fig. 8), with the proposed strategies in yellow and the proposed activities in light blue. Similar analyzes were performed for each of the threats of the ANMI:

Figure 8. Strategies for the ANMI RG-VC. Example (Miradi)

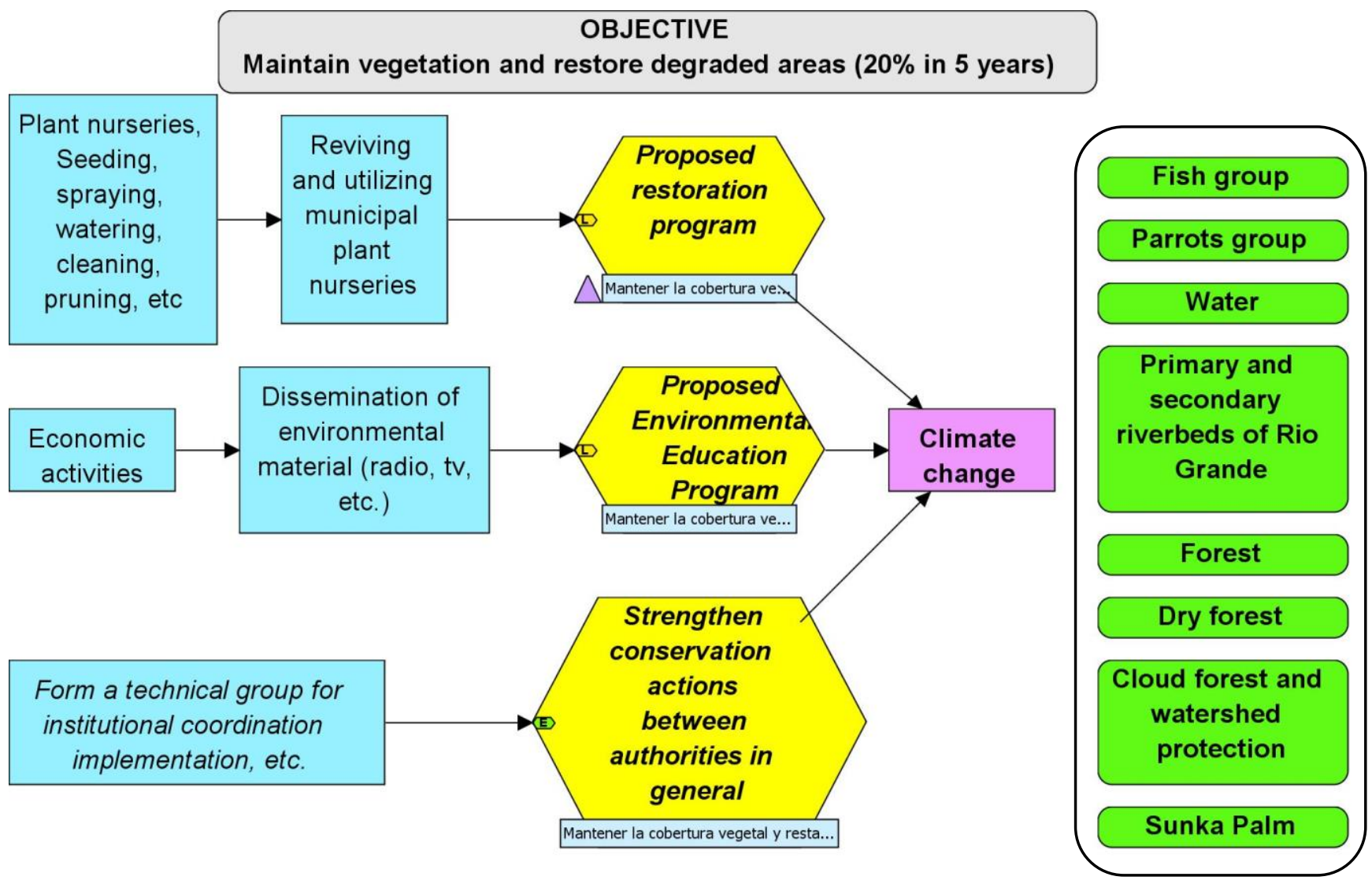

In our study we identified risks (conventional and from climate change) to the protected site: The opinions of the participants gathered in the workshops indicated that climatic phenomena such as temperature increase; altered precipitation regime; increase of fire and extreme weather events (winds, hail, floods, etc.) are the climate risks which will have the greatest impact on the AMNI: The stakeholders said: Climate patterns are altered; climate changes are leading to changes in economic activities (agriculture, livestock, fisheries) and to changes in biodiversity and ecosystems.

For example, the workshop participants suggested the strategy: "Look for alternative production options to improve incomes, diversify production and allow for sustainable land use". After forming this strategy, we looked at the different climate-associated risks which could impact the development 
and feasibility of implementing the strategy: e.g., "Risk of increase in temperature (or increase in precipitation, floods, etc.)", the probability of occurrence in the area (low, medium, high, very high), and the extent that their impact could have (same values) scored. This analysis was performed in order to ensure that the proposed strategies are viable while considering risk as another factor. The participants' final rating of the impact which these climate risks could have on the development and implementation of strategies for the PA, was "high" and the impact magnitude "very high".

The likelihood of occurrence in the PA was rated (low, medium, high, very high), and the magnitude which the impact could have was also rated (same categories). The final rating of the impact of these climate risks on the development of strategies for the PA, according to the opinions of the local residents and the technical team, was "high" likelihood (probability). The magnitude of the impact was rated as "very high".

For example, the opportunity exists in the region to connect conservation work with the protection of ecosystem services: maintaining subterranean water recharge zones and natural vegetative cover in watersheds generates opportunities for the communities to access funding for conservation actions which protect these ecosystem services provided to society.

To monitor and measure the success of protected areas planning, we designed a monitoring plan, similar to that of the conventional CAP, with activities and actions that should be followed or monitored. Our monitoring plan indicated time, location, duration, responsible parties, cost, etc. Due to various institutional factors, not all of this information was completed in the course of the case study workshop but the monitoring plan was completely developed in a parallel exercise by the institution (Fundacion Natura, Bolivia).

An additional result from the extended CAP exercise with AMNI RG -VC (and not published in this paper) was the preparation of a final document, given to the institution (Fundacion Natura) describing step-by-step the methodology, maps of the PA made together with the participants (distribution of CTs, threats and stakeholderss locations), charts of all the ratings analysis, conceptual maps, list of participants and general description of each activity.

\subsection{Regional analysis of climate change in protected areas}

The questionnaire on the perception and opinion of PA managers in Santa Cruz regarding their management approach relative to the issue of climate change was answered by 28 of the 32 protected areas of the department (Fig. 9 Location Map.) We did not receive responses from the following four municipal protected areas: Curichi El Cuajo Nature Reserve; Santa Barbara and Brava Lakes; Muela del Diablo Natural Monument and Santa Cruz La Vieja ANMI and Historical Park.

This was a very good number of responses, considering that many PAs in the region and in Bolivia are remote, with difficult communication and access in addition to low numbers of staff and technical specialists in environmental issues. 
Figure 9. Location Map of Protected Areas in Santa Cruz, Bolivia

\section{PROTECTED AREAS EVALUATED IN SANTA CRUZ, BOLIVIA}

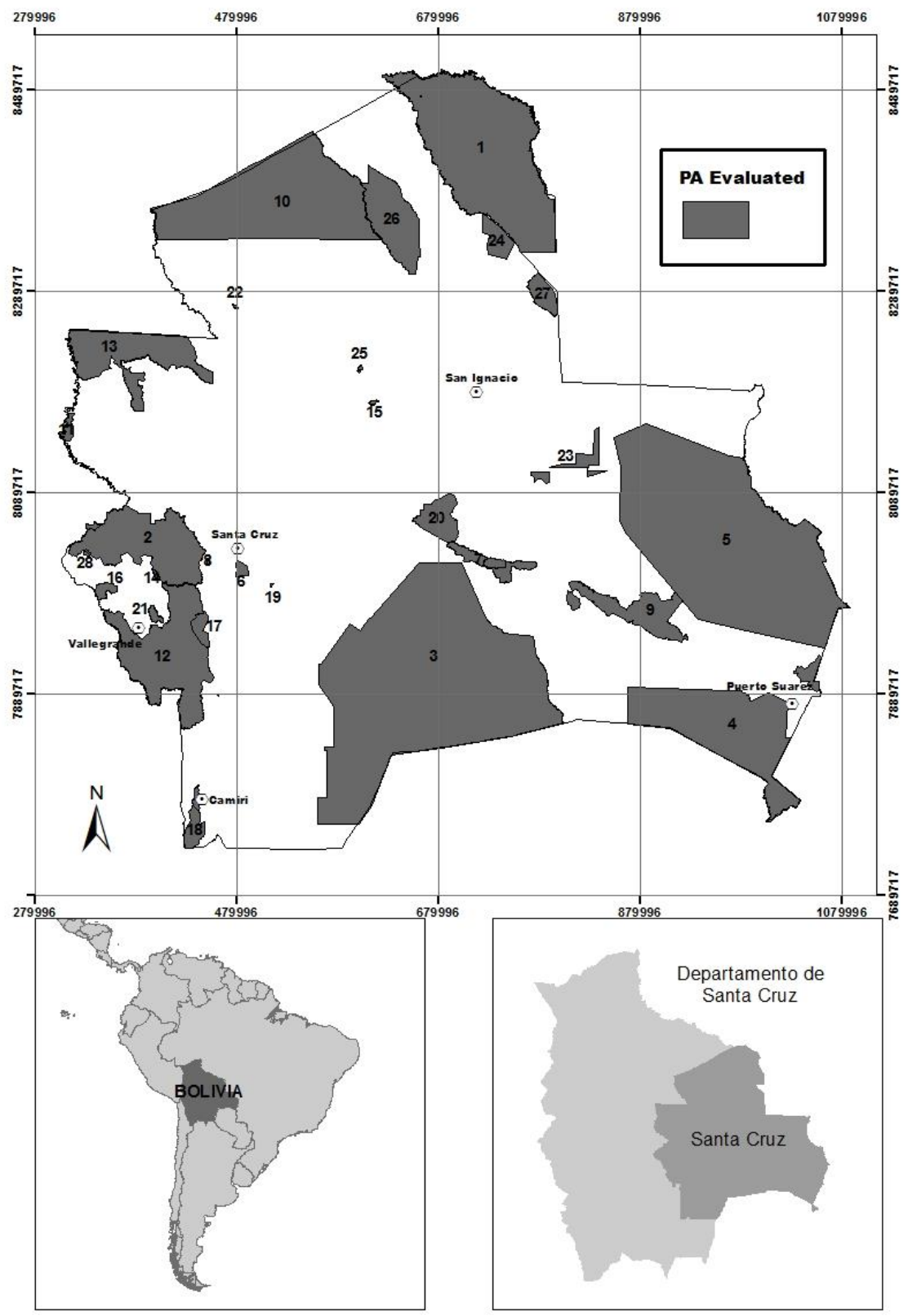

National PAs / Parque nacional (PN): 1. PN "Noel Kempff Mercado"; 2. PN y ANMI "Amboró"; 3. PN y ANMI "KaaIya del Gran Chaco"; 4. PN y ANMI "Pantanal Otuquis"; 5. PN y ANMI "San Matías". Departmental PAs: 6. Parque Regional Lomas de Arena; 7. Parque Historico Santa Cruz La Vieja; 8. Monumento Natural de Espejillos; 9. Reserva Departmental Valle de Tucavaca; 10. Reserva de Vida Silvestre Ríos Blanco y Negro; 11.Meandros del Río Ichilo; 12.ANMI Río Grande Valles Cruceños; 13.Humedales del Norte. Municipal PAs: 14.Municipal Protected Area / Area Protegida Municipal (APM) Microcuenca El Chape; 15. APM Orquídeas del Encanto; 16. APM Jardín de Cactáceas de Bolivia; 17. APM Parabanó; 18. APM Serranía Sararenda Cuevo-Camiri; 19. APM Palmera de Saó; 20. APM Laguna Concepción; 21.APM Laguna Esmeralda; 22.APM Laguna Yaguarú; 23.Reserva Municipal San Rafaél; 24. Reserva Municipal San Ignacio; 25.Laguna de la Represa Zapocó; 26.Reserva Copaibo; 27.Laguna Marfil; 28. Area protegida Churo Negro. 
In the table below (Table 14) we present the results from our evaluation and analysis of the questionnaire responses, summarizing the opinions of managers relative to 79 variables analyzed by protected area and by question. More than one answer per question is possible. For example, Question 2: What is your concept of climate change (CC)? Managers responded: Temperature variations and altered precipitation regime; Natural disaster; etc. The table also includes data which we added for the size of PA, deforested area, type and number of ecoregion(s).

First we present the quantitative results of the questionnaire (Table 14) and then we present each of the qualitative or descriptive responses from the managers which we maintained as text (by nature some answers were only included as descriptive data):

Regarding question \#2 (see Table 14) - What is your concept of climate change (CC)? Almost all managers (excepting one) responded that climate change was an evident phenomenon in their respective PAs; 23 sites mentioned: Anthropic activities which cause pollution, waste, climate modification and natural disasters. At the same time other areas made references to what they observed: Alterations in the regimen of rainfall, floods, droughts; There is variation of temperature; Fire. Examples from their description: "In the Bolivian Pantanal there is less rainfall than before; the summer rains are more intense, causing severe and frequent flooding and during the dry season there are more wildfires (especially due to anthropic activities); There is a loss of species sensitive to water, etc.).

Only 11 of the 28 sites surveyed in the department of Santa Cruz, Bolivia, had management plans to guide their administration and conservation activities (and of these 11 PAs, 8 emphasized that they only recently developed their plan and programs). The PAs which didn't have management plans stated this was due to: Lack of resources or that theirs was a newly-created PA; being in the process of developing a management plan, or they use other documents with ecological management guidelines such as a Forest Management Plan, Protection Plan or ecological survey. 
Table 14. Variables description and results

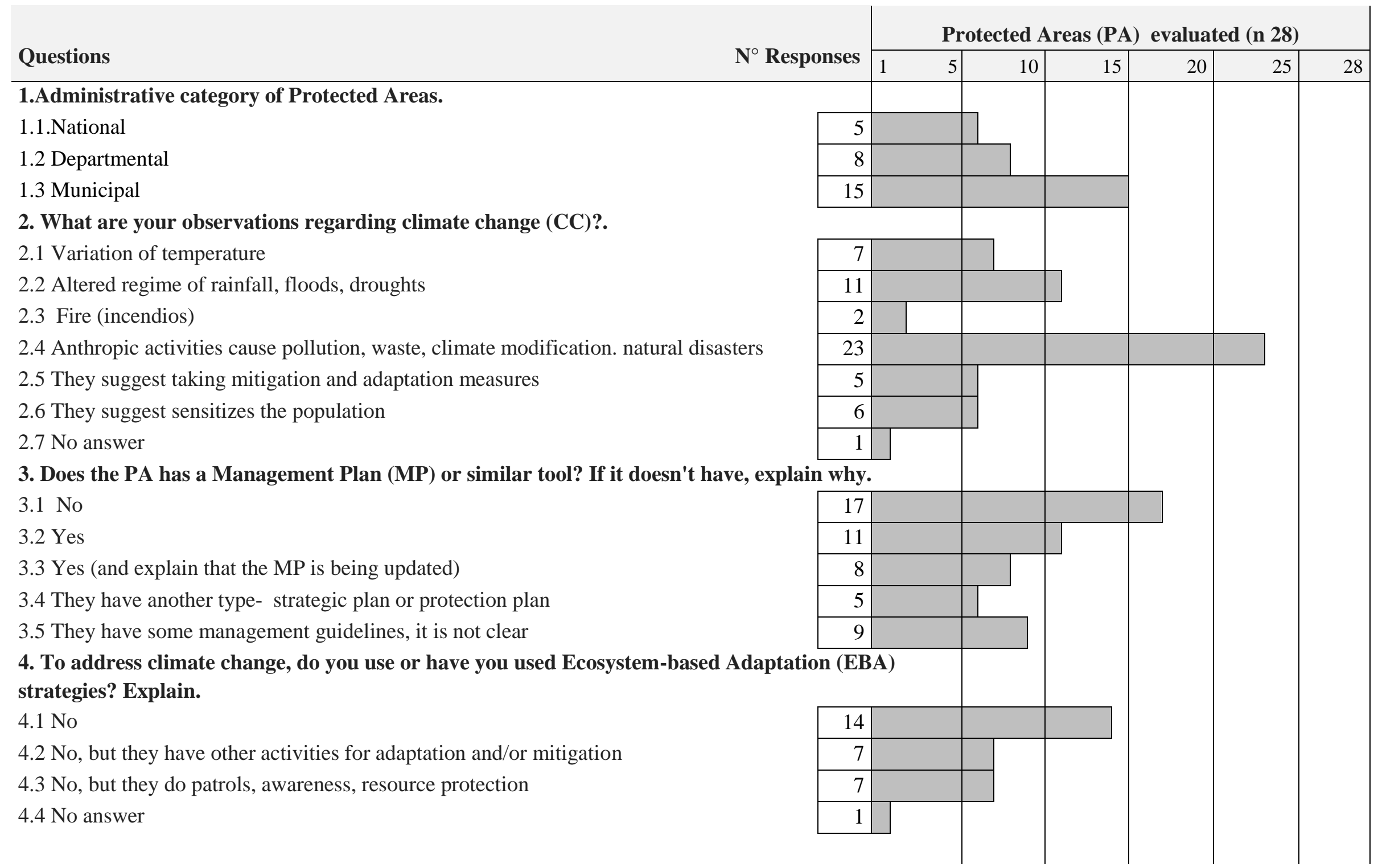




\section{Is some monitoring system is used in the PA? Explain.}

$5.1 \mathrm{No}$

5.2 Yes, patrolling and monitoring of species

5.3 Yes, monitoring administration (gestion) (with the National Service)

\subsection{Other}

6. Do you apply a risk management approach in the PA? Explain.

6.1 Yes, forest fire management and early warning (alerta temprana)

6.2 No, without further explanation

6.3 Only do lectures, workshops, give training on hazards

6.4 No, but the risks are identified as a threat in the areas; they know where the risk are

7. Define the concept of "risk" you work with.

7.1 Do not work with a concept of risk. They don't define the concept

7.2 Concept: risk is threat

7.3 Other responses

8. Presently, which climate change-related risks do you consider most critical in your PA? Explain.

8.1 No answer

8.2 Climate variability (drought, wind, temperature, loss of water sources, etc)

8.3 Illegal logging. clearing new areas for planting (chaqueo) and ranching

8.4 Other

9. In the future, which climate change-related risks do you anticipate will impact your PA?.

9.1 Changes in the Weather

9.2 Impacts on biodiversity

9.3 Impacts on soil, water ( agriculture, livestock )

9.4 In the economy and socially

9.5 No answer

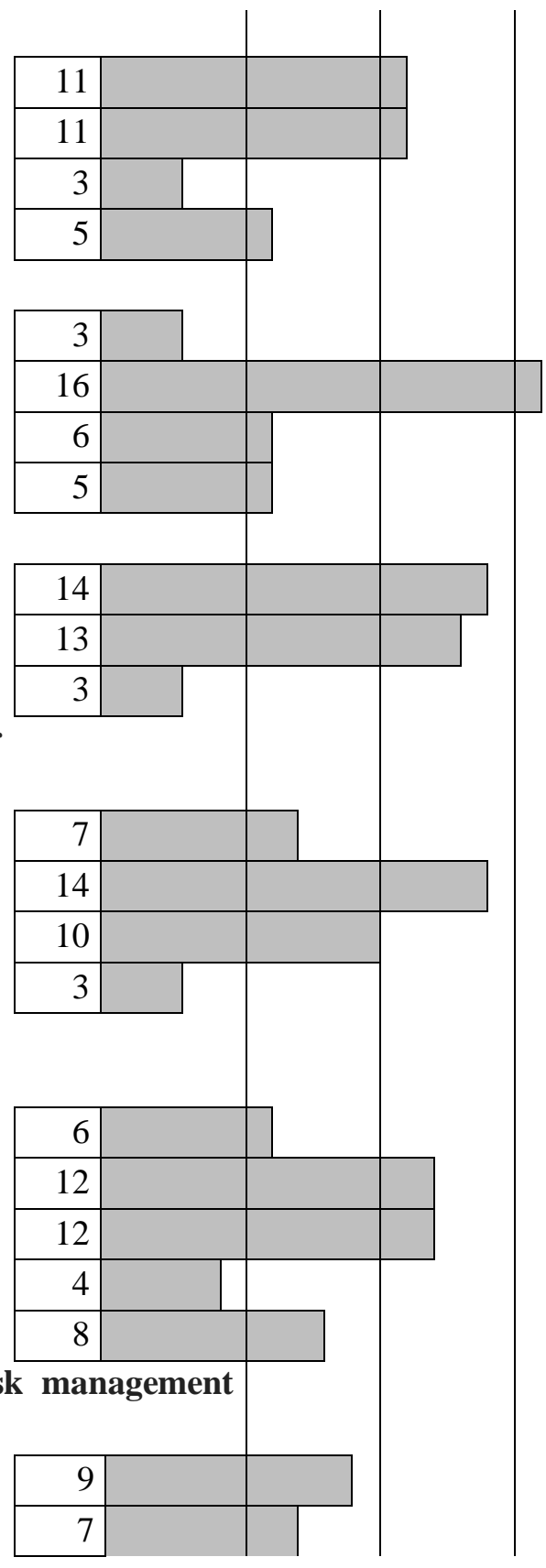


10.3 No answer or they say they don't do risk management

11. Is there any work that you undertake jointly with other protected area(s)?

Explain.

11.1 No work done with any other PA

11.2 Yes, technical and /or legal cooperation

11.3 Yes, attend workshops and trainings conducted by the National Service PA

12. Do you do any work with private neighbors around the protected area? Explain.

12.1 No work done with any private neighbors

12.2 They work together in protection strategies for natural resources

12.3 They are members in the management committee

12.4 They participate in training workshops for biodiv. conservation and fire prevention

13. Do you think conservation now seems to be more difficult / challenging than 20 years ago? If so, why?.

13.1 It is more difficult; by political and social pressures (migration/population growth)

13.2 More difficult because there are legal gaps and loopholes

13.3 Difficult, because more economic resources are needed

13.4 Difficult because of impacts to the forest, climate, etc.

13.5 It is easier,we have more access to information

13.6 It is easier, there is more environmental awareness

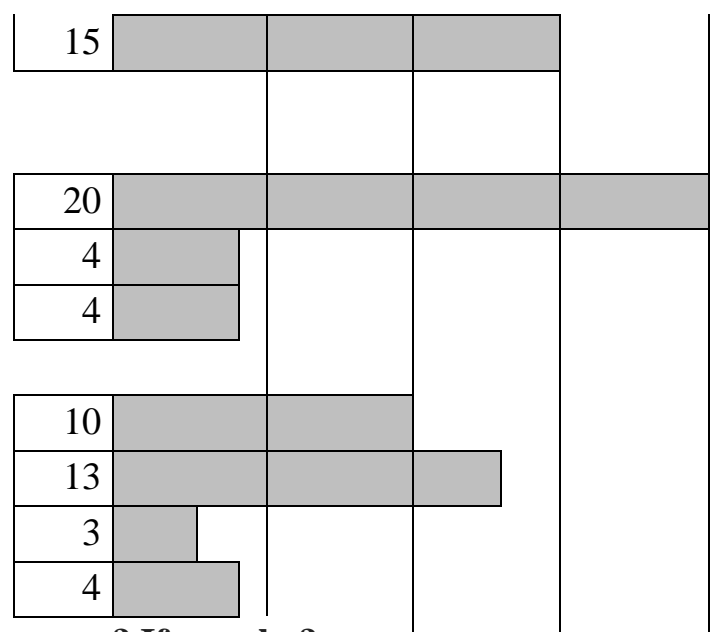

\section{Ecoregions in the Protected areas}

- Lowlands Region

1) 1.1. Amazon Flooded Forest (Bosques Amazónicos de Inundación)

1) 1.2. Amazon Sub-Andean Forest (Bosques Amazónicos Subandinos

1) 1.3. Amazon Pre-Andean Forest (Bosques Amazónicos Preandinos)

1) 1.5. Beni y Santa Cruz Amazon Forest

2) 2.3. Cerrado of the Chiquitano region (Cerrado Chiquitano)

2) 2.4. Cerrado of the Chaqueña region (Cerrado Chaqueño)

3) 3.1. Llanos de Moxos Flooded Savannas

3) 3.2. Pantanal Flooded Savannas

4) 4. Dry Forest Chiquitano

5) 5. Gran Chaco

6) 6. Yungas
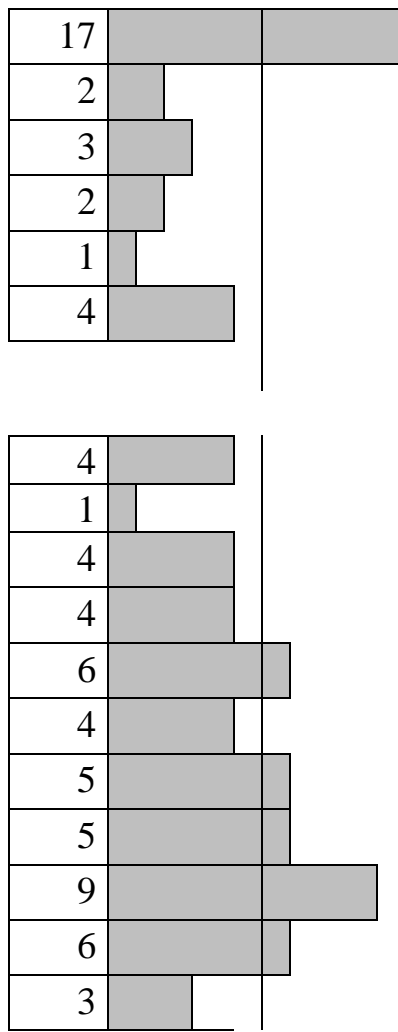
- Regions of the Andes and inter-Andean valleys (Vertiente Oriental y Valles Interandinos)

7) 7. Tucuman-Bolivian forest

8) 8. Chaco Serrano

9) 9 . Dry forests

15. Surface Area of Protected Areas (ha) Categories.

1) $380-129,976$

2) $129,976-596,913$

3) $596,913-1,019,056$

4) $1,019,56-1,617,974$

5) $1,617,974-3,417,546$

16. Deforested Surface Area (ha) Categories.

1) $0-689.58$

2) $689,58-2,536,56$

3) $2,536.56-5,058.72$

4) $5,058.72-18,757.44$

5) $18,757.44-60,333.30$

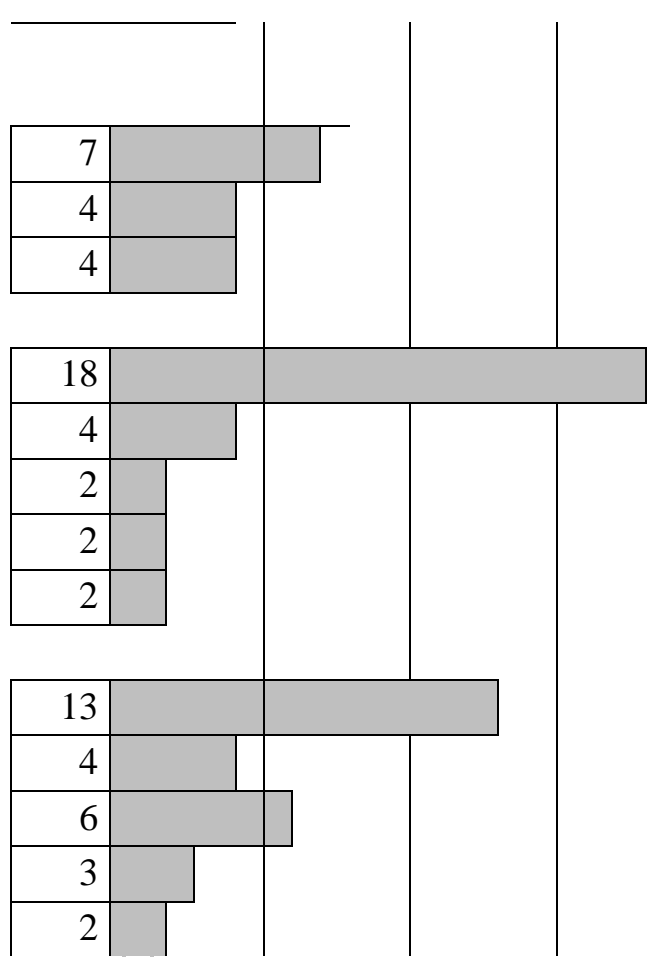


For the question (\#4) regarding Ecosystem-based adaptation (EBA) methodology and whether managers were familiar with it or have used it as a way to address climate change, all responses were negative. Still, managers responded with other strategies which they have implemented in the PAs as: Projects and strategies for Climate Change CC adaptation and mitigation; Proposals to increase the size of the PA; Fire management, prevention of slash-and-burn practices, training and awareness on $\mathrm{CC}$; Work regarding the effects of fire and the different ways of conserving the ecosystem; natural resource use and species protection.

In 11 of the 28 areas managers had some type of monitoring system in use such as: Patrolling and monitoring species (e.g., Population monitoring for a species of flora or fauna). Three of the PAs stated that they do: Monitoring management (with SERNAP National Service of Protected Areas).

We asked 5 questions related to "risk" (questions 6 to 10, see Table 14), to evaluate how managers considered this aspect in the management of their PAs and what importance they give to the isue of risk. Three (3) of the surveyed sites applied risk management and according to the responses, risk management included: Minimizing the threats and monitoring the impacts and resources of the PA; Risk management regarding illegal logging, hunting and fishing; Suppress forest fires. The remaining areas said they did not implement risk management although some added that they: are aware that their areas are considered at risk, yet no risk management strategies are in place.

-In the questionnaire, we asked for their working definition of the concept of "risk" and 13 of the repsondents stated: "risk" is synonymous with "threat" (human and in general) and included some of the effects as: "Natural disasters, threat of fire, harvest of timber, clearing and burning vegetation, non-sustainable use of resources, creation of roads, drought, vulnerability of the area and capacity of resilience, hunting and fishing, climatic risks, changes in hydric regime, cause negative actions in the future. Three respondents defined "risk" as: Lack of legal and administrative framework for management of the PAs. The remainder of responses included: We don't work with any kind of risks; We don't have a definition.

For question \#8, "Regarding the risks related to $\mathrm{CC}$ and which of these do you view as most critical for your PA?", Fourteen (14) of respondents stated: Climatic variability (lack of moisture, altered channel in rivers, strong winds, loss of water sources, dried lakes).

-For the PAs which identified some risks, we asked: How might these climatic risks impact your PA?: Twelve (12) of the respondents stated: Impacts on biodiversity; 12 stated: Impacts on soil, water (agriculture, livestock). (e.g.: causes uncertainty about food security for the local human population(s); Rivers will be affected as transportation routes; Economic losses in agricultural production and poverty). Seven (7) PAs mentioned: Changes in the use of water (flow is low in the rivers, there is excessive irrigation, etc) which particularly affect the economies of the communities (e.g., conflicts between neighbors; Emmigration of families to larger population centers and cities).

-In the case of applying risk management: What importance do you give in terms of activities, time and resources? Nine (9) areas responded: Apply risk management activities (Examples of activities: 
Identify threats and vulnerabilities; Communicate with, educate, raise awareness among, train and guide the community members within and outside the PA so that they can conserve their natural resources and avoid wildfires, and excessive tree-cutting, fishing and hunting). Seven (7) areas responded with: We should be more efficient in managing our finances (in cases where there is funding for the PA) within each time period; Minimize the amount of money wasted on disasters or other adverse situations in the PA and above all assure sustainability by investing in training and awareness of the staff and local residents. The rest of the PAs had no response for this question.

We also asked if the PA worked together with other neighboring or nearby PAs. Our results show that 20 of them do not do any joint work with other areas. Four (4) of those who responded positively regarding joint work mentioned: Technical and/or legal cooperation (e. g.: We created biological connectivity between 2 areas to avoid the risk to natural resources and mitigate climate change.) Another 4 respondents stated: Attend workshops and trainings conducted by the National Service PA.

With respect to "Is there any work done with private neighbors around the protected area?": 13 of the 28 PAs answered affirmatively and in summary said: They work together on strategies for natural resource protection (e.g.: We work with the cattle ranchers who are inside the PA; We reforest areas with farmers and ranchers. We work with indigenous groups inside and outside the PA in joint strategies for management and conservation of natural resources). Another type of cooperation mentioned by 3 areas is the inclusion of private stakeholders in activities pertinent to the PA: They are members in the management committee (private landowner, institutions from neighboring towns); another 4 said: Somethimes they participate in training workshops in biodiversity conservation and fire prevention (e.g.: Climate change adaptation project of integrated watershed management; Building erosion-prevention structures on river banks; honey production projects; reforestation).

On-the-ground conservation work seems to be more difficult and challenging now than it was 20 years ago, according to responses from 24 of the surveyed areas: For 17 of these, the reasons were the following: Due to political and social pressures (migration and population growth) (e.g.: land squatters; The PAs are very close to urban centers which leads to contruction of major highways) and for 7 of them: Conservation is more difficult because there are legal gaps; Lack of funding to deal with climate change impacts, impacts of changes in soil (E.g.: Overexploitation of natural resources; lack of public knowledge/understanding).

Our evaluation here, which groups 28 PAs located in different geographic zones with different administrative situations and which face different social pressures compliments the results from the PA mangers' questionnairewith data which we added for analysis (size, deforested area and number of ecoregions) by PA and which can be seen in the results table (Table 14):

Of the 3 biogeographic regions that characterize the Bolivian geography: Lowlands, Andes and interAndean valleys, and High Cordillera and Altiplano, the PAs in the department of Santa Cruz in our study are for the most part located in the Lowlands Region with 6 ecoregions: 1) Amazonian forests (4 subecoregions); 2) Cerrado (2 subecoregions); 3) Flooded Savannas (2 subecoregions); 4) Chiquitano Forest; 5) Gran Chaco and 6) Yungas Region. Regions of the Andes and inter-Andean valleys 
represented by PAs in our study are: 1) Tucuman-Bolivian forest; 2) Chaco Serrano and 3) Dry forests (Table 14). (See photographs in annex 1).

Looking at the sizes of the areas, on the smaller end, 18 of them had surface areas ranging from 380 to 129,976 hectares. On the larger end, 6 areas had between 596,313 to 3,417,446 hectares. The rest were in the medium size range.

Records for protected area deforested area, demonstrate that 13 of the areas we evaluated had a range of 0 deforested (no deforestation recorded) to 689 hectares deforested (SERNAP 2013) (although in relation to the size of PA vs deforested area, the percentage ranges from 0 to 1\%) and 2 areas had a range of 18,757 to 60,333 hectares deforested (San Matias National Park and ANMI with 60,333 ha ( $2 \%$ deforested area in relation to the size of the PA) and Amboro National Park and ANMI with 44,729 ha $(8 \%)$. The rest of the areas were in the middle of those ranges.

In particular, we show the consideration of climate change in the PAs of Santa Cruz organized by administrative level (5 national PAs, 8 departmental PAs and 15 municipal PAs) and by the response categories from the managers' questionnaire (Fig. 10):

Figure 10. Managers' observations of climate change in their PAs $(n=28)$ by administrative level

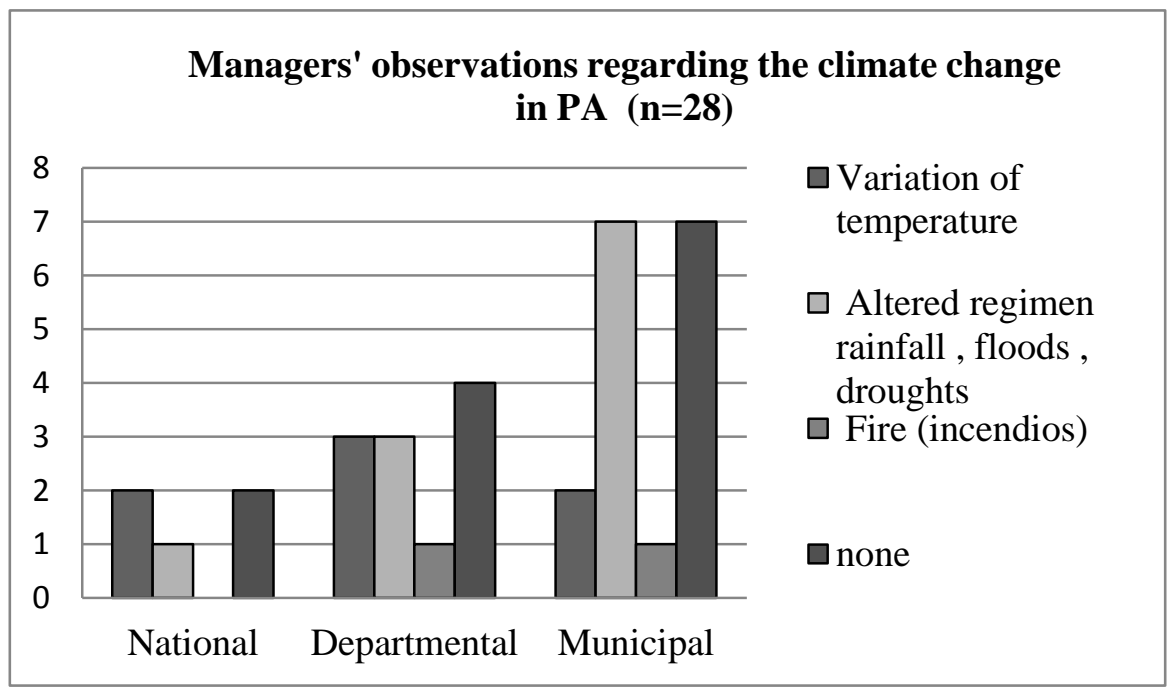




\subsubsection{Evaluation of the vulnerability of the protected areas of Santa Cruz as a function of the manager's observations with respect to the areas' capacity to respond to climate change}

The Climate Vulnerability Index results for the 28 PAs in Santa Cruz, Bolivia come from the matrix exercise and are based on questionnaire data from managers' input regarding the operations of their PAs and how they approach the issue of climate change plus data on the size of the PAs, deforested area and diversity of ecoregions in the PA. The data which were additional to the questionnaire were the figures available at the time of completion of this study (2014), however in the future this analysis could be rerun with more indicators or criteria of adaptive capacity.

We present the results in the framework of two types of analysis:

- The "Management" of the areas, is scored according to the weighting of the four major criteria proposed in the climate vulnerability index (Administration 10\%; Management Plan 30\%; Adaptive management $20 \%$; Protection design $40 \%$.

- The results of analyzing "Management" are shown according to the rating of 4 main criteria and 11 subcriteria, with a final relative rating (perceived climatic vulnerability).

\subsubsection{Climatic vulnerability perceived of the PAs, according to weighted percentages by criterion.}

From the questionnaire responses, we detected "relative differences" between administrative levels in the abilities of protected area management to respond to climate change. We then explored aspects of management capacity and adaptive capacity that would need to be strengthened for each PA.

We present a graph below (Fig. 11) showing comparative weights of the 4 main criteria: Administration (10\%); Management Plan (30\%); Adaptive management (20\%) and Protection design (40\%), which are then combined to give $100 \%$ of the rating capacity for management of PAs in addressing climate change in the department of Santa Cruz. The results are given according to administrative level, which show the percentages grouped by criteria. The vulnerability rating of Total percentages of each of the 4 criteria are the result of the sum of the individual values of each subcriterion: 
Figure 11. Climatic Vulnerability perceived ratings by administrative level of PAs

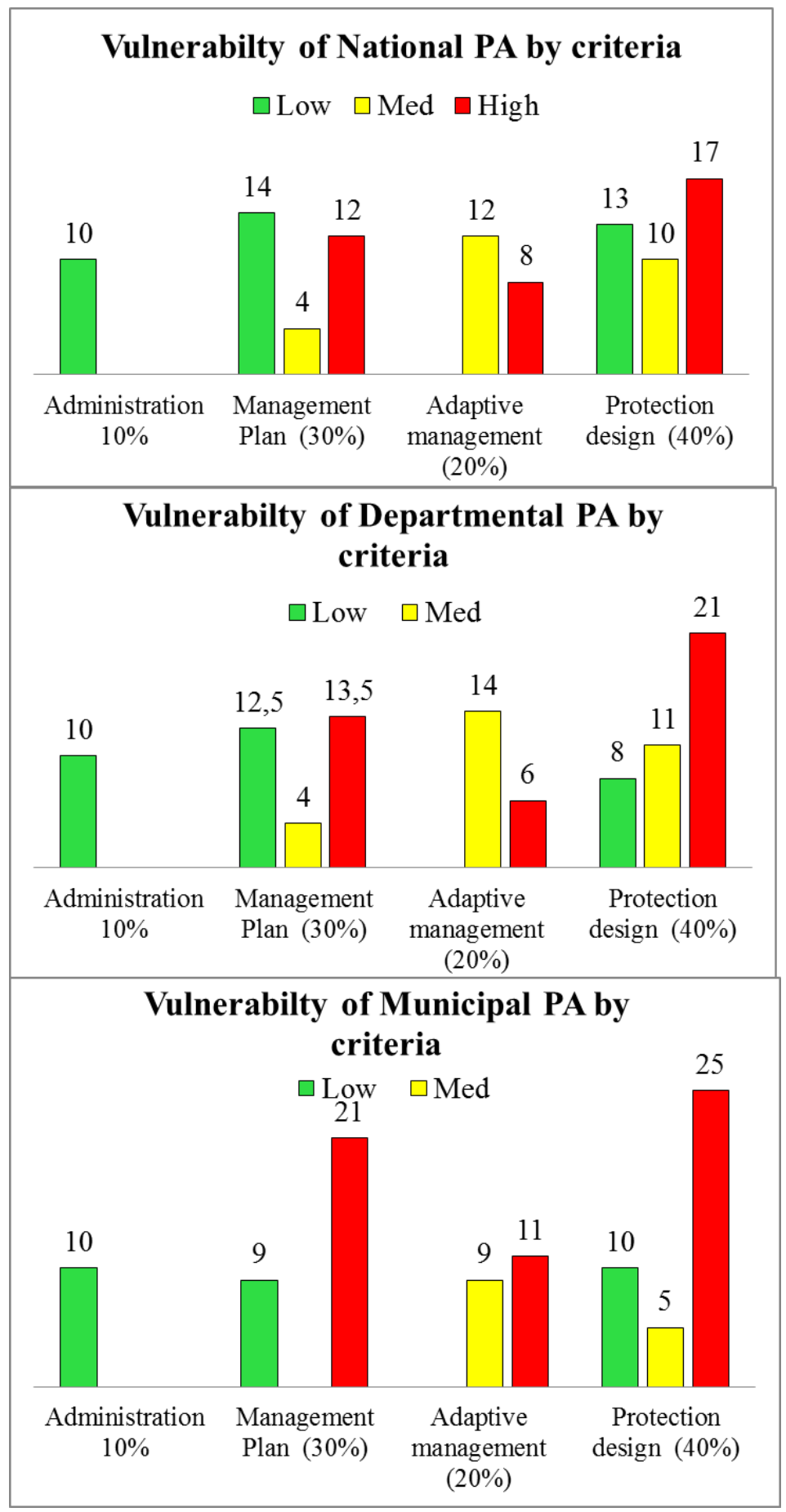

In the Index which we developed, the criterion of "Administration", which accounts for $10 \%$ of the total weight of Management $(100 \%)$ for a PA, consists of a sub-criterion "Self-Administration". In our results, all of the PAs included in our questionnaireare self-administered and so the climate vulnerability is V.low for all of the 3 administrative levels. This subcriterion clearly decreases the overall rating for climate vulnerability by area and may be a bias to the final vulnerability rating. For this subcriterion, we did not do an analysis of the administrative situation of the areas, and so the results only indicate if the PA has or does not has self-administration.

The results of "Management Plan" (30\%) criterion, comprised of 3 sub-criteria: Consideration of the threats of CC (10\%); MP exists (10\%); Biological monitoring and management practices (10\%); show that upon adding the individual values, the ratings are distributed from scores of "low" climatic vulnerability to "high" climatic vulnerability, with municipal PAs of particular note for their high climatic vulnerabilty.

The criterion of "Adaptive management" accounts for $20 \%$ of the total and includes two sub-criteria: Adaptive management strategies or knowledge of EBA (10\%); and Participation of stakeholders in conservation activities and/or public strategies (10\%). Note that across the three administrative levels there is no "low" rating, and most of the PAs fall within the rating of "Medium".

The resulting ratings for "Protection design" are the sum of the values of 5 sub-criteria: Ideal shape (8\%); Networks with neighboring PAs (8\%); Size of PA (8\%); Number of ecoregions in the AP (8\%); and Deforested area in AP (8\%) and show that for the 3 administration levels in the department of Santa Cruz, most PAs have values of "high" vulnerability to climate change. 
In general we can say that there is a trend of "low" values in the ratings and therefore "high" vulnerability to climate change in terms of the capacity for adaptive management, especially in the municipal PAs of the department of Santa Cruz, which are precisely the PAs with the lowest levels of financial and logistical resources.

In this regard, the following table (Table 15) shows the sum of the criteria according to vulnerability and category. This could be taken as a final relative rating for the status of the "Management" criterion for the PAs by administrative level, e.g., the highest result for departmental PAs was 40.5\%, corresponding to "high" vulnerability, with $30 \%$ for the "low" rating and $29 \%$ for the "medium" rating. At the national administrative level, most (37.5\%) of the PAs have "low" vulnerabilty ratings. Among the municipal PAs, 57\% have a value of "high" vulnerability.

Table 15. Vulnerability rating perceived by administrative level

\begin{tabular}{|c|c|c|c|c|c|c|c|c|c|}
\hline Category & \multicolumn{3}{|c|}{ National \% } & \multicolumn{3}{|c|}{ Departmental \% } & \multicolumn{3}{|c|}{ Municipal \% } \\
\hline MANAGEMENT (main Criterion $100 \%$ ) & Low & Med & High & Low & Med & High & Low & Med & High \\
\hline - Administration (10\%) & 10 & & & 10 & & & 10 & & \\
\hline \multicolumn{10}{|l|}{ - Self- Administration (10\%) } \\
\hline - Management Plan $(30 \%)$ & 14 & 4 & 11,5 & 12,5 & 4 & 13,5 & 9 & & 21 \\
\hline \multicolumn{10}{|l|}{-Consideration of threats of CC $(10 \%)$} \\
\hline \multicolumn{10}{|l|}{-Yes, MP (10\%) } \\
\hline \multicolumn{10}{|l|}{-Biological monitoring and manag. (10\%), } \\
\hline - Adaptative management $(20 \%)$ & & 12 & 8 & & 14 & 6 & & 9 & 11 \\
\hline \multicolumn{10}{|l|}{ - Adaptive management (EBA) (10\%) } \\
\hline \multicolumn{10}{|l|}{ - Participation of stakeholders $(10 \%)$} \\
\hline - Protection design $(40 \%)$ & 13,5 & 10 & 17 & 8 & 11 & 21 & 10 & 5 & 25 \\
\hline \multicolumn{10}{|l|}{ - Ideal shape $(8 \%)$} \\
\hline \multicolumn{10}{|l|}{ - Networks with neighboring PA(s) $(8 \%)$} \\
\hline \multicolumn{10}{|l|}{ - Size of PA $(8 \%)$} \\
\hline \multicolumn{10}{|l|}{ - Number of ecoregions $(8 \%)$} \\
\hline - Deforested area in PA (8\%) & & & & & & & & & \\
\hline Management Criterion $100 \%$ Total & 37,5 & 26 & 36,5 & 30,5 & 29 & 40,5 & 29 & 14 & \\
\hline
\end{tabular}




\subsubsection{Results of the climate vulnerability perceived of the PAs, by individual subcriteria}

The results of the analysis of the climate vulnerability index below show the total "perceived" (not absolute) rating for each PA, through the individual ratings of 11 different subcriteria. With this approach we seek to support the selection of prioritized actions for the PAs according to individual themes and interpretations by subcriteria and support the development of a variety of adaptative strategies related to the degree of climate change vulnerability and depending on the interest of the PA.

\subsection{Results of the climate vulnerability of the PAs, by administrative level}

Looking at the climate vulnerabilty ratings by administrative level in the department of Santa Cruz, the ratings for municipal PAs have the "highest" perceived climate vulnerability. The table below (Table 16) shows the ratings for each sub criterion:

Table 16. Rating of climate vulnerability perceived according to administrative level $(\mathrm{CC}=$ Climate change; $\mathrm{MP}=$ Management plan; $\mathrm{PA}=$ Protected area

\begin{tabular}{|c|c|c|c|c|c|c|c|c|c|c|c|c|c|}
\hline \multirow[b]{2}{*}{$\mathrm{N}$} & \multirow{2}{*}{\begin{tabular}{|l} 
Vulnerability: \\
Low=0; Med=1; High=2
\end{tabular}} & \multicolumn{4}{|c|}{$\begin{array}{c}\text { National PA } \\
\quad(n=5)\end{array}$} & \multicolumn{4}{|c|}{$\begin{array}{c}\text { Departmental } \\
\text { PA }(n=8)\end{array}$} & \multicolumn{4}{|c|}{$\begin{array}{l}\text { Municipal PA } \\
\qquad(n=15)\end{array}$} \\
\hline & & $\mathbf{L}$ & $\mathbf{M}$ & $\mathbf{H}$ & Total & $\mathbf{L}$ & $\mathbf{M}$ & $\mathbf{H}$ & Total & $\mathbf{L}$ & $\mathbf{M}$ & $\mathbf{H}$ & Total \\
\hline 1 & Self -Administration & 5 & & & 5 & 8 & & & 8 & 15 & & & 15 \\
\hline 2 & Consideration of the threats of $\mathrm{CC}$ & & 2 & 3 & 5 & 1 & 3 & 4 & 8 & 2 & & 13 & 15 \\
\hline 3 & Yes MP & 4 & & & 5 & 4 & & 4 & 8 & 3 & & 12 & 15 \\
\hline 4 & Biological monitoring and management & 3 & & 2 & 5 & 5 & & 3 & 8 & 9 & & 6 & 15 \\
\hline 5 & Adaptive management & & 3 & 2 & 5 & & 5 & 3 & 8 & & 5 & 10 & 15 \\
\hline 6 & Participation of stakeholders & & 3 & 2 & 5 & & 6 & 2 & 8 & & 9 & 6 & 15 \\
\hline 7 & Size PA & 3 & 2 & & 5 & & 3 & 5 & 8 & & & 15 & 15 \\
\hline 8 & Ideal shape & & & & 5 & 1 & & 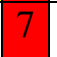 & 8 & 3 & & 12 & 15 \\
\hline 9 & Networks with neighboring PA(s) & & 1 & 4 & 5 & & 3 & $J$ & 8 & & 4 & 11 & 15 \\
\hline 10 & Number of ecoregions in the PA & 2 & 3 & & 5 & 2 & 2 & 4 & 8 & & 6 & 9 & 15 \\
\hline 11 & Deforested area in PA & 3 & & 2 & 5 & 5 & 3 & & 8 & 15 & & & 15 \\
\hline
\end{tabular}

For our results analysis, we included the explanations which managers gave in their responses without converting these responses to numeric values, in addition to the quantitative data. We describe the results below: 
National Areas - The vulnerability ratings of the 5 national protected areas show that the "low" values are distributed in the subcriterion of Self-administration. Every one of these PAs oversees its own administration. For the subcriterion Management plans, all except one (4), have a management plan and/or are updating their management plan. For Biological monitoring, 3 areas are collecting data; For Diversity of ecoregions, in 2 PAs the number of ecoregions was $\geq 4$. For 3 PAs the Deforestated area was less than 5,058 hectares (Fig. 12 below).

For the sub-criterion of Stakeholder participation in conservation activities, the rating was "medium". In the explanations given by managers in the questionnaire, their responses indicate that $60 \%$ of PAs involve stakeholders in conservation activities: Protection strategies for natural resources; and the remaining $40 \%$ of PAs do not engage stakeholders in conservation activities. In the sub-criterion of Adaptive management, none of the areas were using the EBA methodology, although 3 of them listed other activities like: patrols, awareness-raising, natural resource protection, and some initiatives with adaptation and/or mitigation activities.

The final rating for the subcriterion of Coordinated work with staff of nearby protected areas was a "high" climate vulnerability. This kind of cooperation is rare. It is barely measurable that PAs at the national level Take climate change threats into consideration nor do any of these PAs practice risk management. Examples from the questionnaire indicate that less than half of the areas observed changes or variations in climate: "We see changes in temperature variation, altered precipitation regimes, floods, droughts. Forty percent (40\%) of managers of national areas of the department of Santa Cruz said: To us, the concept of "risk" is similar to the concept of "threats".

Figure 12. Climate vulnerability perceived of protected areas at the national administrative level

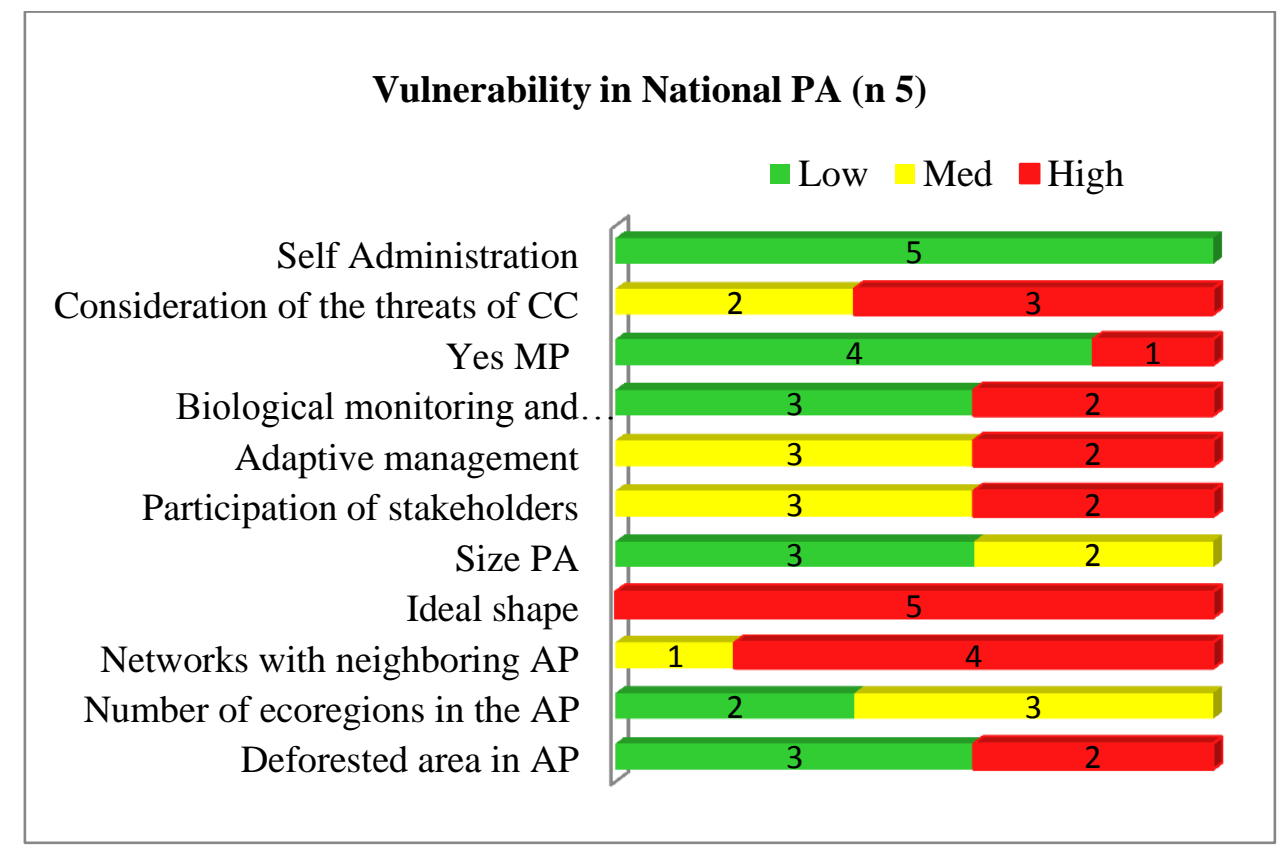


Departmental Areas - The "low" ratings of climate vulnerability for departmental PAs were for the following subcriteria: Self-Adminstration; Deforested Area (5 of the 8 departmental PAs had less than 5,058 ha deforested (see Figure 13 below). Half of departmental PAs, had a Management plan (another sub-criterion) and the other $50 \%$ do not have one. According to the questionnaire responses: We use others types of plans such as a Strategic Plan or Protection Plan. These subcriteria also had "low" climate vulnerability: Monitoring System (5 areas have a system in place); Diversity of (2 PAs have $\geq 4$ ecoregions).

The "medium" vulnerability ratings were distributed in the sub-criteria: Stakeholder participation in conservation activities related to the PA where 6 PAs stated they work jointly with stakeholders. Examples given were: Development of natural resource protection strategies; Participation in management committee; Training and workshops. Five areas did not directly use Adaptive management (EBA methodology) but named the following other activities: Other adaptation and/or mitigation activities (20\%); Patrols, awareness-raising, natural resource protection (40\%); No explanation (40\%). Six areas did not perform any Work with PA neighbors or stakeholders.

For departmental PAs, the "high" vulnerability ratings were for these subcriteria: Shape of protected area: almost all (7) PAs had shapes that were not close to the ideal of a circle; Five (5) PAs did not engage in joint Work with neighboring protected areas and 3 PAs responded positively to this question, giving examples of: Technical and/or legal cooperation, and workshops and trainings. Five (5) PAs had areas $\leq 490,051$ ha which was the smallest Zize class established in our study. Diversity of ecoregions: 4 PAs had $\leq 2$ Ecoregions within their boundaries. With respect to the subcriterion Consideration of threats related to climate change, 4 of the PAs had "high" ratings and did not do any risk analysis (stated: Only do lectures, workshops and give training on hazards (13\%); No, but the PA has identified climate risks which threaten their PA (38\%): The 3 PAs which did consider the Threats related to climate change named: Forest fire management and early warning system (13\%), No, without further explanation ( 38\%). 
Figure 13. Climate vulnerability perceived of protected areas at the departmental administrative level

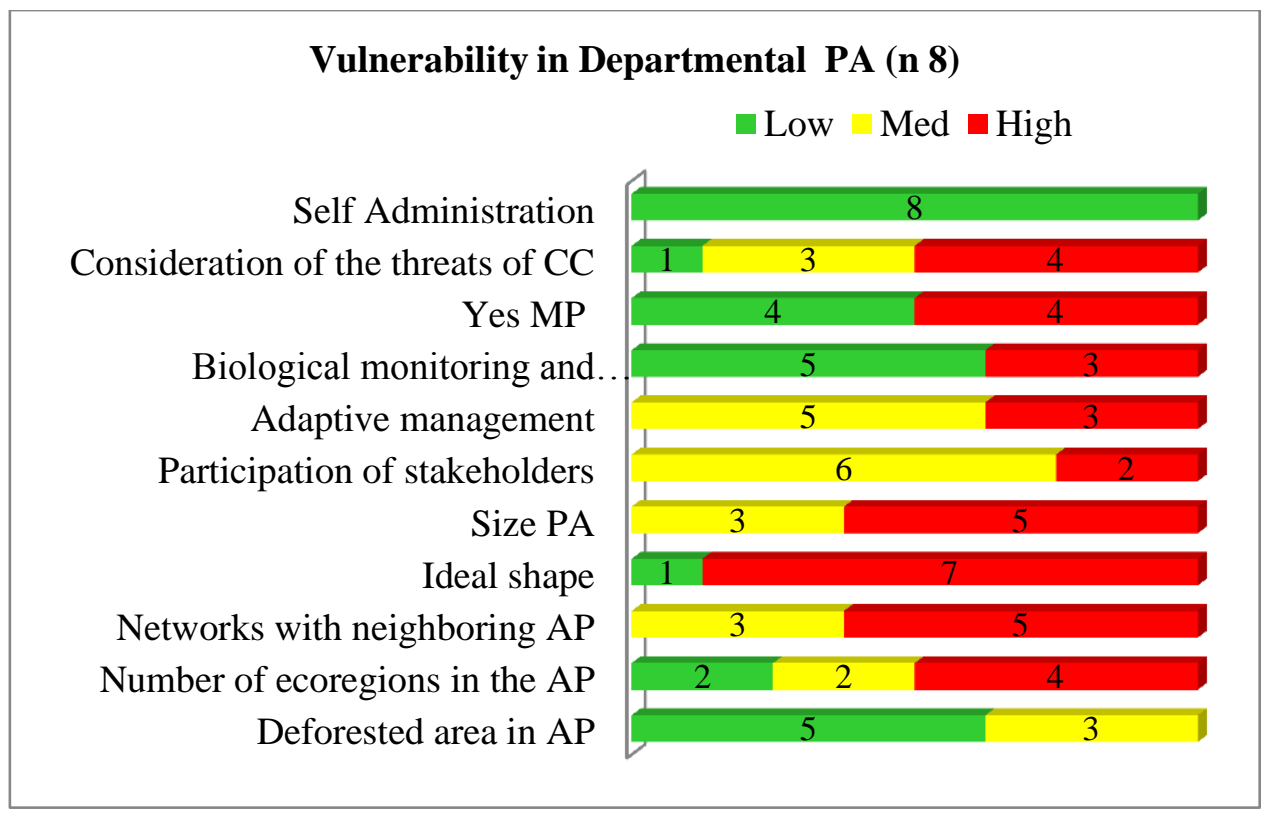

Municipal Areas - There are more PAs at the municipal administrative level in the department of Santa Cruz than at the other administrative levels. Fifteen (15) municipal PAs have: SelfAdministration and therefore a "low" climate vulnerability climate rating (Figure 14 below). At the same time these PAs are the areas with the lowest registered Levels of deforestation; 15 are in the category of $\leq 5,058$ hectares (one of which, the Cactus Garden PA has 0 ha with deforestation) (in this study we did not take into account the relation between area size and deforested surface); Regarding Monitoring, these PAs noted: Patrolling and monitoring of species (33\%) and monitoring administrative practices (7\%); Do not do monitoring (40\%); Other (20\%).

Nine municipal PAs had "medium" climate vulnerabilty ratings based on the subcriterion for Working with private landowners near the PA: the mangers' questionnaireresponses were as follows: Carry out work strategies for the protection of natural resources(67\%); Participate in management committee (22\%); Training workshops (12\%).

The areas which most had "high" climate vulnerability ratings were at the municipal and also departmental level in Santa Cruz. These have the greatest vulnerability. While some of these municipal areas have subcriteria with "low" vulnerability ratings, only 3 areas have a Management plan (V.low); Twelve (12) areas do not have Management plans. For the subcriteria of Considering threats associated with the issue of climate change, 2 areas responded positively and Thirteen (13) areas do not consider the threats associated with the issue of of CC (or explicitly practice risk management): Eighty-seven percent (87\%) of the total responses mentioned other activities including: lectures, workshops, provide training on hazards (33\%) and the remaing 67\% answered that they do not have any risk management practices in place. Two (2) areas (13\%) answered positively that they practice risk management, citing these examples: Forest fire management and early warning. Of the 15 total municipal areas, 10 do not practive Adaptive management (they are not familiar with the EBA 
methodology). The 5 PAs with "medium" climate vulnerability received this rating for small projects for adaptation (e.g., recovery and conservation of some (tree) species in the Chiquitana ecoregion) and / or mitigation (e.g., the NP NKM has had a large mitigation project). None of the 15 municipal protected areas have the ideal Circle-shaped design. Eleven (11) municipal PAs do not Engage with stakeholders for conservation activities. Nine (9) municipal areas are characterized by having $\leq 2$ different Ecoregions within its boundaries.

Figure 14. Perceived climate vulnerability, rating for municipal-level protected areas

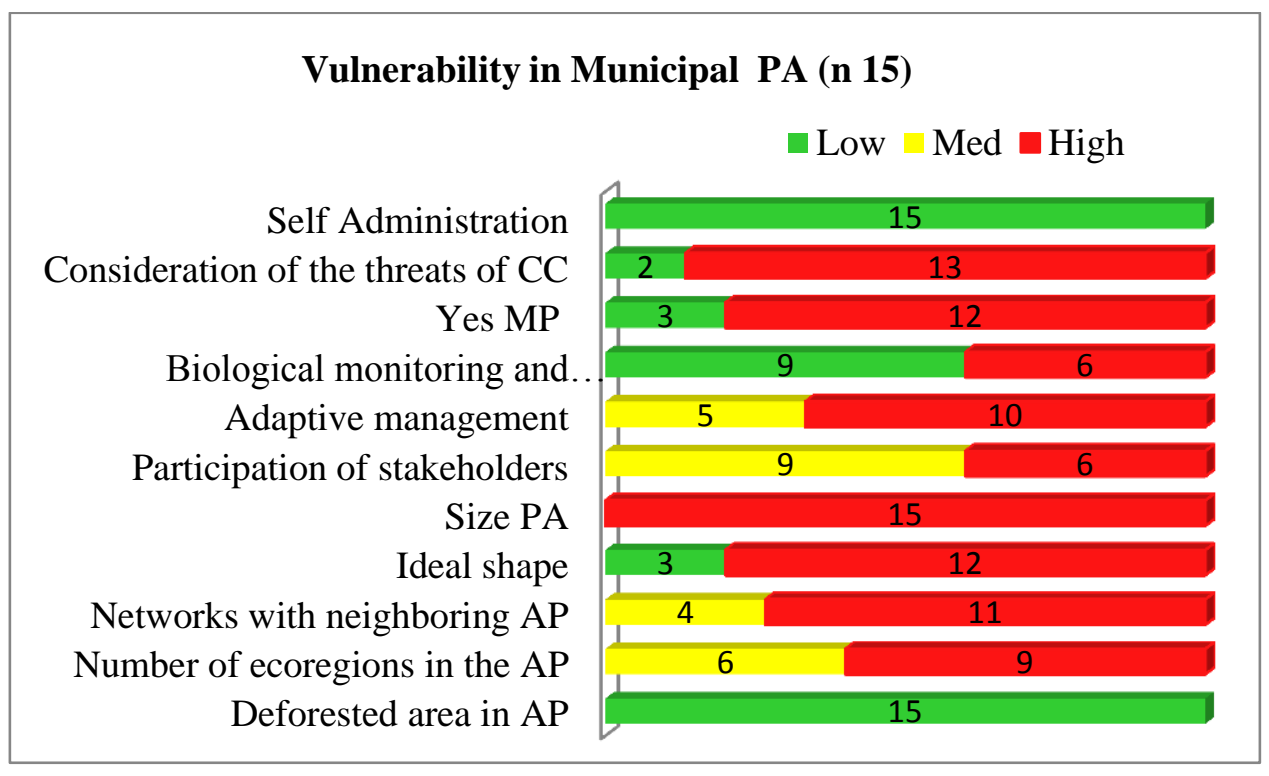

A summary of the analysis of the climate vulnerability rating of the protected areas by administrative level in Table 17 (below) shows that according to the responses from the managers, national-level areas are less vulnerable. From a total of 5 national areas, 4 (80\%) of them had responses which were rated "low" for most of the sub-criteria evaluated. Departmental areas distribute their ratings among the three values: although the majority $(63 \%)$ has high values. All 15 of the municipal areas were rated "high" based on the sum of the subcriteria.

Table 17. Comparison of the vulnerability ratings by administrative level

\begin{tabular}{l|r|r|r|r|r|r} 
Vulnerabiliy & National PA & \% & Departamental PA & \% & Municipal PA & \% \\
\hline Low & 4 & 80 & 1 & 13 & & \\
\hline Medium & & & 2 & 25 & & \\
\hline High & 1 & 20 & 5 & 63 & 15 & 100 \\
\hline Total & $\mathbf{5}$ & $\mathbf{1 0 0}$ & $\mathbf{8}$ & $\mathbf{1 0 0}$ & $\mathbf{1 5}$ & $\mathbf{1 0 0}$
\end{tabular}

Following the same scheme of analysis by management level, in a bar graph (Fig. 15), we show the ratings results of vulnerability by low, medium and high and according to national, departmental and municipal areas: e.g., for departmental areas in Santa Cruz, Bolivia, 30\% of the ratings were for a 
"low" vulnerability; $28 \%$ of the ratings were a "medium" vulnerability and $42 \%$ of the ratings were of a "high" vulnerability.

Figure 15. Percentages of low, medium and high vulnerability according to administrative level

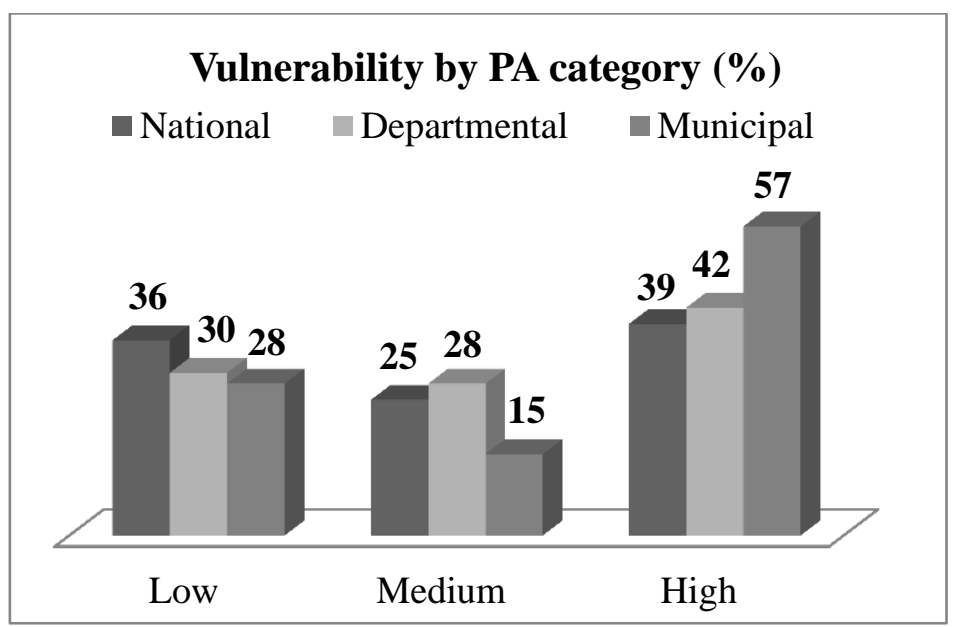

Another way to visualize the climate vulnerability (perceived) ratings in the 28 areas is through the percentages for each of the three rating classes, where we see that $75 \%$ of all of the 11 sub-criteria ratings were "high" vulnerability (Fig. 16):

Figure 16. Vulnerability of the protected areas in Santa Cruz, Bolivia, according to general ratings

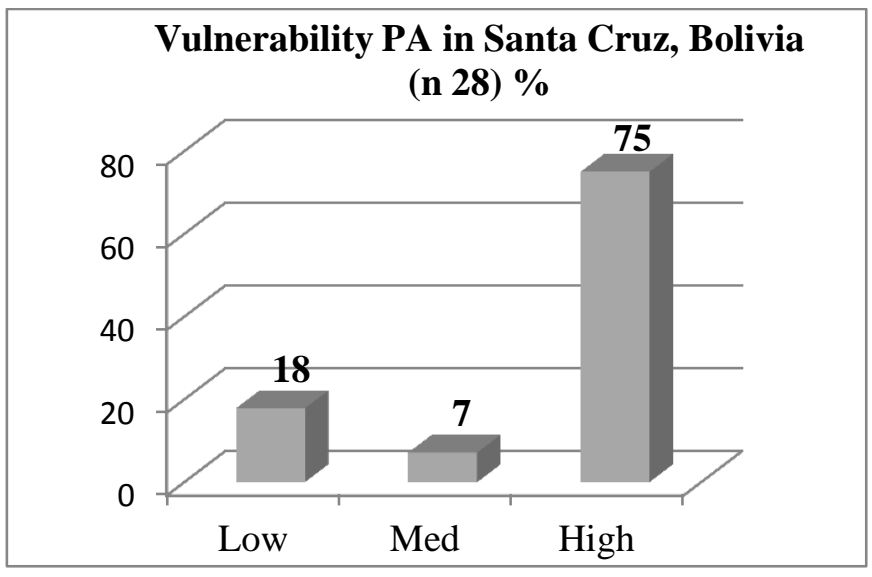

\subsection{Climate vulnerability rating by protected area in the department of Santa Cruz}

The ratings based on the 11 sub-criteria that were used to evaluate the status of climate vulnerability for each of the 28 PAs surveyed in the department of Santa Cruz, are shown in the bar graph below (Fig. 17). In this figure, it can be seen that a few subcriteria had greater numbers of low, medium or high ratings, according to the responses of managers. As an example, for the first area (NP NKM) we see that of the 11 sub-criteria which were rated (y-axis), 5 received "low" ratings and another 5 
received "high" ratings. One (1) of the subcriteria had a "medium" rating, and so on for all the other areas which we evaluated.

From Figure 17 it is clear to see differences among the different administrative-levels for areas in Santa Cruz, where municipal areas had more subcriteria rated "high" values ( $2=$ High Vulnerability), followed by departmental and then national-level according to the responses of the PA managers. 
Figure 17. Ratings of perceived climate vulnerability by protected area, according to the rated subcriteria (Low=0; Medium=1; High=2)

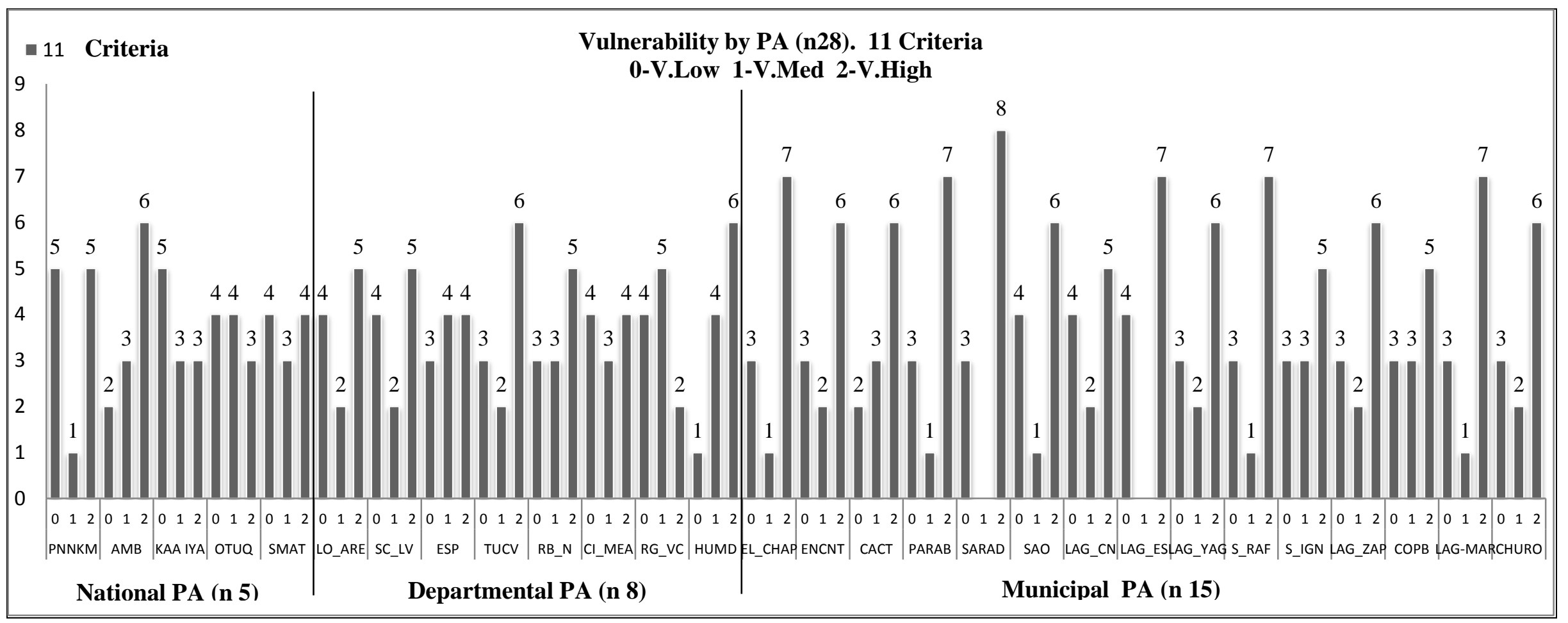

\section{National Parks}

PNNKM_Parque Nacional (PN) Noel Kempff Mercado AMB_PN y Area Natural de Manejo Integrado (ANMI) Amboró

KAA IYA_PN y ANMI Kaa-Iya del Gran Chaco OTUQ_PN y ANMI Pantanal Otuquis

SMAT_PN y ANMI San Matías

\section{Departmental Protected Areas}

LO_ARE_Parque Regional Lomas de Arena

SC_LV_PN Histórico y Arqueológico Santa Cruz La Vieja
TUCV_ Reserva de vida Silvestre (VS) de Tucavaca

RB_N_Reserva de VS Ríos Blanco y Negro CI_MEA_Meandros del Río Ichilo

RG_VC_ANMI Río Grande Valles Cruceños HUM_Humedales del Norte

\section{Municipal Protected Areas}

EL_CHAP_Microcuenca quebrada El Chape ENCNT_Orquídeas del Encanto CACT_Jardín de Cactáceas de Bolivia PARAB_Parabanó SARAD_Sararenda
SAO_ Reserva de VS Palmera de Saó LAG_CN_Reserva de VS Laguna

Concepción

LAG_ES_Santuario de VS y ANMI

Laguna Esmeralda

LAG_YAG_Laguna Yaguarú

S_RAF_Reserva Municipal de San Rafaél

S_IGN_Reserva Municipal de San Ignacio

LAG_ZAP_Laguna de la Represa Zapocó

CPOB_Reserva de Copaibo

LAG_MAR_Laguna Marfil

CHURO_Churo Negro 


\subsection{Graphic patterns of climate vulnerability by protected area}

With the results of the perceived climate vulnerability for each protected area, we developed a series of circular graphs to give visual understanding to the situation of the areas (Fig. 18). Each graph is composed of three concentric circles representing low (center), medium and high vulnerability ratings. Representing our data this way provides understanding at a glance about how climate vulnerability functions under the management of each area assessed in the department of Santa Cruz. Graphs with more of the central spaces filled in represent PAs with overal "low" climate vulnerability in contrast to PAs with "high" ratings and more of the outer circle spaces filled in.

We point out again that national-level areas are the least vulnerable while municipal-level areas had more "high" vulnerability ratings in the majority of the rated subcriteria. 
Figure 18. Graphic patterns of perceived climate vulnerability, by protected area

Subcriteria: 1.-Self Management; 2.-Consideration of the threats of CC; 3.-Yes MP ; 4.-Biological monitoring and management; 5.-Adaptive management; 6.-Participation of stakeholders; 7.-Size PA; 8.-Ideal shape; 9.-Networks with neighboring AP; 10.-Number of ecoregions in the AP; 11.-Deforested area in AP.

National PAs/ Parque Nacional (PN): 1.PN "Noel Kempff Mercado"; 2.PN y ANMI"Amboró"; 3.PN y ANMI"Kaa-Iya del Gran Chaco"; 4.PNy ANMI Pantanal "Otuquis"; 5.PN y ANMI "San Matías". Departmental PAs: 6.Parque Regional Lomas de Arena; 7.Parque Histórico Santa Cruz La Vieja; 8.Monumento Natural Espejillos; 9.Reserva Departamental Valle de Tucavaca; 10.Reserva de vida Silvestre Ríos Blanco y Negro; 11.Meandros del Río Ichilo.

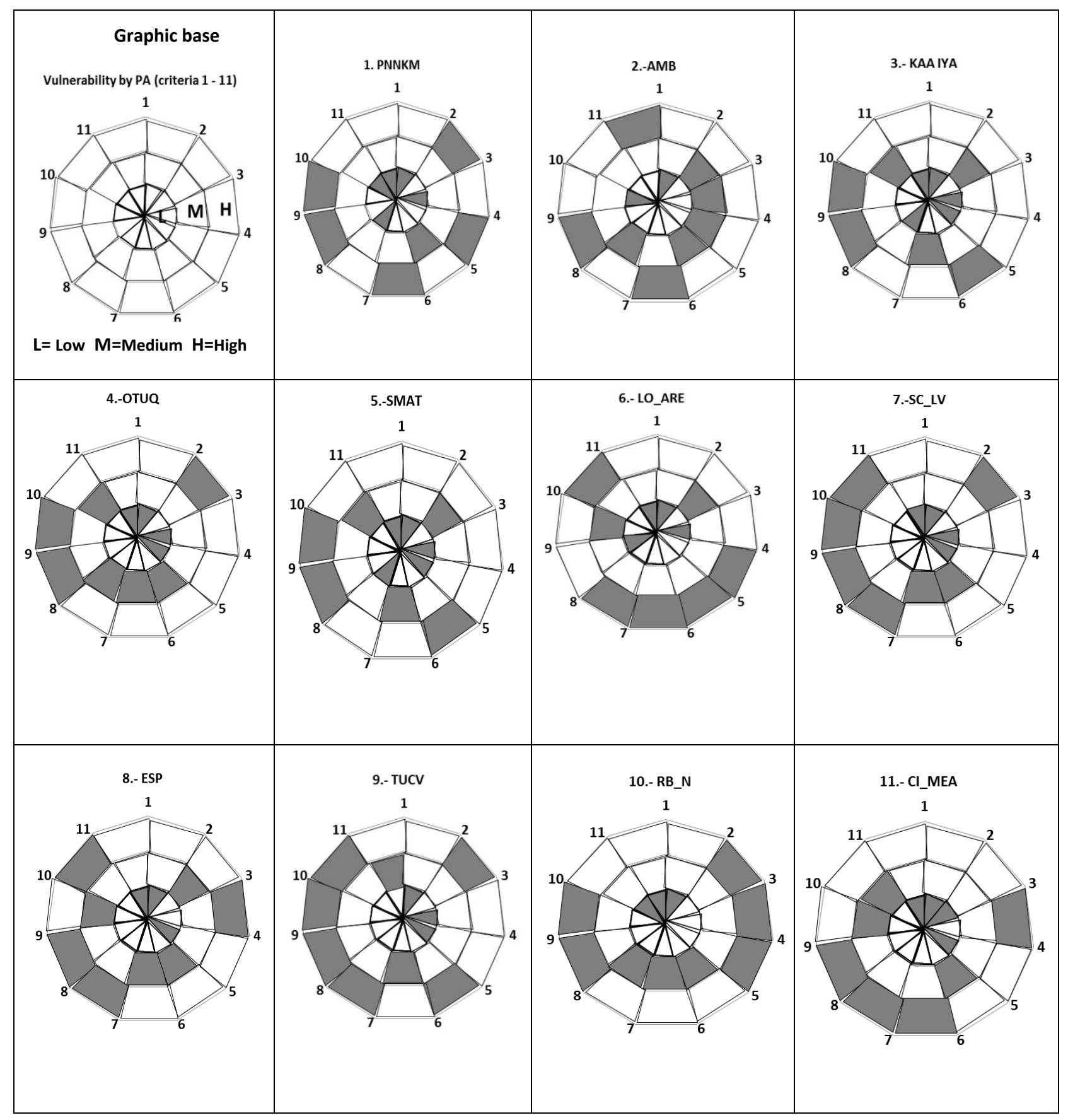


Figure 18 (continued). Graphic patterns of perceived climate vulnerability, by protected area

Criteria: 1.-Self Management; 2.-Consideration of the threats of CC; 3.-Yes MP ; 4.-Biological monitoring and management; 5.-Adaptive management; 6.-Participation of stakeholders; 7.-Size PA; 8.-Ideal shape; 9.-Networks with neighboring AP; 10.-Number of ecoregions in the AP; 11.-Deforested area in AP.

Protected Areas: Departmental PAs: 12.ANMI Río Grande Valles Cruceños; 13.Humedales del Norte; Municipal PAs: 14.Area Protegida Municipal (APM) Microcuenca El Chapé; 15.APM Orquídeas del Encanto 16.APM Jardín de Cactáceas de Bolivia; 17.APM Parabanó; 18.APM Serranía Sararenda Cuevo-Camiri; 19.APM Palmera de Saó; 20.APM Laguna Concepción; 21.APM Laguna Esmeralda; 22.APM Laguna Yaguarú; 23.Reserva Municipal San Rafaél; 24.Reserva Municipal San Ignacio; 25.Laguna de la Represa Zapocó; 26.Reserva Copaibo; 27.Laguna Marfil; 28. Area Protegida Churo Negro.

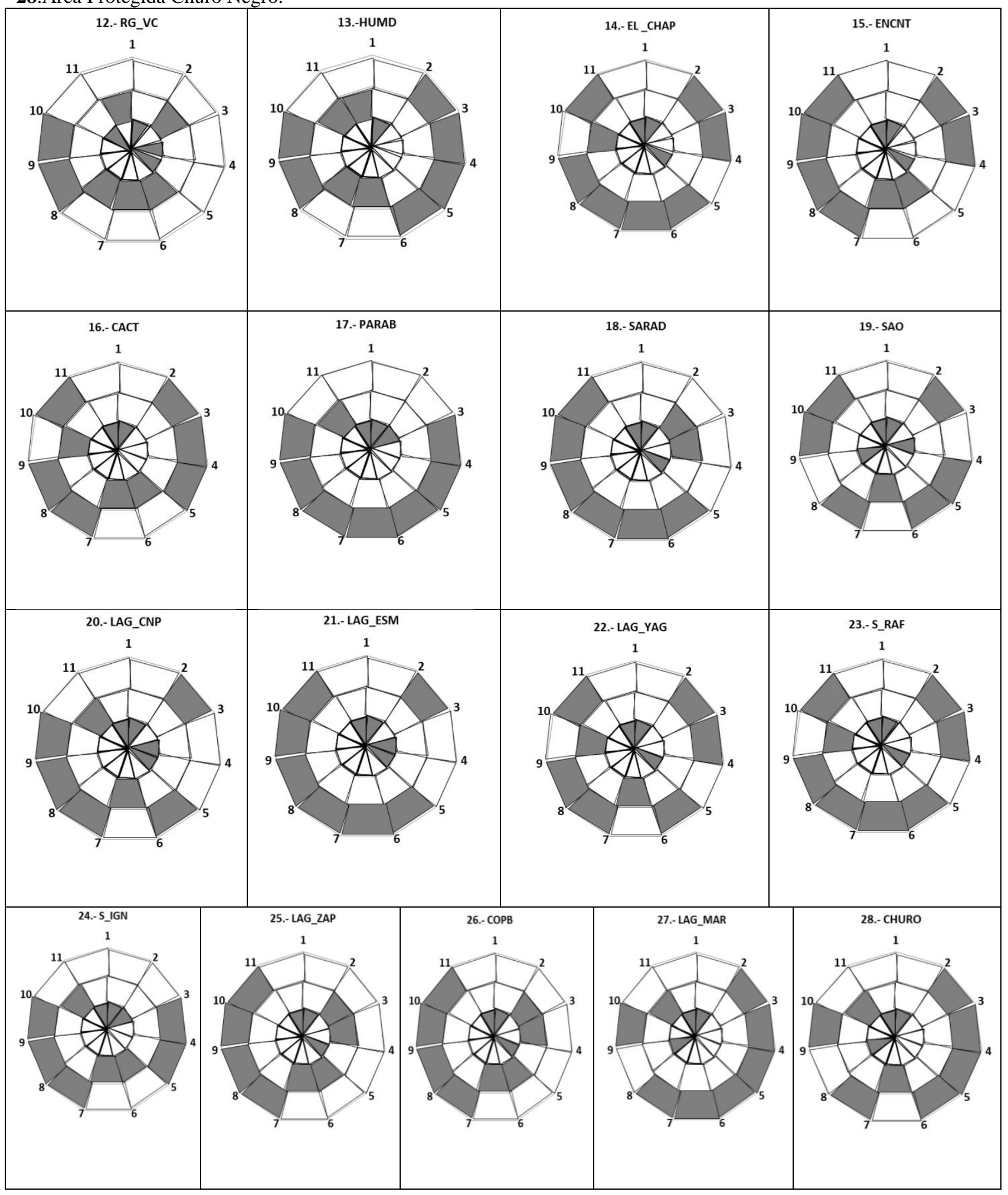




\subsection{Climate vulnerability by management by protected area of Santa Cruz, Bolivia, according to subcriteria with percentages of highest rating}

The perceived climate vulnerability ratings for each of the areas assessed in the department of Santa Cruz also reflect the percentage of PAs which received the highest rating. The climate vulnerability for each of the 28 PAs was calculated based on the 11 sub-criteria according to low, medium and high ratings. Following this rating, we separated the PAs according to the highest percentage, and then we took this as a relative "final" rating for each area. For example, the municipal area SARAD (Sararenda) had a final rating of "high" vulnerability, according to this method. This means that of the 11 criteria ranked for the Sararenda PA, 27\% scored "low" values, none had a "medium" rating, and the remaining $73 \%$ had "high" vulnerability ratings. Therefore, with $73 \%$ of subcriteria rated "high", the Sararenda area had a final rating of "high" vulnerability. We proceeded similarly for all areas.

For this result, we say that the most prevalent climate vulnerability rating (perceived) for each PA gives us the rating of a final "relative" vulnerability.

In this context, Fig.19 shows that 4 national areas (PNNKM, KAA IYA, OTUQ, SMAT) and one departmental area (CI_MEA) had "low" vulnerability ratings in most of their subcriteria ratings. Two (2) national areas (ESP, RG_VC) had "medium" vulnerability ratings in most of their subcriteria. One (1) national area $(\mathrm{AMB})$ and all $(\mathrm{n}=28)$ of the municipal areas had a "high" climate vulnerability rating.

Again, we emphasize that this assessment of climate vulnerability is based on the questionnaire responses from protected area mangers about how they view their conservation work and the issue of climate change in their protected areas. We added addtional data about the PAs, as explained in the methodology. 
Figure 19. Perceived climate vulnerability by percentage of highest rating for protected areas $(n=28)$ of Santa Cruz, Bolivia

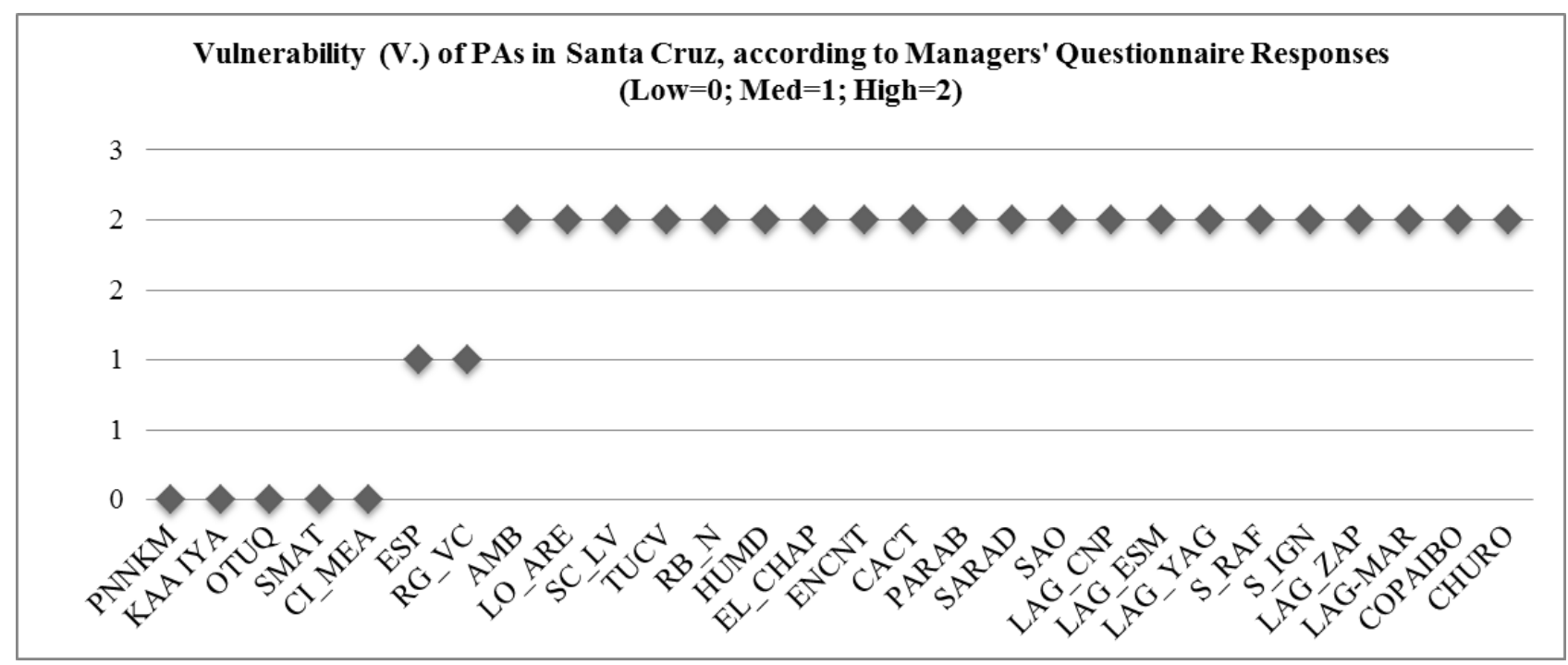

National PAs: PNNKM_Parque Nacional"Noel Kempff Mercado"; AMB_Parque Nacional y ANMI“Amboró"; KAA IYA_PN y ANMI“Kaa-Iya del Gran Chaco"; OTUQ_Parque Nacional y ANMI Pantanal "Otuquis"; SMAT_Parque Nacional y ANMI "San Matías". Departmental PAs: LO_ARE_Parque Regional Lomas de Arena; SC_LV_Parque Histórico Santa Cruz La Vieja; ESP_Monumento Natural de Espejillos; TUCV_Reserva Departamental Valle de Tucavaca; RB_N_Reserva de Vida Silvestre Ríos Blanco y Negro; CI_MEA_Meandros del Río Ichilo; RG_VC_ANMI Río Grande Valles Cruceños; HUMD_Humedales del Norte; Municipal PAs: EL_CHAP_Area Protegida Municipal (A.P.M.) Microcuenca El Chape; ENCNT_A.P.M. Orquídeas del Encanto; CACT_A.P.M. Jardín de Cactáceas de Bolivia; PARAB_A.P.M. Parabanó; SARAD_A.P.M. Serranía Sararenda Cuevo-Camiri; SAO_A.P.M.Palmera de Saó; LAG_CNP_A.P.M. Laguna Concepción; LAG_ESM_A.P.M. Laguna Esmeralda; LAG_YAG_A.P.M. Laguna Yaguarú; S_RAF_Reserva Municipal de San Rafaél; S_IGN_Reserva Municipal de San Ignacio; LAG_ZAP_Laguna de la Represa Zapocó; COPAIBO_Reserva de Copaibo; LAG_MAR_Laguna Marfil; CHURO_Area protegida Churo Negro.

These "final relative" ratings of climate vulnerability for each PA (Fig. 19) are shown in the following map (Fig. 20) in the context of this analysis. 
Figure 20. Map of perceived climate vulnerability by percentage of highest rating for protected areas of Santa Cruz, Bolivia

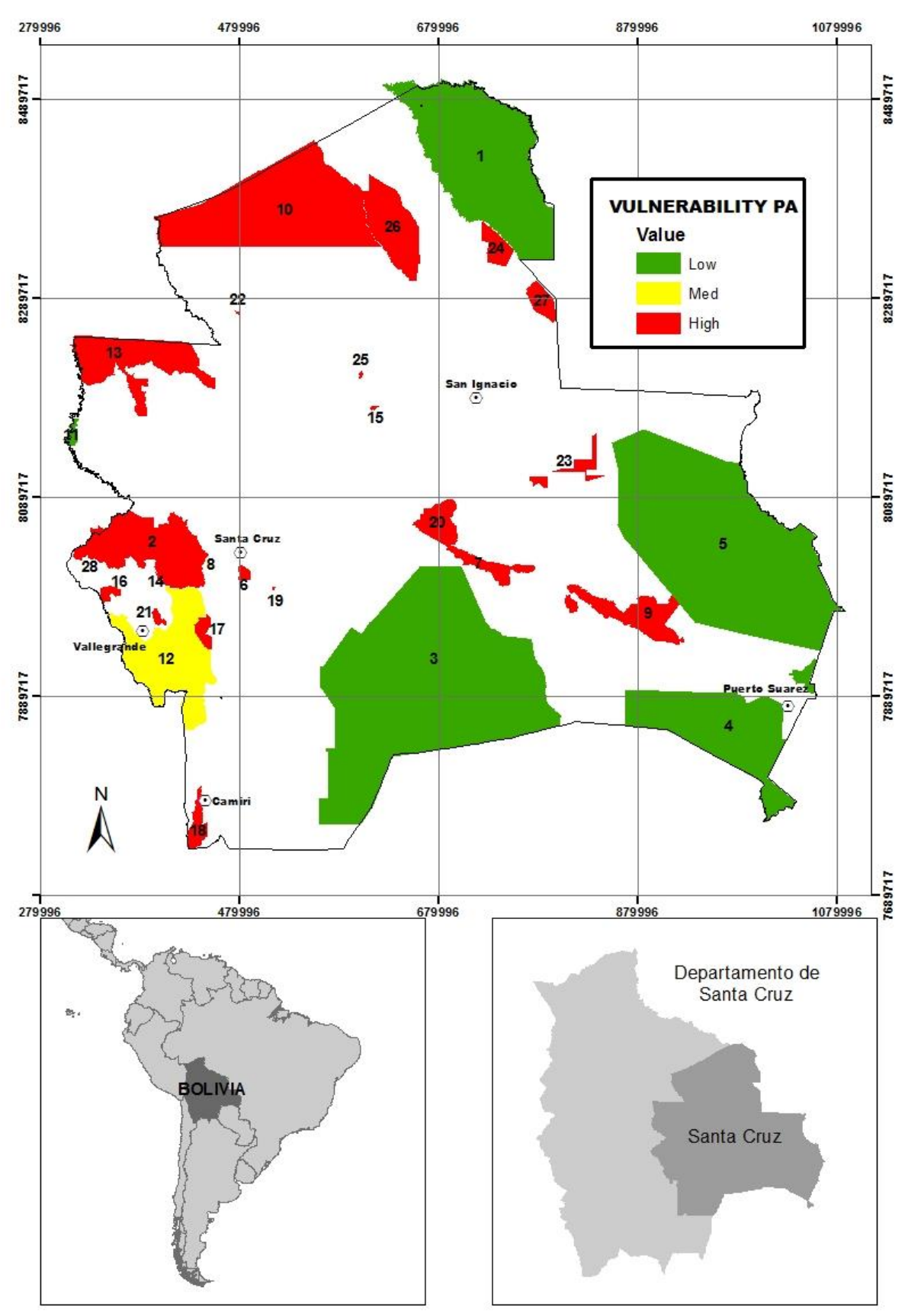

National PAs / Parque nacional (PN): 1.PN "Noel Kempff Mercado"; 2.PN y ANMI "Amboró"; 3.PN y ANMI "Kaa-Iya del Gran Chaco"; 4.PN y ANMI "Pantanal Otuquis"; 5.PN y ANMI "San Matías". Departmental PAs: 6. Parque Regional Lomas de Arena; 7.Parque Historico Santa Cruz La Vieja; 8.Monumento Natural de Espejillos (V.Medium); 9.Reserva Departmental Valle de Tucavaca; 10.Reserva de Vida Silvestre Ríos Blanco y Negro; 11.Meandros del Río Ichilo; 12.ANMI Río Grande Valles Cruceños (V.Medium); 13.Humedales del Norte. Municipal PAs: 14.Municipal Protected Area / Area Protegida Municipal (APM) Microcuenca El Chape; 15.APM Orquídeas del Encanto; 16.APM Jardín de Cactáceas de Bolivia; 17.APM Parabanó; 18.APM Serranía Sararenda Cuevo-Camiri; 19.APM Palmera de Saó; 20.APM Laguna Concepción; 21.APM Laguna Esmeralda; 22.APM Laguna Yaguarú; 23.Reserva Municipal San Rafaél; 24.Reserva Municipal San Ignacio; 25.Laguna de la Represa Zapocó; 26.Reserva Copaibo; 27.Laguna Marfil; 28. Area protegida Churo Negro. 


\section{DISCUSSION}

\subsection{Review of Conservation Action Planning (CAP) in the Americas}

Once again, the value of a standardized tool with a common template, such as CAP, for the comparison and evaluation of management plans across the Americas has been confirmed. The ability to compare plans created in the same format and accessible through the ConPro (Conservation Projects) datbase was invaluable for this study. We conclude that the most important lesson from our study is that it is indeed possible to include climate change related issues in all steps of the CAP (and thus also the Open Standards) framework. Initially our results indicated that of the 103 CAPs written before 2009, a majority of the plans had obvious difficulty integrating climate change into their management and planning processes. When we looked at the 22 CAPs written after 2009 (following the climate change clininc) there was a marked increase in the consideration of climate change issues.

It was common for there to be little consideration and inclusion of climate change 10-15 years ago. This is consistent with similar findings of interview-based case studies conducted in Canada (Lemieux \& Scott 2011), and Germany (Fee et al. 2009; Reyer et al. 2011; Geyer et al. 2014 (accepted, in revision).

It should also be noted that the plans located in ConPro might not reflect the current reality, since it is possible that some plans that were developed long ago may have only recently been uploaded when the plan was enacted. Several newer plans that are currently being written are not available in ConPro yet, and these plans might actually reflect and address climate change more thoroughly (Poiani 2011; Groves et al. 2012).

We are convinced that after the 2007 Intergovernmental Panel on Climate Change (IPCC) report and following TNC's 2009 climate change clinic, more conservation plans are integrating climate change into conservation planning. For the majority of conservation projects, climate impacts will require significant management changes. These may include redefining project area boundaries, reprioritizing or even abandoning some ecosystems or species, revising conservation goals for ecosystems or species, and modifying management actions or interventions.

The comparison of CAPs reveals that while only $25 \%$ of CAPs had mentioned climate change as a specific threat before the clinic, $50 \%$ did so after 2009. There was a similar increase in the numbers of KEAs related to climate. Only $45 \%$ of CAPs included such KEAs prior to the climate change clinic, whereas $59 \%$ included them after the clinic.

Viability assessments are a crucial element of vulnerability analyses. Identifying climate-relevant KEAs is a first step towards creating and implementing successful climate change adaptation strategies. In this sense, in order to assess current and potential future viability, we recommend that planners include as many climate-dependent KEAs as possible (e.g., temperature and precipitation regimes, vulnerability against extreme precipitation events, and fire regime). It may be necessary to use a different set of stress classifications (from the suggested stress 
classifications) for a threat analysis that includes climate change parameters (Geyer et al. 2011). This can be done by examining each of the conservation targets and the identified climate-changerelated stresses which eventually (and under specific scenarios) may become relevant. Importantly, threats and stresses related to climate change must be addressed not in generic terms of "climate change", but rather as explicitly and in as much detail as possible. At the same time, plans should clarify how to design adaptation strategies.

The integration of the analysis of future threats with that of currently observed threats remains a challenge as well in conservation planning. The available standardized tools of adaptive conservation management such as CAP or the Open Standards for the Practice of Conservation do not incorporate options for handling future scenarios and vulnerability analyses. New methods such as the Adaptive Management of Risk and Vulnerability at Conservation Sites (MARISCO), which is based on the Open Standards, might fill this gap and thus help to address future scenarios while planning for conservation (Ibisch \& Hobson 2014).

As part of this thesis project work, we suggest an additional new guide, which we name extended $C A P$, for conservation planning that uses a combined approach towards adaptive conservation planning and risk management, and which improves the existing manual for the steps within the Open Standards. We developed the extended CAP based on some of the experiences while refining the MARISCO methodology. We recommend the use of this extended CAP approach with the opinion that typical reactive adaptive management will fail to address climate change and that a combination of adaptive management with proactive risk management is needed to secure effective conservation over the long-term. For us, a key step in the CAP methodology is the conservation target selection, which we think is not sufficiently directed towards integrating climate change and for this reason in the process of this project, we proposed an extended CAP instead of a tradtional CAP. We carried out a case study experience using the pilot extended CAP, oriented to ecosystem process targets rather than specific targets such as species or ecosystems.

Climate change will make the management of sites for very specific and small targets, increasingly difficult or even futile, especially if the targets prove to be highly vulnerable. Thus, some authors have called for more (eco-)system and functional targets (Noss 1990; Ibisch \& Kreft 2008). Following these suggestions, many conservation sites are already shifting away from single species targets and are managing for communities or ecosystems. However, even communities and ecosystems will change and shift with climate change, while processes most likely will stay in place. Many sites have well-elaborated target and threat analyses, but the monitoring part of the management plan is weak in many cases. The inclusion of climate change in the monitoring seems to be gaining ground, with further development required.

\subsection{The local case study experience with ANMI Rio Grande Valles Cruceños (ANMI RG- VC)}

From the results of our comparison of protected areas across the Americas, the a pilot extended CAP planning process with a protected area in Santa Cruz, Bolivia allowed us to evaluate the experience of a real application in the field and test the feasibility of the systematic incorporation of climate change throughout the planning process. Through the process of applying the extended 
CAP with its standardized consideration of climate change in each of the steps, it became clear that knowledge about climate change and allowing for adaptation in conservation planning, is still limited. Looking at examples around the world, Ford et al. (2011) notes that while there is an emerging scholarship proposing assessment approaches and adaptation options, few studies have systematically examined current adaptation actions at a regional or national level. Reports in the scientific literature on adaptation actions from developing nations is limited.

As the climate change field evolves, however, new literature review approaches are needed if we are to identify and characterize what we know, don't know, and need to know (Hulme 2009; Hulme et al. 2010).

Our results show that despite the guidance developed for this case study/pilot experience and the proposed criteria for selecting conservation targets, the selection of conservation targets remained focused on tangible objects such as species, communities and/or ecosystems. These represent a more conventional concept of biodiversity on the part of workshop participants in this protected area. This tendency was also seen in similar exercises as noted Rouget et al. (2003) and Araujo et al. (2010) where the focus of conservation planning clearly focus upon aspects of ecological and biogeographical patterns rather than processes.

From our local case study experience, we suggest that the first key step in the workshops selection of conservation targets for the area- is more manageable if you start by selecting species, communities or ecosystems as biodiversity representatives of the PA and then follow by discussing how intangible targets such as processes or functions also represent biodiversity and can be considered as conservation targets themselves. As Ibisch \& Nowicki point out in Araujo et al. (2010) (and which we also saw at ANMI RG-VC) it remains difficult for workshop participants to consider biological and ecological processes and not rely solely on static and current patterns of biodiversity and also to understand the interaction between humans and ecosystems as a dynamic process. Since the knowledge and understanding of stakeholders is key to the selection of conservation targets, it is important that facilitators create workshops which are well-attended by a large and diverse group of relevant participants. This requires coordinating logistics, funding, participants, technical equipment, materials, time, transportation, etc.).

Despite the important consideration and inclusion of processes and functions as CTs, there are still many strong arguments to support selection of 'conventional' CTs. For example, with spatial ecological units (SEU) e.g., 'Forest' as a CT, the reasons to consider such units as representative of the biodiversity of the PA are that: "They are diverse ecosystems and therefore even if (hypothetically) there is low abundance of some species, many functions are maintained, such as ecological processes, resilience to environmental changes, and they [forests] act as an umbrella to protect the biodiversity that characterize them, even without undertaking a study of the diversity of the protected area." In this sense, the key ecological attributes of many ecosystems could be interchangable, and subject to the same threats and require the same interventions (e.g., interception of precipitation (fog) by forests, soil erosion control).

Therefore we define an important aspect about it is - as Ibisch \& Bertzky (2006) and Araujo et al. (2010) stated - if the preservation of some or many components of the non-functional biodiversity 
of an ecosystem is preferable, or a functional system in which some key roles are provided by non-native species, but where native species could to long, persist and follow developments.

As per Ibisch \& Bertzky (2006) and Araujo et al. (2010), a key concept we used when explaining the importance of CT selection is that sometimes it is preferable to conserve some or many components of biodiversity (even though they may not have a known function in the ecosystem) and other times it is preferable to protect a functioning ecosystem (even one in which some some key roles are filled by non-native species) since often native species are part of such a system and will continue to persist and evolve.

In theory, it is possible to maintain or restores processes, without conserving all of the original biodiversity, especially in the simplest and most-altered ecosystems. Thus, in the ANMI RG-VC we selected individual species, SEUs and ecological process as conservation targets. Salzer \& Salafsky (2006) comment that when selecting conservation targets, it is better to choose an ecoregion where a rare species or small population is known to occur. With this approach the strategies and actions are broader and more integrated than they would be for just a single species or population.

In our case study experience, the selection of "water" (in all its states/forms) as a CT was challenging since it is integral to ecological processes and yet was defined under strictly functional criteria, such as in watersheds which are excellent natural units of integrated natural resources management. There was quite a bit of discussion on how to treat water, which is directly impacted by climate change, as a target for the PA. Ultimately water was selected as a CT. One of the important factors in selecting water as a CT were the 40,000 inhabitants of the ANMI and areas around (CLAS 2008) who directly depend on the cultural and aesthetic resources and ecosystem services the PA provides in addition to traditional activities such as irrigated agriculture and fishing. Using the criteria in the extened CAP manual for species selection was a quite useful exercise but in the future we suggest allowing more time for group work and explaining the concepts with examples. A more continuous flow of activities and keeping people in the same small groups would improve participants' understanding about how to incorporate climate change in all steps of the planning process.

We agree with Ibisch \& Kreft (2007), that conservation is in need of a paradigm shift to thinking in larger and more complex dimensions of time and space, to conserving ecosystem functions and all ecosystem processes, to focus less on individual species conservation and on current or past patterns. The end goal of this shift is to maintain the greatest potential for mitigation of anticipated environmental changes, especially those related to hydroclimatic processes.

"Ideal" climate vulnerability analyses require projected climate as suggested by Hansen et al. (2003). Several major tools are available for assessing the impact of climate change on biodiversity. These include: Global climate models, regional climate models, equilibrium and dynamic vegetation models, species bioclimatic envelope models and site-specific sensitivity analyses. Depending on the objectives of a climate vulnerability analysis, as with the case of ANMI RG-VC, it is possible to do a vulnerability analysis for PAs for which data specific to the 
area is lacking by using our tested methodology with general data from the literature, local observations and knowledge (of the stakeholders and experts).

The target viability analysis took more time and effort than we had anticipated and so part of this activity had to be completed outside of the workshop. More time was also needed to identify and rate key ecological attributes (KEAs) for each target. This step is requires additional attention and explanation to orient participants from remote areas and those with previous conservation planning experience. Even for work groups of protected area staff and outside of a workshop environment, the viability analysis is the step which requires the most time and concentration of all the activities involved in the planning process. If there are $8 \mathrm{CTs}$ and an average of 3 KEAs for each CT that means there are 24 individual viability analyses to discuss and rate and indicators, acceptable ranges, current viability thresholds. Considering climate vulnerability on top of the usual analysis requires additional time and effort on the part of the staff teams, beyond the workshops. As an examples from our case study, for the viability rating of the CT "Primary and secondary river channels of Rio Grande" we had a KEA of "riparian vegetation cover" and an indicator of "fragmented areas (due to slash and burn practices)". We rated the "landscape context" of the target based on defined percentages of threshold values for each attribute as follows: Poor ( $\leq 75 \%)$; Fair (75-50\%); Good (50-25\%); very good ( $\geq 25 \%)$.

The threats (and the opportunities and risks which come with them) are symptoms of the same root causes biodiversity loss, soil degradation / desertification and climate change all are symptoms of the same root causes (Ibisch et al. 2010).

Regional or macro ecological conservation approaches are required in order to enhance the ability of biodiversity to adapt to accelerated climate changes. However, adaptive management can be highly reactive, simply responding to changes detected in the system. It should therefore be used in combination with a proactive risk management approach to make it more comprehensive and effective (Ibisch \& Nowicki 2011). Climate change was expected to be a threat to the ANMI, but had the lowest rating percentage compared to conventional threats. Based on our results from the case study process, the knowledge and treatment (by technicians, researchers, local residents, etc.) of the issue of climate change in planning is still at a very general and basic level, focused mainly on increase temperature or increase/decrease of rainfall, etc. These would be the most notable changes according to the knowledge and perception of the ANMI local residents. This same observation is affirmed by Hoffman (2010) for other parts of Bolivia. It is a complex process to work with the uncertainties of climate change.

As our results and those from other projects and initiatives demonstrate, conservation planners continue to choose conventional actions and strategies to address the effects of climate change. In the pilot extended CAP we observed that the proposed strategies were particulary based on various "programs" such as an environmental education program and programs for early detection and warning of forest fires, intended to address the threats identified in the area. In the past, according to Ibisch \& Nowicki (2011), it was enough to support the functionality of biodiversity and reduce the threats affecting conservation targets. Now, however, in these times of rapid environmental change, conservation efforts must also facilitate and contribute to a reduction in vulnerability. 
There are different ways to achieve this, such as reducing sensitivity, improving adaptive capacity and facilitating adaptation.

Within all macro-ecological (landscape) approaches including ecosystem management, bioregional or ecoregional management, the conservation objectives are more integrated and more ambitious than they were under classical conservation visions that focused merely on the representation of current patterns of biodiversity.

Increasingly, climate change is seen as a major challenge to biodiversity conservation, and subsequent actions to mitigate the effects of climate change are being viewed as a welcome opportunity for the introduction of innovative conservation action (Ford et al. 2011).

In Bolivia, consideration of the issue of climate change is increasing little by little among different sectors (government, scientists, policy makers, NGOs, etc.) (PNCC 2007; PNUD 2011; Seiler 2009; Seiler \& Moene 2011; Rios et al. 2013). It is important to emphasize that in Bolivia, due to the complexity and diversity of its ecosystems, as in much of Latin America, it is normal to work under conditions of high uncertainty and therefore continually assess and modify the impact and results of a project as needed.

We report that in our local case study, the pilot extended CAP methodology, its objectives and the participation of stakeholders in conservation for their PA was a positive and successful process.

\subsubsection{Current state of the ANMI Rio Grande and Valles Cruceños protected area}

\subsubsection{Management Plan ANMI RG-VC}

The extended CAP as a local case study experience took place in parallel to the independent development of an official Management Plan for the ANMI RG-VC by staff of Fundacion Natura Bolivia. By comparing the 2 resulting management plans, we can show that the outcome of the official Management Plan, presented by DIAP (2009) included some of the general content from the extended CAP process but the focus on climate change was left out. The official plan referred to the methodology they used as Conservation Action Planning (CAP) with no reference made to the incorporation of climate change, which was a goal a focus of our extended CAP. The CTs in the official MP were reduced from 8 (in the extended CAP) to 6. Fundacion Natura Bolivia created the official MP using a manual proposed by SERNAP (Pabon et al. 2002) "Guía para la elaboración de planes de manejo para áreas protegidas de Bolivia" (Manual for creation of management plans for protected areas of Bolivia). This particular manual provides guidelines but doesn't limit the number of CTs or approaches for the management of a protected area. Here we summarize the objectives from the official Management Plan for ANMI RG-VC from DIAP in 2009: 1) Ensure the maintenance of the natural richness present in ecosystems of high biodiversity; 2) Raise awareness among people about natural resources and the need for their protection and conservation; 3) Ensure the health and integrity of important water sources and environmental services they provide towards hydrological stability, carbon sequestration and climate regulation; and 4) To contribute to food security, economic and social development of 
local communities and improve living conditions. Only one of the objectives incorporates and considers of the issue of climate change in management. Programs, subprograms and projects are subsequently developed in the MP for each of the objectives. From our point of view, the resulting official MP only considers climate change in a very general way, compared to our goal for MPs developed through the extended CAP to have a strong focus on climate change. The official Management Plan also proposes research programs and monitoring (deforestation and land use change); a subprogram to mitigate environmental impacts; sustainable management, protection and restoration of watersheds; fire suppression and management; and management of and payment for ecosytem services. The official MP also suggests an 1) environmental monitoring program for ecosystem use and species, 2) development of research on climate change mitigation and adaptation and 3) programs to reduce deforestation in the ANMI to 2005 levels.

\subsubsection{Institutional support for ANMI Rio Grande and Valles Cruceños protected area}

At present (2014) Fundacion Natura Bolivia continues to work in the ANMI RG-VC protected area and its surroundings, carrying out the official Project Management Plan with the objective of conserving critical ecosystems and improving human livelihoods through financial and nonfinancial mechanisms. Some of the overarching themes and project initiatives that are taking place under the official plan and which are related to the climate change focus we want to highlight in this study: Theme 1)Climate change adaptation and mitigation, with two initiatives (both in the ANMI RG-VC) a) climate change adaptation and mitigation through payments for ecosystem services, sustainable forest management and conservation in the department of Santa Cruz; and b) sustainable management of water and soil as a way to adapt to and reduce vulnerability to climate change (in the town of Moro Moro). Theme 2) Conservation of ecosystem services associated with water: Four programs at the municipal level within the ANMI RG-VC which provide payments for ecosystem services (watershed protection) Theme 3) Initiative to create and consolidate protected areas: Management and business planning initiative for ANMI RG-VC. Theme 4) Impact assessment of conservation and development initiatives: a) Creating a conservation ethic, incentives for conservation activities and training in understanding and applying conservation law within social norms, and b) Conserving Hydrological and Ecological functions through payments of ecosystem services, in south-central Bolivia. Additionally, Fundacion Natura, Bolivia continues to generate jobs related to the above themes: Robertson \& Wunder (2005 ); Müller (2005 ); Asquith et al. (2008); Le Tellier et al. (2009); Azurduy \& Acosta (2009); among others.

\subsubsection{Local case study of Extended CAP experience (consolidated methodology + MARISCO) at ANMI RG-VC}

As we explained earlier, the "extension" of the original CAP methodology emphasizes the incorporation of climate change and this is the methodology we used in our case study as a pilot planning experience for ANMI RG-VC. As a planning methodology, the extended CAP and another with similar approaches were applied in different countries outside of Bolivia (Costa Rica, Ecuador, Peru and China). Following years of work, trials and discussion, the authors presented the consolidated methodology known as MARISCO (acronym of the Spanish name Manejo 
Adaptativo de RIesgo y vulnerabilidad en Sitios de COnservación or Adaptive Management of Risk and Vulnerability in Conservation Sites) (Ibisch \& Nowicki 2012, Geiger et al. 2012; Ibisch \& Hobson 2014). The MARISCO method is based on Open Standards, with the incorporation of new elements to the iterative analysis and planning process. It is a methodological approach used to integrate concepts of risk and vulnerability into the management of conservation projects and sites. It is designed to take into account the impact of climate change in the strategic management of protected areas, although it does not solely focus on climate change. The MARISCO methodology was developed as a result of workshops and projects carried out in Germany, Ukraine, China, Guatemala and Peru (Ibisch \& Nowicki 2011).

As we explained throughout this study, the extended CAP was an initial basis following the same logic (CAP). It evolved into a more systematic and comprehensive version, the MARISCO methodology. The following table (Table 18) presents the main features of the MARISCO methodology, compared with the features of the extended CAP methodology which was used in our case study: 
Table 18. Comparison of the MARISCO methodology, with the extended CAP methodology which was used in our case study

\section{\begin{tabular}{l|l} 
Extended CAP local case study & MARISCO methodology
\end{tabular}}

-General principles are shared and very similar to TNC's CAP method and to Open Standards (CMP)

-Not restricted to use only for protected areas. Can be used for any site with conservation targets

-Process requires 2-3 workshops and 2-3 days per workshop

-A diversity and quantity of participants validate the outcome

-Use basic reference materials such as topographical, hydrological, ecological and socioeconomic maps

-Allow for additional site biodiversity data (habitats, species, distribution maps) to be included and considered outside of the workshops

-Simple satelite images can be tools for conservation work

-Facilitated by trained coordinators/moderators

-Use conceptual models and color-coded activity cards. The ratings are similiarly named: high, medium and low

Additional activities and competencies (the majority of which should be

completed, they are not optional):

-Spatial analysis, diagnostic ecosystem analysis and and exhaustive

evaluation of stresses: scenario planning, concepts of risk and vulnerability

in adaptive management for conservation.

-Situational analysis of the conservation site (context) and analysis of

ecosystem-based climate change adaptation.

In the framework of the pilot case study experience, the Extended CAP began directly with selection of conservation targets (CT)

\section{Steps:}

\section{1) Systems}

Step I.- Conservation targets -Identify the focal conservation targets (ecological systems and species groups)

-Determine the characteristics of viable conservation targets

-Rank the focal conservation targets for viability

-Determine "Biodiversity Health" of the site

\section{Steps:}

0. Diagnostic ecosystem analysis. Includes activities such as gathering exisiting available data, defining the geographic scope of the project and the selection of conservation targets which include biodiversity targets as well as target of human well-being which are ecosystem-dependent

1. Scope of management and study focus

2. Biodiversity targets. Centered on ecosystem targets (ecosystem-based focus) and represent species as nested targets. A nested (holarchical) structure of biodiversity should be considered

3. Ecosystem services/human wellbeing targets 


\footnotetext{
-An approach to target selection which maintains functionality (and resilience) rather than representation of biodiversity patterns by specific tangible targets, normally no ecosystem processes targeted

-Location and distribution of targets is drawn on maps of the area
}

Step II.- Key Ecological Attributes (KEAs)

What factors, including key ecological processes, must be maintained to ensure the long-term viability of the conservation targets? Select and rate - Current viability analysis and climate-dependent viability analysis for each of the targets (Identification de climate-dependent Key Ecological Attributes (KEAs)
4. Initial management vision

5. Current situation analysis of biodiversity conservation targets:

(Extensive process which requires more time than in the extended CAP)

(Targets: Natural elements which have an important function recognized for

the maintenance of ecosystem integrity, and which also provide tangible benefits to humanity: Select targets of human wellbeing (which depend on biodiversity and especially ecosystem functions at the landscape level and nested targets)

-Key attributes (includes an additional attribute: information. Ecosystems and organisms generate, store and use information

-Stresses (this analysis should not be skipped). Analysis of function (viability) could be optional

6. Threats (The stresses, threats and contributing factors- independent of climate change can't be understood in isolation.) Look beyond local, individual threats and consider more complex regional/gloabl threats (e.g., world demand for agricultural production or global climate change). Analyze current and future (in 20 years) threats

-Prioritize threats (according to categories in Salafsky et al. 2008)

-Place the location and distribution of threats on the site maps

7. Identify positive and negative factors which contribute to vulnerability (contributing factors)

8. Group the contributing factors (biophysical, socioeconmic, socioeconomic, governmental, institutional, spatial)

9. Spatial analysis and priority setting (optional step)

10. Analysis of criticalness of stresses, threats and underlying factors:

Current; 20 years ago; present trends

11. Future scenarios (Highly recommended) stakeholders in adressing the most critical threats and management needs (favorable and unfavorable stakeholders, timeframe for action, obstacles, 
13. Analysis of the systemic activity and strategic importance

14. Analysis of manageability and knowledge (Important for the

formulation of strategies and to validate existing knowledge)

15. Analysis of participants and stakeholders (optional)

16. Review and validation

Step IV.- Conservation objectives (goals) and strategies

What types of destruction, degradation, or impairment are significantly reducing the viability of each focal conservation target at the site?

-Identify major stresses to the focal conservation targets; Rank the stresses -To guide the strategy development more intensively. Too often, strategies follow standard 'recipes' or strategy templates and are not sufficiently customized to the viability and threat analyses

-The strategies must extend beyond the site into the landscape matrix (exceptions might be transboundary/adjacent areas)

-Prioritize the strategies (Miradi rating Impact+feasibility=Effectiveness). -Review the strategies for appropriateness: are they adaptable to CC, are they viable, cost-effective, proactive and do they allow for a landscapecontext management focus?

\section{Step V.- Risk analysis}

-Includes a preventive, risk management approach

-Considers climate change scenarios, land use etc

-Considers the likehood and impact magnitude

Success: measures of biodiversity health and threat abatement at a site.

Are threats being abated, and is the viability of conservation targets being

\section{Identify existing strategies, including mapping on the vulnerability} model

18. and 21. Rank and set priorities (optional)

-Viability: (a) resources, (b) acceptance, (c) use of opportunities,

(d) effectiveness in the face of risks, (e) adaptability. Impact: (a) creation of conflicts, (b) contribution to vulnerability, (c) synergies with strategies, (d) conflicts with other strategies, (e) threats reduction, (f) increase the function of the targets, $(\mathrm{g})$ potential regret

-Analysis of risks relative to viability (opportunities arise which may favor or support a strategy)

19. and 22. Visualize systemic relations between the strategies and other aspects of the conceptual model

20. Analysis of strategic gaps and strategy modification and if continuing, formation of complementary strategies

23. Overall consistency and plausibility of strategy, spatial requirements for applying strategy, revision of scope and vision

24. Results webs, establish goals and objectives, design monitoring (optional) (How, who, when, where?) 


\subsection{Applied climate vulnerability index. Regional study case}

There is a growing base of scientific literature on the role of protected areas relative to climate change adaptation or mitigation which serves to support and inform research conducted in Bolivia and particularly in Santa Cruz (PNCC 2007; PNUD 2011). What does not yet exist in the field of climate change science are specific guidelines and a legal framework for biodiversity management (Miranda 2011, in PNUD 2013). The protected areas have been designated. The next steps: put strong laws, policies, institutions, administration, knowledge, staff and capacity in place to transform the proteced areas into significant and effective tools for conservation. The ability for natural areas management practices to adapt and mitigate the effects of climate change will depend on the environmental, socio-economic circumstances and the availability of information and technology.

We based the "climate vulnerability rating" (V.) on the ability of protected areas management in Santa Cruz, Bolivia, to consider and respond to climate change. We gauged this by the degree of knowledge and understanding the managers head of climate change issues. For the PAs which were part of our study, the managers demonstrated only a general knowledge and understanding climate change issues, despite access to specialized information and specific studies from Santa Cruz, Bolivia about the vulnerability of the PAs under their management and administration (Hoffman et al. 2012; Quiroga et al. 2011; 2012; PNUD 2013).

The practice of adaptive management in the PAs should be a dynamic process that includes risk and vulnerability assessments, studies of feasible alternatives, implementation of measures and ongoing monitoring and reassessment. However this is not yet a reality. We demonstrated through our regional case study that it is possible to use the available, existing local information and include the perspectives and observations of the managers on their PA. We suggest that such data can be used to guide adaptive management, even when accurate and scientific information is difficult to obtain (time, cost, etc.). Although results based on "perceptions of climate change" cannot substitute for scientific research, as stated by Hoffman \& Requena (2012), they add value to the debate on the impacts of climate change, the rapid and urgent responses necessary and possible means of adaptation.

We mention the nature of the survey (opinion and observation) data which we used in determing the climate vulnerability ratings because these are not indicators commonly used in evaluating the management of natural areas, such as used by the Management Effectiveness Evaluation (MEE) (Rivero \& Gabaldon 1992; Cifuentes 2000; Hockings et al. 2004; 2006), and in other methodologies such as MEMS (Metodología de Evaluación de Efectividad de Manejo or Methodology for Evaluating Management Effectiveness) used by Bolivia's National Protected Areas Service (SERNAP) to evaluate the management of its protected areas. (Guachalla \& Zegada 2001; Guachalla et al. 2002). MEMS measures annual management effectiveness by focusing on certain aspects of the protected areas.

This approach does not focus on the conservation and management of a specific measures program, project or donor. It does not measure the success of a protected area in biodiversity conservation, threat reduction, or other critical aspects of conservation. The evaluation uses a scorecard adapted 
from the Parks in Peril Site Consolidation Scorecard with defined evaluation criteria specific to the Bolivian protected area system. The adapted scorecard includes additional indicators and subindicators specific to Bolivian conditions (Leverington et al. 2008). Another evaluation methodology is the Integrated Monitoring System for the Conservation of the Protected Areas SMAP (Sistema de Monitoreo Integral para la Conservación en Áreas Protegidas, Bolivia) wich has five components: Conservation targets, Human activities, Socioeconomic dynamics, Sociopolitical conflicts, and Protected area management.

Our evaluation and rating was based on information from the questionnaires, characterized by openended questions that could be answered in many ways. Most of the answers given by the managers of our areas were very extensive in their responses or were quite precise or gave answers unrelated to the question asked. Other managers only responded with affirmations or denials. Despite the time window that managers had to complete the questionnaire, after more than three months we had still not received many responses and so undertook extensive follow up to obtain the completed questionnaires. From the nature of the responses, we presume that for some of the areas, the managers only recently began working there. Other responses indicated that the respondent had not taken much time to thoughtfully and completely fill out their answers. We also gathered that some of the respondents have little career experience or knowledge of climate issues. This apparent lack of knowledge about climate issues is unexpected, given that the managers self-identified as follows: 10 Foresters, 5 Biologists, 3 Lawyers, 1 Veterinarian and 9 Municipal technicians. One area reached out to us for clarification of some of the questions, but no others did.

It was possible to adapt the index of Kreft et al. 2013, for our climate vulnerability ratings because we had the information needed to assess the "Management" of the PAs from the questionnaire survey. For our study, we looked at both management practices for biodiversity conservation and the organizational management (business administration and human resources) practices of the protected area when determining the ratings. We rated each subcriteria and from that determined the total Management rating, based on the information from the survey responses. Organizational management is essentially a human factor but one which is critical to the success or failure of protected areas management. As such, including information from the managers' responses about the way their PA is administered allows us to gauge the weakness or strength of this human factor and its role in climate vulnerability.

The questionnaire answers reflect a strong consensus that the $\mathrm{CC}$ is an obvious threat to all protected areas of Santa Cruz. Most managers described their perceptions of CC in terms of different weather patterns or extremes events such as floods, droughts, etc. None mentioned nonnative invasive species, or a decrease or loss of flora or fauna. In line with the managers' responses about extreme weather events, in recent decades the extreme events in Bolivia have been very noticeable, especially in lowland areas of the PAs in our study. Weather records show an increase in the number of days with precipitation and a decrease in the intensity of rainfall, as indicated by the respondents. Seiler (2009), states that due to the Pacific Decadal Oscillation (PDO) and the phenomena, there has been a marked and steady increase in general temperature trends in Bolivia beginning in 1976-77. The same study explains that $25 \%$ of climate variability in Bolivia is explained by the PDO and $15 \%$ of climate variability is due to the phenomena of El Niño/La Niña. The managers indicated the following in their responses as sources of CC: human activities, 
combustion of fuels, and emission of pollutants, among others. These responses were mostly repetitive.

We could speculate that the managers' limited knowledge of climate change issues is due to lack of specific training on climate change and its impacts to their PAs in Santa Cruz or that access to scientific literature is still difficult, but, from our experiences with the case study and the climate vulnerability analysis topic is mentioned frequently and known among the conservation sector. While the answers weren't as descriptive as we expected, the results show that half of the surveyed areas have management plans (MP) and therefore an obligation to propose programs and climate strategies as part of sustainable development policy under the development Guide to Creating Plans regulated by the national government (Pabon et al. 2002). This local situation is echoed globallythe Convention on Biological Diversity revealed that less than a third of protected areas in the world have management plans.

Although the responses show that the Management Plans (MP) were only recently created or updated and despite the difficulties in research and conservation in the country, there are many initiatives that could strengthen cooperative work together against climate change and the critical role of protected areas in mitigating climate change. In 1998, the Programa Nacional de Cambio Climático (PNCC) or National Climate Change Program was created in Bolivia. In 2007 the Mecanismo Nacional de Adaptación al Cambio Climático / National Mechanism for Adaptation to Climate Change (MNACC) was created, comprised of several programs, one of which is the Adaptation of ecosystems to climate change. This program proposed policies for national protected areas to coordinate work between buffer zones and secondary escape routes, biological corridors promote climate change adaption of both plants and animals. The program also generated dialogues about adaptation, connectivity corridors, expanding protected areas, etc. The Secretary of Sustainable Development and the Environment created a policy for Mitigation and Adaptation to Climate Change, and a part of its action plan is to conserve the protected areas of the department of Santa Cruz. Also in recent years more local literature about it has been published and could be used in protected areas of Santa Cruz (CEPAL 2007; Ministry of Development Planning 2007; OXFAM 2008; Peñarrieta 2009; Andrade \& Blacutt 2010; Quiroga et al. 2011; 2012; Seiler 2009; Seiler et al 2013; Rios et al. 2013) There has also been an increase in the number of methodological tools available to integrate climate change into management planning for proposed or existed PAs (Hannah et al. 2002; Heller \& Zavaleta 2009; Lawler 2009; Mawdsley et al. 2009; CMP 2010; Ibisch \& Nowicki 2011; Ibisch \& Hobson 2014).

Data provided by Hoffman et al. (2012), show that it in Bolivia it has only been in the last decade that CC has slowly been included in management plans and was only identified primarily as a "threat". At present, this situation has changed very little- there was only one PA in our study, the NP and ANMI San Matías in the Pantanal which included CC projections which indicate that gradual decreases in precipitation are expected. According to the same author, these planning tools share a weakness through their low level of consideration of climate change, scarce monitoring and little adaptation and mitigation of $\mathrm{CC}$.

This situation (little consideration of CC) is seen in other tropical Andean countries and in Germany (Kreft et al. 2013). Our results seem to suggest that protected areas have more urgent management priorities than planning for actions against $\mathrm{CC}$. 
Even though climate change is a common topic of conversation in the field of conservation in Santa Cruz, we saw from the questionnaire responses that many of the PAs had no knowledge of the strategies outlined in Ecosystem-based adaptation (EBA) methodology. The EBA considers actions that use biodiversity and ecosystem services to generate adaptation strategies and to include sustainable management, protection and restoration of ecosystem services. For our climate vulnerability index, we interpreted the responses to this question to determine whether the PA practices adaptive management.

No PA refered to adaptive management explicitly (they aren't familiar with EBA), but they described other strategies and projects for adaptation and mitigation of $\mathrm{CC}$, including proposals to enlarge existing protected areas. Another example of note is Fire Management or Proyecto de Acción Climática Noel Kempff Mercado, considered the largest undertaking of carbon dioxide mitigation in the world (over 600,000 ha of tropical forest), which offer carbon offset credit and stop exploitation of timber and conversion of forests to agricultural land (SERNAP 2007). Countries like Colombia are also incorporating an ecosystem approach and the EBA to planning and management. Under this approach it is possible to identify and implement a range of strategies for the management, conservation and restoration of ecosystems to ensure that they increase their resilience and reduce their vulnerability and thus continue to provide services that enable humans to adapt to the impacts of climate change (Hoffman et al. 2012).

Half of the surveyed areas do at least some monitoring: 25\% of the sites monitor their own management (administration) and another $44 \%$ of the monitoring is of populations of flora or fauna. The answers vaguely described the monitoring activities: e.g., monitor populations of macaws (Ara spp.); Chiquitana almond (Dipteryx alata) populations. There were no additional descriptions or bibliographic references or project titles, except in a protected area of the Chaco (NP ANMI Kaa Iya) which reported its monitoring study of jaguars (Panthera onca). Their questionnaire response indicated that based on the density of 1 individual every $20-25 \mathrm{~km} 2$, they estimate a population of more than 1,500 adult jaguars within the protected area (Maffei et al. 2004). Another PA, Microcuenca El Chape, which is in the Andean valleys, takes flow measurements of water sources, studies of water pollution indicators and does patrols. On the other hand, a review of the literature (which is not named in the surveys) shows that in Bolivia, projects such as the Gloria network of protected areas monitoring in the Andes, makes baseline studies on biodiversity by measuring flora, amphibians, reptiles and insects (PNUD 2013). SERNAP has an Institutional Strategic Plan (PEI) for all of Bolivia, which includes research of climate change and its influence on protected areas. There is potential for the integration of the subject in the comprehensive system of planning, monitoring, control, evaluation and monitoring through indicators (PNUD 2013). With the actual climate variability recorded in Santa Cruz, as mentioned by the respondents, it is urgent to conduct monitoring of climate variables and measure the real impact of these climate events in relation to biodiversity and the environment. There must be long-term monitoring of species and ecosystems, taking into account the impacts of land use change on biodiversity, focusing in particular on altitudinal gradients and high altitudes and monitoring species which are sensitive to habitat changes (algae, bats, birds, ants and others). Another important factor for long-term monitoring of climate change impacts is the movement of different taxa along altitudinal and longitudinal gradients, especially in areas with 1) diverse ecoregions such as in Santa Cruz (up to 5 Ecoregions in one PA), 2) where high biodiversity and endemism coincide with high variability to climate 
change. Examples are dry valleys, cloud forests and other "refuge" areas for species during climate change. Most of the PAs which reported that they do monitoring, are municipal and as reflected in the results of this evaluation, have a "high" climate vulnerability.

Almost nothing was mentioned in the responses about the issue of risk management. This might be explained by the fact that the question needed further description to tease out the type of response we were looking for. Many respondents answered that "risk" is synonymous with "threat." With the current situation of climatic phenomena in the PAs of Santa Cruz, we anticipated answers with longer descriptions but most refered to the risk of fires, deforestation and extreme weather events. It was the same when asked about the "most critical climate-related risks which they observe in their PAs". The responses were: temperature rise, changes in rainfall and in the rainy season, winds, etc. Data from SERNAP (2007) indicate that the national protected area in the Pantanal, NP San Matías, was threatened by a recent increase in the price of minerals located in the vicinity of the PA. Logging also seriously affects the same park as 9 of the 10 logging concessions in national protected areas $(6,200 \mathrm{~km} 2)$ are in NP San Matías, and there has been an increase in illegal cutting, creating hazards for rangers who perform operational forfeiture of wood in coordination with the relevant national authority. The survey responses from PN San Matias did not mention mineral prices nor logging as threats. Data on identified wildfire incidents (mainly through satellite images) indicate a high degree of wildfire in NP San Matias and other national parks in the department (Amboró, Noel Kempff and Otuquis) (SERNAP 2013). These wildfire are mainly attributable to intentinoal burning along the agricultural frontier to increase cropland and pasture for livestock (Urioste 2010; SERNAP 2013; Müller et al. 2013; 2014). Despite these threats, the rating of climatic vulnerability for national parks in Santa Cruz is "low" (they are large surface areas, some of them without much social pressure, most have management plans. See the vulnerability results by PA, figures 19 and 20 .

While most national parks had "low" climate vulnerability, NP Amboró, in the Sub-Andean sector of the department, had an overall "high" climate vulnerability. Other threats we reviewed and recorded for this area: hydrocarbon activities and coca (Eritroxylum coca) plantations (illegal cultivation of this species has fueled migration to the area), logging and land acquisition. All these activities threaten the rich biodiversity (5 ecoregions are within this PA) which PN Amboró is designed to protect. However, in the repsonses to the questionnaire, this PA only refered to climate change, contruction of roads, hunting and fishing, deforestation, etc. as threats. Piepenstock \& Maldonado (2011) comment that floods and fires, and their indirect impacts, are the main risks to biodiversity in this area of NP Amboró. Also Quiroga et al. 2011 indicate that of the total area of the department of Santa Cruz, 1\% has high concentrations of species of restricted distribution; $21 \%$ has areas characterized by greater complexity of landscapes (high heterogeneity); $14 \%$ is characterized by higher production potential of forest biomass; and 2\% of the total area of the department is of high importance for the generation of water. These data are reflected in $75 \%$ of "high" climate vulnerability ratings of the subcriteria for the 28 areas of Santa Cruz. For conservation experiences with risk management, currently being tested and developed in several tropical and subtropical protected areas in Latin America and derived from the Open Standars; see Ibisch \& Nowicki (2011).

With respect to funding and technical expertise for implementing planning strategies or management of PAs, the responses indicate that most of the PAs are weak in this regard, even more 
so if we take into account their large sizes and the difficulty of access to and within the PAs. The responses discuss risks and planned activities, but the allocation of time and resources for risks management, is not addressed in the questionnaire answers. Protected areas can play an important and strategic role in risk management, adaptation to the impacts of climate change, biodiversity conservation, water and forest resources conservation, maintenance of ecosystem resilience and the provision of environmental services. According SERNAP (2007) various initiatives have already been put in place to prevent deforestation and forest degradation in protected areas and surrounding buffer areas. There is a legal framework for protected areas- Law on National Parks Wildlife Fishing and Hunting (Ley de Vida Silvestre, Parques Nacionales, Caza y Pesca), Forestry Act 1700 (Ley Forestal 1700) and the Regulation on Protected Areas (Reglamento de Áreas Protegidas), but these are still incomplete and relatively weak. Under Article 2 of Law 233541, the national government dedicates $0.15 \%$ of public expenditure for risk reduction and disaster/emergencies (PAs create joint strategies with neighboring populations).

Here we highlight some of our results across the categories of administrative level, PA size and the history of creating protected areas in the department of Santa Cruz. The first protected areas (5) which were created in Bolivia were at the national level, but none of them were designed with the ideal circle shape (they have a V.high) according to our criteria. These are the PAs with the largest surface areas in the department and in the country. Three (3) PAs between 1,523,446-3,441,500 ha (V.low), 2 PAs between 490,051-1,523.446 ha (V.medium). Three (3) PAs report deforestation ranges $\leq 5,058$ ha and therefore have V.low and 2 PAs reports deforestation ranges between 18,75766,333 ha and therefore have V.high. There are 2 areas which have more than 4 ecoregions present in their territory (V.low) and 3 areas with 3 ecorgiones (V.medium). Theses national PAs have a larger budget allocation than PAs of lower administrative levels. The SNAP budget for the 5 national parks in the Santa Cruz department was USD 13,439,445 from 1990-1998.

During the period of 1990-1998, two of the 19 existing national areas, The NP Noel Kempff Mercado and the Estación Biológica del Beni, absorbed more than $40 \%$ of the total national budget for PAs, while at the other extreme some PAs received no money from national funding for their budgets and management. At present there is still a high financial vulnerability due to excessive dependence on foreign aid and cooperation for protected areas management. However, policies do exist which address this problem, such a policies to create entities which can capture funding; promotion of tourism in the protected areas and development of the important potential in ecosystem services and ecotourism (Loaiza 2003).

Across all of Bolivia, there are 350 rangers for 22 areas, an average of 15 rangers per PA for what are the largest PAs in the country. Despite the limited resources currently allocated, these large national areas received the most government support of any other PAs and therefore have V.low as reported in our climate vulnerability index.

Thirty-five percent (35\%) of the area of the department of Santa Cruz contains areas with a high value for biodiversity conservation value. These areas are largely contained in existing protected areas (Quiroga et al. 2012). According to our general ratings, $80 \%$ of the national areas have subcriteria with low climate vulnerability. This is important, taking into account that these are key sites within the department for biodiversity conservation. The conservation value of these sites is based on bio-ecological indicators that were identified in a study by Quiroga et al. 2011, which 
states that: NP ANMI Amboró, NP Noel Kempff Mercado and ANMI San Matías have High and Very High potential species richness; NP ANMI Amboró, NP Noel Kempff Mercado are likely concentrations of restricted species; AMNI San Matías, AMNI Otuquis, NP AMNI Kaa Iya, NP Noel Kempff Mercado have habitat heterogeneity; NP ANMI Amboró has moderate to high potential to mitigate the effects of climate change in the department of Santa Cruz due to the distribution of woody plant cover and aboveground biomass; NP ANMI Amboró and NP Noel Kempff Mercado are key to generating water sources.

Departmental PAs have medium to high overall ratings (25\% V.medium, $63 \%$ V.high) of climate vulnerability for the criteria of Management. These areas are also key in terms of biodiversity, according to the same study (Quiroga et al. 2011): Reserva de Vida Silvestre Ríos Blanco y Negro has high and very high potential for species richness; Reserva de Vida Silvestre Cicatrices de Meandros Antiguos del Río Ichilo and AMNI Rio Grande Valles Cruceños have likely concentrations of restricted species; AMNI Rio Grande Valles Cruceños and Monumento Natural Espejillos have potential to mitigate the effects of climate change due to the distribution of woody plant cover and aboveground biomass; ANMI Río Grande y Valles Cruceños and Reserva de Vida Silvestre Ríos Blanco y Negro are key to generating water sources. According to our data, 7 of the 8 departmental areas do not meet the design subcriteria for ideal shape (V.high) (except Parque Regional Lomas de Arena LO_ARE). Three (3) PAs have V.medium based on their sizes within the range of 490,051-1,523,446 ha. For the 5 PAs with areas $\leq 490,051$ ha, their vulnerability is high (V.high). Two (2) areas have more than 4 ecoregions (V.low) and 2 PAs have three ecoregions (V. medium). Four (4) have $\leq 2$ ecoregions (V.high). Deforestation data show that 5 areas have $\leq 5,058$ ha (V.low) and 3 areas have 5,058-18,757 ha deforested (V.medium).

The municipal areas are the most vulnerable in the face of climate change as 100\% (15 areas) had the highest vulnerability ratings for most of the subcriteria. Biologically (again according to Quiroga et al. 2011) the areas are considered as such: San Rafael, San Ignacio, Sapocó, Orquídeas del Encanto, Churo Negro PAs have high and very high potential species richness; Microcuenca El Chape, Churo Negro, Laguna Esmeralda, Parabanó have likely concentrations of restricted species; Represa Sapocó, Orquídeas del Encanto, Churo Negro are key to generating water sources. According to our ratings, 12 of these 15 did not meet the subcriteria fully or ideally and so have a climate vulnerability rating of V.high. All of these areas were rated with a V.high for surface areas since they are smaller ( $\leq 490,051 \mathrm{ha}$ ). Six areas contain 3 different ecoregions (V.medium) and 9 areas have $\leq$ ecoregions (V.high). Deforestation data show the highest rates of deforestation for these municipal areas (18,757-66,333 ha) (V.high).

These results can be explained by other influencing factors. Current legislation provides clearer management mechanisms for national-level protected areas (created between 1988 and 1997) and for departmental-level protected areas (created between 1990 and 2012), while there are still legislative gaps concerning protected areas at the municipal level (created since 2001 and others still in process) (DIAP 2013). The 5 national-level areas in Santa Cruz represent $71 \%(9,629,211$ ha) of the total protected area in the department. The 8 departmental-level areas represent $22 \%$ of the total protected area in the department. Municipal-level PAs represent $7 \%$ of the protected area for the department, despite being the most numerous. 
We note that, in general, the climate vulnerability rating of the management of the municipal areas in Santa Cruz, is due to the fact that very few municipalities (local governments), include an Environment Department or similar organizational structure to oversee the leadership and planning for the management of their protected areas. Of the total of 19 municipal areas of the department, 18 have been formally declared (one, Área Protegida Municipal Palmera de Sao by national law). At the time of this writing, the ANMI Parque Historico Santa Cruz La Vieja (departmental-level PA) is in the process of being created. Across Bolivia, Santa Cruz is the only department to date which has formally established a departmental system of protected areas (Sistema Departamental de Áreas Protegidas, SDAP). This departmental system was created though Prefectural Resolution 027/05 on February 25, 2005 which granted authority and made the administration and enforcement of the areas operational through the Dirección de Áreas protegidas (DIAP). Legal organization alone is not sufficient to effectively manage the PAs, which is reflected in the high vulnerability ratings for the municipal areas. The municipal PAs are administered by their respective local governments in coordination with DIAP. Civic organizations have been providing funding to DIAP for the development of management plans for areas that don't yet have MPs and to support protection and monitoring measures, implementation of alternative production projects, environmental education and ecotourism in the PAs (PROMETA 2009). The municipal protected areas are recognized by the National System of Protected Areas (SNAP), although the mechanisms for coordination are still unclear and there are grey legal areas in the agreement guidelines. According to data from DIAP (2014) there are 117 (theoretically an average of 4 per area) park rangers for all the PAs in Santa Cruz. The current reality is that this staffs do not have established institutional support and even with this number of rangers, most are located in national PAs and the municipal PAs are without protection staff.

Our results on joint work and goals between areas show that there is only a very low level of this type of cooperation and coordination. The only times that staff from SERNAP, SNAP and DIAP are in contact with each other is during training or workshops on management and planning. There are very few other opportunities for exchanges or joint efforts even though many areas are adjacent to each other or face the same challenges. A report from SERNAP (2007) itself, based on studies of the IPCC (2011) points out a greater need in the face of changing climate to establish more refuges and corridors between PAs to mitigate fragmentation and to help plants and animals in their process of migration and adaptation to changing environments and habitats.

The departmental PAs serve to fill gaps and ensure connectivity of ecological corridors and also meet multiple objectives to maintain vital ecosystem services for local communities (Araujo et al. 2010). If we review the proposed and official ecological corridors in Bolivia, some PAs of Santa Cruz are within the Amboró-Madidi (official) biological corridor which was the first corridor that was named and studied in Bolivia and was created with the institutional support of the Secretary General for Biodiversity of the Ministry for Sustainable Development (Araujo \& Ibisch 2000). Other PAs are located in corridor areas of the Pantanal and of the Tucumano-Boliviano forest, although these corridors are not official nor with a solid foundation for their creation. Some examples given by Hole et al. (2011) on the role of protected area networks worldwide emphasize the importance of networks for climate resilience. These networks form large areas of different habitats and altitude gradients among which species may move and shift and adapt. A well-designed network of protected areas reduces barriers and obstacles between different areas. Protected area networks are the most important tool for biodiversity consideration globally. Protected areas are 
recognized for their role in capturing and sequestering carbon and the mitigating effect this has on CC (Dudley 2008; Sandwith 2008). Using protected areas to conserve biodiversity in the face of climate change requires cooperation between protected areas and also between nations (or other geographical/managerial jurisdictions), strengthening the arguments for transboundary protected areas. (Hansen et al. 2003).

In Bolivia, the relationship between the general population and protected areas is regulated under the Environmental Law, which states that protected areas are natural areas with or without human presence. In the early years of PA creation, indigenous peoples and local communities in and around the areas were organized into Management Committees, which ensured direct participation of local people in the protection process. Some protected areas are also designated as Original Communal Lands (Tierras Comunitarias de Origen - TCOs) which recognize the territorial right of indigenous groups and indigenous populations to those spaces. The "Parks with People" initiative was launched in Bolivia in 2005 to engage indigenous communities in the management of protected areas (Peredo-Videa 2008). In the survey responses, managers indicated that work and cooperation with the human communities of their PAs is ongoing. This subcriterion was rated as "medium" vulnerability in all three administrative levels. Managers should seek the involvement of as many potential stakeholders to exchange and share viewpoints, training, awareness and ultimately make decisions together in the activities which promote management of the protected area. Effective local participation in project design and implementation is key to equitably and sustainably optimizing multiple benefits. In rural Bolivia, there is a strong organizational capacity and tradition among people, with great potential for progress, and as real social capital from the viewpoint of biodiversity management (Ibisch \& Merida 2003).

The managers of 24 areas (out of 28) in the department of Santa Cruz, say it is now more difficult in general to work in conservation than it was 20 years ago. As we noted in the discussion of the situation of the PAs and their management responses by category and as we saw in the results, $80 \%$ of managers of national PAs, stated that conservation is more difficult now than it was 20 years ago and yet these responses are for the areas which were rated as less vulnerable. In the departmental PAs $87 \%$ of managers claimed that conservation work is more difficult now than 20 years ago. For municipal protected areas, those most vulnerable in their capacity to respond to impending climate change, $80 \%$ of the managers said conservation work was more difficult now than 20 years ago.

The results of the climate vulnerability index rating by subcriteria show that of 28 PAs, 5 have a "low" climate vulnerability rating, 2 have a "medium" climate vulnerability rating and the remaining 21 have a "high" climate vulnerability rating. The status and vulnerability of areas in the department of Santa Cruz is clear, and managers are making efforts to improve administration and address current challenges with respect to maintenance, preservation and conservation of biodiversity. At present (2014) in the department of Santa Cruz, DIAP is working through a local institution, Fundacion Amigos de la Naturaleza (FAN), to develop, among other initiatives, a Master Plan to strengthen the Departmental System of Protected Areas (SDAP) to strategically guide the management of protected areas to care for the natural heritage and ecosystem services of the department of Santa Cruz, Bolivia. 
According to Fuessel and Klein (2002), there has been a recent development of a variety of vulnerability assessments, which provide options for the climate change and risk management communities to join forces in reducing the vulnerability of societies to climate-related risks. 


\section{CONCLUSIONS}

Through this research, we have shown that conservation planning with a more specific approach to climate change is not easy, but is possible. It often requires the questioning of conventional conservation tools and strategies and the implementation of new, different and innovation practices. Incorporating adaptive capacity for addressing climate change in conservation planning will also likely represent a significant shift in the allocation of resources and the approach of conservation managers towards planning. It is needed to shift towards pragmatic strategic actions to cope with and adapt to climate change. To establish and meet planning standards related to climate change, large non-governmental organizations will probably have to require their managers to apply new methods and planning tools.

Under the framework of this research, after reviewing many conservation plans from different countries of the American continent, and the experience and results from our case study of a pilot extended CAP process which incorporated climate change, provide evidence that it is possible to include a climate change approach in conservation planning within Latin America, and particularly for protected areas of Bolivia. In addition we could measuring that is also possible to work with the institutional and technical capabilities of a conservation's team in a real experience in Bolivia, and rescue assess of the participant perceptions on the climate change issue, from their perspective.

The use of the extended CAP instruction manual in the local case study exercise ensured that participants followed the methodology step-by-step and guided the discussion and analysis of different topics, which might have appeared otherwise too complicated and complex. The proposed extended CAP process created a participatory experience for the planners by drawing them in to discussions about the concepts and definitions relative to climate change at each of the steps for the PA. Additionally, stakeholders developed a sense of ownership through the activities of selecting conservation targets to represent the biodiversity of the PA, rating the vulnerability, naming the risks and discussing the social context of the PA and conservation, etc. The extended CAP exercise is systematic and follows a logical sequence, allowing for a consistent approach throughout the planning process.

From the beginning, the planning exercise at the ANMI RG - VC tried to maintain an adaptive management approach, allowing for subsequent adjustments and adaptations of the initial ideas and proposals. Climate change and adaptation were recognized in the case study as cross-cutting themes, but a step-by-step process and guide was required and useful in order to consider these themes in a systematic and ordered manner.

The proposed methodology was well received by the institution (Fundacion Natura Bolivia) and the participants, and some of the overall results were included in the final Management Plan for the PA.

This local case study reflects some of the challenges in addressing the issue of climate change in biodiversity conservation. At the same time, it especially emphasizes the potential (of the institution and of the participants in general) for any planning framework which aims to address climate change adaptation, showing that such planning frameworks are necessary to develop conservation strategies which are effectively adaptable and feasible when properly carried out. 
Along with similar projects and experiences in other countries, this pilot activity contributed in some way, to the elaboration of the "MARISCO" methodology which is currently being used in some Latin American countries, among others.

Regarding perceived climate vulnerability, as a regional case study, the PA managers in the department of Santa Cruz have a general understanding about what climate change is and how to mitigate it through protected areas management. All managers reported observing some effects of climate change and with different levels of knowledge and action they are looking for ways to adapt their management for a changing climate. According to the survey answers, extreme weather events such as temporary flooding, droughts and forest fires have occurred with greater frequency and intensity in recent years in the PAs (particularly those in the Amazon).

In the department of Santa Cruz, there are adequate laws and regulations regarding the issue of climate change, but the results from our study on climate vulnerability, show that there is a large gap between theory and practice. The survey responses indicate that each PA manager/staff is working independently, with little or no government support or coordination, to develop conservation strategies to mitigate the environmental risks and threats associated with climate change. Our analysis shows that climate change in the protected areas management throughout to Bolivia is not yet a priority.

There is not an absolute rating of perceived climate vulnerability for the evaluated PAs. The ratings for each subcriteria can be interpreted separately or together, and lead to the development of a variety of adaptation strategies according to the degree of climate vulnerability and depending upon the sectors where the actions will be focused (climatic risks, environmental education, research, etc.). The results of the estimated climate vulnerability index should be interpreted in the context and scope of our objectives (in this study); Additional criteria could be used to do a specific analysis of a selected PA, depending on the data available for that PA.

There is an obvious disparity in the adaptive capacity of the national PAs compared to that of the municipal PAs. While the national areas allocate some funding towards protecting natural systems against climate change, the municipal areas have limited (or no) financial resources address the risks and threats associated with climate change.

Some of the biodiversity conservation professionals currently working in Bolivia and who have leadership roles in the protected areas of Santa Cruz are trained specialists with backgrounds in scientific field research or in flora and fauna species collections. Other PA leaders have education and experience in economics, policy or law. These demographic background factors of the survey respondents may have influenced their answers relative to how they each approach the issue of climate change in their PAs. Science in Bolivia is not (nor has been in the past) a government priority, wages are low and the working conditions for conservation professionals are difficult, especially in the field and in remote areas. Within the past 20 years in Bolivia there has been an increase in the education, training and job opportunities for conservation professionals working in biodiversity protection.

Biodiversity conservation activities directed to address climate change in both mitigation an adaptation actions- in the sense of management and administration of Pas- is still at an early stage 
and in the most cases there is not yet enough knowledge or understanding about the issue. The climate vulnerability of the PAs in our study is high in terms of administration and the ability to respond to current and expected climate changes in the department of Santa Cruz, Bolivia.

Factors such as lack of training by the PAs managers (referring to climate change), lack of expertise in environmental issues, etc., in addition to the pressure of time, and a fixed deadline for responding to the questionnaire may have influenced the quality and quantity of information the provided by the PA managers. The results of this diagnosis based in the approach that Pas managers gave in their answers, show us a few consideration on the climate change issue, and also a valuation of high climatic vulnerability perceived in the management for most of the areas evaluated.

There is no single solution or strategic planning guide to face the challenges posed by climate change. Through systematic evaluation, adjustment of priorities and common sense, PA managers and conservation professionals in the department of Santa Cruz, can come together in their efforts for conservation planning in response, at the beginning, with immediate short-term measures and then thinking in a long-term vision for the future, taking climate change into account.

With this study we aim to encourage conservation managers to adopt and share a proactive vision toward the process of planning and a managing protected area for biodiversity conservation in a manner which is systematic, documented, and considers climate change.

\section{RECOMMENDATIONS}

It is essential to expand conservation efforts beyond the boundaries of protected areas because the future composition, distribution and extent of present ecosystems and biomes could change. It is crucial to allow for adaptation to climate change in the protected areas of Latin America, especially given the global biological richness within these PAs. Additionally these PAs could suffer the greatest consequences and could be exposed to greater impacts from climate change due to the vulnerabilities associated with geographic and socio-economic pressures.

Urgent measures are needed to the decision makers (at all levels) to do efforts to continue researching and developing strategies increasingly holistic and multidisciplinary; including others researches (climatic and non ) but also on awareness, adequate monitoring systems and technical capacities, investments, integrated assessments across sectors (conservation, social, economic ) and assess the impacts of different policy options proposed to reduce vulnerability and / or increasing adaptive capacity, especially in the protected areas of Santa Cruz, Bolivia.

In conservation work, the adaptive approach should continually evolve and constantly improve with feedback from different experiences and data in order to meet the conservation challenges of different situations and realities according to the individual needs of each protected area.

Professional development activities and training regarding climate change should be provided to those responsible for meeting conservation goals and carrying out appropriate management practices of protected areas. With this training, PA staff and managers can propose and evaluate new opportunities and additional efforts for adaptation, in addition to the incorporation of the issue 
of climate change at all levels of education, both formal and informal, to make possible the development of human resources and sensitize the general public.

The existence of protected sites or proposals to create additional protected areas, are not sufficient for successful conservation without adequate and appropriate management practices, human and financial resources for administration of the protected area. The importance of conserving ecosystems through PAs is not limited to protecting wildlife but includes the provision of ecosystem services such as potable water, clean air, flood and erosion control and soil fertility, which are necessary to human populations, especially in developing countries with already high vulnerability in general and to climate change.

Advantageously, Bolivia and the department of Santa Cruz still have a high percentage of healthy ecosystems, which combined with increasingly specific and accessible biological data present conservation professionals with good opportunities for planning and practicing sustainable management for biodiversity conservation.

More effort and resources should be dedicated to 1) developing and supporting climate changerelated research projects in the protected areas of Santa Cruz, 2) training and development of PA staff, 3) disseminating and exchanging information and lessons learned, and 4) implementing tools systematization and learning collaborative.

Since climate change data (e.g. regional climate models, scenarios, etc.) there is not yet, or these are not accessible for the regions or PAs in our study, it is necessary to work within a framework of "uncertainty" throughout the planning process for these PAs and to use practices and approaches that permit quick responses and sound decision-making.

We hope that the results of this research serve to reorient the leadership and administration of both Protected Areas (DIAP) in the department of Santa Cruz and of the National Service of Protected Areas (SERNAP) and the greater conservation community. We hope that climate change will be considered in the approach and prioritization of actions for short, medium and long term conservation goals. The decision-makers for these PAs should promote a proactive, positive change in the conservation activities of their PA to go beyond basic research and begin to include on-theground management, adaptation, recommendations and environmental education. It is essential for the managers of PAs to participate more in education, research and monitoring.

Through this paradigm shift in the approach to conservation planning, it will be possible to address the threats of climate change. This shift must move toward plans and practices which focus on reducing climate vulnerability and incorporate adaptation measures which are appropriate to each local or regional situation for the management and conservation of biodiversity. 


\section{REFERENCES}

Acosta, L. \& H. Azurduy (2009): Nuevos registros y apuntes sobre la carachupa de agua Chironectes minimus, en los valles cruceños (Bolivia) Revista Kempffiana 5(1):83-89 ISSN: 19914652.

Aldous, A., P. Gonzalez \& K. Popper (2007): A method for incorporating climate change into Conservation Action Plans. The Nature Conservancy Global Climate Change Initiative. The Nature Conservancy of Oregon. Oregon.

Allen, CD. (2007): Cross-scale interactions among forest dieback, fire, and erosion in northern New Mexico landscapes. Ecosystems 10:797-808.

Andersen, L. \& R. Mamani (2009): Cambio Climático en Bolivia hasta 2100: Síntesis de Costos y Oportunidades. Proyecto "Estudio Regional de Economía del Cambio Climático en Sudamérica". La Paz.

Andrade, M. \& L.A. Blacutt (2010): Evaluación del modelo climático regional PRECIS para el área de Bolivia: Comparación con datos de superficie, en: Revista Boliviana de Física No.16, pp 1-12, Instituto de Investigaciones Físicas-Universidad Mayor de San Andrés. La Paz- Bolivia.

Aparicio, J. \& M. Ocampo (2010): Novedad zoogeográfica, Liolaemus Grupo Montanus Etheridge, 1995 (Iguania - Liolaemidae). En: Cuad. Herpetol., 24 (2): 133 - 135.

Araujo, N., R. Müller, C. Nowicki, C. \& P.L. Ibisch (eds.) (2010): Prioridades de Conservación de la Biodiversidad de Bolivia. SERNAP, FAN, TROPICO, CEP, NORDECO, GEF II, CI, TNC, WCS, Universidad de Eberswalde. Editorial FAN, Santa Cruz, Bolivia.

Araújo, M. (2009): Climate change and Spatial Conservation Planning. In Spatial Conservation Prioritization: quantitative methods and computational tools (eds.) A. Moilanen, H. Possingham, K. Wilson). Oxford University Press.

Araujo, N. \& P.L. Ibisch (eds.) (2000): Hacia un Plan de Conservación para el Bio-Corredor Amboró - Madidi, Bolivia. Editorial FAN, Santa Cruz de la Sierra, Bolivia (CD-ROM; ISBN 99905-801-7-0).

Archie, K., L. Dilling, J. Milford \& F. Pampel (2012): Climate change and western public lands: a survey of U.S. federal land managers on the status of adaptation efforts. Ecology and Society 17(4): 20. http://dx.doi.org/10.5751/ES-05187-170420.

Asquith N., M. T. Vargas \& S. Wunder (2008): Selling two environmental services: In-kind payments for bird habitat and watershed protection in Los Negros, Bolivia. Fundación Natura. Ecological Economics. ScienceDirect 65 . 675-684.

Bardwell, L. (1991): "Problem-Framing: A Perspective on Environmental Problem-Solving". Environmental Management Vol.15 No.5, pp. 603-612.

Baron, J., L. Gunderson, C. Allen, E. Fleishman, D. McKenzie, L. Meyerson, J. Oropeza \& N. Stephenson (2009): Options for national parks and reserves for adapting to climate change. Environmental Management. 44: 1033-1042. 
Barra de la F. (2011): Evaluación ecológica de los incendios en el norte amazónico de Bolivia. Componente: Base de datos geográfica histórica de focos de calor. Cobija - Bolivia.

Bernstein, L., et al. (2007): Climate Change. Synthesis Report. An Assessment of the Intergovernmental Panel on Climate Change. Report IPCC Plenary XXVII (Valencia, Spain, 12-17 November 2007), Working Group contributions to the Fourth Assessment Report.

Berrang-Ford L., J. Ford \& J. Paterson (2011): Are we adapting to climate change? Global Environmental Change 21:25-33.

Bezaury, C. J. \& L. Pabón (2009): Valuation of Environmental Goods and Services Provided by Mexico's Protected Areas. The Nature Conservancy-Programa de México-Comisión Nacional de Áreas Naturales Protegidas, México D.F. 32 pp.

Calder, I. R. (1998): "Water-Resource and Land-Use Issues". SWIM Paper 3. International Water Management Institute. Colombo. Sri Lanka.

Castro, M. (2012): La investigación estratégica, un aporte al desarrollo sostenible de las áreas protegidas. Tinkazos v.15 n.31 . ISSN 1990-7451. La Paz.

Convention on Biological Diversity (CBD) (2014): Article 2.Use of Terms. Marzo 2014. http://www.cbd.int/convention/articles/default.shtml?a=cbd-02.

Centro de Levantamientos Aeroespaciales y Aplicaciones SIG para el Desarrollo Sostenible de los Recursos Naturales (CLAS -UMSS) (2008): Producción hídrica y de sedimentos en la cuenca media del río Grande. Universidad Mayor de San Simón, Cochabamba. Para: Fundación NATURA, Santa Cruz, Bolivia.

CEPAL (2007): Alteraciones climáticas en Bolivia: impactos observados en el primer trimestre de 2007. Bolivia.

Chape, S., M. Spalding \& M. Jenkins (2008): The World's protected areas. Prepared by UNEP World Conservation Monitoring Centre. University of California Press, Berkleley, USA.

Chávez, V. (2006): Plan de Conservación de Sitio (PCA) de la Unidad de Conservación AmboróCarrasco. Bolivia. Consultoria para The Nature Conservancy, Bolivia (Document to internal use) Santa Cruz, Bolivia.

Chávez, V. (2004): Plan de Conservación de Sitio (PCA) del Parque Nacional Noel Kempff Mercado. Bolivia. Consultoria para The Nature Conservancy, Bolivia (Document to internal use) Santa Cruz, Bolivia.

Cherrett J. M. (1989): Ecological concept: the contribution of ecology to an understanding of a natural world. Blackwell, Oxford.

Cifuentes, M., A. Izurieta \& H. de Faria (2000): Measuring protected area management effectiveness. Technical Series No. 2. WWF, IUCN, GTZ, Costa Rica, 105 pp.

Climate Change Science Program (CCSP) (2008): Preliminary review of adaptation options for climate sensitive ecosystems and resources (SAP 4.4). U.S. Environmental Protection Agency, Washington, D.C., USA.

[online] URL: http://www. climatescience.gov/Library/sap/sap4-4/final-report/.Accessed November 2009. 
CMP (Conservation Measures Partnership) (2004): Open Standards for the Practice of Conservation (version 1.0) CMP: Washington DC. Available from: www.ConservationMeasures.org. Accessed May 2008.

CMP (Conservation Measures Partnership) (2007): The Open Standards for the Practice of Conservation. Version 2.0. Conservation Measures Partnership, Washington D.C. Available from http://conservationmeasures.org/CMP/Site_Docs/CMP_Open_Standards_ Version_2.0. pdf. Accessed December 2008.

CMP (Conservation Measures Partnership). Miradi (2007): Adaptive management software for conservation projects. https://miradi.org. Accessed June 2010.

CMP (Conservation Measures Partnership) (2010) The Conservation Measures Partnership http://www.conservationmeasures.org. Accessed June 2010.

Craig R., E. Game, G. Anderson, M. Cross, C. Enquist, Z. Ferdaña, E. Girvetz, A. Gondor, R. Hall, J. Higgins, R. Marshall, K. Popper, S. Schill \& S. Shafer (2012): Incorporating climate change into systematic conservation planning. Biodivers Conserv (2012) 21:1651-1671 DOI 10.1007/s10531012-0269-3.

DeFries R., A. Hansen, B. Turner, R. Reid \& J. Liu (2007): Land use change around protected areas: management to balance human needs and ecological function. Ecological Society of America. Ecological Applications, 17(4), 2007, pp. 1031-1038.

Del Milenio, Objetivos de Desarrollo (2008): "Informe". Naciones Unidas. Nueva York.

Diamond J. (1975): The island dilemma: lessons of modern biogeographic studies for the design of natural reserves. Biol. Conserv. 7: 129-146.

Dirección de Áreas Protegidas (DIAP)., Fundación Natura Bolivia., Centro para el Desarrollo Institucional Humano y Ecológico (2009): Plan de Manejo Área Natural de Manejo Integrado Río Grande Valles Cruceños. Santa Cruz, Bolivia.

Dudley, N, O. Maldonado \& S. Stolton (2007): Conservation Action Planning: A review of use and adaptation in protected area planning and management. The Nature Conservancy.

Dudley, N. (Editor) (2008): Guidelines for Applying Protected Area Management Categories. Gland, Switzerland: IUCN. $x+86 p p$. ISBN: 978-2-8317-1086-0.

Edwards, M., L. Brubaker, A. Lozhkin \& P. Anderson (2005): Structurally novel biomes: a response to past warming in Beringia. Ecology 86:1696-1703.

EUROPARC-España (2010): Lucio J., J. Atauri, M. Muñoz, M. Múgica \& J. Puertas. Herramientas para la evaluación de las áreas protegidas: modelo de memoria de gestión. Ed. Fundación Interuniversitaria Fernando González Bernáldez para los Espacios Naturales. Madrid. 121 páginas.

Fee, E., K. Gebert, J. Rust, K. Haggenmueller, H. Korn \& P.L. Ibisch (2009): Stuck in the clouds: bringing the CBD's Ecosystem Approach for conservation management down to Earth in Canada and Germany. Journal for Nature Conservation 17: 212-227. 
Ferdaña et al. (2010): Adapting to Climate Change, in Pérez, A., B. Herrera \& R. Cazzolla (eds.) (2010): Building Resilience to Climate Change: Ecosystem-based adaptation and lessons from the field. Gland, Switzerland: IUCN. 164pp.

Fernández, H. (2000): Zoogeografía aplicada: Conservación de la biodiversidad. FCN e IML Serie Monográfica y didáctica n0 16: 19 p. Argentina.

Feuerstein, R. (1986): Experiencias de Aprendizaje Mediado. Revista Siglo Cero. 106. España.

Field et al. (2014): Climate Change 2014: Impacts, Adaptation, and Vulnerability. Summary for policymakers. Approved SPM - Copyedit Pending IPCC WGII AR5 Summary for Policymakers. WGII AR5 Phase I Report Launch 131 March 2014, in IPCC (2014): http://www.ipcc.ch/report/ar5/wg2/. Accessed April 2014.

Fontúrbel, F. (2007): Las categorías mixtas de manejo en las áreas naturales protegidas de Bolivia: ¿Son responsables de la fragmentación del hábitat?. Nuevos paradigmas. Universidad de Los Lagos. Chile. Octubre. Revista Virtual REDESMA.

Ford, J., L. Berrang \& J. Paterson (2011): A systematic review of observed climate change adaptation in developed nations. Climatic Change Letters DOI:10.1007/s10584-011-0045-5.

Fuessel, H. \& R. Klein (2002): Evaluaciones de la vulnerabilidad y adaptación al cambio climático: una evolución del pensamiento conceptual. In: Programa de Naciones Unidas para el Desarrollo (PNUD) (2002): Un enfoque de manejo de riesgo climático para la reducción de desastres y adaptación al cambio climático. La Habana, PNUD; Caribbean Risk Managemente Initiative (CRMI), 2002. p.38-46, graf.

Geiger, L., S. Kreft, P.L. Ibisch (2012): Reducing blindspots: MARISCO, a planning approach that integrates risk management into biodiversity conservation. In: Ibisch, P.L., L. Geiger \& F. Cybulla (eds.): Global change management: knowledge gaps, blindspots and unknowables. Nomos, Baden Baden.

Geyer, J, I. Kiefer, S. Kreft, V. Chávez, N. Salafsky, F. Jeltsch \& P.L. Ibisch (2011): Classification of climate change-induced stresses on biological diversity. Conservation Biology, 25, no. doi: $10.1111 / \mathrm{j} .1523$ 1739.2011.01676.x.

Geyer, J., L. Strixner, S. Kretf, F. Jeltsch \& P.L. Ibisch (2014) (accepted in revision): Adapting conservation to climate change - a case study on feasibility and implementation in Brandenburg, Germany.

Glick, P., H. Chmura \& B.A. Stein (2011): Moving the conservation goalposts: A review of climate change adaptation literature. Washington, DC: National Wildlife Federation.

Granizo, Tarsicio et al. (2006): Manual de Planificación para la Conservación de Áreas, PCA. Quito: TNC y USAID.

Groves, C., L. Valutis, D. Vosick, B. Neely, K. Wheaton, J. Touval \& R. Runnels (2000): Diseño de una geografía de la esperanza. Manual para la planificación de la conservación ecorregional. The Nature Conservancy TNC, USA.

Guachalla, MCZOP \& J. Zegada (2001): Metodología medición de la efectividad del manejo del SNAP (MEMS). Ministerio de Desarrollo Sostenible, Servicio Nacional de Áreas Protegidas de Bolivia (SERNAP), La Paz, Bolivia. 
Guachalla, MCZOP., J. Zegada \& F. Cadima (2002): Metodología medición de la efectividad del manejo del SNAP (MEMS). Ministerio de Desarrollo Sostenible, Servicio Nacional de Áreas Protegidas de Bolivia (SERNAP), La Paz, Bolivia.

Hannah, L., G. Midgley, T. Lovejoy, W. Bond, M. Bush, J. Lovett, D. Scott, \& F. Woodward (2002): Conservation of biodiversity in a changing climate. Diversity. Conservation Biology, Volume $16 \mathrm{~N}^{\circ} 1$ : 264-268.

Hannah, L. (2008): Protected areas and climate change. New York Academy of Sciences. Ann. N.Y. Acad. Sci. 1134: 201-212 (2008). doi: 10.1196/annals.1439.009.

Hansen, L., J. Hoffman, C. Drews \& E. Mielbrecht (2010): Designing Climate-Smart Conservation: Guidance and Case Studies. Conservation Biology, 24: 63-69. doi: 10.1111/j.15231739.2009.01404.x.

Hansen, L., J. Biringer \& J. Hoffman (2003): Buying Time: A User's Manual for Building Resistance and Resilience to Climate Change in Natural Systems. 246. WWF. Available online from http://assets.panda.org/downloads/buyingtime_unfe.pdf.

Heller, N. \& E. Zavaleta (2009): Biodiversity management in the face of climate change: A review of 22 years of recommendations. Review. Science Direct. Biological Conservation 2009., 142: 1432.

Herzog, S., R. Martinez, P. Jorgensen \& H. Tiessen (eds.) (2012): Cambio climático y biodiversidad en los Andes tropicales. Instituto interamericano para la Investigacion del Cambio Global (IAI), Sao José dos Campos, y Comité Cientifico sobre Problemas del Medio Ambiente (SCOPE), Paris. 426 pp. ISBN: 978-85-99875-06-3.

Hockings, M., S. Stolton \& N. Dudley (2004): Management effectiveness: assessing management of protected areas? Journal of Environmental Policy and Planning 6:157-174.

Hockings, M., S. Stolton, F. Leverington, N. Dudley \& J. Courrau (2006): Evaluating effectiveness: A framework for assessing management effectiveness of protected areas. In Best practice protected area guidelines. Series No 14 (2nd edition). Gland, Cambridge: IUCN.

Hoffmann, D. (2010): El cambio climático y las áreas protegidas de Bolivia. In: Beck, S.G, N. Paniagua, R. P. López \& N. Nagashiro (eds.) (2010): Biodiversidad y Ecología en Bolivia Simposio de los 30 años del Instituto de Ecología. Instituto de Ecología, Universidad Mayor de San Andrés, La Paz. 700 p. (Pp. 618 - 627).

Hoffmann, D. \& D. Weggenmann (2011): Climate change induced glacier retreat and risk management. Glacial Lake Outburst Floods (GLOFs) in the Apolobamba mountain range, Bolivia, Worldwide online Climate Conference CLIMATE 2011 "Climate Change and Disaster Risk Management", 7 al 12 de noviembre de 2011, www.climate2011.net.

Hoffman, et al. (2012): Cambio Climático y Areas Protegidas en los Andes Tropicales. En: Herzog, S., R. Martinez, P. Jorgensen \& H. Tiessen (eds.) (2012): Cambio climático y biodiversidad en los Andes tropicales. Instituto interamericano para la Investigacion del Cambio Global (IAI), Sao José dos Campos, y Comité Cientifico sobre Problemas del Medio Ambiente (SCOPE), Paris. 426 pp. ISBN: 978-85-99875-06-3. 
Hoffmann D \& C. Requena (2012): Bolivia en un mundo 4 grados más caliente. Escenarios sociopolíticos ante el cambio climático para los anos 2030 y 2060 en el altiplano norte. La Paz: Instituto Boliviano de la Montana; Fundación PIEB, 2012. 168 p.; cuads.; grafs; maps: 23 cm. -(Serie Investigaciones Coeditadas) D.L.: 4-1-3224-12 ISBN: 978-99954-57-57-0: Encuadernado.

Hole D., R. Kenneth, A Seimon, C. Gomez, D. Hoffman, K. Schutze, S. Sanchez, D. Muchoney, R. Grau \& E. Ramirez (2012): Manejo Adaptativo para la Conservación de la Biodiversidad frente al Cambio Climatico_Perspectiva en los Andes Tropicales. In: Herzog, S., R. Martinez, P. Jorgensen \& H. Tiessen (eds.) (2012): Cambio climático y biodiversidad en los Andes tropicales. Washington: MacArthur Found, IAI, SCOPE.

Hole, D., B. Huntley, J. Arinaitwe, S. Butchart, Y. Collingham, L. Fishpool, D. Pain \& S. Willis (2011): Toward a Management Framework for Networks of Protected Areas in the Face of Climate Change. Conservation Biology, 25: 305-315. doi: 10.11 Seimon 11/j.1523-1739.2010.01633.x.

Holling, C. (ed.) (1978): Adaptive environmental assessment and management. Chichester: Wiley.

Hooper, D., et al. (2002): Species diversity, functional diversity and ecosystem functioning. In: Loreau, M., S. Naeem \& P. Inchausti (eds.) (2002): Biodiversity and ecosystem functioning: syntheses and perspectives. Oxford University Press, Oxford, UK.

Horstmann, B. (2006): Climate, Climate Variability and Climate Change in the Bolivian Andes, La Paz. Accessed 21 June 2010.

Hulme, M. (2009): Mapping climate change knowledge: an editorial essay. Wiley Interdisciplinary Reviews: Climate Change 1.

Hulme, M., et al. (2010): IPCC: Cherish it, tweak it or scrap it?. Nature 463:730-732.

Ibisch, P. L., K. Columba \& S. Reichle (eds.) (2002): Plan de Conservación y Desarrollo Sostenible para el Bosque Seco Chiquitano, Cerrado y Pantanal Boliviano. Editorial FAN, Santa Cruz, Bolivia.

Ibisch, P. L. \& G. Mérida (eds.) (2003): Biodiversidad: la Riqueza de Bolivia. Estado de conocimiento y conservación. Santa Cruz de la Sierra: Fundación Amigos de la Naturaleza.

Ibisch, P. L., S.G. Beck, B. Gerkmann \& A. Carretero (2003): La diversidad biologica. Ecoregiones y ecosistemas. En: Ibisch \& Merida (eds.) (2003): Biodiversidad: la Riqueza de Bolivia. Estado de conocimiento y conservación. Santa Cruz de la Sierra: Fundación Amigos de la Naturaleza.

Ibisch P. L. \& N. Araujo (2003): Conservación regional y corredores biológicos. En: Ibisch \& Merida (eds.) (2003): Biodiversidad: la Riqueza de Bolivia. Estado de conocimiento y conservación. Santa Cruz de la Sierra: Fundación Amigos de la Naturaleza.

Ibisch, P.L. \& M. Bertzky (2006): Halting biodiversity loss: fundamentals and trends of conservation science and action, in Biodiversity: Structure and Function, from Encyclopedia of Life Support Systems (EOLSS), Developed under the Auspices of the UNESCO, Eolss Publishers, Oxford ,UK, [http://www.eolss.net] [Retrieved February 28, 2006].

Ibisch, P.L. \& S. Kreft (2007): Las funciones y procesos bio-ecologicos, funcionalidad y servicios. En: Ibisch P.L., N. Araujo \& C. Nowicki (eds.) (2007): Vision de conservación de la biodiversidad del Corredor Amboro-Madidi. FAN-WWF-TNC-CI.Editorial FAN 141-143. 
Ibisch, P.L. \& S. Kreft (2008): Anpassung an den Klimawandel: eine systematische Analyse von Handlungsoptionen für den Naturschutz. ANLiegen Natur 32: 3-23.

Ibisch, P.L., B. Kunze \& S. Kreft (2009): Biodiversitätserhaltung in Zeiten des (Klima-) Wandels: Risikomanagement als Grundlage eines systemischen nichtwissenbasierten Naturschutzes. In: Ministerium für Infrastruktur und Landwirtschaft (MIL) des Landes Brandenburg, Landeskompetenzzentrum Forst Eberswalde (LFE) (Ed.) (2009): Wald im Klimawandel - Risiken un Anpassungsstrategien. Eberswalder Forstliche Schriftenreihe Band 42: 44-62.

Ibisch, P.L. \& A. Vega, T.M. Herrmann (eds.) (2010): Interdependence of biodiversity and development under global change. Technical Series No. 54. Secretariat of the Convention on Biological Diversity, Montreal (second corrected edition).

Ibisch, P.L. \& C. Nowicki (2012): Vulnerability analysis and strategies for climate change adaptation in the El Sira Community Reserve, Peru. Experiences using the methodology in the El Sira-GIZ project, Peru. Application of the method: Adaptive Risk and vulnerability Management at Conservation Sites (MARISCO) in the Peruvian Amazon. Ed.: Deutsche Gesellschaft für Internationale Zusammenarbeit (GIZ) $\mathrm{GmbH}$, Proyecto Biodiversidad y Cambio Climático en la Reserva Comunal "El Sira”, Lima, Peru.

Ibisch, P. L. \& P. R. Hobson (eds.) (2014): MARISCO. Adaptive MAnagement of vulnerability and RISk at COnservation sites. A guidebook for risk-robust, adaptive and ecosystem-based conservation of biodiversity. Centre for Econics and Ecosystem Management, Eberswalde (ISBN 978-3-00-043244-6).

IPCC (2007): Cambio climático: Informe de síntesis. Contribución de los Grupos de trabajo I, II y III al Cuarto Informe de evaluación del Grupo Intergubernamental de Expertos sobre el Cambio Climático [Equipo de redacciónprincipal: Pachauri, R.K. y Reisinger, A. (directores de la publicación)]. IPCC, Ginebra, Suiza.

IPCC (2013): Annex III: Glossary [Planton, S. (ed.)]. In: Climate Change 2013: The Physical Science Basis. Contribution of Working Group I to the Fifth Assessment Report of the Intergovernmental Panel on Climate Change [Stocker, T.F., D. Qin, G.-K. Plattner, M. Tignor, S.K. Allen, J. Boschung, A. Nauels, Y. Xia, V. Bex and P.M. Midgley (eds.)]. Cambridge University Press, Cambridge, United Kingdom and New York, NY, USA.

IPCC (2013a): Summary for Policymakers. In: Climate Change 2013: The Physical Science Basis. Contribution of Working Group I to the Fifth Assessment Report of the Intergovernmental Panel on Climate Change [Stocker, T.F., D. Qin, G.-K. Plattner, M. Tignor, S.K. Allen, J. Boschung, A. Nauels, Y. Xia, V. Bex and P.M. Midgley (eds.)]. Cambridge University Press, Cambridge, United Kingdom and New York, NY, USA.

Knowles, N., M. Dettinger \& D. Cayan (2006): Trends in snowfall versus rainfall in the Western United States. Journal of Climate 19:4545-4559.

Kramer, R., D. Richter, N. Sharma \& S. Pattanayak (1995): Ecological and economic analysis of watershed protection in eastern Madagascar. Durham, NC. School of Environment, Duke University.

Kreft, S., F. Tucci, M. Schluck, L. Strixner, I. van Ahee, M. Bienek, N. Linke \& P. L. Ibisch (2013): Indexbasierte Vulnerabilitätsabschätzung für Schutzgebiete und Ableitung von Handlungsoptionen. Pp. 177-216. In: Vohland, K., F. Badeck, K. Böhning-Gaese, G. Ellwanger, J. Hanspach, P.L. Ibisch, S. Klotz, S. Kreft, I. Kühn, E. Schröder, S. Trautmann \& W. Cramer (eds.) 
(2013): Schutzgebiete Deutschlands im Klimawandel - Risiken und Handlungsoptionen. Bundesamt für Naturschutz, Bonn. (Naturschutz und Biologische Vielfalt 129) 232 pp. (Includes a CD.).

Laurance, W., T. Lovejoy, H. Vasconcelos, E. Bruna, R. Didham, P. Stouffer, C. Gascon, R. Bierregaard, S. Laurance \& E. Sampiao (2002): Ecosystem decay of Amazonian forest fragments: a 22-year investigation. Conservation Biology 16:605-618.

Lawler, J. (2009): Climate Change Adaptation Strategies for Resource Management and Conservation Planning. Annals of the New York Academy of Sciences, 1162: 79-98. doi: 10.1111/j.1749-6632.2009.04147.x.

Le Tellier, V., A. Carrasco \& N. Asquith (2009): Attempts to determine the effects of forest cover on stream flow by direct hydrological measurements in Los Negros, Bolivia. Elsevier. Forest Ecology and Management. Volume 258, Issue 9, Pages 1881-1888.

Leary, N., J. Adejuwon, V. Barros, I. Burton, J. Kulkarni \& R. Lasco (eds.) (2008): Climate change and adaptation. London: Earthscan.

Lemieux, C. J. \& D. J. Scott (2011): Changing Climate, Challenging Choices: Identifying and Evaluating Climate Change Adaptation Options for Protected Areas Management in Ontario, Canada. Environmental Management (2011) 48:675-690. DOI 10.1007/s00267-011-9700-x.

Lemieux, C. J., T. T. Beechey \& P. A. Gray (2011): Prospects for Canada's protected areas in an era of rapid climate change. Land Use Policy. Volume 28, Issue 4, Pages 928-941.

Lemieux, C. J., T. J. Beechey, D. J. Scott \& P. A. Gray (2010): Protected areas and climate change in Canada: opportunities and challenges for adaptation. Canadian Council on Ecological Areas (CCEA) Technical Report No. 19. Canadian Council on Ecological Areas, Ottawa, Ontario, Canada.

Lemmen D.S., F. J. Warren \& J. Lacroix (2008): Synthesis. In: Lemmen D.S., F. J. Warren, J. Lacroix \& E. Bush (eds.): From impacts to adaptation: Canada in a changing climate 2007. Government of Canada, Ottawa, ON, pp 1-20.

Leverington F., M. Hockings, H. Pavese, C. Lemos \& J. Courrau (2008): 'Management Effectiveness evaluation in protected areas - a global study. Supplementary Report No1: Overview of approaches and methodologies.' The University of Queensland, Gatton, TNC, WWF, IUCNWCPA, Australia.

Loaiza, F. (2012): Sostenibilidad económica y financiera del sistema nacional de áreas protegidas. En: Ibisch \& Merida (eds.) (2003): Biodiversidad: la Riqueza de Bolivia. Estado de conocimiento y conservación. Santa Cruz de la Sierra: Fundación Amigos de la Naturaleza.

Loreau, M., N. Mouquet \& R.D. Holt (2003): Meta-ecosystems: a theoretical framework for a spatial ecosystem ecology. Ecology Letters 6, 673-679. [This contribution proposes the metaecosystem concept as a natural extension of the metapopulation and metacommunity concepts].

Maffei, L., E. Cuellar \& A. Noss (2004): One thousand jaguars (Panthera onca) in Bolivia's Chaco?. Camera trapping in the Kaa-Iya National Park. Journal of Zoology (Lond.) 262:295-304.

Magrin, G., C. Gay, D. Cruz, J.C. Giménez, A.R. Moreno, G.J. Nagy, C. Nobre \& A. Villamizar (2007): Latin America. Climate Change 2007. Impacts, Adaptation and Vulnerability. Contribution of Working Group II to the Fourth Assessment Report of the Intergovernmental Panel, on Climate 
Change, Parry, M. L., O. F. Canziani, J. P. Palutikof, P. J. van der Linden \& C. E. Hanson (eds.) Cambridge University Press, Cambridge, UK, 581-615.

March, I., H. Cabral \& Y. Echeverría (2010): Una Metodología para diseñar Estrategias y Planes de Acción orientados a la Adaptación al Cambio Climático para la Conservación de Biodiversidad, Ecosistemas y Servicios Ecosistémicos. TNC- Región México y Norte de Centroamérica.

Margoluis, R., \& N. Salafsky (1998): Measures of Success: designing, managing, and monitoring conservation and development projects. Washington, D.C: Island Press. ISBN 9781559636124.

Mawdsley, J., R. O’Malley \& D.S. Ojima (2009): A Review of Climate-Change Adaptation Strategies for Wildlife Management and Biodiversity Conservation. Conservation Biology, Volume 23, No. 5, 1080-1089. Society for Conservation Biology. DOI: 10.1111/j.1523-1739.2009.01264.x.

McCarthy, J., O. Canziani, N. Leary, D.J. Dokken \& K.S. White (eds.) (2001): Climate change 2001. Impacts, adaptation and vulnerability. IPCC Working Group II. - Cambridge (Cambridge University Press): 533-590.

McClanahan, T., J. Cinner, J. Maina, N. Graham, T. Daw, S. Stead, A. Wamukota, K. Brown, M. Ateweberhan, V. Venus \& N. Polunin (2008): Conservation action in a changing climate. Conservation Letters, 1: 53-59. doi: 10.1111/j.1755-263X.2008.00008_1.

McGray, H., A. Hammill \& R. Bradley (2007): Weathering the Storm. Options for Framing Adaptation and Development. World Resources Institute. All rights reserved. ISBN 978-1-56973672-2.

Meffe G., C. Caroll et al. (1999): Principles of conservation biology. 2nd Ed. Sinauer.

Mendoza, F. (2010): Las Áreas Protegidas en Bolivia, sobreposición de territorios, evolución de la normativa, la acción de las organizaciones sociales y la viabilidad de las APs. Fernando Mendoza. Étude de cas à dimensions multiples (ECADIM).

Ministerio de Planificación del Desarrollo (2007): Mecanismo Nacional de Adaptación al Cambio Climático. República de Bolivia.

Montaño, F. (2007): Fenologia reproductiva de murcielagos tropicales en Bolivia. Pp 23-27. In: Historia natural, distribucion y conservacion de los murcielagos en Bolivia, editado por L.F. Aguirre. Santa Cruz de la sierra: Editorial Centro de Ecologia y Difusion Simon I. Patiño.

Moyle, P. \& G. Sato (1991): On the design of preserves to protect native fishes. pp. 155-169 In: W. Minckley \& J. Deacon (eds.) (1991): Battle against extinction, native fish management in the American West. The University of Arizona Press, Tucson, Arizona.

Müller, R. (2005). A diagnostic analysis of the potential of 10 Boliviar watersheds for PES systems. Report to Fundacion Natura. Bolivia.IIED. Bolivia.

Müller, R., T. Pistorius, S. Rhode, G. Gerold \& P. Pacheco (2013): Policy options to reduce deforestation based on a systematic analysis of drivers and agents in lowland Bolivia. Land Use Policy, Vol.30,1, 895-907. 
Müller, R., P. Pacheco \& J. C. Montero (2014): El contexto de la deforestación y degradación de los bosques en Bolivia: Causas, actores e instituciones. Documentos Ocasionales 101. Bogor, Indonesia: CIFOR. ISBN 978-602-1504-29-1.

Navarro, G. \& M. Maldonado (2002): Geografía ecológica de Bolivia. Vegetación y ambientes acuáticos. Editorial: Centro de Ecología Simón I. Patiño-Departamento de Difusión. Cochabamba. Bolivia. ISBN: 99905-0-225-0.

Noss, R. (1990): Indicators for monitoring biodiversity: a hierarchical approach. Conservation Biology.44:355-364.

Noss, R. (2001): Beyond Kyoto: forest management in a time of rapid climate change. Conservation Biology: 578-590.

Ogden, A. \& J. Innes (2009): Application of Structured Decision Making to an Assessment of Climate Change Vulnerabilities and Adaptation Options for Sustainable Forest Management. Ecology \& Society. 2009, Vol. 14 Issue 1, p1-29. 29p.

Oxfam/Fundepco/NCCR (2008): Atlas de amenazas, vulnerabilidades y riesgos de Bolivia, La Paz, Oxfam/ Fundepco/NCCR.

Pabón, L., J. A. Peres \& C. Czerwenka (2002): Guía para la elaboración de planes de manejo para áreas protegidas de Bolivia. SERNAP-GTZ-MAPZA, La Paz.

Parmesan, C. (2006): Ecological and evolutionary responses to recent climate change. Annual Review of Ecology, Evolution and Systematics 37:637-669.

Parry, M.L., O.F. Canziani, J. P. Palutikof, P. J. Van Der Linden \& C.E. Hanson (eds.) (2007): Climate change 2007. Impacts, adaptation and vulnerability. Contribution of Working Group II to the Fourth Assessment Report of the Intergovernmental Panel on Climate Change. - Cambridge. Grosbritannien (Cambridge University Press): 982 S.

Pauchard, A., M. Aguayo \& P. Alaback (2006): Cuantificando la fragmentación del paisaje: las métricas y sus significados ecológicos. Pp 41-68. En: Grez, AA., J.A. Simonetti \& R.O. Bustamante (eds.) (2006): Biodiversidad en Ambientes Fragmentados de Chile: Patrones y Procesos a Diferentes Escalas. Editorial Universitaria, Santiago de Chile.

Peñarrieta, E. (2009): Escenarios de cambio climático para Bolivia. En: Memorias Taller Nacional Incorporación de la Gestión del Riesgo y/o Adaptación al Cambio Climático en el Sector Agropecuario La Paz, Bolivia. 22 pp.

Peters, R. \& J. Darling (1985): The greenhouse effect and nature reserves. BioScience, 35: 707717.

Peters, R. \& T. Lovejoy (1992): Global warming and biological diversity. Yale University Press. London.

Peters, R. \& J. Myers (1991): Preserving biodiversity in a changing climate. Issues Sci. Technol, 66-72.

Pidgeon, N. \& C. Butler (2009): Risk analysis and climate change. Environmental Politics. Issue 5, 2009, Pages 670 - 688. DOI: 10.1080/09644010903156976. 
Piepenstock, A. \& R. Maldonado (2011): Cambio climático y justicia - El tiempo ya no es como antes - Mapeo de actores, percepción y adaptación al cambio climático en áreas rurales de la región andina - Bolivia. Fundación AGRECOL Andes.

PIK (Potsdam Institut fur Klimafolgenforschung) (2003): Environmental Vulnerability Assessment (EVA). - URL: http://www.pik-potsdam.de/research/past/2001-2003/topik2/ va (letzter Zugriff: 4.8.2011).

PNCC (2007): El cambio climático en Bolivia (Análisis, síntesis de impactos y adaptación). Programa Nacional de Cambios Climáticos_PNCC. Ministerio de Planificación Del Desarrollo. Bolivia. La Paz, Bolivia.

PNCC (2010): Estrategia Nacional de Bosque y Cambio Climático. Programa Nacional de Cambios Climáticos_PNCC. La Paz - Bolivia.

PNUD (2010): América Latina y el Caribe es una superpotencia de biodiversidad. Copyright (C) UNDP 2010 Todos los derechos reservados. Producido en los EUA.

PNUD (2013): "El Impacto del Cambio Climático en la Biodiversidad (Bolivia)”. Avances en el conocimiento, de la serie "Tras las huellas del cambio climático en Bolivia". La Paz.

Poiani K., R. Goldman, J. Hobson, J. Hoekstra \& K. Nelson (2011): Redesigning biodiversity conservation projects for climate change: Examples from the field. Biodiversity and Conservation 20: $185-201$.

Programa de las Naciones Unidas para el Desarrollo (PNUD) (2011): Tras las huellas del cambio climático en Bolivia, estado del arte del conocimiento sobre adaptación al cambio climático agua y seguridad alimentaria. La Paz (BO).144 p.

PROMETA - Protección del Medio Ambiente (2009): Áreas protegidas Municipales, una realidad en Bolivia. Tarija.

Quiroga, D., N. Araujo, S. Espinoza \& D.M. Larrea-Alcázar (2011): Estudio de Identificación de Prioridades de Conservación para el Sistema Departamental de Áreas Protegidas (Proy. Fortalecimiento Gestión, Control, Monitoreo de Áreas Protegidas, Dpto. Santa Cruz). Informe Final de Consultoría. Gobierno Departamental Autónomo Santa Cruz, Santa Cruz de la Sierra, Bolivia, $174 \mathrm{p}$.

Quiroga, D., N. Araujo, S. Espinoza \& D.M. Larrea-Alcázar (2012): Prioridades de Conservación de la Biodiversidad del Departamento de Santa Cruz. Fundación Amigos de la Naturaleza (FAN), Dirección de Áreas Protegidas (DIAP), Secretaría de Desarrollo Sostenible y Medio Ambiente (SDSyMA) del Gobierno Departamental Autónomo de Santa Cruz, Editorial FAN, Santa Cruz de la Sierra, Bolivia.

Reyer, C., J. Bachinger, R. Bloch, F. Hattermann, P. L. Ibisch, S. Kreft, P. Lasch, W. Lucht, C. Nowicki, P. Spathelf, M. Stock, \& M. Welp (2012): Climate change adaptation and sustainable regional development: a case study for the Federal State of Brandenburg, Germany. Reg Environ Chang 12:523-542.

Richard, E., F.E. Fontúrbel \& G.A. García-Crispieri (2006): Evaluación de objetivos de conservación de áreas protegidas a partir del análisis del área de campeo y población mínima viable 
de especies de félidos y cánidos. El Parque Nacional Torotoro (Potosí, Bolivia) como ejemplo. Ecología Aplicada 5: 101-110.

Ríos B., D. Larrea, C. Seiler, S. Espinoza \& S. Cuellar (2013): Posibles escenarios de cambios climáticos en Bolivia: una comparación entre tres modelos de circulación climática y dos escenarios propuestos por el IPCC. Revista Boliviana de Ecología y Conservación Ambiental, Norteamérica. Disponible en:

<http://www.cedsip.org/rebeca/index.php/rebeca/article/view/14>. Fecha de acceso: 07 marzo 2014.

Rivero, B. \& M. Gabaldon (1992): The evaluation of natural protected area systems: a numeric method. Parks 3:11-13.

Robertson, N. \& S. Wunder (2005): Fresh tracks in the forest: assessing incipient payments for environmental services initiatives in Bolivia. CIFOR, Bogor, Indonesia, 2005. Natura.

Rouget, M., R. Cowling, L. Pressez \& M. Richardson (2003): Identifying the spatial components of ecological and evolutionarz processes for regional conservation planning in the Cape Floristic Region. Diversity and Distribution 9:191-210.

Ryan, M., S. Archer, R. Birdsey, C. Dahm, L. Heath, J. Hicke, D. Hollinger, T. Huxman, G. Okin, R. Oren, J. Randerson \& W. Schlesinger (2008): Land resources. Pages 75-120. In: The effects of climate change on agriculture, land resources, water resources, and biodiversity in the United States. Report by the U.S. Climate Change Science Program and the Subon Global Change Research. Washington, DC., USA.

Salafsky, N., et al. (2008): A standard lexicon for biodiversity conservation: unified classifications of threats and actions. Conservation Biology 22:897-911.

Salamanca, L. (2008): Propuesta técnica Bolivia VI Plan de acción DIPECHO: La Paz Salinas E. 2007.Conflictos ambientales en áreas protegidas de Bolivia. Programa de Conservación del Gran Paisaje Madidi. Wildlife Conservation Society (WCS).

Salzer, D. \& N. Salafsky (2006): Allocating resources between taking action, assessing status, and measuring effectiveness of conservation actions. Natural Areas Journal 26: 310-316. doi:10.3375/0885 8608(2006)26[310:ARBTAA]2.0.CO:2.

Samaniego, J. (2009): Cambio climático y desarrollo en América Latina y el Caribe: una reseña. Comisión Económica para América Latina y el Caribe (CEPAL). LC/W.232. Copyright @ Naciones Unidas.

Sandwith, T. (2008): Protected areas and climate turnaroun strategy (PACT)-an insurance policy for the world's gratest risk. Policy Matters 16:119-126.

Schwartz, M., K. Deiner, T. Forrester, P. Grof-Tisza, M. Muir, M. Santos, L. Souza, M. Wilkerson \& M. Zylberberg (2012): Perspectives on the Open Standards for the Practice of Conservation. Biological Conservation 155: 169-177.

Scott, D. \& C. Lemieux (2007): Climate change and protected areas policy, planning and management in Canada's boreal forest The Forestry Chronicle, 2007, Vol. 83, No. 3 : pp. 347-357 (doi: 10.5558/tfc83347-3. 
Seiler, C. (2009): Implementation and validation of a RCM for Bolivia. Fundacion Amigos de la Naturaleza(FAN)-Bolivia. Santa Cruz.

Seiler, C. \& A. Moene (2011): Estimating Actual Evapotranspiration from Satellite and Meteorological Data in Central Bolivia. Earth Interact., 15, 1-24. doi: http://dx.doi.org/10.1175/2010EI332.1.

Seiler, C., R. Hutjes \& P. Kabat (2013): Likely Ranges of Climate Change in Bolivia. J. Appl. Meteor. Climatol., 52, 1303-1317. doi: http://dx.doi.org/10.1175/JAMC-D-12-0224.1.

Seiler, C., et al. (2014): Modeling forest dynamics along climate gradients in Bolivia, J. Geophys. Res. Biogeosci., 119, doi: 10.1002/2013JG002509.

SERNAP (2001): Sistema Nacional de Áreas Protegidas de Bolivia. Información técnica. Ministerio de Desarrollo Sostenible y Planificación. Servicio Nacional de Áreas Protegidas. La Paz.

SERNAP (2007): Bolivia. Informe sobre el Sistema Nacional de Áreas Protegidas. II Congreso Latinoamericano de Parques Nacionales y otras Áreas Protegidas. Bariloche. 89 p.

SERNAP (2013): Deforestación y regeneración de bosques en Bolivia y en sus áreas protegidas nacionales para los periodos 1990-2000 y 2000-2010. (ed.). Servicio Nacional de Áreas Protegidas (SERNAP), Museo de Historia Natural Noel Kempff Mercado y Conservación Internacional Bolivia. La Paz, Bolivia. 36 pp.

Smith, R. \& T. Smith (2001): Ecología. 4 edición, Ed. Addison-Wesley, Madrid, pp 319-322, $442-587$.

Stein, B., A. Staudt, M. Cross, N. Dubois, C. Enquist, R. Griffis, L. Hansen, J. Hellmann, J. Lawler, E. Nelson \& A. Pairis (2013): Preparing for and managing change: climate adaptation for biodiversity and ecosystems. Front Ecol Environ 2013; 11(9): 502-510, doi:10.1890/120277.

Stocker, T., et al. (2013): Technical Summary. In: Climate Change (2013): The Physical Science Basis. Contribution of Working Group I to the Fifth Assessment Report of the Intergovernmental Panel on Climate Change [Stocker, T., D. Qin, G.-K. Plattner, M. Tignor, S. Allen, J. Boschung, A. Nauels, Y. Xia, V. Bex \& P. Midgley (eds.)]. Cambridge University Press, Cambridge, United Kingdom and New York, NY, USA.

Swaffield, S. (1998): Frames of reference: a metaphor for analyzing and interpreting attitudes of environmental policy makers and policy influencers. Environmental Management 22, 4: 495-504.

The Nature Conservancy (TNC) (1996): Conservation by design: A Framework for mission success.

The Nature Conservancy (TNC) (1998): Implementing conservation by design: A strategic focus for the next 10 years" (1998).

The Nature Conservancy (TNC) (2000): Esquema de las cinco S para la conservación de Sitios. 2da Edición. TNC, Washington.

The Nature Conservancy (TNC) (2003): The five-S framework for site conservation: A practitioner's handbook for site conservation planning and measuring conservation success (C) 2003 by The Nature Conservancy. 
The Nature Conservancy (TNC) (2007): Conservation Action Planning Handbook: Developing Strategies, Taking Action and Measuring Success at Any Scale. The Nature Conservancy, Arlington, VA.

The Nature Conservancy (TNC) (2008): The conservation project database (ConPro). [WWW document] URL http://conserveonline.org/workspaces/ConPro (accessed 2007-2008-2009).

Thomas, C. \& W. Kunin (1999): The spatial structure of populations._J. Anim. Ecol. 68: 647_657.

Thuiller, W., C. Albert, M. Araujo, P. Berry, M. Cabeza, A. Guisan, T. Hickler, G. Midgely, J. Paterson, M. Schurr, M. Sykes \& E. Zimmermann (2008): Predicting global change impacts on plant species distributions: future challenges. Perspectives in Plant Ecology Evolution and Systematics 9:137-152.

UNEP-WCMC (2008): State of the world's protected areas: an annual review of global conservation progress. UNEP-WCMC, Cambridge.

Urioste, A. (2010): Deforestación en Bolivia una amenaza mayor al cambio climático. Documento de Trabajo. Foro de desarrollo y democracia. Departamento de Biocomercio Sostenible . Fundación Amigos de la Naturaleza - Bolivia.

Urrutia, R. \& M.Vuille (2009): "Climate change projections for the tropical Andes using a regional climate model: Temperature and precipitation simulations for the end of the 21 st century", en Journal of Geophysical Research, vol. 114.

Welch, D. (2005): What should protected area managers do in the face of climate change?. George Wright Forum, 22: 75-93.

West, J., S. Julius, P. Kareiva, C. Enquist, J. Lawler, B. Petersen, A. Johnson \& M. Shaw (2009): U.S. natural resources and climate change: Concepts and approaches for management adaptation. Environmental Management 44: 1001-1021.

Williams, J., S. Jackson \& J. Kutzbach (2007): Projected distributions of novel and disappearing climates by 2100AD. Proceedings of the National Academy of Sciences 104: 5738-5742.

Zambrana, G. \& C. Silva (2008): Las áreas de conservación comunitarias en el marco de las políticas públicas en Bolivia. 
ANNEX 


\section{Annex 1. Photographs Protected areas of Santa Cruz, Bolivia. Examples ${ }^{3}$}

\section{Category National (N), Departmental (D), Municipal (M)}

1.Wildlife Municipal Reserve Laguna Concepción (M); 2.Reserve Copaibo (M); 3.National Park (NP) Noel Kempff Mercado (N); 4.NP and Natural Area of Integral Management (NAIM) Amboró (N); 5.Regional Park Lomas de Arena (D); 6.Tucavaca Wildlife Reserve (D); 7.8.9 (Parajubaea sunkha) NAIM Rio Grande Valles Cruceños (D); 10.PN NAIM Kaa Iya (N) (Panthera onca).11.Orquídeas del Encanto (M) (Cattleya nobilior).

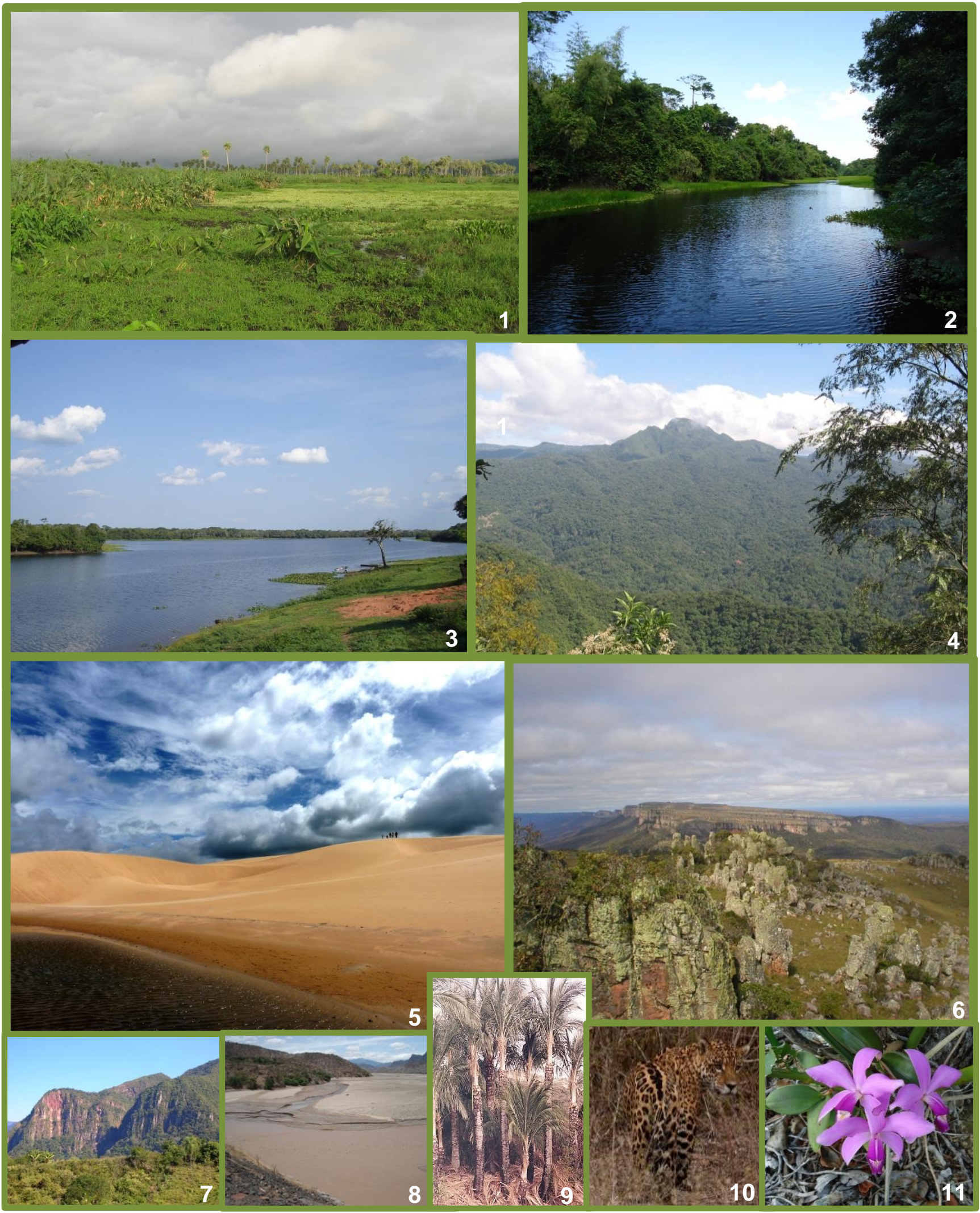

${ }^{3}$ Photos: 1,2,3,4,6, 11. F. Del Águila; 5. Regional Park Lomas de Arena; 7,8,9 Fundación Natura; 10.Kaa Iya National Park 
Annex 2. List of Conservation Projects from The Nature Conservancy's (TNC) ConPro database and other protected areas documents relating to the pre-2009 Conservation Action Plans (CAP)

\begin{tabular}{|c|c|c|c|}
\hline & Protected Area & $\begin{array}{c}\text { Effective date of } \\
\text { CAP data } \\
\text { (dd-mm-yr) }\end{array}$ & $\begin{array}{l}\text { No. CAP's } \\
\text { by country }\end{array}$ \\
\hline 1 & Altamachi-Cotacajes (Bolivia) & 2003 & \multirow{7}{*}{7} \\
\hline 2 & Noel Kempff Mercado National Park (Bolivia) & 2002 & \\
\hline 3 & $\begin{array}{l}\text { Aguarague Park and Integrated Management Natural Area } \\
\text { (Bolivia) }\end{array}$ & 1997 & \\
\hline 4 & Eduardo Avaroa Andean Fauna National Reserve (Bolivia) & 2006 & \\
\hline 5 & $\begin{array}{l}\text { Río Grande and Santa Cruz Valleys Departmental Integrated } \\
\text { Management Natural Area (Bolivia) }\end{array}$ & 2008 & \\
\hline 6 & $\begin{array}{l}\text { Tariquia Flora and Fauna Reserve } \\
\text { (Bolivia) }\end{array}$ & 2007 & \\
\hline 7 & Amboró-Carrasco Conservation Unit (Bolivia) & $16-05-2002$ & \\
\hline 8 & Araucaria (Brazil) & 04-01-2005 & \multirow{4}{*}{4} \\
\hline 9 & Cuiaba watershed conservation program (Brazil) & $05-01-2005$ & \\
\hline 10 & Pantanal (Brazil) & $15-01-2002$ & \\
\hline 11 & National Park das Emas e Arredores (Brazil) & $07-12-2001$ & \\
\hline 12 & Punta Curinanco (Chile) & $05-03-2003$ & \multirow{2}{*}{2} \\
\hline 13 & Valdivian Coast Reserve (Chile) & $01-08-2005$ & \\
\hline 14 & $\begin{array}{l}\text { Andean Conservation Corridor-Guantiva-La Rusia-Iguaque } \\
\text { (Colombia) }\end{array}$ & 23-07-2004 & \multirow{3}{*}{3} \\
\hline 15 & Llanos (Colombia) & $07-02-2005$ & \\
\hline 16 & Sierra Nevada Santa Marta (Colombia) & 07-03-2005 & \\
\hline 17 & Coast Cordillera Dry Forests (Ecuador) & $24-12-2009$ & \multirow{4}{*}{4} \\
\hline 18 & Podocarpus Nacional Park (Ecuador) & $01-02-2002$ & \\
\hline 19 & El Cóndor Reserve (Ecuador) & $15-01-2005$ & \\
\hline 20 & Chimborazo Wildlife (faunística) Reserve (Ecuador) & $02-06-2005$ & \\
\hline 21 & Sandy Island/Oyster Bed Marine Protected Area (Granada) & $01-09-2001$ & 1 \\
\hline 22 & Amistad (Guatemala) & 2005 & \multirow{14}{*}{14} \\
\hline 23 & $\begin{array}{l}\text { Atitlan Volcanoes. Economic-productive Conservation Action Plan } \\
\text { (CAP) (Guatemala) }\end{array}$ & 2008 & \\
\hline 24 & $\begin{array}{l}\text { Atitlan Volcanoes Site (Atitlan lake, watershed Multiple Use } \\
\text { Reserve Natural Conservation Action Plan (CAP) (Guatemala) }\end{array}$ & 2005 & \\
\hline 25 & Buenos Aires Private Natural Reserve (Guatemala) & 2004 & \\
\hline 26 & $\begin{array}{l}\text { Cerro San Gil, Natural Reserve (Reserva Protectora de } \\
\text { Manantiales) (Guatemala) }\end{array}$ & $13-10-2005$ & \\
\hline 27 & El Retiro (Guatemala) & 2004 & \\
\hline 28 & Motagua (Guatemala) & 01-04-2005 & \\
\hline 29 & Izabal lake Watershed (Guatemala) & $01-11-2005$ & \\
\hline 30 & Protected Areas of Southwestern Petén. Master Plan. (Guatemala) & 2008 & \\
\hline 31 & Wildlife Refuge Punta de Manabique. Master Plan (Guatemala) & $15-01-2004$ & \\
\hline 32 & $\begin{array}{l}\text { Natural Private Reserve San Jerónimo Miramar and Quixayá } \\
\text { (Guatemala) }\end{array}$ & 2003 & \\
\hline 33 & Sierra del Lacandón Natural National Park (Guatemala) & $03-10-2004$ & \\
\hline 34 & Tikal Natural National Park (Guatemala) & $08-08-2002$ & \\
\hline 35 & Yaxha-Nakum-Naranjo Natural National Park (Guatemala) & $15-03-2005$ & \\
\hline 36 & Cockpit Country (Jamaica) & $01-08-2005$ & 1 \\
\hline 37 & Akumal Tulum (Mexico) & No data & \multirow{3}{*}{18} \\
\hline 38 & National Park Bahia de Loreto (Mexico) & $15-01-2003$ & \\
\hline 39 & Bahia de San Quintin (Mexico) & $15-03-2007$ & \\
\hline
\end{tabular}




\begin{tabular}{|c|c|c|c|}
\hline 40 & Bahia Magdalena (Mexico) & $15-07-2008$ & \\
\hline 41 & Chiapas Coastal Watersheds (Mexico) & $15-01-2004$ & \\
\hline 42 & San Cosme- El Mechudo, corridor (Mexico) & $15-10-2005$ & \\
\hline 43 & Veracruz Coast - Central (Mexico) & 09-09-2004 & \\
\hline 44 & Cuatro Cienagas (Mexico) & $15-06-2002$ & \\
\hline 45 & Coatzacoalcos Wetlands (Mexico) & $15-05-2004$ & \\
\hline 46 & La Sepultura, Lagartero river basin Chiapas, (Mexico) & $15-01-2004$ & \\
\hline 47 & La Soledad, Natural pastures (Mexico) & $15-09-2005$ & \\
\hline 48 & Mayan Mosaic (Mexico) & 2009 & \\
\hline 49 & Centla Marshes and Términos Lagoon (Mexico) & $01-12-2004$ & \\
\hline 50 & National Park Arrecife Alacranes (Mexico) & $15-09-2008$ & \\
\hline 51 & San Pedro Watershed in Sonora (Mexico) & $15-05-2007$ & \\
\hline 52 & Sian Ka'an Platform Site (Mexico) & $15-06-2008$ & \\
\hline 53 & Sierra San Luis Sonora (Mexico) & $15-06-2008$ & \\
\hline 54 & Yucatan Northeast area (Mexico) & $15-03-2007$ & \\
\hline 55 & Bosawas (Nicaragua) & 2004 & 1 \\
\hline 56 & Upper Chagres 2003 (Panama) & 2003 & \\
\hline 57 & Western Pacific (Panama) & 2009 & 3 \\
\hline 58 & Upper Chagres 2007 (Panama) & 2007 & \\
\hline 59 & Central Selva Protection Area (Peru) & $15-06-2005$ & \\
\hline 60 & Pacaya-Samiria (Peru) & $15-01-2005$ & 3 \\
\hline 61 & Paracas National Reserve (Peru) & $01-07-2003$ & \\
\hline 62 & $\begin{array}{l}\text { Mesoamerican reef: Mexico, Belize, Guatemala, Honduras } \\
\text { (Regional) }\end{array}$ & $15-09-2006$ & \\
\hline 63 & $\begin{array}{l}\text { Atlantic Forest Restoration and Conservation Brazil Paraguay } \\
\text { Argentina (Regional) }\end{array}$ & 01-01-2005 & 4 \\
\hline 64 & Janos Grasslands, Mexico, USA (Regional) & $30-06-2005$ & \\
\hline 65 & National Park Serra do Divisor, Peru and Brasil (Regional) & $01-11-2000$ & \\
\hline 66 & $\begin{array}{l}\text { Del Este National Park - Terrestrial-Coastal Systems (Dominican } \\
\text { Republic) }\end{array}$ & $05-10-2006$ & 2 \\
\hline 67 & National Park Juan Bautista Pérez Rancier (Dominican Republic) & $1999-2006$ & \\
\hline 68 & Altamaha Coastal Marine, Georgia (USA) & $15-02-2007$ & \multirow{22}{*}{36} \\
\hline 69 & Arbuckle Plain Blue River, Oklahoma (USA) & $2000-2004$ & \\
\hline 70 & Boone River, Iowa(USA) & $2004-2007$ & \\
\hline 71 & Delaware River Basin Program, New York (USA) & $10-02-2005$ & \\
\hline 72 & Duck and Buffalo Rivers, Tennesse (USA) & $05-12-2005$ & \\
\hline 73 & East Mississippi Sound, Mississippi (USA) & 08-03-2005 & \\
\hline 74 & Everglades/South Florida Ecosystems, Florida (USA) & $12-04-2004$ & \\
\hline 75 & Grand Bay Banks Lake, Georgia (USA) & $15-08-2006$ & \\
\hline 76 & Grand River Watershed, Ohio (USA) & $10-06-2005$ & \\
\hline 77 & Grand Rivers Corridor, Kentucky (USA) & $26-09-2005$ & \\
\hline 78 & Great Bay Estuarine System, New Hampshire (USA) & $15-03-2007$ & \\
\hline 79 & Great Sand Dunes, Colorado (USA) & $01-10-2005$ & \\
\hline 80 & Ka'u Hawaii, Hawaii (USA) & $01-05-2004$ & \\
\hline 81 & Kennebec River and Estuary Project, Maine (USA) & $07-06-2004$ & \\
\hline 82 & Laguna Madre, Texas (USA) & $15-07-2008$ & \\
\hline 83 & Lake Alexander Landscape, Minnesota (USA) & 15-06-2007 & \\
\hline 84 & Laramie Foothills Laramie Foothills, Colorado (USA) & 2004 & \\
\hline 85 & Little Miami River Watershed, Ohio (USA) & 2006 & \\
\hline 86 & Long Island Central Pine Barrens, New York (USA) & 09-04-2006 & \\
\hline 87 & Longleaf Ridge, Texas (USA) & $01-05-2002$ & \\
\hline 88 & Lower Missouri River (USA) & 2005 & \\
\hline 89 & Massachusetts Military Reservation, Massachusetts (USA) & 04-10-2004 & \\
\hline
\end{tabular}


Maunalua Bay, Island of O`ahu, Hawaii (USA)

0-10-2005

Mid Atlantic Seascape - ILT Version with Nearshore Targets,

15-02-2008

$91 \quad$ Virginia (USA)

92 New Jersey Pine Barrens, New Jersey (USA) $04-12-2004$

$93 \quad$ Northern Lake Huron, Michigan (USA) 15-01-2009

94 Ocala-Wekiva, Florida (USA) 15-05-2004

95 Paw paw River, Michigan (USA) 2005

$96 \quad$ Roanoke River, North Carolina (USA) 2006

97 Roaring Fork Watershed, Colorado (USA) 15-07-2007

98 San Miguel/Lower Dolores River Project, Colorado (USA) 15-12-2004

99 Snake Range and Spring Valley, Nevada (USA) 2004

100 Taunton River watershed, Massachusset (USA) 01-09-2004

101 Waianae Conservation Area (Island of O`ahu, Hawaii (USA) 15-04-2005

102 Yampa River - Upper, Colorado (USA) 15-12-2004

103 Zumwalt Prairie Conservation Area, Oregon (USA) 22-04-2005 
Annex 3. List of Conservation Projects (ConPro) data base from The Nature Conservancy (TNC) and other protected areas documents relating to the post-2009 Conservation Action Plans (CAP) analysed in the study.

*This project information could not be shared outside of TNC organization

\begin{tabular}{|c|c|c|c|c|c|}
\hline & Protected Area & $\begin{array}{c}\text { Effective } \\
\text { date of CAP } \\
\text { data } \\
\text { (dd-mm-yy) }\end{array}$ & $\begin{array}{l}\text { No. CAP's } \\
\text { by } \\
\text { country }\end{array}$ & Update & $\begin{array}{l}\text { Sharing } \\
\text { Status }\end{array}$ \\
\hline 1 & $\begin{array}{l}\text { Patagonian Grasslands of Argentina } \\
\text { (Argentina) }\end{array}$ & 20-01-2009 & 1 & & $*$ \\
\hline 2 & $\begin{array}{l}\text { Reducing Emissions from } \\
\text { Deforestation and forest Degradation } \\
\text { (REDD) CORE Strategy (Brazil) }\end{array}$ & $0-12-2010$ & 1 & & $*$ \\
\hline 3 & $\begin{array}{l}\text { Pacific Salmon Ecosystems (Canada- } \\
\text { USA) }\end{array}$ & 01-10-2008 & & & $*$ \\
\hline 4 & $\begin{array}{l}\text { Western Lake Erie Basin (Canada- } \\
\text { USA) }\end{array}$ & 03-12-2009 & 2 & & $*$ \\
\hline 5 & Forever Costa Rica (Costa Rica) & 07-08-2009 & 1 & & $*$ \\
\hline 6 & Cerro Nambiyugua (Mexico) & 19-04-2010 & 2 & $\begin{array}{l}\text { Project last modified by } \\
\text { clasch on July } 08,2010 .\end{array}$ & Public \\
\hline 7 & Sierra Juarez (Mexico) & $30-09-2008$ & & & $*$ \\
\hline 8 & $\begin{array}{l}\text { Calakmul-Balam Kin-Balam Ku } \\
\text { (Fauna) (Mexico and Central america) }\end{array}$ & $15-12-2010$ & 1 & $\begin{array}{l}\text { Project last modified by } \\
\text { clasch on March 24, } 2010\end{array}$ & Public \\
\hline 9 & $\begin{array}{l}\text { East Maui Watershed area, Hawaii } \\
\text { (USA) }\end{array}$ & 03-05-2010 & & $\begin{array}{l}\text { Project last modified by } \\
\text { dsalzer on July } 26,2010 .\end{array}$ & Public \\
\hline 10 & $\begin{array}{l}\text { Horse Creek Conservation Area, } \\
\text { Colorado (USA) }\end{array}$ & $15-08-2010$ & & $\begin{array}{l}\text { Project last modified by } \\
\text { tschulz on September 15, } \\
\text { 2010. Project Created By: } \\
\text { The Nature Conservancy. }\end{array}$ & Public \\
\hline 11 & Little Sioux, Iowa (USA) & $22-06-2009$ & & & $*$ \\
\hline 12 & $\begin{array}{l}\text { Lower Meramec River, Missouri } \\
\text { (USA) }\end{array}$ & $15-06-2010$ & & & $*$ \\
\hline 13 & $\begin{array}{l}\text { Presque Isle Shoreline, Michigan } \\
\text { (USA) }\end{array}$ & $05-06-2008$ & & & $*$ \\
\hline 14 & Raccoon Creek, Georgia (USA) & 09-12-2010 & & $\begin{array}{l}\text { Project last modified by } \\
\text { sgottlieb on December 09, } \\
2010\end{array}$ & Public \\
\hline 15 & $\begin{array}{l}\text { Salmon River Conservation Action } \\
\text { Plan, Oregon (USA) }\end{array}$ & 2010 & 14 & $\begin{array}{l}\text { Project last modified by } \\
\text { dsalzer on August 16, } 2010 . \\
\text { Project Created By: The } \\
\text { Nature Conservancy }\end{array}$ & Public \\
\hline 16 & St. Marys River, Michigan (USA) & 16-04- 2009 & & & $*$ \\
\hline 17 & Table Rocks, Oregon(USA) & $15-05-2010$ & & & $*$ \\
\hline 18 & $\begin{array}{l}\text { Tallgrass Aspen Parkland, Minnesota } \\
\text { (USA and Canada) }\end{array}$ & $\begin{array}{l}\text { Project Start } \\
\text { Date } \\
15-12-2005 \\
\end{array}$ & & $\begin{array}{l}\text { Project last modified by } \\
\text { mcornett on July 20, } 2011\end{array}$ & Public \\
\hline 19 & Tehachapi, California (USA) & $15-05-2009$ & & & $*$ \\
\hline 20 & $\begin{array}{l}\text { Tri-State Bear River, Utah and } \\
\text { Wyoming (USA) }\end{array}$ & 15-01-2009 & & & $*$ \\
\hline 21 & $\begin{array}{l}\text { Upper Conasauga River Watershed, } \\
\text { Georgia and Tennessee (USA) }\end{array}$ & 11-03-2009 & & & $*$ \\
\hline 22 & $\begin{array}{l}\text { Verde River - Verde Valley Reach, } \\
\text { Arizona (USA) }\end{array}$ & 15-09-2008 & & & $*$ \\
\hline
\end{tabular}




\section{4) Dry forest}

Relative to other ecoregions and natural features of the area:

Quality of community type: The plant communities of these dry forests are generally well preserved and relatively undisturbed (by livestock or human activities). There are medicinal plants and wildlife. The main municipalities in the ANMI are Moro Moro and Pucara including the communities of San Lorenzo, Pampillas, Peñones, Mizque, Zapallar, El Cerro, El Estanque and others (see distribution map).

Geographic distribution: Although the area covered by dry forest in the IMNA is not extensive (see map), protection is a high priority, since no other protected area in Bolivia preserves these types of forest (Xeric and dry) and these forests are only exist in parts of the departments of Santa Cruz, Chuquisaca and Cochabamba.

Overall, the dry forest is in good condition, although the northern area is more fragmented. Within the landscape context and the spatial patterns of this Spatial Ecology Unit (SEU), there is not a lot of agriculture and livestock. The human settlements within the ANMI are small communities located in humid areas, not in areas of dry forest. There is little human pressure on the diversity of the forests, only collection of firewood in small quantities. Protection of dry forest will protect watersheds in dispersed throughout the ANMI.

This is an area of relative ecological importance as habitat for characteristic species of xeric forest including endemic cactus and plants for traditional medicine.

The area has a high conservation value in terms of biodiversity and endemism. The presence of endemic mammals, like the bat Phyllotis wolffsohni in the dry valleys, is important as they are distributed in areas of high conservation value around Mizque and Santa Rosa. Promoting and maintaining corridors between these two areas is essential. More than 44 species of cacti are known from the dry forests of the ANMI and more are expected to be discovered.

The following endemic plant species are known from the dry forests: Cardenasiodendron brachypterum, Espostoa guentherii, Loxopterigium grisebachii, Neocardenasia herzogiana, Parajubaea sunkha, Podocarpus parlatorei, Samaipaticereus corroanus, Schinopsis haenkeana. (Fundación Natura 2008)

One of the most important conservation targets is the red-fronted macaw (Ara rubrogenys) which is endemic to these valleys and nests in the ANMI RG-VC. It is listed as CITES I and as "Endangered" under IUCN.

The range of the military macaw (Ara militaris) is within these dry forests. This bird is also listed as CITES I and as "Threatened" by IUCN. Several individuals of the Andean condor (Vultur gryphus) have been recorded which is considered "Near Threatened" by IUCN. 
Two bird species, endemic to dry forest may be distributed within the ANMI. The little parrot (cotorrita) Myiopsitta luchsi and the thrush Oreopsar bolivianus have been observed in El Oro, a neighboring area similiar to the ANMI.

In the xeric Andean Valleys (which includes dry forest) there are 161 endemic or "restricted known distribution" species from 40 plant families. The families with the largest number of endemic species are Cactaceae (44 endemic species), Bromeliaceae (17), Orchidaceae (15), Asclepiadaceae (10), Lamiaceae (9), Acanthaceae (7), Fabaceae (6), Asteraceae (5), Mimosaceae (4) and Anacardiaceae (3) (Azurduy 2008).

Within the ANMI, the xeric forests of the Rio Grande have the greatest numbers endemic plants and animals. The highest number of birds in the dry forests has been recorded from the Alto Seco region, with about 138 species.

There is some disturbance to the xeric forest ecosystem from human activity. This target is considered an altered ecosystem because cattle are present throughout. According to participants: 10 years ago they say more wildlife species than they see today. There are selective logging activities in some regions, and almost no logging in the driest areas, where the climate limits the growth of economic timber species. There is goat grazing in these driest areas.

Species which are of key importance in terms of resilience and adaptability to environmental changes in these xeric forests: plant communities which are adapted to dry conditions are more resilent to and tolerant of drought conditions. Dry forest is inherently drought-resistant. The natural rate of regeneration is low.

Xeric Forest is important in terms of these goods and services provided to humans: conservation of genetic resources; provides "alternative" sources of income (cactus as ornamental plants for horticultural trade). Dry forest provides forage for livestock, especially browsing animals.

The conservation of these forests is important for protecting key processes. The Rio Grande region along the border of the PA and where dry forest is located is a breeding and migration site for economically important fish species; an important bird migration route, with both hortizontal and vertical which allow bird populations to move with seasonal changes.

According to the classification of "dry forest" under the life zones of Holdridge (Arana et al. 2007), this area would be considered a temperate dry forest target, given that climate scenarios at the national level will reduce its current area a total of $3.9 \%$ to $2.3 \%$ as of the year 2100 . The most striking trend, according to the same source, is that all areas zones in the sub-Andean slopes and valleys will become drier than today.

The temperate dry forest ecosystem is very fragile to fluctuations in rainfall and temperature. They are on a trajectory to becoming marginal ecosystems by the year 2030. The recorded water balance already indicates deficits as a clear trend (NPCC 1999).

(Source: Experience of the extended CAP planning process, for Fundacion Natura, Bolivia ) 
Annex 5. Distribution of the selected conservation targets in the ANMI RG-VC

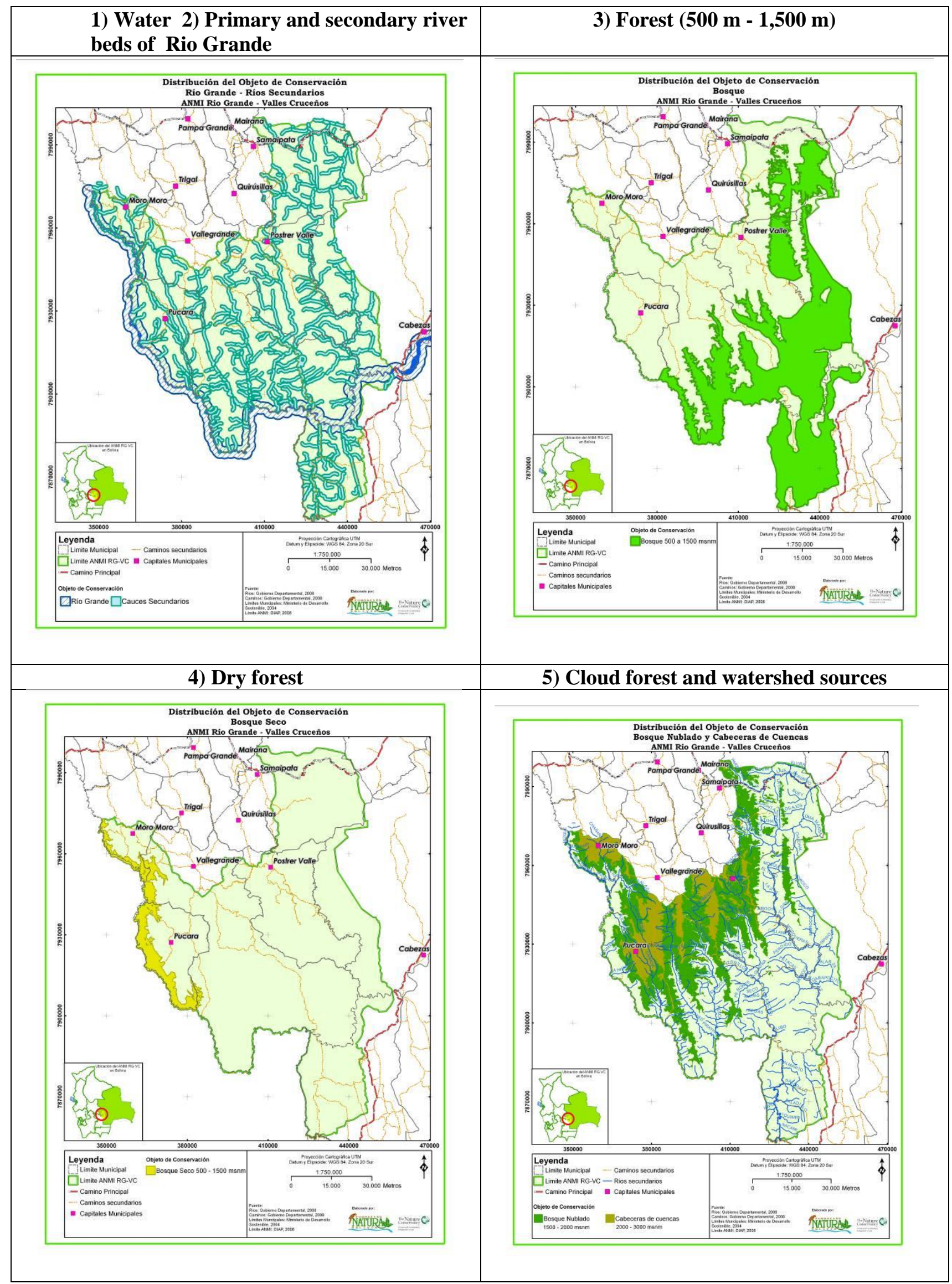

Source: Fundación Natura Bolivia (The author was part of the team and process to collect data and create the target distribution maps) 
Annex 5. Continued. Distribution of selected secondary conservation targets in the ANMI RG-VC

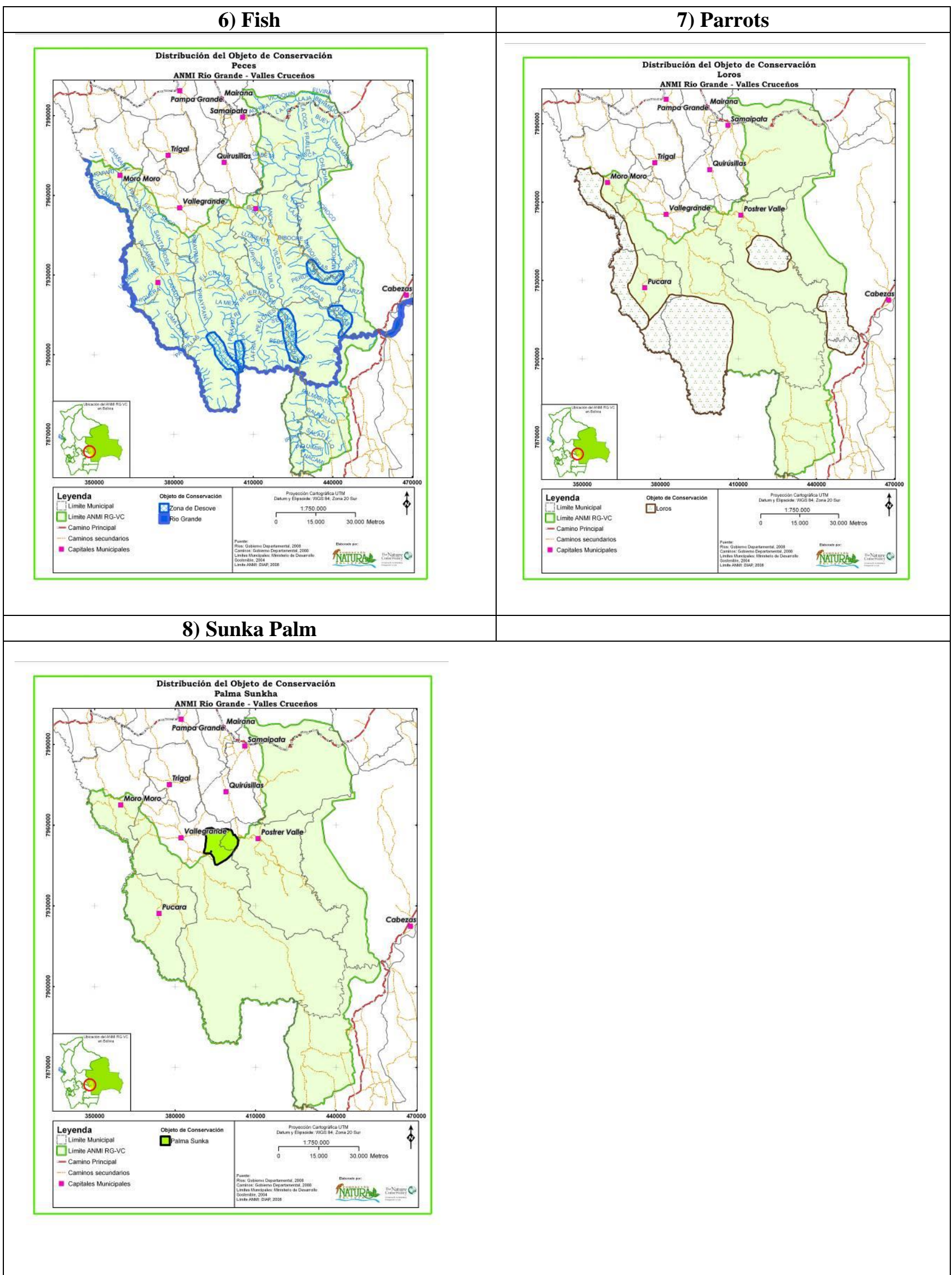

Source: Fundación Natura Bolivia (The author was part of the team and process to collect data and create the target distribution maps) 
Annex 6. Current viability analysis of conservation targets for ANMI RG-VC

Example conservation target: Water, Miradi Report

\begin{tabular}{|c|c|c|c|c|}
\hline \multicolumn{5}{|c|}{ Legend } \\
\hline$U_{\text {Project }}$ & $\bigcirc_{\text {Conservation Target }}$ & $\stackrel{F}{*}$ Key Ecological Attribute & $\triangle$ Indicator & $\triangle$ Measure: $\triangle$ Unspecified স Increasing \\
\hline
\end{tabular}

\begin{tabular}{|c|c|c|c|c|c|c|}
\hline \multirow{2}{*}{ Item } & \multirow{2}{*}{ Status } & \multirow{2}{*}{ Type } & \multicolumn{4}{|c|}{ RATING THRESHOLDS } \\
\hline & & & Poor & Fair & Good & Very Good \\
\hline Rio Grande Valles Cruceños & Good & & & & & \\
\hline Water & Fair & & & & & \\
\hline As habitat/principal rivers & Good & Size & & & & \\
\hline $\begin{array}{l}\triangle \text { Width/flow, channel } \\
\text { permanence (comparable to } \\
10 \text { years ago) }\end{array}$ & Good & & & $\begin{array}{l}\text { Size and channel of rivers } \\
\text { changeable (banks are } \\
\text { deforested, sedimentation etc.) }\end{array}$ & $\begin{array}{l}\text { Channel width and flow is } \\
\text { maintained at levels of } 10 \text { years } \\
\text { ago }\end{array}$ & $\begin{array}{l}\text { Width and flow } \\
\text { of the river is } \\
\text { maintained }\end{array}$ \\
\hline , & & & & & স & \\
\hline Wildlife associated with water & Good & Condition & & & & \\
\hline $\begin{array}{l}\triangle \text { Presence of fish and macro } \\
\text { invertebrate populations }\end{array}$ & Good & & & & $\begin{array}{l}\text { Fish and macro invertebrate } \\
\text { populations are normal (healthy in } \\
\text { size of populations, aspect, etc. } \\
\text { "subjective measure"). }\end{array}$ & \\
\hline
\end{tabular}


Annex 7. Current and future climate viability analysis for the ANMI RG-VC

Example KEA: Temperature Regime, Miradi Report

\begin{tabular}{|c|c|c|c|c|c|}
\hline O ANMI RG-VC & & GOOD & & & FAIR \\
\hline $\begin{array}{l}\text { Analyzed conservation } \\
\text { targets }\end{array}$ & & Current rating & & & Future rating \\
\hline $\begin{array}{ll}\text { - } & \text { Forest } \\
\text { - } & \text { Dry forest } \\
\text { - } & \text { Cloud forest and } \\
& \text { watershed } \\
& \text { protection } \\
\text { - } & \text { Parrots } \\
\text { - } & \text { Sunkha Palm }\end{array}$ & $\begin{array}{l}\text { Indicators / } \\
\text { Thresholds }\end{array}$ & GOOD & Type & Indicators / Thresholds (Scenarios) & FAIR \\
\hline $\begin{array}{ll}0 & \text { Temperature } \\
\text { regime }\end{array}$ & $\begin{array}{l}\text { Annual average } \\
\text { temperature }\end{array}$ & Good & & $\begin{array}{c}\text { Based on data from scenario IS92a (optimistic) (PNCC, } \\
\text { 1999) } \\
\text { Years 2030, 2050, 2100 } \\
\text { (Arana et al. 2007). }\end{array}$ & Fair \\
\hline $\begin{array}{l}\text { Sub-andean and valley } \\
\text { elevation range }(<1900 \\
\text { m) }\end{array}$ & $\begin{array}{l}\text { Abapó } 23.4^{\circ} \mathrm{C} \\
\text { Cabezas } 23.8^{\circ} \mathrm{C} \\
\text { Masicurí } 25^{\circ} \mathrm{C}\end{array}$ & Good & Condition & $\begin{array}{l}1.5^{\circ} \mathrm{C} \text { increase in temperature In the West and in the Chaco. } \\
\text { General increase between } 0.8^{\circ} \mathrm{C} \text { to } 2.3^{\circ} \mathrm{C} \text {. }\end{array}$ & Fair \\
\hline $\begin{array}{l}\text { Montane elevation range } \\
(1900 \mathrm{~m}-3100 \mathrm{~m})\end{array}$ & $\begin{array}{l}20.8^{\circ} \mathrm{C} \text { Max } \\
\text { (Postrervalle } 18.4^{\circ} \mathrm{C}, \\
\text { Vallegrande } 16^{\circ} \mathrm{C}, \\
\text { Samaipata } 23.2^{\circ} \mathrm{C} \text { ) }\end{array}$ & Good & Condition & $\begin{array}{l}\text { Changes in } \mathrm{CO}_{2} \text { concentration associated with other factors } \\
\text { such as increase in } \mathrm{T}^{\circ} \text {, accelerating photosynthesis leading to } \\
\text { greater biomass and indirect effects of adaptation to pathogens, } \\
\text { etc. } \\
\text { Montane systems will be less resistant to increases in } \mathrm{T}^{\circ} \text { and } \\
\text { will have to compete with species adapted to higher } \mathrm{T}^{\circ} \text { which } \\
\text { migrated from warmer to cooler areas. } \\
\text { Montane forest, will possibly be replaced by dryer forests such } \\
\text { as those of the Chaco. }\end{array}$ & Fair \\
\hline
\end{tabular}


Annex 8. Map of distribution of threats in the ANMI RG-VC

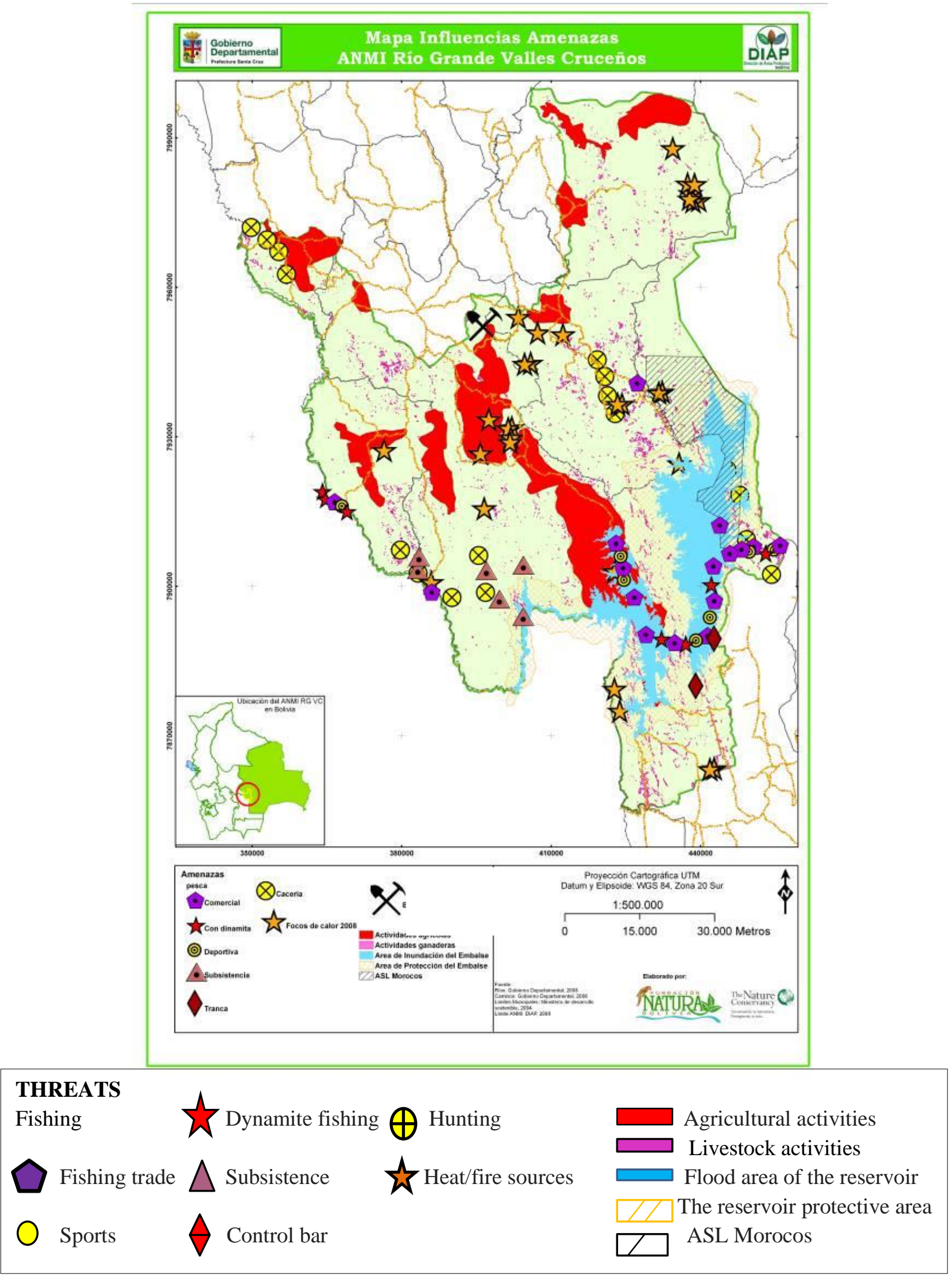

\section{THREATS}

Fishing

Fishing trade

$\triangle$

Annex 8. Map of distibution of threats in the ANMI RG-VC

Source: Fundación Natura Bolivia (The author was part of the team and process to collect data and create the target distribution maps) 
Annex 9. Example Opportunity Analysis relative to threats

\begin{tabular}{|c|c|c|c|c|c|c|}
\hline \multirow{2}{*}{$\begin{array}{l}\text { Conservation } \\
\text { Targets (CT) in } \\
\text { the ANMI RG- } \\
\text { VC }\end{array}$} & \multirow{2}{*}{$\begin{array}{l}\text { Prioritized } \\
\text { threats }\end{array}$} & \multirow{2}{*}{$\begin{array}{l}\text { Current } \\
\text { threat } \\
\text { rating }\end{array}$} & \multirow[t]{2}{*}{ Stakeholders } & \multicolumn{3}{|c|}{ OPPORTUNITIES } \\
\hline & & & & $\begin{array}{c}\text { Key to conserving } \\
\text { the target }\end{array}$ & $\begin{array}{l}\text { Create a situation to } \\
\text { reduce/mitigate/control threats }\end{array}$ & $\begin{array}{l}\text { Context to act upon the } \\
\text { opportunity }\end{array}$ \\
\hline \multirow{2}{*}{$\begin{array}{l}\text { - Fish } \\
\text { - Water } \\
\text { - Primary and } \\
\text { secondary } \\
\text { rivers bed of } \\
\text { the Rio Grande } \\
\text { - Sunka } \\
\text { palma } \\
\text { - Parrots } \\
\text { - Forest } \\
\text { - Dry forest } \\
\text { - Cloud } \\
\text { forests } \\
\text { watershed and } \\
\text { protection }\end{array}$} & $\begin{array}{l}\text {-Unsustainable } \\
\text { agricultural } \\
\text { practices }\end{array}$ & High & \multirow[t]{2}{*}{$\begin{array}{c}\text { Farmers } \\
\text { (mid-scale } \\
\text { farming) } \\
\text { Illegal timber } \\
\text { poachers }\end{array}$} & $\begin{array}{l}\text {-Management and } \\
\text { control of threat in } \\
\text { the affected habitat } \\
\text { and to the related } \\
\text { CTs }\end{array}$ & $\begin{array}{l}\text {-Alternative/diversified } \\
\text { agricultural production } \\
\text {-Sustainable farming practices } \\
\text {-Organized association of farmers. } \\
\text {-Defined practices in place to } \\
\text { maintain soil capacity }\end{array}$ & $\begin{array}{l}\text {-Conservation activities } \\
\text { strengthened between local and } \\
\text { departmental governments and } \\
\text { non-profits, } \\
\text {-Adequate capacity of local } \\
\text { institutions }\end{array}$ \\
\hline & $\begin{array}{l}\text {-Climate } \\
\text { change }\end{array}$ & High & & $\begin{array}{l}\text {-Extended CAP } \\
\text { for the ANMI } \\
\text { (based on targets } \\
\text { analysis) }\end{array}$ & $\begin{array}{l}\text {-Access to results from studies } \\
\text { (data, projections, scenarios). } \\
\text {-Extended CAP planning exercise } \\
\text { for the ANMI. } \\
\text {-Establish National Program of } \\
\text { Climate Change. } \\
\text {-Environmental Education } \\
\text { Program. }\end{array}$ & $\begin{array}{l}\text {-Capacity of financing Program } \\
\text { of Environmental Services } \\
\text {-Strengthened conservation } \\
\text { actions between local } \\
\text { authorities, departmental } \\
\text { authorities and NGOs. } \\
\text {-Adequate municipal capacity } \\
\text {-Adequate Conservation } \\
\text { institution in place to support the } \\
\text { ANMI }\end{array}$ \\
\hline
\end{tabular}




\section{LEBENSLAUF}

Name:

Verónica Lizet Chávez Calvimontes

Geburstsdatum: $\quad$ 3. Februar. 1977

Gerburtsort: Tarija, Bolivien

Staatsangehörigkeit: Bolivianisch

\section{Schulausbildung}

1983-1994

Gymnasium "San Antonio de Los Sauces", Monteagudo, Bolivien.

Abitur.

\section{Studium}

2003-2005

Master in Nachhaltige Entwicklung (ohne Thesis), in "NUR"

Privatuniversität, Santa Cruz de la Sierra (SC), Bolivien.

1995-2000 Diplom-Biologin (Licenciada). Staatliche Universität "Gabriel Rene

\section{Berufserfahrung}

2010-2010

Moreno (UAGRM)", Santa Cruz de la Sierra, Bolivien.

2006-2007

2006-2007

Ausarbeitung Plan Dokument: Plan Ordenamiento Predial, Alta Vista, für Fundacion para la Conservacion del Bosque Chiquitano_FCBC. SC, Bolivien.

Artenschutzberatung für die Vermarktung von wilder Fauna. Fundacion Amigos de la Naturaleza (FAN) SC, Bolivien.

Fachreferentin für Artenschutz, Schwerpunkt Fauna der Stadt (departamento) SC Gobernacion: Departamento Biodiversidad, SC., Bolivien.

2004-2006

Fachreferentin für Schutz Plannung Nationalpark Noel Kemffp Mercado und Unidad Amboro-Carrasco. The Nature Conservancy, SC., Bolivien.

2003-2004 Fachreferentin für Projekt: Corredor Amboro-Madidi. Fundacion Amigos de la Naturaleza (FAN) SC, Bolivien.

2002-2003

2002-2002

$1998-2006$

Fachreferentin für Projekt fauna: Ordenamiento departamental Gobernacion "Departamento Biodiversidad”: SC, Bolivien.

Säugetiere Wildtierprojekt Departamento Pando, für Herencia, Cobija, Pando, Bolivien.

Artenstudien Biodiversität, für der Nationalpark Noel Kempff Mercado. Museo de Historia Noel Kempff Mercado, SC, Bolivien.

\section{Promotion}

Seit 04/2007

Studentin an der Abteilung Landschaftsökologie des Geographischen Instituts der Georg-August-Universität Göttingen

Dissertation zum Thema

"Adaptation to climate change as a key element in strategic planning of biodiversity conservation in Latin America, with special reference to the Santa Cruz department, 
